\title{
A Cost Benefit Analysis of Secondary Glazing as a Retrofit Alternative for New Zealand Homes
}

\author{
Nick Smith
}

November 2009

A thesis submitted to the School of Architecture, Victoria University of Wellington in fulfilment of the requirements for the degree of Master of Building Science. 
A Cost Benefit Analysis of Secondary Glazing as a Retrofit Alternative for New Zealand Homes

Nick Smith 


\section{Acknowledgements}

I would like to thank the Primary Supervisor, Nigel Isaacs for his continued support, feedback and guidance throughout this project. I would also like to thank John Burgess for his role as a secondary supervisor and his excellent planning and administrative assistance with the testing process. Both supervisors were also very helpful in securing funding for this research.

Thank you to Building Research who provided financial assistance for this project.

Thank you to Beacon Pathway who provided additional funding for the extensive testing.

I would like to thank BRANZ for the use of their test facilities. I would also like to thank IanCox Smith, Mark Hearfield and Roger Stanford of BRANZ for their assistance in the assembly and testing.

Finally, I would like to thank friends and family for helping make this research possible. 
A Cost Benefit Analysis of Secondary Glazing as a Retrofit Alternative for New Zealand Homes

Nick Smith 


\section{Preface}

This thesis was submitted as part of the requirements for a Master of Building Science degree at the School of Architecture, Victoria University of Wellington.

Author: Nick Smith

School of Architecture

Victoria University of Wellington

Email:ndsmith1@gmail.com

Primary Supervisor: Nigel Isaacs

Teaching \& Research Fellow

Victoria University of Wellington

Email: nigel.isaacs@vuw.ac.nz

Secondary Supervisor: John Burgess

Senior Scientist (Sustainability)

BRANZ Ltd.

Email: john.burgess@branz.co.nz 
A Cost Benefit Analysis of Secondary Glazing as a Retrofit Alternative for New Zealand Homes

Nick Smith 


\section{Contents}

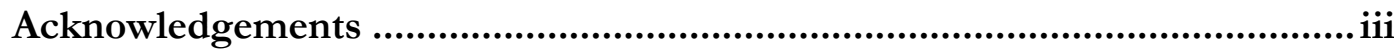

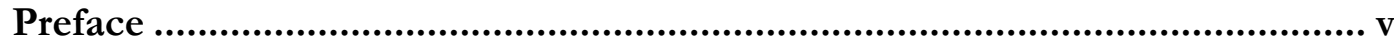

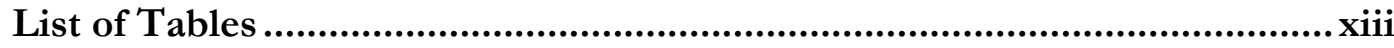

List of Figures.........................................................................................

List of Equations ..................................................................................... xvii

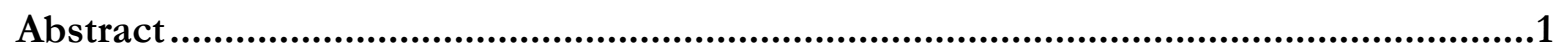

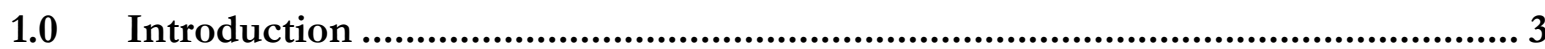

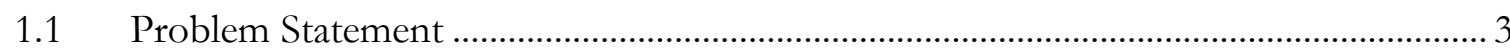

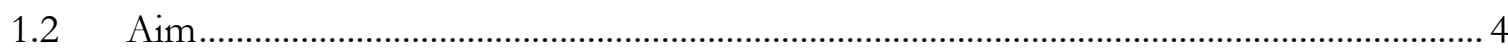

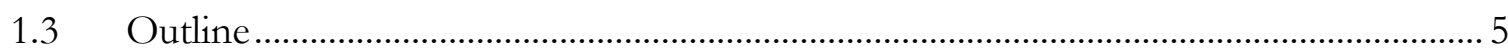

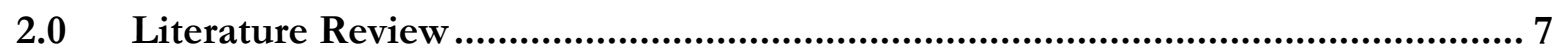

$2.1 \quad$ Outline

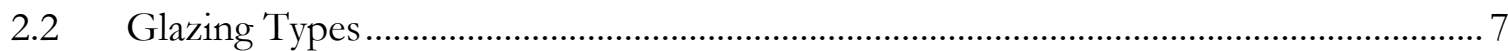

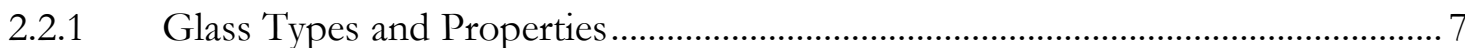

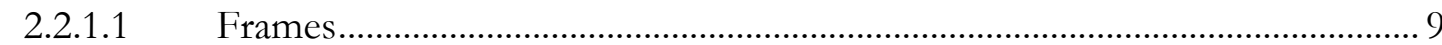

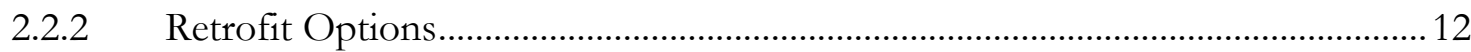

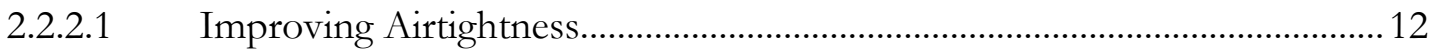

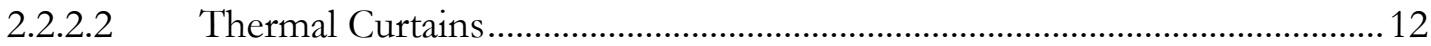

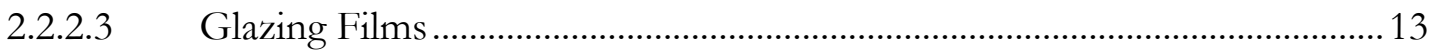

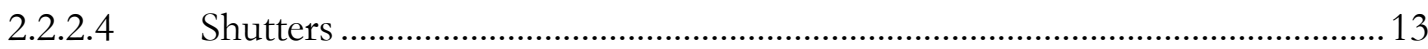

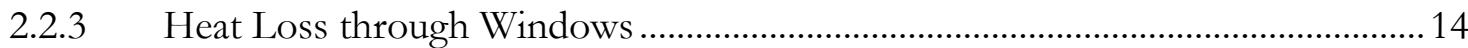

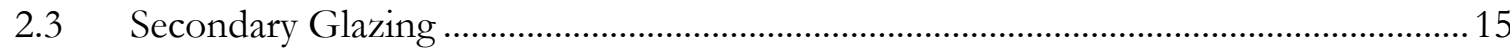

2.3.1 History

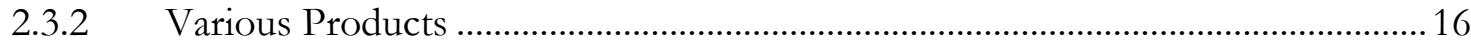

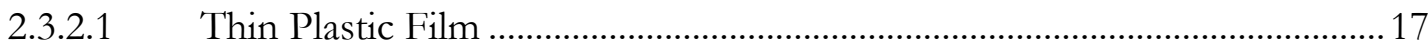




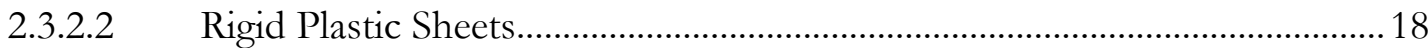

2.3.2.3 Framed Secondary Glazing Windows ..............................................................2 20

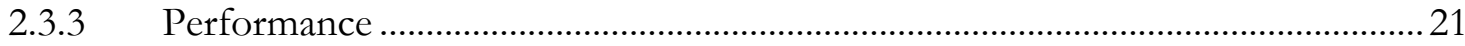

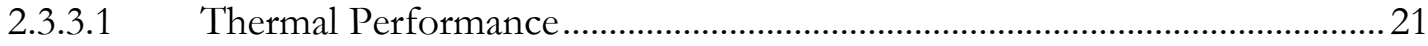

2.3.3.2 Acoustic Performance ………....................................................................... 24

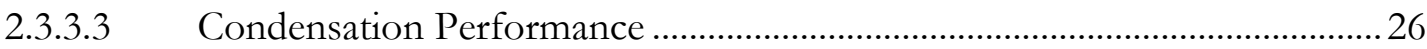

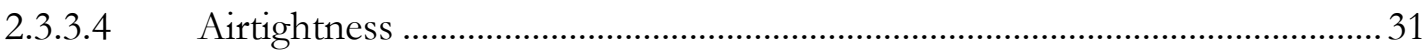

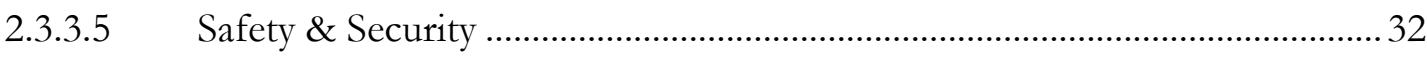

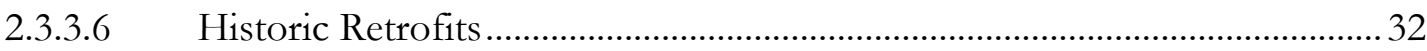

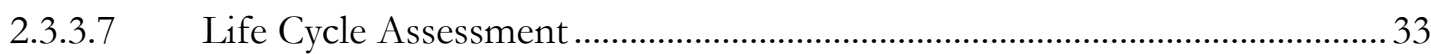

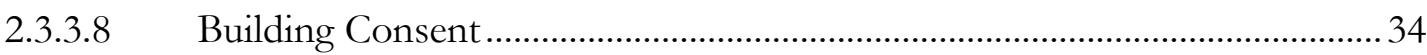

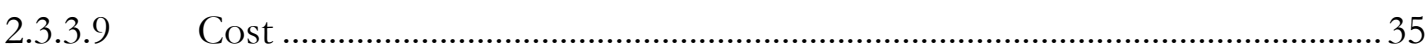

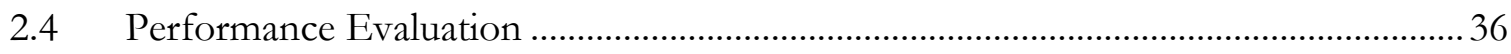

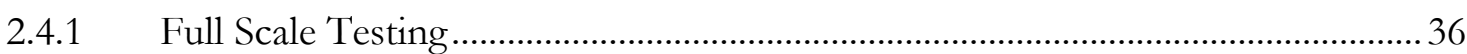

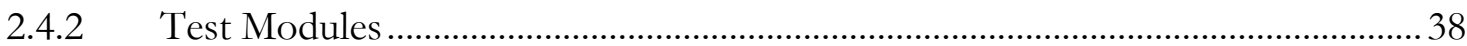

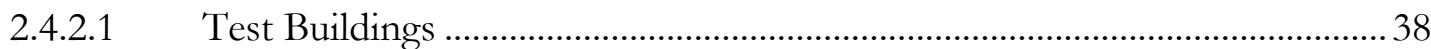

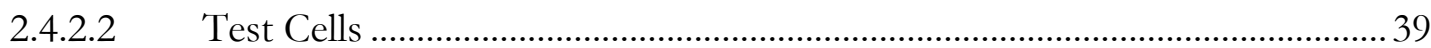

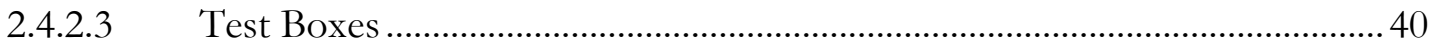

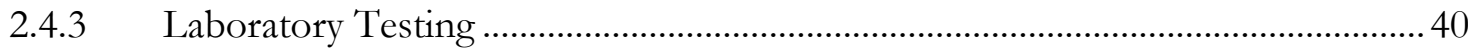

2.4.3.1 Guarded Hot Box.......................................................................................... 40

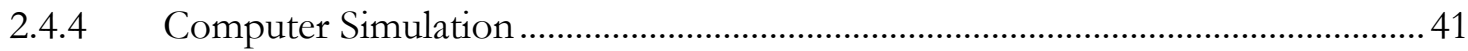

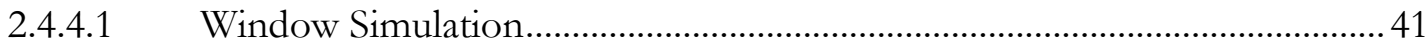

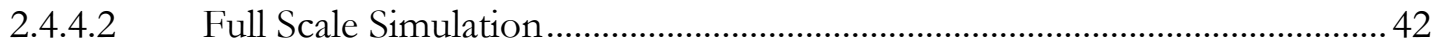

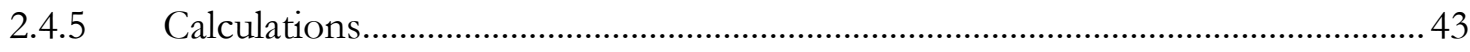

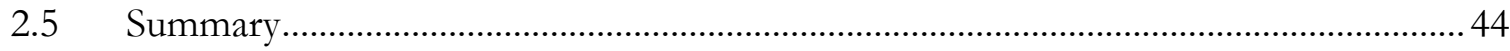

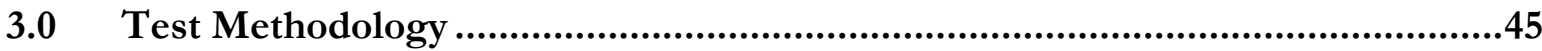




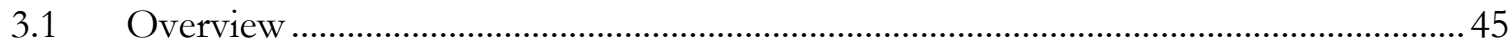

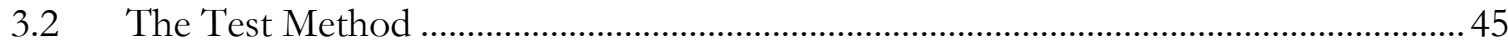

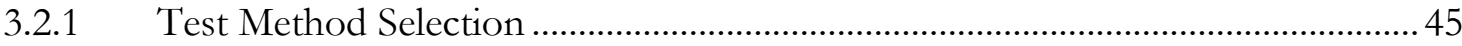

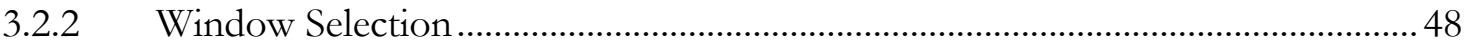

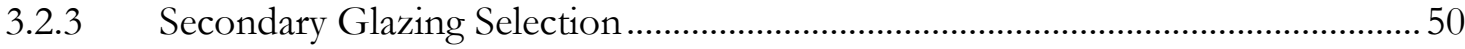

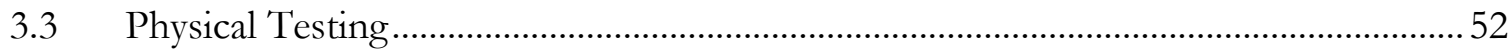

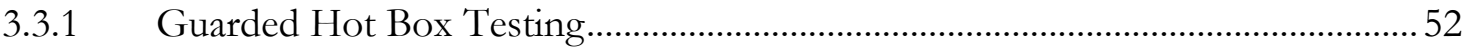

3.3.1.1 Procedure

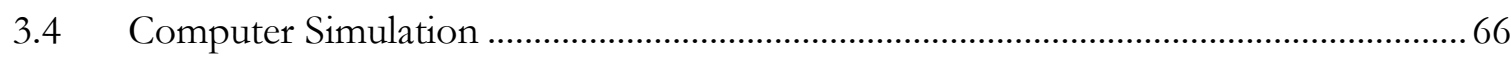

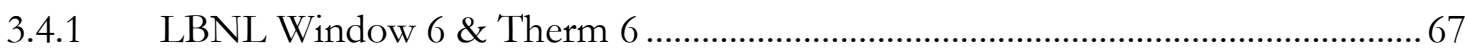

3.4.1.1 Comparison between GHB and Thermal Simulation Results .......................69

3.4.1.2 Simulation to NFRC-100 Standards ................................................................... 70

3.4.1.3 Simulation in accordance with NZS 4218 …................................................. 71

3.4.1.4 Surround Panel Calculation and Removal ....................................................... 72

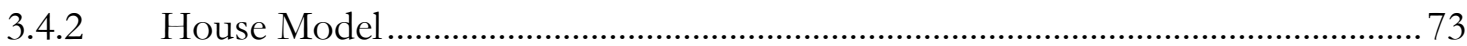

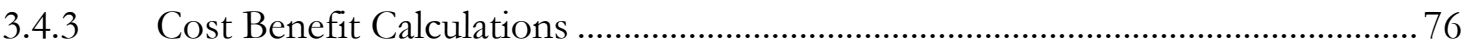

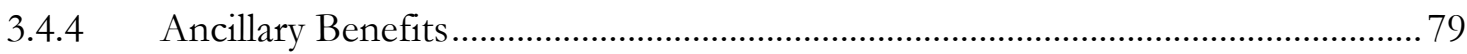

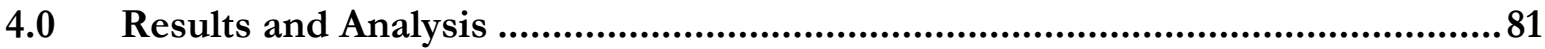

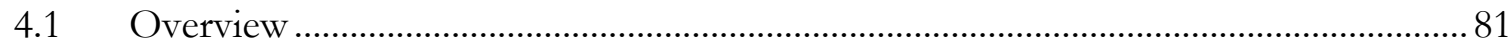

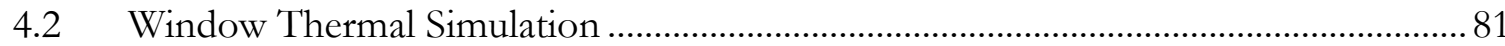

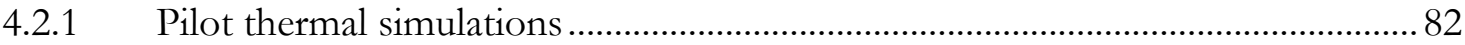

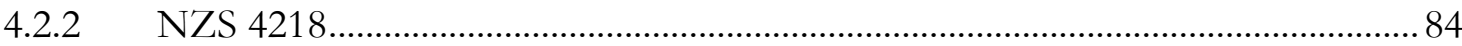

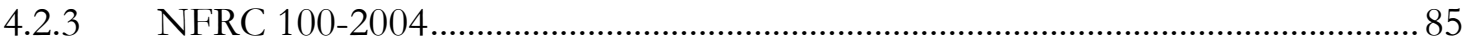

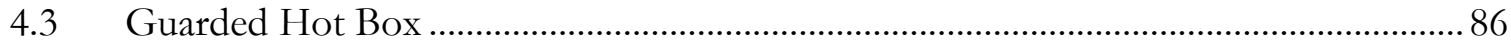

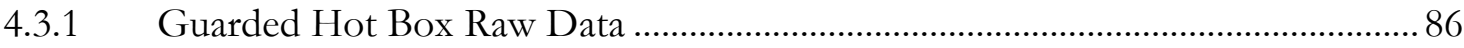

4.3.1.1 Uncertainty Estimation, Precision and Bias .................................................... 89 


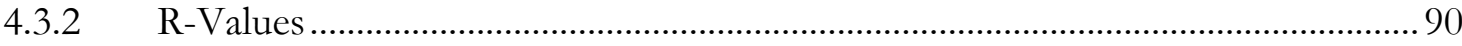

4.3.3 Surround Panel Calculation and Removal ................................................................ 92

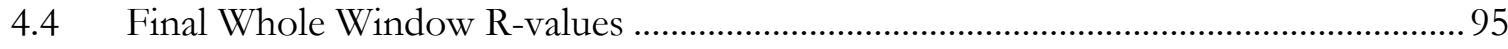

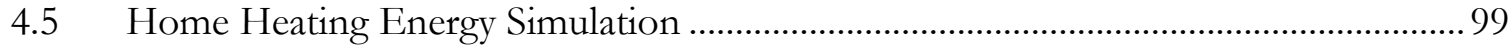

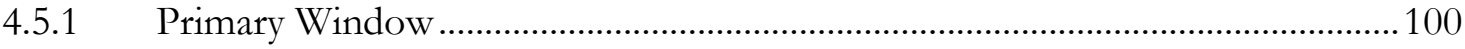

4.5.2 Magnetically-Attached Acrylic Sheet ....................................................................... 104

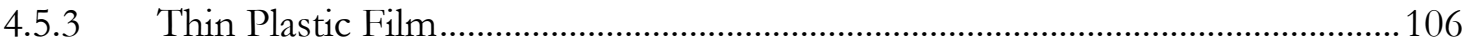

4.5.4 Clear Glazed Aluminium Secondary Glazing ........................................................ 107

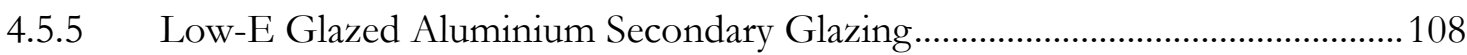

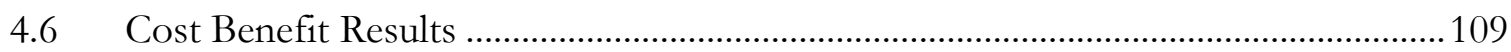

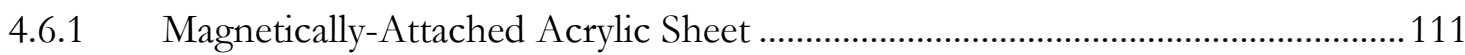

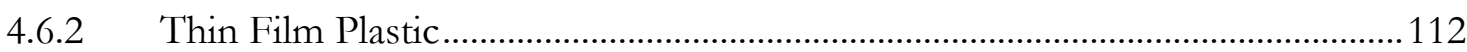

4.6.3 Standard Aluminium-framed Secondary Glazing .................................................115

4.6.4 Low-E Aluminium-framed Secondary Glazing .................................................117

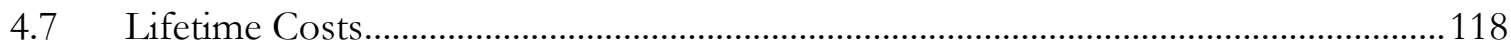

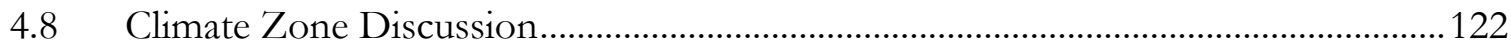

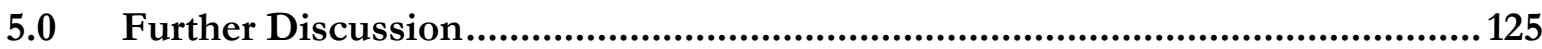

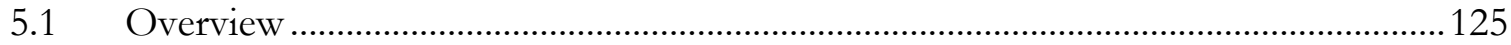

5.2 Secondary or Double Glazing - A Retrofit Comparison................................................ 125

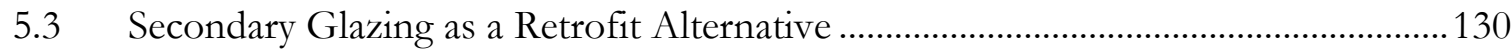

5.4 Ancillary Benefits of Secondary Glazing .......................................................................133

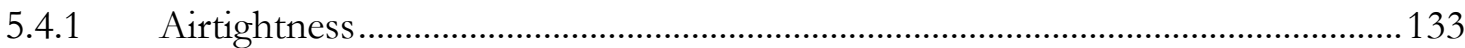

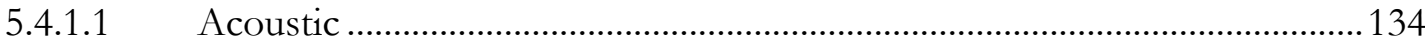

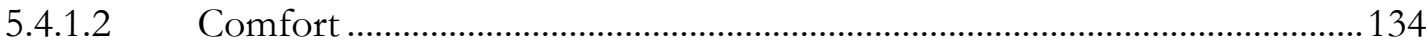

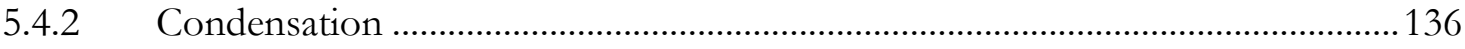

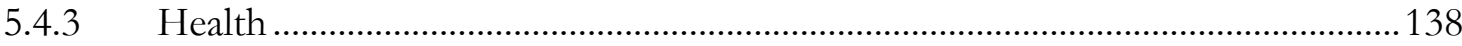


5.5 Quantifying Non Energy Benefits

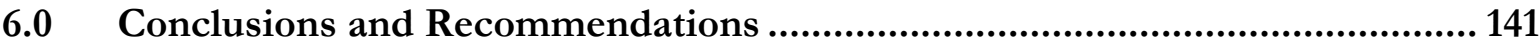

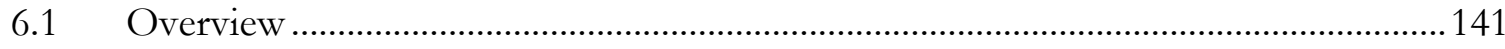

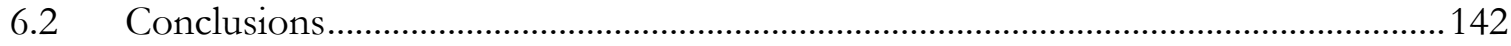

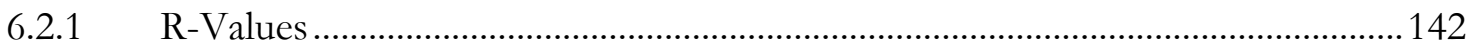

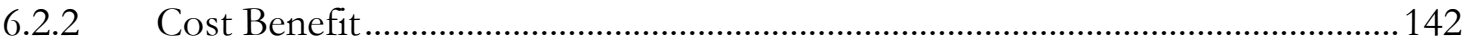

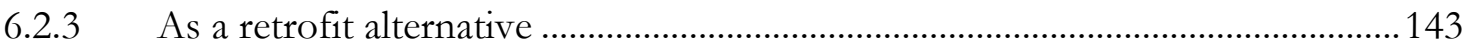

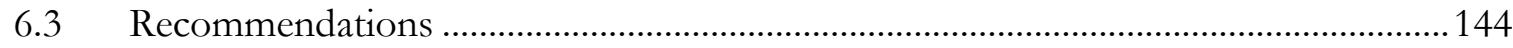

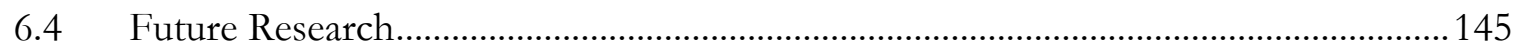

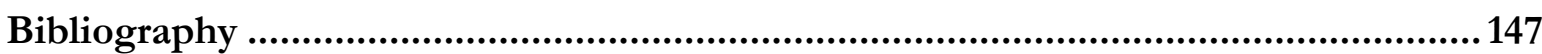

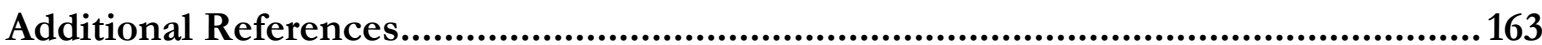

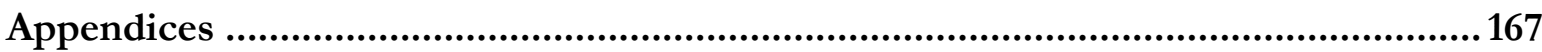

Appendix A Guarded Hotbox Testing ............................................. 167

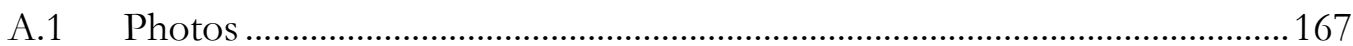

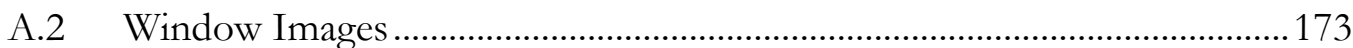

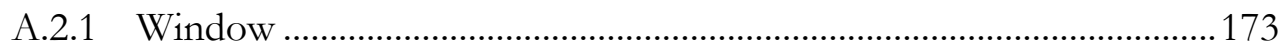

A.2.2 Magnetically-Attached Acrylic Sheet..................................................173

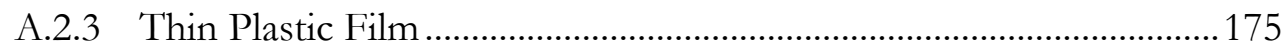

A.2.4 Aluminium \& Low-E Aluminium .......................................................176

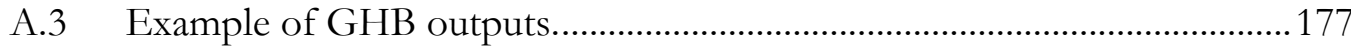

Appendix B Thermal Modelling .......................................................179

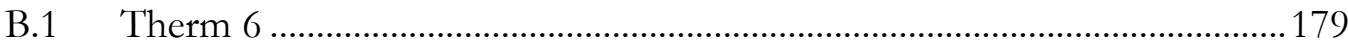

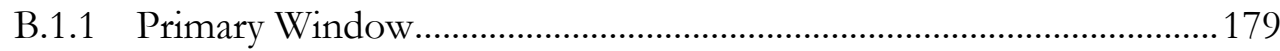

B.1.2 Thin Plastic Film Secondary Glazing ………....................................... 180

B.1.3 Magnetic Attached Acrylic Secondary Glazing......................................180

B.1.4 Aluminium Framed and Low-E Secondary Glazing............................181 


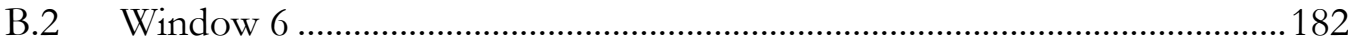

B.2.1 Glass Properties..................................................................................182

B.2.2 Glazing Systems................................................................................. 183

Appendix C Home Heating Energy Simulation: ALF .......................... 185

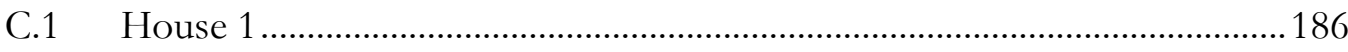

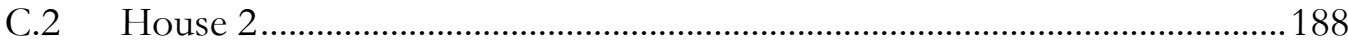

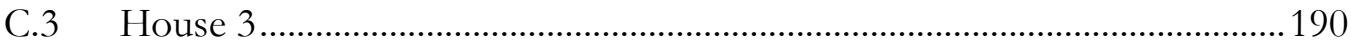

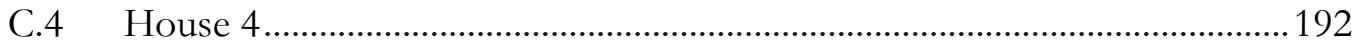

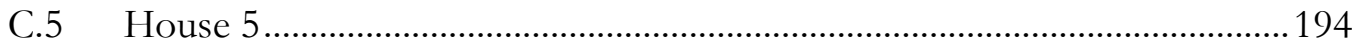

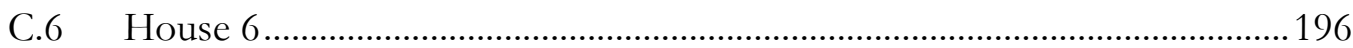

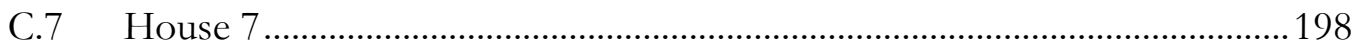

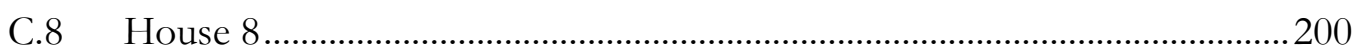

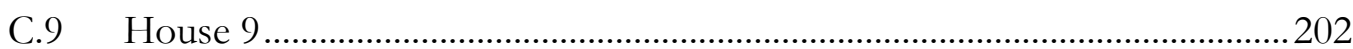

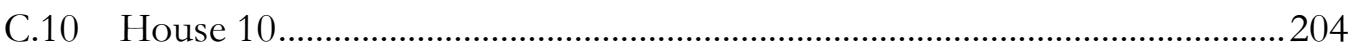

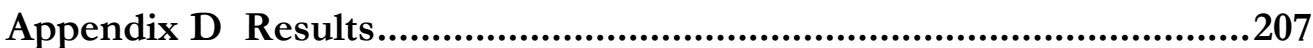

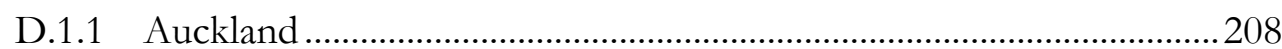

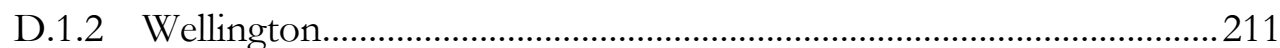

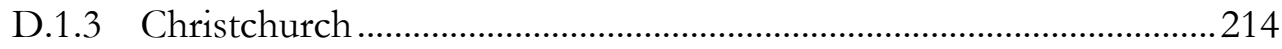

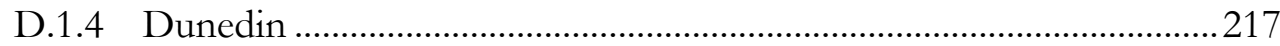




\section{List of Tables}

Table 2-1: Approximate thermal effects of glazing technologies (Bennett \& Burgess, 2006) .. 11

Table 2-2: Achievable performance with glazing films (BRANZ, 2001) ………......................... 13

Table 2-3: Before and After Airtightness Results (Drumheller, Kohler, \& Minen, 2007)......... 31

Table 2-4: Cost of Plastic Thin Film Secondary Glazing Kits(CEA, 2008b) .............................. 35

Table 3-1: Percentage of Window Types in a sample of New Zealand Homes (Clark, Jones, \&

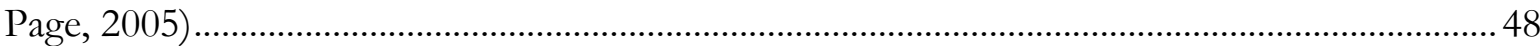

Table 3-2: Chosen Climate Zones for ALF Simulation ..................................................................... 73

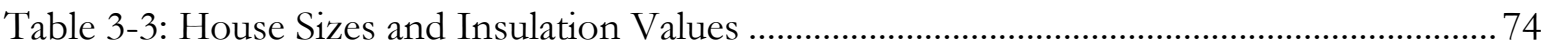

Table 3-4: Heating Seasons for each Climate ……............................................................................ 75

Table 3-5: Thin Plastic Film Secondary Glazing Prices ................................................................... 78

Table 4-1: Pilot Thermal Resistance Simulation Results for Selected Secondary Glazing ........ 82

Table 4-2: Thermal Resistance Simulation to NZS 4218 .................................................................. 85

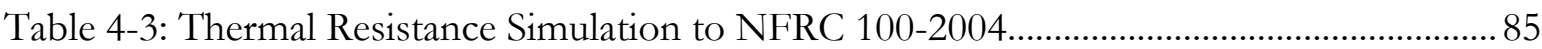

Table 4-4: Average, Stable Guarded Hot Box R-values (Including Surround) ............................ 87

Table 4-5: Results from 7 Interlaboratory Guarded Hot Box Comparisons................................ 90

Table 4-6: Estimated Uncertainty for Measured GHB Results ..................................................... 90

Table 4-7: Guarded Hot Box Measurements including Surround Panel....................................... 91

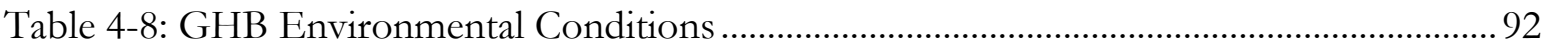

Table 4-9: Simulation Results using GHB Conditions.................................................................... 93

Table 4-10: Comparison between Measured and Calculated Results .......................................... 93

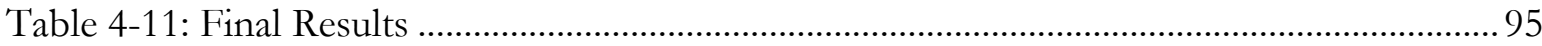

Table 4-12: Comparison between R-values for all methods ......................................................... 96

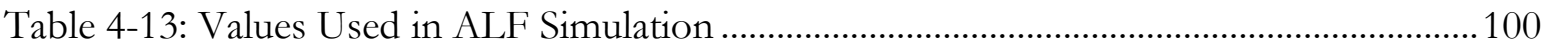

Table 4-14: Primary Window Simulated Heating Energy Results ................................................. 101

Table 4-15: Average HEEP annual space heating energy consumption (Isaacs, et al., 2006).102

Table 4-16: Single Glazed Home Heat Losses .................................................................................... 103

Table 4-17: Magnetic Acrylic Simulated Heating Energy Results ...............................................104

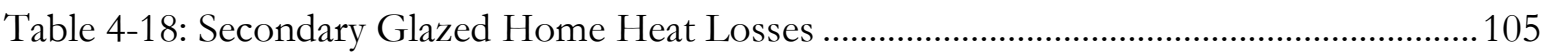

Table 4-19: Thin Film Simulated Heating Energy Results .......................................................... 106

Table 4-20: Aluminium Simulated Heating Energy Results .......................................................... 107 
Table 4-21: Low-E Aluminium Simulated Heating Energy Results 108

Table 4-22: Size Details of Quoted Home Windows 109

Table 4-23: Manufacturing and Installation Cost Quotes .............................................................110

Table 4-24: Magnetically-Attached Acrylic Sheet Energy Savings (\$/yr) ....................................111

Table 4-25: Magnetically-Attached Acrylic Sheet Payback Period .................................................111

Table 4-26: Adhesive Plastic Secondary Glazing Costs ...............................................................113

Table 4-27: Annual Thin Film Returns for Energy Savings ......................................................... 113

Table 4-28: Aluminium-framed Secondary Glazing Energy Savings .........................................115

Table 4-29: Aluminium-framed Secondary Glazing Payback Period.............................................116

Table 4-30: Low-E Aluminium-framed Secondary Glazing Energy Savings .............................117

Table 4-31: Low-E Aluminium-framed Secondary Glazing Payback Period ............................. 117

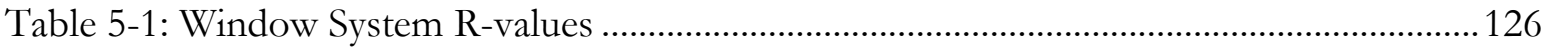

Table 5-2: Installation Cost and R-value of Various Glazing Systems. .......................................128

Table 5-3: Annual NEB values by technology and NEB type in New Zealand dollars

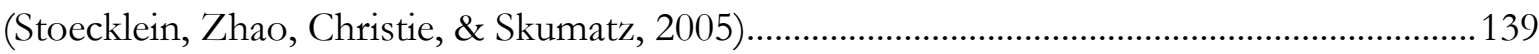

Table A-1: Sample of the GHB test output from the single glazed window test. .....................177

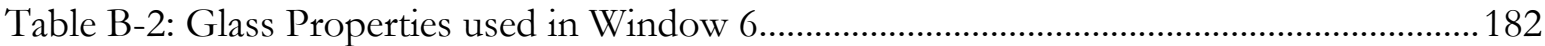

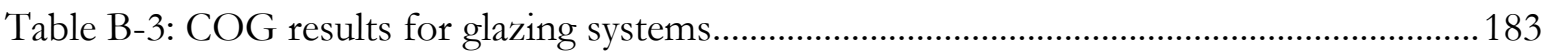

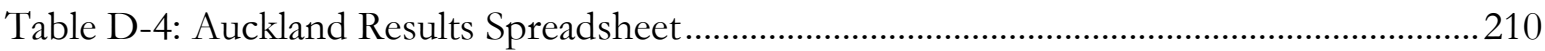

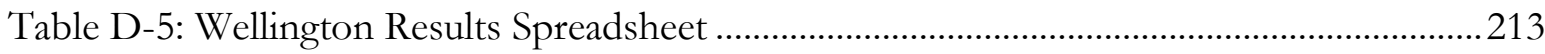

Table D-6: Christchurch Results Spreadsheet..............................................................................216

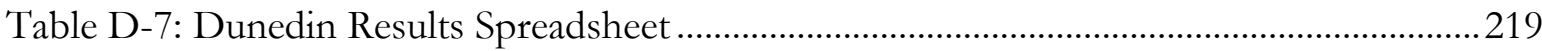




\section{List of Figures}

Figure 2-1 \& Figure 2-2: The Practical Householder, December 1959 (The Window Man, 2008) 16

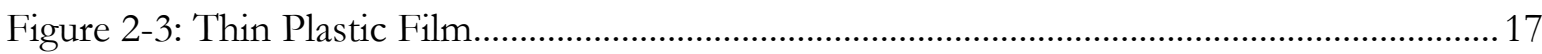

Figure 2-4: Thick Plastic Magnetically-attached Sheets .................................................................. 18

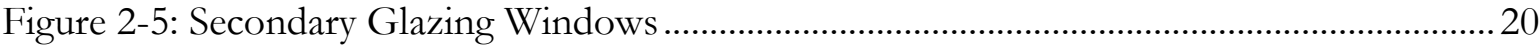

Figure 2-6: Effect of cavity Width on R-Value (Godfrey, 1972) ................................................21

Figure 2-7: Typical acoustic insulation curves for three types of window. (BRE, 1993) ...........26

Figure 2-8: Temperature across a Secondary Glazed Window Cavity ............................................ 30

Figure 3-1: 3D Perspective of the Single Glazed Aluminium Window......................................... 50

Figure 3-2: The BRANZ Guarded Hot Box ………….................................................................... 52

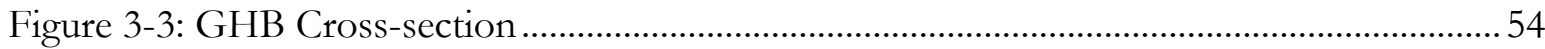

Figure 3-4: Guarded Hot Box Surround Figure 3-5: Construction of the Surround ............... 55

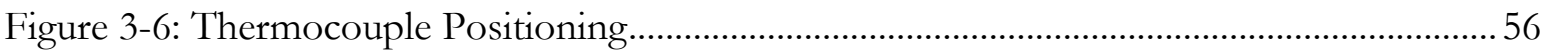

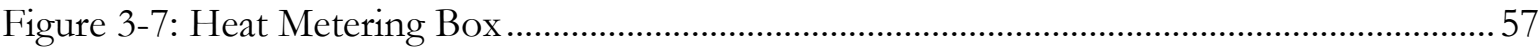

Figure 3-8: Aluminium Coated Radiant Heat Shield In Place........................................................... 60

Figure 3-9: Hot Box Open with Single Glazed Sample in Position................................................ 62

Figure 3-10: Magnetically-Attached Acrylic Sheet Positioned in Place ........................................... 63

Figure 3-11: Perspective View of Thin Plastic Film Secondary Glazing .......................................64

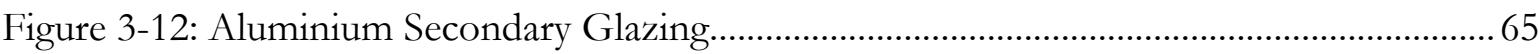

Figure 3-13 \& Figure 3-14: Therm 6 Model of Aluminium Secondary Glazed Sill..................... 69

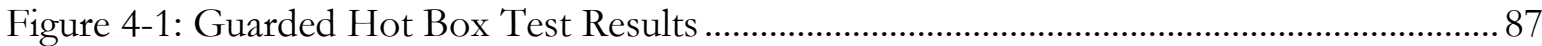

Figure 4-2: Lifetime Cumulative Secondary Glazing and Heating Costs from 0 - 25 Years... 119

Figure 4-3: Map of Climate Zones (NZS 4218, 2009) …............................................................122

Figure 5-1: Initial and Discounted Recurrent Costs from $0-15$ years (Lloyd, Bishop, \& Callau, 2007) 131

Figure 5-2 (above) and Figure 5-3: The effect of a second pane on internal window

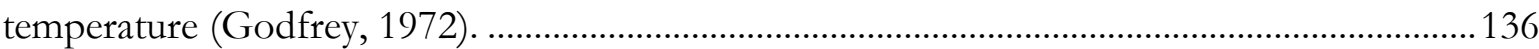

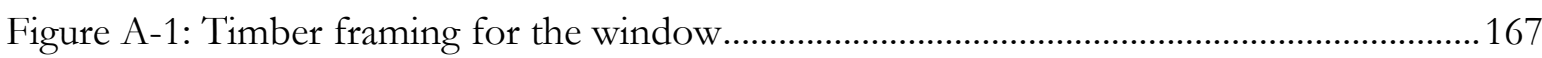

Figure A-2 \& Figure A-3 Assembly of the GHB surround ..................................................... 168

Figure A-4: GHB open with surround constructed …….............................................................. 168

Nick Smith 
Figure A-5: GHB closed with surround in between 169

Figure A-6 \& Figure A-7: Thermocouples positioned between the radiant shield and the window installed in the surround

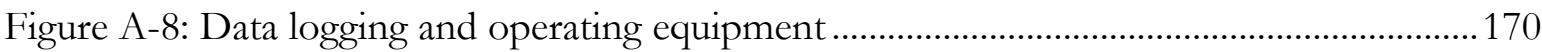

Figure A-9: The heat pumps which service each chamber............................................................170

Figure A-10: Inside of the chamber showing the heat metering box .......................................171

Figure A-11 Real-time GHB Measurements ..............................................................................171

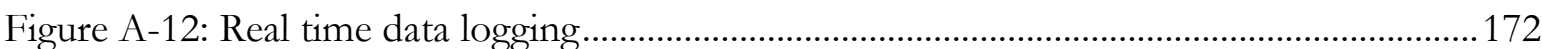

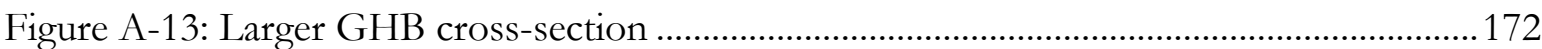

Figure A-14 \& Figure A-15: The primary aluminium single glazed window..............................173

Figure A-16: The magnetic fixed acrylic secondary glazing .....................................................173

Figure A-17, A-18, A-19 \& A-20: Magnetic attached acrylic secondary glazing ........................ 174

Figure A-21 \& A-22: Thin plastic film secondary glazing ...........................................................175

Figure A-23 \& A-24: Aluminium framed secondary glazing close-up........................................176

Figure A-25 \& A-26: Aluminium framed secondary glazing front and back..............................176

Figure A-27: Enlarged version of Figure 4-1: Guarded Hot Box Test Results.......................... 178

Figure B-28\& B-29: Primary Window Sill and Head Sections......................................................179

Figure B-30 \& B-31: Thin Plastic Film Sill and Head Sections .................................................. 180

Figure B-32\& B-33: Magnetic Acrylic Sill and Head Sections .................................................... 180

Figure B-34 \& B-35: Aluminium Secondary Glazing Sill and Head Sections ............................. 181

Figure B-36 \& B-37: Aluminium Secondary Glazing Jamb and Mullion Section......................181 


\section{List of Equations}

Equation 2-1: Surface Temperature Calculation (Richardson, 2001) ...........................................2

Equation 2-2: Internal Surface Temperature of Single Glazing ...................................................27

Equation 2-3: Internal Surface Temperature of Secondary Glazing...........................................28

Equation 2-4: Secondary Glazing R-value Calculation ....................................................................28

Equation 2-5: Heat-Loss across a Secondary Glazed Window ……..............................................2 29

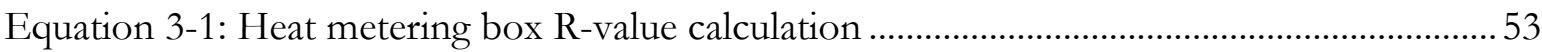


A Cost Benefit Analysis of Secondary Glazing as a Retrofit Alternative for New Zealand Homes 


\section{Abstract}

Homes with single glazing represent a large majority of the New Zealand housing stock. With the recent changes to the NZ Building Code Clause H1 Energy Efficiency, new homes require higher glazing thermal performance. This will lead to an increased need for cost effective methods to improve window thermal performance in existing single glazed homes without completely replacing the windows, which includes 'secondary' glazing.

There are several secondary glazing options available including 'stick-on' plastic glazing as well as aluminium framed glass solutions that are installed inside the existing joinery. Secondary glazing is marketed as a cost effective alternative to insulated glazing units, providing both improved acoustic and thermal insulation to existing windows. There is little information regarding the inuse performance and cost benefits of secondary glazing in New Zealand. This thesis explores the efficacy of the secondary glazing products when installed in existing single pane frames.

A guarded hotbox was used to make thermal resistance measurements on a typical single glazed aluminium window with timber reveal liner. Four common secondary glazing systems were retrofitted into the window - (1) thin plastic film; (2) magnetically-attached acrylic sheet; (3) aluminium framed secondary glazing; and (4) aluminium framed low emissivity (low-E) secondary glazing. Models of 'typical' New Zealand homes created in the ALF building thermal simulation programme were used to explore the heating energy savings and cost benefits provided by the different secondary glazing systems in a range of locations.

Of the tested products, the low-E secondary glazing produces the largest cost-benefits. At current energy and material costs, secondary glazing was found to not be a financially viable solution in warmer climates such as Auckland. In cooler climates such as Christchurch and Dunedin, secondary glazing was found to be a cost effective retrofit alternative for existing single glazed homes. 
A Cost Benefit Analysis of Secondary Glazing as a Retrofit Alternative for New Zealand Homes 


\subsection{Introduction}

\subsection{Problem Statement}

With the recent New Zealand wide introduction of higher domestic glazing insulation requirements in the building code $(\mathrm{DBH}, 2007)$ and the introduction of a Household Energy Rating Scheme (HERS) (EECA, 2007), there is a need to provide an economic means for existing housing to upgrade their window thermal performance without the need to completely replace windows. Windows are a thermally weak point of the envelope, responsible for between $26 \%$ and $48 \%$ of the heat lost from a building, depending on the insulation levels in the roof, wall and floor (Pollard, 2005). Existing single glazed homes make up a large percentage of the New Zealand housing stock - 87\% in Christchurch and 99.7\% in Auckland (Clark, Jones, \& Page, 2005). Research has shown that these homes often struggle to reach acceptable temperatures during the winter time (French, Camilleri, Isaacs, \& Pollard, 2007). Many of these homes lose much of their heat through the single glazed windows.

Newer homes are warmer during winter than older homes; reasons for this may include higher levels of thermal insulation and increased airtightness (French, Camilleri, Isaacs, \& Pollard, 2007). Recent changes to clause H1 will continue to improve the winter performance of new homes but the existing homes within New Zealand are not covered by the requirements. It may not be viable to upgrade the existing single glazed housing stock to double glazing. There is research regarding the benefits of upgrading from single glazed windows to double glazed windows in new homes (Burgess, 2007) and current research is looking at the effect of retrofitting with double glazed windows (Burgess, 2008). There is no information regarding the cost benefits of secondary glazing in New Zealand. Secondary glazing is marketed as a cost effective alternative to double glazed windows, providing acoustic and thermal insulation but using existing windows. With no research comparing how these secondary glazing systems perform in use, it is difficult to make any comparisons. 
There are several 'stick-on' plastic secondary glazing options available, and many window companies offer extruded aluminium frames that are installed inboard of the existing joinery. These systems are potentially much easier and cheaper to install when compared to products such as double glazing, with some even being advertised as a DIY solution. The project that is required would look at the efficacy and cost benefit of installing a variety of secondary glazing systems to add to this body of knowledge. The affordable nature of secondary glazing systems means that there is potential for these products to be cost effective solutions for existing home owners.

\subsection{Aim}

The project reported in this thesis tested a variety of key questions relating to secondary glazing systems. The aim of this research was to see if these products are a financially viable retrofit option for existing single glazed homes. The result of this project is a cost benefit analysis of laboratory tested and computer simulated secondary glazing systems. The plan of this research was to measure and calculate the thermal resistance provided by secondary glazing systems when retrofitted into single glazed windows. These results would provide a comparison with other insulated glazing systems.

The thermal resistance results were then used to calculate and evaluate the influence secondary glazing would have on household heating energy. This could then be analysed with regards to electricity and secondary glazing prices. This analysis will find the efficacy, cost benefit and performance advantages of the secondary glazing products when installed in existing single pane frames. The cost benefit of the secondary glazing systems could then be compared with other retrofit insulation options such as wall insulation and double glazing. The comparative benefits of a secondary glazing retrofit could then be assessed.

The project also aims to provide a comparison between physical and computer simulated results. Not only does this allow comparison between both methods, but also provides insight into the suitability of window simulation for products such as secondary glazing. 
This research will focus on the cost benefits of secondary glazing systems when retrofitted onto existing single glazed windows. The cost benefit will be limited to the purchase and installation cost when compared to the potential energy savings provided by the unit. Other single glazed window retrofit options such as external storm windows, thin film coatings, drapes and shutters will not be tested. As the study was New Zealand specific, only technologies readily available in New Zealand were tested under New Zealand conditions. Aspects such as embodied energy and non-energy benefits will be discussed however this research will not attempt to quantify and include these as part of the cost benefit analysis.

This study uses $\mathrm{R}$-value $\left(\mathrm{m}^{2} \cdot \mathrm{K} / \mathrm{W}\right)$ as the measure of thermal resistance. The use of $\mathrm{R}$-value was favoured over $\mathrm{U}$-value $\left(\mathrm{W} / \mathrm{m}^{2} \cdot \mathrm{K}\right)$ due to its use in NZS 4218:2009. Where necessary, U-values have been converted to R-values. To allow easy conversion, the U-values are also presented alongside $\mathrm{R}$-values in tables presenting the thermal resistance results from measurements and calculations. All prices are in NZ $\$$ and were current at the time of the research.

\subsection{Outline}

This paper begins with an overview of current glazing technologies. Previous international and New Zealand research into a variety of secondary glazing systems was documented in detail and compared with the other glazing technologies. Various test methods were explored and a suitable test method was established and documented. The performance of various secondary glazing systems was then measured. The thermal resistance results of each of the systems were then used to evaluate the potential energy savings provided by each unit. The annual energy and resulting cost savings were then factored into the cost and installation costs of the secondary glazing system, thus providing an estimate of the payback period for the secondary glazing. These payback periods could be compared with other retrofit options to determine if secondary glazing is a financially viable retrofit option. 
A Cost Benefit Analysis of Secondary Glazing as a Retrofit Alternative for New Zealand Homes 


\subsection{Literature Review}

\subsection{Outline}

This section begins with Section 2.2 - Glazing Types outlining the fundamental technologies available today for fenestration systems. The various attributes and performance properties of fenestration systems are discussed, moving towards a focus on retrofit technologies. The physical heat loss and gain abilities of fenestration systems with a focus on New Zealand homes are discussed. In Section 2.3 - Secondary Glazing the various performance attributes of secondary glazing are discussed in detail with an emphasis on the previous research conducted into secondary glazing. Section 2.4 - Performance Evaluation examines the advantages and disadvantages of different methods available to test secondary glazing while also analysing the methods which have been used previously.

\subsection{Glazing Types}

\subsubsection{Glass Types and Properties}

There are a large variety of manufactured glazing panels on the market, all adding different properties to the commonly available clear single pane glazing. A key development in the history of glass was in the 1950's when post war development saw the innovation of float glass replace the more visually distorted sheet glass. Float glass is made by floating a thin layer of molten glass on molten tin where it flows to a uniform thickness (NRC, 1988). This process gave the glass very flat, parallel surfaces with an even thickness and few visual deformations, which is needed for the thin covering applied to today's specially designed glasses (Bennett \& Burgess, 2006).

Tints and Reflective Coatings have the ability to absorb or reflect some of the heat and light that would typically enter a building if clear glass was used. They can also add privacy and change the aesthetic of a building. There are two types of tinted glass, the first is conventional tint which 
diminishes both light and heat gains and comes in many colours. The second is spectrally selective tints. These are more technically advanced and can allow the daylight portion of the solar spectrum to pass through while absorbing the near infra-red radiation. They typically come in light blue and green tints (Mitchel, Kohler, \& Arasteh, 2006). For more of a reduction in the solar heat gain coefficient (SHGC) a reflective film can also be applied to a clear or tinted piece of glass. The SHGC is the fraction of incident solar radiation admitted through a window, both directly transmitted, and absorbed and subsequently released inward (WERS, 2008a). Measured between 1 and 0, a high SHGC means a large amount of solar heat is allowed to pass through the window while a lower number means less passes through. Solar heat can be harnessed to reduce purchased heating energy in buildings in cold climates, while it needs to be blocked to reduce the heating load and cooling costs in warm climates. One of the typical properties of reflective coatings is in the reduction of ultra violet (UV) penetration (Bennett \& Burgess, 2006).

Low emissivity (low-E) coatings can be applied to sheets of glass to increase the thermal performance. As a microscopically thin coating of metal or metal oxide on a pane of glass, low-E glazing allows short wave solar radiation into the building when the low-E surface is oriented towards the inside. However, it reflects long wave thermal radiation from the interior back into the room. The lower the emissivity, the less radiation is emitted from the window to the outside environment - and the better the effective R-value (Energy Savings Trust, 2006a). There are two types of low-E coating available, sputtered or soft coats and pyrolytic or hard coats. Soft coats are very thin, fragile and must be protected from humidity and abrasion. Hard coats are very durable and can be exposed to air and cleaned with everyday cleaning products (Bennett \& Burgess, 2006). Uncoated clear glass typically has an emissivity (En) of 0.84 , whereas the typical emissivity of coated glass ranges from 0.15 to 0.20 for hard and 0.05 to 0.10 for soft coatings (Energy Savings Trust, 2006a).

Insulating Glass Units (IGU) are two or more layers of glass panes spaced apart and permanently sealed together with dry air or special gases in the cavity space. When compared to a single pane window, IGUs provide modifications to the transfer of heat, sound and light, and consequentially energy use and comfort (BRANZ, 2006). While the IGU has an increased thermal resistance it has a decreased SHGC. The SHGC of an IGU is the second most important factor after R-value (BRANZ, 1999). Double glazing using ordinary clear glass reduces 
the heat loss from a window by approximately $45 \%$ and the solar heat gain during the day by about 10\% (BRANZ, 1993). IGU made from two sheets of glass are commonly termed 'double glazing'.

Dry air is normally used in the inter-pane filling, although argon gas filling is becoming more common due to its improved thermal performance, although it may slowly leak out of the IGU over its lifetime. Other higher technology fills are becoming commonly available overseas giving improved thermal and acoustic operation by using aerogels, a highly porous silica material with a thermal conductivity lower than still air (Schultz, Jensen, \& Kristiansen, 2005), or having a vacuum instead of a gas filling (BRANZ, 2006) as used by Nippon Sheet Glass SPACIA (Nippon, 2008).

Glasses which respond actively or passively to the environment are commonly known as 'smart glasses' or 'switchable glasses'. Those which are currently available tend to be extremely expensive (Woolley \& Kimmins, 2000). Passive systems can be photochromics which change transparency with varying light levels or thermochromics which change transparency with varying temperature (Bennett \& Burgess, 2006). The term 'active system' is used to describe glazing such as Electrochromics, Liquid Crystal Glazing and Particle Dispersed Glazing. These active systems change transparency when a small voltage is applied to them allowing it to be controlled manually or as part of an overall environmental management system (Woolley \& Kimmins, 2000).

\subsubsection{Frames}

The thermal resistance of a wood or plastic window frame can contribute usefully to the insulation value of the whole window but the reverse is true of metal-framed windows (because of the relatively high conductance of the metal frame) unless thermal breaks are introduced to offset the cold bridge effect. These are thermally broken aluminium frames which incorporate insulating plastics or resin insets in the frame section to break the thermal conductivity of the aluminium (BRE, 1993). 
Aluminium frames make up the majority of the New Zealand window market. A report conducted in 2002 shows aluminium frames comprise $96 \%$ of the New Zealand market for new windows and another 1\% consisting of thermally broken aluminium windows. The final 3\% is split between PVC, timber, steel and other composite window framing technologies (BRANZ, 2002).

If correctly installed and maintained well, timber windows can still be operating after 80-100 years (BRANZ, 2007). The embodied energy of timber framing for windows is much lower than aluminium, with an embodied energy of only 3.1MJ/Kg (Baird, 1997). New timber windows are much less common. A lack of large scale production has caused them to become expensive when compared to aluminium windows, partly due to customers requiring certain designs. Typical softwood timber windows have a service life of around 30 - 40 years (NGS, 2007).

Aluminium window frames have a very large embodied energy of $226 \mathrm{MJ} / \mathrm{kg}$ for extruded anodised and $218 \mathrm{MJ} / \mathrm{kg}$ for extruded factory painted (BRANZ, 2007). Advantages of aluminium windows are their durability, and low cost. Aluminium windows are very durable with a service life of around 30 - 50 years (NGS, 2007).

PVC has a significantly better thermal performance than the standard aluminium-based windows and the thermally improved aluminium windows available in New Zealand (Bennett \& Burgess, 2006). The manufacturing of PVC frames produces high levels of dioxins and other organochlorins. Although the manufacturing techniques are improving, disposal of the frames at the end of their life still poses a problem (CAT, 2007). The expected service life for PVC framed windows is around $25-40$ years (NGS, 2007).

Table 2-1 shows the thermal performance advantages that are achievable with the various glazing and frame technologies on the market today. 
Table 2-1: Approximate thermal effects of glazing technologies (Bennett \& Burgess, 2006)

\begin{tabular}{|c|c|}
\hline Technology & $\begin{array}{l}\text { Approximate increase in } \mathrm{R} \text {-value from the } \\
\text { base-case - combination of technologies } \\
\text { are not necessarily additive }\end{array}$ \\
\hline $4 \mathrm{~mm}$ clear glass in aluminium frame & Base case \\
\hline Composite frame & $5-20 \%$ \\
\hline Thermally broken $\mathrm{Al}$ frame & $20-40 \%$ \\
\hline PVC/timber frame & $30-50 \%$ \\
\hline Insulated fibreglass frame & $40-70 \%$ \\
\hline Engineered timber frames & $30-60 \%$ \\
\hline $6 \mathrm{~mm}$ clear glass & $5 \%$ \\
\hline Airtight weather-stripping & $10 \%$ \\
\hline Plastic panes & $10 \%$ \\
\hline Tinted glass & Nil \\
\hline Electrochromics & $0-70 \%$ \\
\hline Reflective glass & $-20 \%$ \\
\hline Spectrally selective glass & $0-20 \%$ \\
\hline Clear double glazing (IGU) & $70-100 \%$ \\
\hline Gas fill in an IGU & $105-120 \%$ \\
\hline Low emissivity glass in an IGU & $120-150 \%$ \\
\hline Vacuum in an IGU & $200 \%$ \\
\hline Triple glazing & $90-220 \%$ \\
\hline Warm edge spacers in an IGU & $105 \%$ \\
\hline Aerogel & $150 \%$ \\
\hline $\begin{array}{l}\text { SuperWindow (incorporating many of the } \\
\text { above) }\end{array}$ & $500 \%$ \\
\hline
\end{tabular}




\subsubsection{Retrofit Options}

For homes that have previously installed windows it is possible to improve the performance of the window by retrofitting them. A 'retrofit' is defined by the Penguin Dictionary of Building (Maclean \& Scott, 1993) as;

"To fit extra equipment or strengthening to an existing building."

Retrofitting existing windows can allow for an increase in thermal, acoustic or shading performance.

\subsubsection{Improving Airtightness}

Reducing infiltration through windows can be particularly effective on older model windows. Many old timber windows suffer from poor airtightness which results in excessive amounts of heat being lost to the outside. This is due to the window deteriorating over time and forming a less effective air seal. Draft stripping these windows with a rubber or foam strip to ensure that the sash forms a tight seal against the frame is a low cost exercise which can result in large energy savings. The performance increase varies depending on the original condition of the window and the performance of the seals.

\subsubsection{Thermal Curtains}

Thermal curtains vary from simple drapes with pelmets to insulated blankets which can be fully sealed around the window. The performance of the different styles varies greatly, however they are an affordable and decorative solution that can reduce space-conditioning energy consumption. As drapes typically require occupants to operate them, the advantages depend on the user's ability and behaviour regarding the opening and closing of them at specific times. 


\subsubsection{Glazing Films}

There are many different types of glazing films and coatings. Tinted and reflective films have the ability to lower light transmission to reduce solar heat-gain, limit glare, filter ultra-violet light and change the aesthetic appearance. Low emissivity films can reduce heat transfer. There are also films available to alter properties of the strength of glass to improve safety and security. Films can also provide more than one function. The range of reported performances of the various films and coatings is very wide. Examples are provided in the following table:

Table 2-2: Achievable performance with glazing films (BRANZ, 2001)

\begin{tabular}{|l|c|}
\hline Heat rejection & $30-80 \%$ \\
\hline Ultraviolet rejection & up to $99 \%$ \\
\hline Glare Reduction & 10 to $90 \%$ \\
\hline Visible light transmission & 6 to $63 \%$ \\
\hline Shading Coefficient & 20 to $80 \%$ \\
\hline
\end{tabular}

These films use water-activated or pressure-sensitive adhesives and should be applied to the window by a professional. Some problems which could arise from the application of films include the film deteriorating, fading, the edges lifting, or becoming scratched over time. It is also possible that the film may increase the risk of glass breaking due to thermal stresses, due to increased absorption of solar energy. This risk will vary depending on the type of film used and is a particular concern when the film is applied to the inside pane of an IGU. Increased expansion of the glass may also result in breaking the putty seals in older windows with hard putty (BRANZ, 2001).

\subsubsection{Shutters}

External shutters are another way to increase the performance of windows. They are very popular in hot climates as an effective measure to stop solar gain. Many shutters in these climates are louvered to block out solar gain but still allow light to enter. Solid shutters are more useful for thermal improvement and are often highly insulated to stop heat loss during the night. An insulated shutter with a resistance of 2 to 3 times that of a window will substantially alter the 
energy loss of that window, particularly at night when the home receives no solar radiation (Quirouette, 1980).

\subsubsection{Heat Loss through Windows}

Windows are often a thermally weak area in a building's envelope. While they allow for solar gains and the entry of daylight, their comparatively low thermal resistance causes them to be a large source of heat loss. On average, in a completely uninsulated dwelling, windows are accountable for $26 \%$ of the heat lost from the building. If the roof is insulated then windows are responsible for on average $35 \%$ of the heat loss while if the building is fully insulated (complying with NZS 4218:1996) then windows are responsible for 48\% of the average heat lost (Pollard, 2005). Windows are also responsible for a large amount of the air leakage in a building which makes up a further $7-13 \%$ of the heat lost, depending on the airtightness of the windows. This means that there is a lot that can be improved. Where a building has some insulation, then the percentage of heat lost through a particular element will depend on the level of insulation provided and will vary from the figures above.

During June and July the average amount of heat lost (mainly at night) through an uncurtained single glazed window in Wellington is about $1 \mathrm{kWh} / \mathrm{m}^{2}$ of glass per day, for typical double glazing the amount is $0.55 \mathrm{kWh} / \mathrm{m}^{2}$ (BRANZ, 1993). This heat loss would require the equivalent amount of heating to replace. Heat is lost through a window as a result of convection, conduction, radiation and air leakage around the frame. Heat is more readily lost and gained through the windows than through the rest of the house structure (BRANZ, 1993).

Despite the heat lost by glazing there is also the positive aspect of solar gain. Solar radiation which passes through the windows can heat up interior spaces. The heat gained (on average) from the sun during the day through windows on the north face of the building is greater than the heat lost from the window over the colder night period (BRANZ, 1993). In summer the additional solar radiation through the windows may lead to overheating. 


\subsection{Secondary Glazing}

Secondary Glazing is defined by the Penguin Dictionary of Building as (Maclean \& Scott, 1993):

"Double glazing formed by adding an extra pane of glass inside the existing glazing."

The dictionary then continues to explain how secondary glazing can be installed to wooden windows by the householder themselves using either synthetic rubber profiles, or with edging strips and clips (Maclean \& Scott, 1993).

This research found secondary glazing to be commonly referred to as 'internal windows' or 'indoor storm windows' in the United States and also occasionally called 'secondary windows' (Rayment \& Morgan, 1985), 'double windows' (Godfrey, 1972), 'non-sealed double glazing' (NRC, 1988) and 'secondary double glazing' (Childerstone, 1982).

There are a few ways to improve the performance of old windows without going to the expense of double glazing. A simple, cheaper alternative is to fit secondary glazing, which can be an additional glass or plastic sheet fitted on the inside of the existing frame, or an adhesive or magnetically-attached glass or plastic pane to fit to the frame, or just clear plastic film stuck to the interior frame (CAT, 2007). Secondary glazing is a typical home-owner's retrofit to single timber framed glazing, often made to control condensation. A second pane of glass is placed inside the sash and fixed to the frame with timber beading.

\subsubsection{History}

The first insulating glazing units originated in cold climate countries in the form of 'secondary glazing'. Typically, two panes of glass were puttied into a timber window frame, or two sashes were fixed together. This was cumbersome and condensation between the two panes or sashes was a problem (BRANZ, 2006). Before 1965, anything more than single-glazed glass was very rare, although there have been patents as early as the turn of the 19th century for welding the edges of two adjacent glass sheets to form insulating glass (Bennett \& Burgess, 2006). This 
research found many early patents for secondary glazing with the earliest being a removable secondary glazing system which had its patent first filed in July 1954 (Llyon, 1957). The patents for storm windows date back to the late 1800's. It is difficult to note a time when internal storm windows first became common however one patent was found in 1940 (Flynn, 1940). Plastic secondary glazing also appeared on the market very early as shown by this December 1959 issue of The Practical Householder magazine (Camm, 1959). While it is more difficult to identify the first use in New Zealand, documentation shows acoustic insulation tests performed on installed secondary glazed windows in 1973 (Thermosash, n.d.).
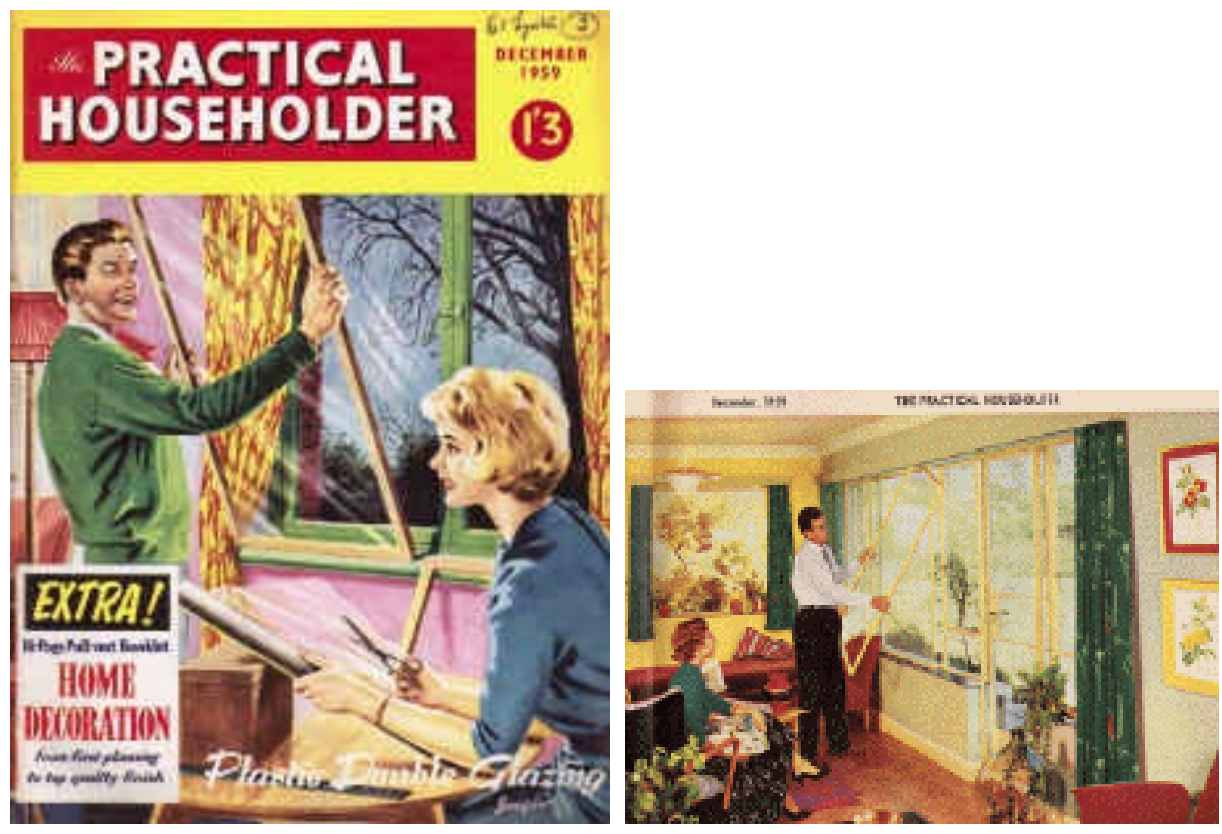

Figure 2-1 \& Figure 2-2: The Practical Householder, December 1959 (The Window Man, 2008)

\subsubsection{Various Products}

Secondary glazing comes in a variety of different forms. These different types can be categorised into 3 commonly used types:

- Thin Plastic Film

- Rigid Plastic Sheets

- Framed Secondary Glazing Windows

The differences between each of these three types are discussed in the following sections. 


\subsubsection{Thin Plastic Film}

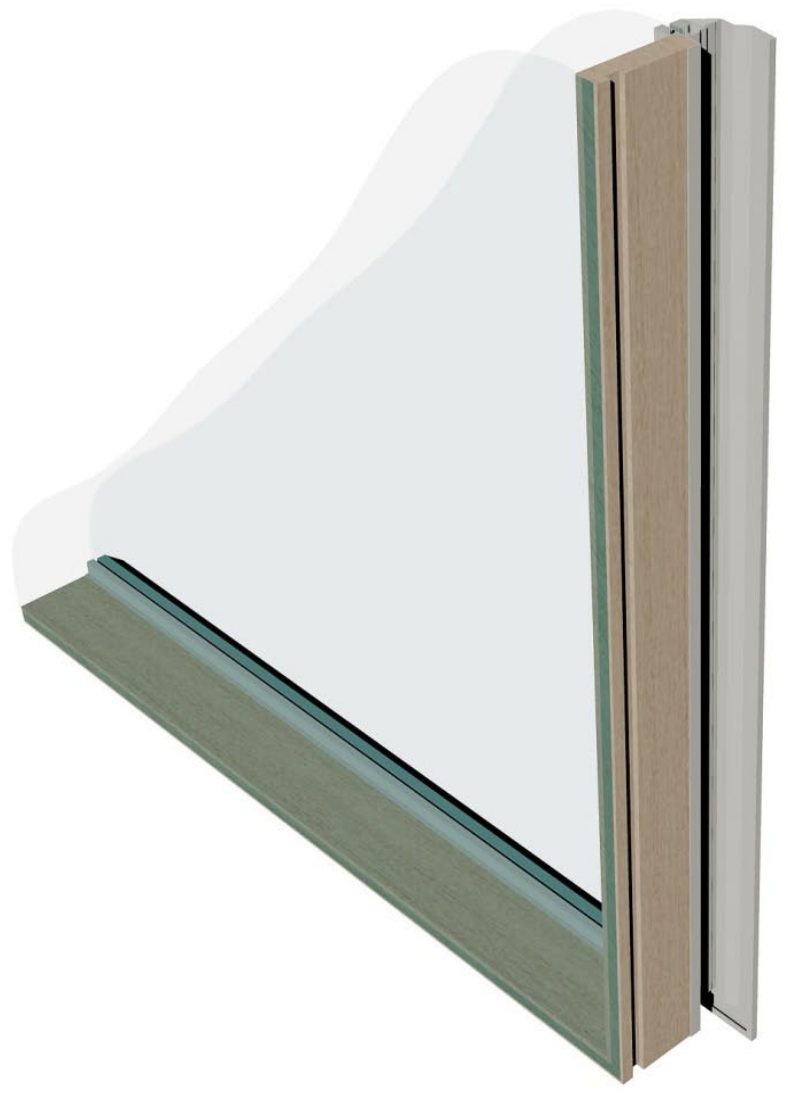

Figure 2-3: Thin Plastic Film

Thin plastic film is the simplest form of secondary glazing. It consists of a plastic sheet that is attached to the sash or frame of an existing window depending on the window type. The adhesive used is commonly double sided tape, although as this type of glazing is very much a DIY solution many variants can be used. The plastic sheet can range from cheap plastic film from the local hardware store to plastic sold packaged for the specific task. Plastic film sold for this specific purpose is designed to be shrunk when applied with heat from a hot air gun or a blow-dryer.

Often kits can be purchased consisting of removable double sided adhesive tape and clear plastic film. The kits are designed to be used for one heating season only, meaning that they need to be replaced annually. The kits are recommended to be removed at the end of winter and disposed of with a new kit attached at the beginning of the following heating season. The plastic is 
designed to be installed over the entire window. This prevents the window from being opened. In some timber windows it may be possible to install the plastic over the opening sash, leaving the window operable. It is also possible to install the plastic over separate, removable frames, allowing removal of the unit for cleaning and storage outside the heating season.

The advantage of this type of system is that it is very low cost and is marketed as a DIY solution resulting in no additional costs for labour. It can also stop condensation forming on the inner most pane, reduce infiltration and increase the thermal resistance.

Problems that can occur are that the plastic can discolour over time, the adhesive can fail and condensation can form between the plastic and the glass. When removed, the adhesive can peel off cracked or previously worn coatings. The plastic is also easily damaged or ripped.

\subsubsection{Rigid Plastic Sheets}

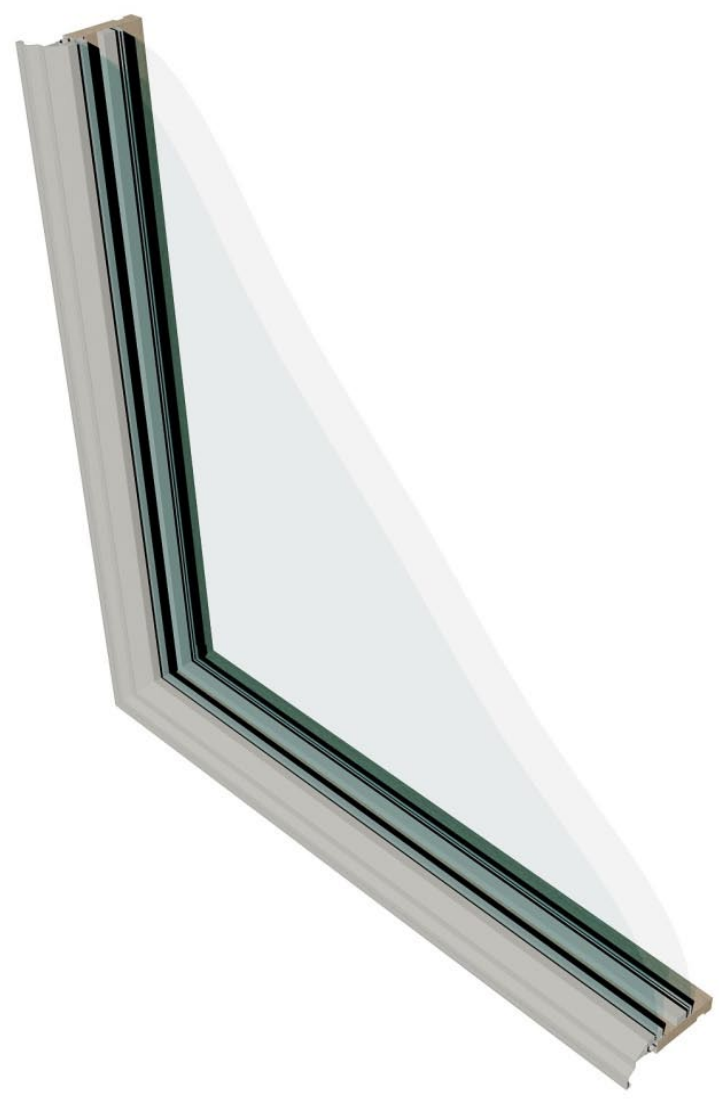

Figure 2-4: Thick Plastic Magnetically-attached Sheets 
A more permanent form of secondary glazing, acrylic sheets are much more durable than the plastic film. Rigid plastic sheets are also commonly used as a commercial retrofit, and can be fitted to aluminium frames, but some plastic is easily scratched and may lose transparency with exposure to UV (BRANZ, 1999). The most commonly used glazing plastics in building today are clear acrylics which are widely available and relatively cheap (Bennett \& Burgess, 2006). Other commonly used plastics are polycarbonate, polyvinyl chloride (PVC) and glass reinforced polyester (BRANZ, 1994). The thickness of the sheets can vary, but for glazing purposes they are typically a similar thickness to that of domestic glazing.

Thick plastic sheets commonly come with a small frame, often a small plastic clip on model. These are usually sold by specialist manufacturers who have various methods of installing them. Many choose to use adhesive magnetic strips allowing easy removal, while others have plastic brackets which are either fastened using screws or adhesive. Some of these systems are marketed as DIY, while other manufacturers will specify an installer. As such the price and performance of these systems can vary considerably. The panels are typically fixed to the sash of the window, allowing many types of windows to still be opened. The air gap in between the sheet and the window can be quite small but the systems can be mounted with spacers if they need the acoustic benefit that a larger air gap can provide. This acoustic benefit will be discussed further in section 4.3.2. 


\subsubsection{Framed Secondary Glazing Windows}

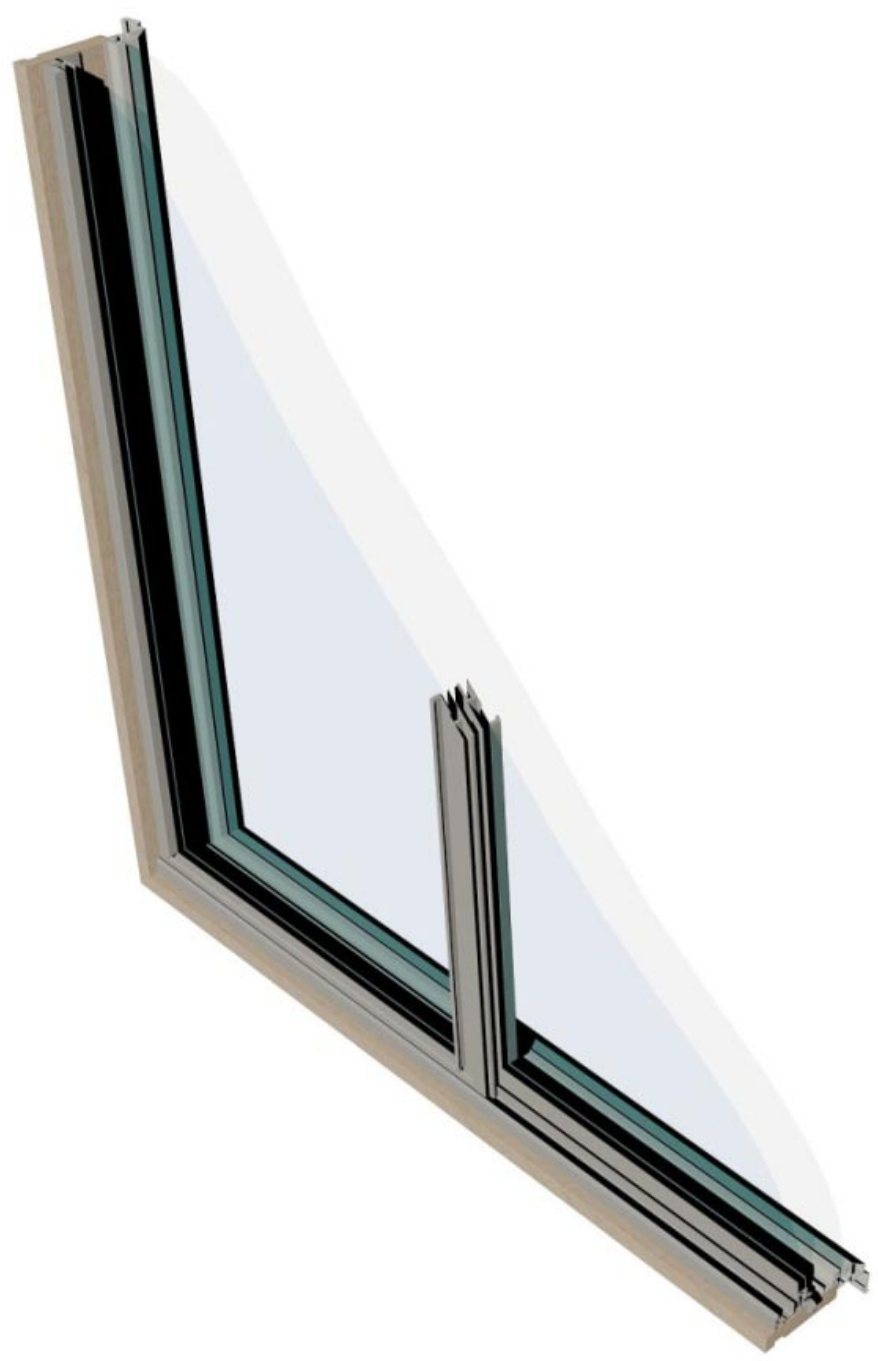

Figure 2-5: Secondary Glazing Windows

These are the most permanent style of secondary glazing. They consist of a rigid frame, typically either aluminium or timber beading, containing float glass. Aluminium frames need to be custom built by a window manufacturer. This allows other glass options such as low-E glazing to be used. If they are well looked after, these systems have the ability to last for long periods of time. Depending on the system used the secondary glazing can be detached or opened to allow for opening of the external windows and cleaning of the gap in between the two windows. Aluminium secondary glazing allows for large air gaps, giving it good thermal and acoustic properties. The downside to this type of system is that it is the most expensive to manufacture and install. 


\subsubsection{Performance}

When retrofitted into an existing window, secondary glazing is able to improve the performance of a variety of factors. Each of these factors is described in detail in the following sections. These descriptions are supported by relevant literature and prior research into secondary glazing.

\subsubsection{Thermal Performance}

As with double glazing the thermal resistance of secondary glazing depends on the size of the air gap as shown by the graph below.

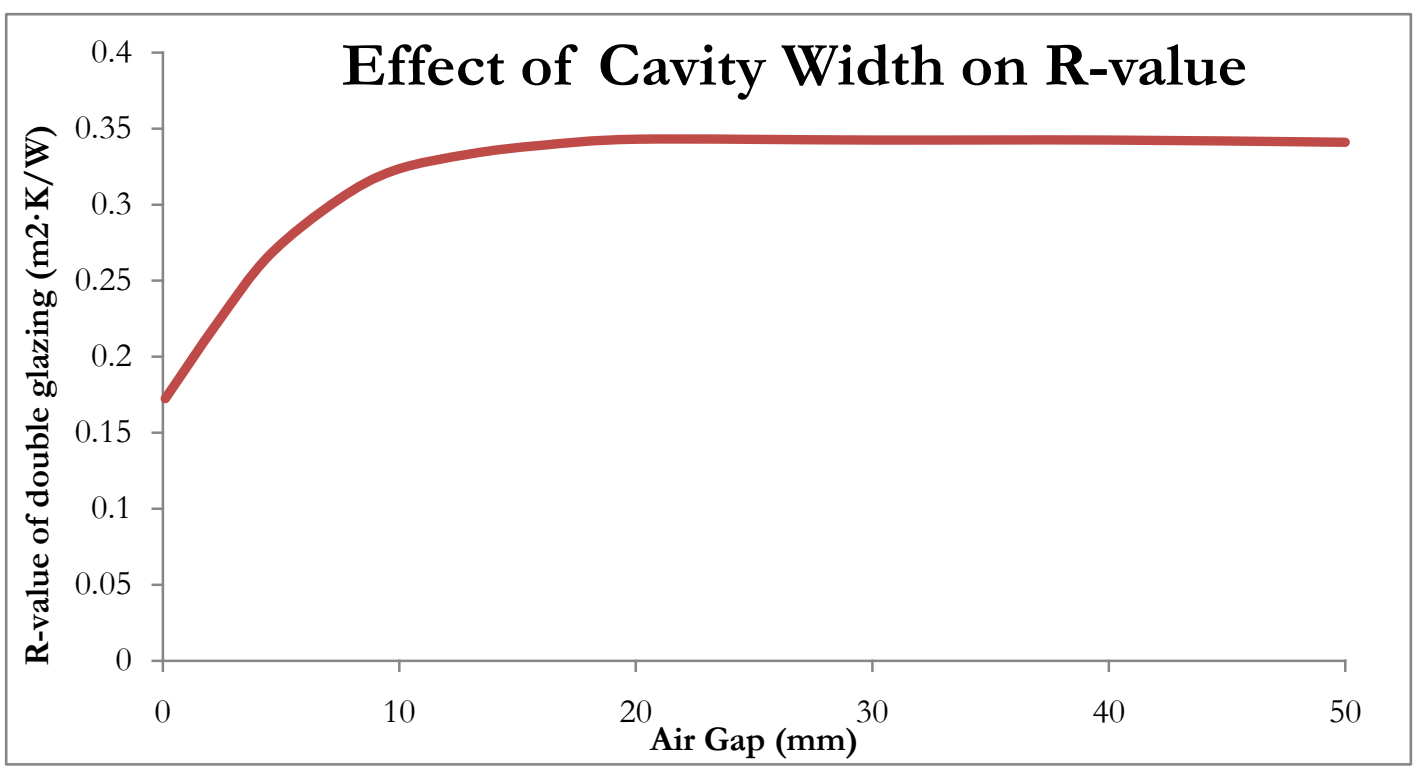

Figure 2-6: Effect of cavity Width on R-Value (Godfrey, 1972)

For best practice, a minimum $20 \mathrm{~mm}$ gap between existing and secondary glazing is required. In a timber window this results in an R-value of approximately $0.34 \mathrm{~m}^{2} \cdot \mathrm{K} / \mathrm{W}$ for the complete window, and in a metal window approximately $0.29 \mathrm{~m}^{2} \cdot \mathrm{K} / \mathrm{W}$ (Energy Savings Trust, 2006b). Of course much of the thermal resistance depends on the quality of the existing window. Secondary glazing increases the thermal performance of a window by creating a still air gap between the secondary glazing and the existing window frame (BRANZ, 2002). This still air gap provides the majority of the window's thermal resistance. A small additional amount of insulation is provided by the still air that 'sticks' to the outside of the panes and an even smaller amount comes from 
the thermal resistance of the glass itself (BRANZ, 1999). Figure 2-8 provides an example of how each of these changes improves the thermal resistance of a window.

The increase in the thermal resistance depends on the material, type and the air tightness of the existing frame as well as the type of secondary glazing used. It would be expected that typical Rvalues for secondary glazing vary depending on the product. Apart from the reduction in heat loss gained, the increase in surface temperature of the glass facing the room may improve the comfort, particularly of persons sitting or working near the windows due to reduced radiation losses and cold convection currents (BRE, 1993).

Thin film plastic secondary glazing has had very little research conducted into it; however a manufactured $3 \mathrm{M}^{\mathrm{TM}}$ Indoor Window Insulator Kit film claims to help lower energy costs by improving the R-value of a single pane window by $90 \%$ (3M, 2006). A study which saw it used to retrofit the living room of a state house in Otago found window plastic reduced heat loss by around $28 \mathrm{~W} / \mathrm{K}$, which resulted in the equivalent R-value of the plastic film windows to be 0.24 $\mathrm{m}^{2} \cdot \mathrm{K} / \mathrm{W}$ (Lloyd, Bishop, \& Callau, 2007). This is a 33\% improvement over the windows original R-value which was measured to be $0.16 \mathrm{~m}^{2} \cdot \mathrm{K} / \mathrm{W}$ (Lloyd \& Callau, 2006).

The Otago study also found the heat loss reduction of the plastic film to be the same as when thick acrylic sheets were used. As the acrylic sheets were only tested with a range of other changes and had a large margin of error, there is no guarantee that the performance of the two products is identical. Another possible reason for these findings is the study reported that after several months some of the magnetic strips didn't seal effectively, causing air infiltration between the acrylic and the windows which in turn caused condensation in the air gap. The study reports that the magnetic strips did not provide a sufficiently sealed air gap for good thermal performance (Lloyd, Bishop, \& Callau, 2007).

Acrylic Sheet Secondary glazing is the next step and can vary between manufacturers. New Zealand based 'MagicSeal' claims that their magnetically-attached acrylic sheet secondary glazing has an R-value of $0.37 \mathrm{~m}^{2} \cdot \mathrm{K} / \mathrm{W}$ (MagicSeal, 2007). This R-value was manually calculated using a method similar to that prescribed by Section 7.2 of NZS: 4214 (MagicSeal, n.d.). 
WERS certification is calculated using the computer window modelling programs; Window 5, Optics 5 and Therm 5 (WERS, 2008b). WERS certification calculated an Australian magnetically-attached acrylic sheet product 'Magnetite' to produce a whole window R-value of $0.37 \mathrm{~m}^{2} \cdot \mathrm{K} / \mathrm{W}$ when used in conjunction with a cedar awning window where the air gap between the two sheets of glazing is $68 \mathrm{~mm}$. This was an $81 \%$ improvement for heating over the standard $3 \mathrm{~mm}$ timber window. When used in an aluminium framed window there was only a $40 \%$ increase for heating giving an R-value of $0.22 \mathrm{~m}^{2} \cdot \mathrm{K} / \mathrm{W}$ (WERS, 2008c). Initial WERS studies conducted by Dr. Peter Lyons found Magnetite able to produce R-values as high as $0.4 \mathrm{~m}^{2} \cdot \mathrm{K} / \mathrm{W}$ (Magnetite, 2006).

Selectaglaze of the UK manufacture a variety of fixed internal aluminium framed units. The Centre for Window Cladding and Technology (CWCT) calculated R-values for their full range of secondary windows in combination with existing single glazed windows constructed from different materials with various air gaps. The R-values for these products ranged from 0.38 to $0.34 \mathrm{~m}^{2} \cdot \mathrm{K} / \mathrm{W}$ when using standard glass and then from $0.51-0.56 \mathrm{~m}^{2} \cdot \mathrm{K} / \mathrm{W}$ when used in conjunction with low-E glass and finally $0.59-0.63 \mathrm{~m}^{2} \cdot \mathrm{K} / \mathrm{W}$ when used with double glazed units (Selectaglaze, 2008a). The CWCT calculated the thermal transmittance of these windows using the standards BS EN ISO 10077-1:2000 Thermal performance of windows, doors and shutters. Calculation of thermal transmittance. Simplified method and BS EN ISO 10077-2:2003 Thermal performance of windows, doors and shutters. Calculation of thermal transmittance. Numerical method for frames.

Another advantage of framed secondary glazing is the ability to use it in conjunction with low-E glass. This further reduces the heat loss of the window. A test-cell measurement of an interior low-E storm window found it to have an R-value of $0.42 \pm 0.05 \mathrm{~m}^{2} \cdot \mathrm{K} / \mathrm{W}$, a significant improvement from the original windows R-value of $0.23 \pm 0.07 \mathrm{~m}^{2} \cdot \mathrm{K} / \mathrm{W}$ and only $0.05 \mathrm{~m}^{2} \cdot \mathrm{K} / \mathrm{W}$ less than replacing the original window with a low-E argon filled IGU (Klems, 2003). A study in the United States found storm windows to provide a 100\% performance increase to a single glazed timber window, while low-E storm windows were able to provide a $158 \%$ increase. This study recommends the use of low-E glazing over clear glazing within storm windows (Mattinson, DePaola, \& Arasteh, 2002). A field evaluation of low-E storm windows has recently been conducted by Craig Drumheller in Chicago. The project looked at the energy savings and payback period for storm windows with both clear glass and low-E glass. The low-E storm 
windows were 30\% more expensive than the clear glass models although they had an average payback period of 4.3 years in comparison with 10.3 years for the clear glass (Anonymous, 2008).

The thermal resistance improvement to a building's envelope also results in a decrease in energy required to heat and cool the dwelling. Rather than measure or calculate the R-value of a secondary glazed window, another method to assess the performance is to measure the energy savings provided by a secondary glazing retrofit. The United Kingdom Building Research Establishment measured these energy savings by retrofitting two semi-detached three bedroom, $56 \mathrm{~m}^{2}$ houses built in the late 1960s using conventional English brick-cavity-block construction. The houses used simulated occupancy to provide a controlled estimate on energy consumption and various heat gains (Rayment \& Morgan, 1985). They were located in Watford which is subject to a similar summer (although with more extreme low temperatures) when compared to New Zealand. The results demonstrated a mean reduction in energy consumption of 12 per cent ( \pm 3 per cent, 95 per cent confidence limits) for secondary glazing in these houses (Rayment \& Morgan, 1985). A retrofit study in suburban Washington D.C. found that retrofitting an uninsulated house with timber framed storm windows produced energy savings for space conditioning of $25.2 \%$ (Burch \& Hunt, 1978).

Following the completion of the results for this research, a New Zealand specific cost benefit analysis of a large variety of retrofit options was published (Page, 2009). Among the retrofit options explored was aluminium-framed secondary glazing. The study simulated the retrofit options under four New Zealand climates and concluded that secondary glazing was only a cost effective retrofit option in Invercargill.

\subsubsection{Acoustic Performance}

The acoustic insulation of windows can be simply improved by increasing the thickness of the glass or using laminated glazing (Lilly, 2004). A substantial improvement can be achieved more easily by using a double pane construction. In this case, it is essential that the air gap between the panes is wide enough to give the required insulation at low frequencies and that operable windows are well sealed (BRE, 1993). Wider air spaces for acoustic control are more easily 
incorporated into secondary glazing than into IGUs and secondary glazing is often used specifically for sound control (BRANZ, 1999).

For secondary window systems, the air in the cavity behaves like a spring and causes a resonance which reduces the transmission at low frequencies. A wide cavity reduces the frequency at which this resonance occurs and, although the width is not critical, $100 \mathrm{~mm}$ is generally considered to be the smallest space that gives a worthwhile improvement (Turner, 1971). For sound below the resonant frequency of the window, the benefit of two leaf construction is lost. Flexible edgemounting of the glass, e.g. in neoprene gaskets, can also improve insulation by damping resonances of the glass panes (BRE, 1993).

Wide air spaces between panes of $100 \mathrm{~mm}$ or more and laminated glass are effective in reducing the transmission of noise. An IGU cannot be satisfactorily manufactured with a $100 \mathrm{~mm}$ or greater air space. Therefore, for acoustic attenuation, secondary glazing is a more appropriate approach (BRANZ, 1999). Figure 2-7 shows the typical acoustic performance of three different window systems. The base is a typical $4 \mathrm{~mm}$ single glazed window. The IGU consists of a 6-12$6^{1}$ unit in a PVC-U frame and the secondary glazing is able to be opened and uses a large 4-2004 system with absorbent reveals.

\footnotetext{
${ }^{1}$ This standard description gives the thickness of the glass $(6 \mathrm{~mm})$ followed by the thickness of the gap $(12 \mathrm{~mm})$ and then the thickness of the next piece of glass $(6 \mathrm{~mm})$.
} 
water vapour in the air is less likely to form condensation on the interior glazing surface. This is because the window surface temperature is more likely to be above the dew point of the air. One problem with secondary glazing however is that, when the secondary glazing is closed, normal room air is trapped between the double glazing space, this having the same dew point as the room air. One of the effects of secondary glazing is to substantially reduce the temperature of the inner surface of the original single glazing, thus greatly increasing the risk of condensation in between the panes. As glazing has very little thermal mass, the surface temperature of the glass can be calculated using the following thermal transmittance calculations.

Equation 2-1: Surface Temperature Calculation (Richardson, 2001)

$R=R_{S_{i}}\left(T_{i}-T_{o}\right) /\left(T_{i}-t_{i}\right)$

$\mathrm{R}=\mathrm{R}$-value of the window in $\mathrm{m}^{2} \cdot \mathrm{K} / \mathrm{W}$

$\mathrm{R}_{\mathrm{Si}}=$ Internal surface resistance of the inner pane $=0.123 \mathrm{~m}^{2} \cdot \mathrm{K} / \mathrm{W}$ (High emissivity glass)

$\mathrm{T}_{\mathrm{i}}=$ Internal temperature $\left({ }^{\circ} \mathrm{C}\right)$

$\mathrm{T}_{\mathrm{o}}=$ External temperature $\left({ }^{\circ} \mathrm{C}\right)$

$\mathrm{t}_{\mathrm{i}}=$ Internal glazing temperature $\left({ }^{\circ} \mathrm{C}\right)$

Therefore

$t_{i=} \quad\left(R \cdot T_{i}\right)-\left(R_{S i} \cdot T_{i}\right)+\left(R_{S i} \cdot T_{o}\right)$

$\mathrm{R}$

If it is assumed that the internal air in a room has a temperature of $20^{\circ} \mathrm{C}$ and the external air has a temperature of $0^{\circ} \mathrm{C}$ during winter conditions, the internal surface temperature of single glazing with an $\mathrm{R}$-value of 0.18 would be $6.3^{\circ} \mathrm{C}$.

\section{Equation 2-2: Internal Surface Temperature of Single Glazing}

$\mathrm{t}_{\mathrm{i}}=\quad\left(0.18^{\mathrm{x}} 20\right)-\left(0.123^{\mathrm{x}} 20\right)+\left(0.123^{\mathrm{x}} 0\right)$

$\mathrm{t}_{\mathrm{i}}=6.3^{\circ} \mathrm{C}$

If the calculations are repeated for secondary glazing with an air gap in excess of $20 \mathrm{~mm}$, the temperature of the secondary glazing surface in contact with the room is $13.2^{\circ} \mathrm{C}$, considerably 
warmer because of the improved thermal insulation value of the secondary glazing and therefore reducing the risk of condensation on this surface.

\section{Equation 2-3: Internal Surface Temperature of Secondary Glazing}

$\mathrm{t}_{\mathrm{i}}=\quad\left(0.36^{\mathrm{x}} 20\right)-\left(0.123^{\mathrm{x}} 20\right)+\left(0.123^{\mathrm{x}} 0\right)$

$\mathrm{t}_{\mathrm{i}}=13.2^{\circ} \mathrm{C}$

However, the inner surface of the original single glazing is now isolated from the warmth of the room and now only has a temperature of $3.2^{\circ} \mathrm{C}$, so that the risk of condensation on the inner surface of the original glazing is enormously increased by the installation of the secondary double glazing.

This temperature can be calculated by adding together each resistance to determine the whole window R-value using Equation 2-4:

\section{Equation 2-4: Secondary Glazing R-value Calculation}

$\mathrm{R}=\mathrm{R}_{\mathrm{Si}}+\mathrm{R}_{\mathrm{G} 1}+\mathrm{R}_{\mathrm{C}}+\mathrm{R}_{\mathrm{G} 2}+\mathrm{R}_{\mathrm{So}}$

$\mathrm{R}=\mathrm{R}$-value of the window in $\mathrm{m}^{2} \cdot \mathrm{K} / \mathrm{W}$

$\mathrm{R}_{\mathrm{Si}}=$ Internal surface resistance of the inner pane $=0.123 \mathrm{~m}^{2} \mathrm{~K} / \mathrm{W}$ (High emissivity glass)

$\mathrm{R}_{\mathrm{So}}=$ External surface of the outer pane $=0.055 \mathrm{~m}^{2} \cdot \mathrm{K} / \mathrm{W}$ (High emissivity glass, normal conditions)

$\mathrm{R}_{\mathrm{G} 1} \& \mathrm{R}_{\mathrm{G} 2}=$ Resistance of the glass $=0.003 \mathrm{~m}^{2} \cdot \mathrm{K} / \mathrm{W}$ ( $3 \mathrm{~mm}$ clear glass)

$\mathrm{R}_{\mathrm{C}}=$ Resistance provided by the cavity $=0.176 \mathrm{~m}^{2} \cdot \mathrm{K} / \mathrm{W}$ (Width in excess of $20 \mathrm{~mm}$ )

$\mathrm{R}=0.123+0.003+0.176+0.003+0.055$

$\mathrm{R}=0.36 \mathrm{~m}^{2} \cdot \mathrm{K} / \mathrm{W}$

Assuming that the heat loss across each of these elements is directly related to the resistance of each aspect, it is possible to determine how much heat is transferred to the outside by knowing the indoor and outdoor temperatures. This equation is presented in the following table. 


\section{Equation 2-5: Heat-Loss across a Secondary Glazed Window}

$\mathrm{R}=0.123+0.003+0.176+0.003+0.055=0.36$

\section{Resistance \& Heat-Loss Across a Secondary Glazed Window}

\begin{tabular}{|l|l|l|l|l|l|l|}
\hline & & Rsi & Rg1 & Rc & Rg2 & Rso \\
\hline Resistance & & 0.123 & 0.003 & 0.176 & 0.003 & 0.055 \\
\hline Cumulative Resistance & 0 & 0.123 & 0.126 & 0.302 & 0.305 & 0.360 \\
\hline Percentage & $0 \%$ & $34 \%$ & $35 \%$ & $84 \%$ & $85 \%$ & $100 \%$ \\
\hline & Inside & $\begin{array}{l}\text { Inner Pane } \\
\text { (Internal) }\end{array}$ & $\begin{array}{l}\text { Inner Pane } \\
\text { (Cavity) }\end{array}$ & $\begin{array}{l}\text { Outer Pane } \\
(\text { Cavity })\end{array}$ & $\begin{array}{l}\text { Outer Pane } \\
(\text { Outside) }\end{array}$ & Outside \\
\hline Temperature & $20^{\circ} \mathrm{C}$ & $13.2^{\circ} \mathrm{C}$ & $13.0^{\circ} \mathrm{C}$ & $3.2^{\circ} \mathrm{C}$ & $3.1^{\circ} \mathrm{C}$ & $0.0^{\circ} \mathrm{C}$ \\
\hline
\end{tabular}

The table above presents the resistance of each element of a secondary glazed window $\left(\mathrm{m}^{2} \cdot \mathrm{K} / \mathrm{W}\right)$. The cumulative resistance shows how the resistance of each element adds together to provide the total thermal resistance of the window, in this example it is $0.36 \mathrm{~m}^{2} \cdot \mathrm{K} / \mathrm{W}$. The percentage shows the proportion of resistance each element provides to the total resistance of the window. This percentage is related to the heat-loss across the window. As such the temperature of each surface can be calculated. In this example the internal temperature is $20{ }^{\circ} \mathrm{C}$ and the external temperature is $0{ }^{\circ} \mathrm{C}$. This transfer of heat has been presented in a visual form on Figure 2-8. 


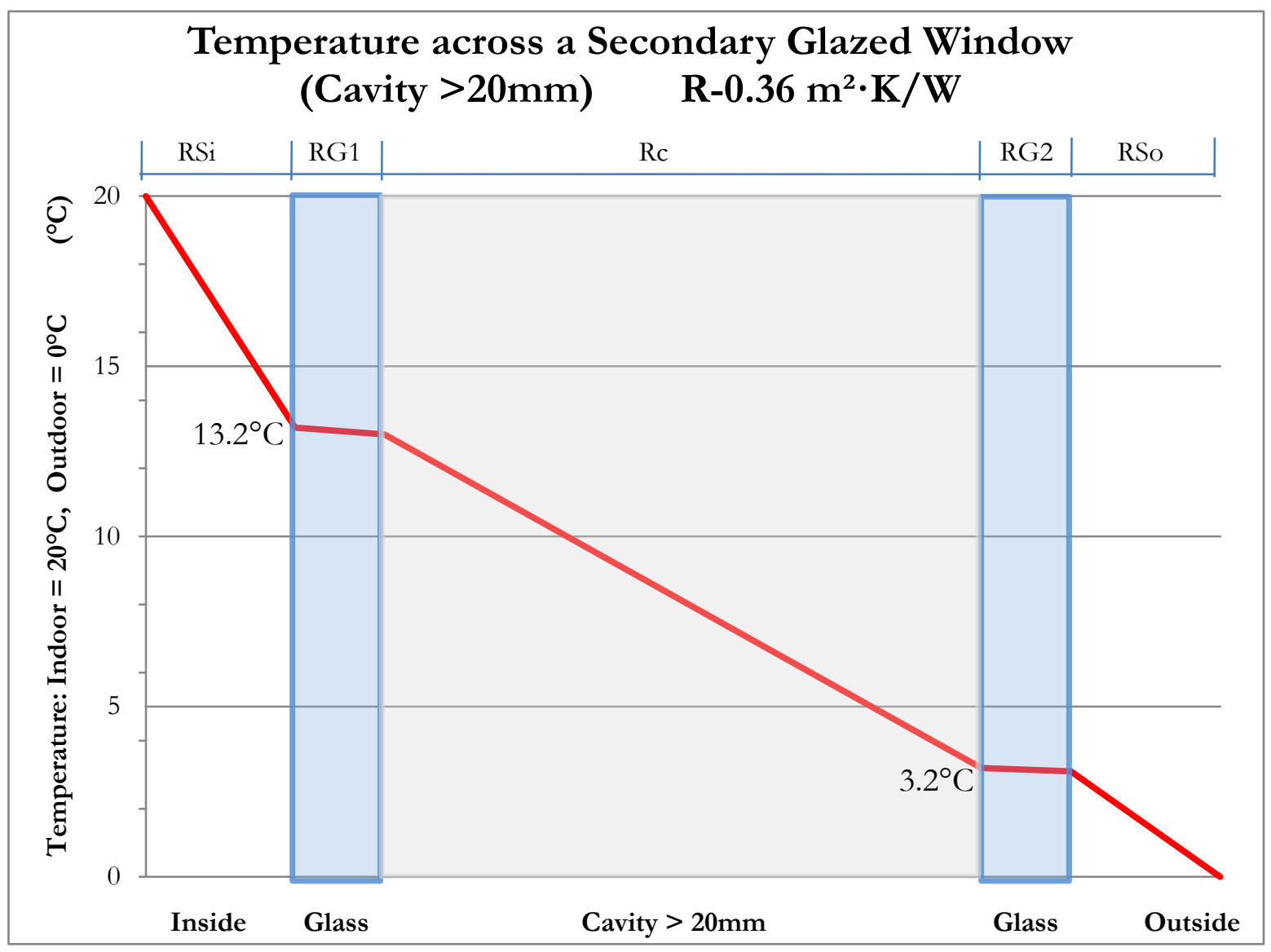

Figure 2-8: Temperature across a Secondary Glazed Window Cavity

Manufacturers of secondary double glazing do not usually appreciate these dangers and often make grossly misleading claims in relation to the condensation-reducing benefits of their system. In fact, the danger of condensation within the air gap can only be reduced by ensuring that both the original windows and the secondary double glazing are efficiently sealed, and providing a desiccant within the air gap to reduce the humidity and hence dew point of the trapped air (Richardson, 2001).

Alternatively, the space between the panes of glass can be ventilated to the outside air to prevent condensation forming on the inside of the outer pane (BRANZ, 1993). If the secondary glazing is permanently fixed to the window then the cavity needs breather holes to the outside to prevent condensation on the outer pane. The secondary glazing would still need to be removed for cleaning about once a year (Maclean \& Scott, 1993). It is recommended that this is done with one $3 \mathrm{~mm}$ diameter hole per $\mathrm{m}^{2}$ of glass and the airspace should not be vented to the inside as warmer, moist inside air will readily mist up the inter-pane space (BRANZ, 1999). Another suggestion is to drill a $6 \mathrm{~mm}$ hole per $0.5 \mathrm{~m}^{2}$ of window. The holes should then be plugged with 
an air-permeable material such as glass fibre insulation or nylon to exclude dust or insects. The secondary glazing should be installed under relatively dry conditions (preferably in cold weather) to prevent trapping humid air in the airspace and the internal glazing should be sealed as effectively as possible (BRE, 1993).

The use of curtains also has a similar effect of increasing the risk of condensation on a window. When curtains are closed the air temperature on the inside of the innermost pane of glass is reduced. The curtains are permeable to the water vapour in the warm inside air which then condenses when it comes into contact with the cold glass.

\subsubsection{Airtightness}

Another performance benefit of secondary glazing is that it can reduce the air infiltration through the existing window frames. As older operable windows begin to deteriorate they become susceptible to air leakage. Air leakage contributes to $10-17 \%$ of heat loss in a fully insulated house and 6-9\% in an uninsulated house (Pollard, 2005). A New Zealand study found that the airtightness of a house could be improved by 30\% by taping all the opening joints on timber windows (Bassett, 1996). This 30\% decrease would provide a $2-3 \%$ decrease in heat loss of an uninsulated building or a $3-5 \%$ percent decrease for an insulated building. Sealed secondary glazing units fixed to the timber reveal, and not the sash, could potentially have a comparable effect. A United States study on retrofitting timber windows with storm windows conducted airtightness tests before and after installation. The airtightness results are presented on the table below.

Table 2-3: Before and After Airtightness Results (Drumheller, Kohler, \& Minen, 2007)

\begin{tabular}{|c|l|l|r|}
\hline House & $\begin{array}{l}\text { Before Storm Windows } \\
\left(\mathbf{M}^{3} / \mathbf{h r} \text { at } \mathbf{5 0} \mathbf{~ P a}\right)\end{array}$ & $\begin{array}{l}\text { After Storm Windows } \\
\left(\mathbf{M}^{3} / \mathbf{h r} \text { at } \mathbf{5 0 ~} \mathbf{~ P a}\right)\end{array}$ & \multicolumn{1}{l}{ \% Reduction } \\
\hline 1 & 8,891 & 8,381 & $5.7 \%$ \\
\hline 2 & 8,090 & 7,580 & $6.3 \%$ \\
\hline 3 & 5,370 & 4,930 & $8.2 \%$ \\
\hline 4 & 8,381 & 7,812 & $6.8 \%$ \\
\hline 5 & 6,103 & 5,710 & $6.4 \%$ \\
\hline 6 & 6,545 & 5,984 & $8.6 \%$ \\
\hline
\end{tabular}

Nick Smith 
On average the installation of storm windows reduced the air leakage of the houses by $7 \%$. The study noted that while reduced infiltration is not a direct benefit of the second pane of glass, it appears to be a consistent and repeatable improvement in the homes' performance, reducing infiltration by $15-43 \mathrm{~m}^{3} / \mathrm{hr}$ per window under the test conditions (Drumheller, Kohler, \& Minen, 2007).

One study tested the air leakage of two old timber windows before and after the retrofit of external storm windows over a variety of pressure levels. It found that the installation of external storm windows reduced the infiltration of each window by $82 \%$ and $63 \%$ respectively (Desjarlais, Childs, \& Christian, 1998). The same study also conducted extensive maintenance of the first window to increase the airtightness. They found that the maintenance was somewhat less successful at improving the airtightness than adding a storm window (Turrell, 2000).

\subsubsection{Safety \& Security}

Secondary glazing also has the ability to increase the safety and security of a dwelling. The second layer of glass is able to be safety glass, which makes it harder to break the glass, and helps to prevent intruders from entering the building. This could even be blast proof glass, bullet proof glass or fire resistant glass. These products are often similar sizes to typical glazing and once specified, would be able to be used in fixed frame aluminium secondary glazed windows. Selectaglaze UK manufacture secondary glazing units with the ability to achieve increased performance in physical attacks, bomb blasts, ballistic attacks and fire. To prove this they have had their products tested to a variety of standards for each of the issues (Selectaglaze, 2008b).

\subsubsection{Historic Retrofits}

Another use of secondary glazing is for retrofitting historic buildings. Many of these buildings have windows which must remain to preserve the aesthetic of the original building. Other homeowners may just wish to retain the aesthetic of their timber windows. This makes replacement of windows with IGUs difficult and expensive. Historic timber is likely to be of better quality than modern replacements. Repair and draught-proofing or secondary glazing can 
be a viable alternative and retains the historic appearance of the house (Norfolk County Council, 2007).

\subsubsection{Life Cycle Assessment}

The embodied energies of glazing products are high. Float glass has an embodied energy of 15.9 $\mathrm{MJ} / \mathrm{kg}$ (BRANZ, 2007). The embodied energy for plastics varies depending on the type but these are even higher still (VUW, 1999). Despite this, an aluminium framed secondary glazing system still uses less embodied energy than a replacement IGU due to the simpler manufacturing process and the smaller amount of glass and aluminium required. On the other hand, a Life Cycle Assessment (LCA) of secondary glazing may not be as good as an IGU due to increased operating energy use.

It is often assumed that by replacing old, sound windows with double glazing, an overall energy saving can be achieved. A Norwegian life cycle assessment (Fossdal, 1996) compared the impacts of replacing old windows with new double glazing units, with inert gas filled double glazing fitted with low energy glass, and fitting the existing windows with secondary glazing. All units had wooden frames. The smallest overall impact (manufacturing impacts balanced against energy savings in use) was shown if existing windows were supplied with a single glazed secondary glazing, followed by old windows supplied with double glazed secondary glazing (Woolley \& Kimmins, 2000). Impacts were expressed in terms of fossil fuel consumption, global warming potential, acidification, photo-oxidant formation and eutrophication over a 90 year period. However it was assumed that the building was heated by electricity generated by hydropower with no emissions to air as around the time of this study Norway was producing over $100 \%$ of their electricity from renewable recourses with a part of the domestic generation exported to other countries (EEA, 2008). This is not representative of New Zealand, where around 64\% of New Zealand's electricity production is from renewable resources such as hydropower, geothermal, and wind (Statistics New Zealand, 2006). Thus for many countries, this Norwegian analysis will include a severe underestimate of the additional environmental costs incurred by the higher R-values of secondary glazing compared to low energy double glazing. Therefore, in countries relying on fossil fuels for heating, the energy and pollution balance for secondary glazing will be different (Woolley \& Kimmins, 2000). Should the same embodied energy and saved energy values be used with a New Zealand energy model where only $64 \%$ of the energy is

Nick Smith 
generated by renewable sources, double glazed secondary glazing would be the most energy efficient. This is followed by single glazed secondary glazing, argon filled double glazing with low-E glass and finally, coupled double glazed windows.

\subsubsection{Building Consent}

One advantage of secondary glazing is that a building consent is not required to attach secondary glazing to existing window frames. As a result of this secondary glazing may be a more affordable and easily achieved retrofit option when compared to replacing entire windows with double glazed equivalents, which may be more expensive and can also require a building consent. Research conducted by BRANZ has found that not everyone in the industry is in agreement about whether retrofitting with double glazed windows needs a building consent (Burgess, 2008).

\footnotetext{
"Installers generally considered the replacement of windows as 'like for like' and 'a maintenance issue' rather than a building and structural modification issue. The building consent authority considered the replacement of windows to be a modification to the exterior envelope of the house and therefore required consent for at least weathertightness reasons. BRANZ also recommends obtaining a building consent in these situations."
}

Schedule 1 of the Building Act 2004 outlines that a building consent is not required for (Building Act, 2008):

\footnotetext{
"any lawful repair and maintenance using comparable materials, or replacement with a comparable component or assembly in the same position, of any component or assembly incorporated or associated with a building Except complete or substantial replacement of a specified system.”
}

This means that if an existing window is in need of repair it could be replaced by a double glazed window of the same size in the same position. The replacement of a substantial amount of windows in a house however would not be exempt from a building consent. 
Another advantage of secondary glazing is that it can be carried out completely from inside the property. This makes it very useful for taller buildings where external access to windows can become difficult, expensive and potentially dangerous. Taller buildings will often require scaffolding to access the windows when replacing the window with an IGU. Scaffolding is not considered a "building" in the Building Act and as such a Building Consent is not required, however the additional time and cost of erecting scaffolding along with the required health and safety precautions greatly increases the price of replacing windows.

\subsubsection{Cost}

One large advantage of secondary glazing is its low cost. Basic plastic film kits are the lowest cost item available. The most affordable kit comes in at around just less than $\$ 2$ per $\mathrm{m}^{2}$. These kits contain the plastic film as well as the double-sided tape and are manufactured by $3 \mathrm{M}$. Sometimes DIY stores in New Zealand sell a limited number of the kits (Environment Canterbury, 2008). They are also available from stores online (Sustainable Design, 2008) (CEA, 2008b).

Table 2-4: Cost of Plastic Thin Film Secondary Glazing Kits (CEA, 2008b)

\begin{tabular}{|l|c|c|c|}
\hline Size & Dimensions in Metres & Length of Tape & Price / Kit \\
\hline Small & $1.07 \times 1.57$ metres & 5.49 metres & $\$ 9.50$ \\
\hline Large & $2.13 \times 3.05$ metres & 10.59 metres & $\$ 13.40$ \\
\hline Long & $1.57 \times 5.33$ metres & 27.40 metres & $\$ 16.20$ \\
\hline
\end{tabular}

A Housing New Zealand Corporation commissioned report looking at retrofit alternatives tested both thin plastic sheet and magnetically-attached acrylic sheet secondary glazing. For these retrofit options the project only investigated the living room, which had a window size of $8.79 \mathrm{~m}^{2}$ and a floor area of $18.08 \mathrm{~m}^{2}$ (Lloyd \& Callau, 2006). The project found that thin film plastic cost $\$ 50$ or $\$ 5.70 / \mathrm{m}^{2}$, while magnetically-attached acrylic sheet secondary glazing cost $\$ 934$ or $\$ 106.30 / \mathrm{m}^{2}$ (Lloyd, Bishop, \& Callau, 2007). It is important to note that while they are cheaper, the thin film plastic sheet windows are only recommended to be used for one heating season. It would take 19 years for the cost of the thin film plastic secondary glazing to exceed the cost of the magnetically-attached acrylic sheet glazing. The plastic film has been known to last for more than one year if it is treated with care, particularly when used on fixed lites.

Nick Smith 
Full aluminium framed secondary glazing kits are more expensive than the plastic sheet kits as they need to be manufactured to fit the house and be installed by a professional. While secondary glazing used to be supplied and installed by a builder, for many years now it has become normal practice to employ a specialist firm to supply and fix complete (Cooper \& Buckland, 1985). A quote for a $1 \mathrm{~m}$ x $1 \mathrm{~m}$ secondary glazed window installed in Wellington, New Zealand found the prices to be $\$ 374.29$ for clear $4 \mathrm{~mm}$ glass or $\$ 574.29$ for low-E glass (Fisher, 2008).

\subsection{Performance Evaluation}

\subsubsection{Full Scale Testing}

Full scale testing monitors the performance of the windows by installing them within a test building, a test cell or a test box. The full scale tests are conducted using observation and analysis. Observation often involves data collection that can be as simple as the manual reading of a thermometer or as complex as the collection of comprehensive data sets using sophisticated electronic sensors and computerised data logging equipment (Skates, 2006).

There are a variety of different methods which can be used to undertake this. The most commonly used experiments for retrofit studies are on - off experiments, before - after (B-A) experiments, test reference (T-R) experiments and simulated occupancy experiments (Fracastoro \& Lyberg, 1983). On - off experiments are useful for monitoring the changes of an introduced or modified system such as an HVAC system and are not relevant to this research.

Before - After experiments measure the temperatures and/or energy use of test modules prior to retrofit and then once again after the retrofit installation. The test period can vary in length; however climate variables such as external temperatures and solar radiation must be taken into account in order to draw conclusions from the data. Should occupants be involved in the B-A experiment it is likely that their behaviour will not be consistent. The introduction of the retrofit may alter the occupant's expectations of the future performance of the building. Such expectations may lead to a change in the behaviour and attitudes of the occupants which may affect the outcome of the experiment (Fracastoro \& Lyberg, 1983). Examples of before and after 
experiments being used to monitor secondary glazing can be found in (Lloyd, Bishop, \& Callau, 2007) and (Burch \& Hunt, 1978).

Test reference experiments rely on access to at least two test modules. One of the test modules remains standard while the other test module receives the retrofit measure. The environmental conditions and or the energy consumption between the two modules can then be compared and analysed. The advantage of test reference experiments over Before - After experiments is that the climatic conditions during the test period will be the same.

Aside from the retrofit, the buildings need to be as identical as possible. In practice this can be achieved with test boxes and test cells, although it is often difficult with houses. Therefore one will have to compare the temperatures and or energy consumption before the retrofit (the calibration phase) and after the retrofit (the comparison phase) (Fracastoro \& Lyberg, 1983). Once again if occupants are involved then obtaining accurate results will be very difficult due to the differences between the occupants of the different buildings. Examples of this type of experiment being used to measure the benefits of secondary glazing can be found in (Klems, 2003) and (Rayment \& Morgan, 1985).

Simulated occupancy tests allow for more accurate data collection by removing one of the largest variables of an experiment, the occupant. Inside the building occupant behaviours such as heating and cooling patterns, plug loads and even window operation are recreated using schedules to replicate behaviour of occupants without variables. These experiments allow for energy consumption and temperature variations with and without the retrofit to be monitored. The disadvantage of this type of experiment is that at least one full size unoccupied dwelling is required for a period of time. This can be very difficult to obtain and costly. Simulated occupancy tests can be used with before and after experiments or with test reference experiments if there is more than one building, e.g. (Rayment \& Morgan, 1985).

The comparison of the energy consumptions in two buildings (T-R experiments), or in two different heating seasons (B-A experiments), will in general produce a result which differs from the retrofit effect. This difference is in B-A experiments mainly due to variations of the weather from one heating season to another. It is mainly due to occupancy differences in T-R 
experiments. However, while a fairly accurate correction is possible in B-A experiments, when a relatively small number of meteorological quantities are measured, in T-R experiments such a correction would require the monitoring of a great number of activities performed by the occupants. (Fracastoro \& Lyberg, 1983) This kind of approach therefore can become time consuming and expensive. A better way of reducing the error in these experiments is to perform a calibration before the measurement campaign, assessing the relevant differences between the occupants of the two buildings.

\subsubsection{Test Modules}

\subsubsection{Test Buildings}

Possibly the most realistic method of evaluating the performance of a secondary glazing system in a residential property is to install and monitor a system in an actual house. This may be done to evaluate energy flows for the individual windows or to evaluate the energy consumption of the whole building (Skates, 2006).

The difficulty of testing full scale buildings is that there can be a large number of variables which make monitoring the small $\mathrm{R}$-value change provided by secondary glazing very difficult to conduct accurately.

It is also very difficult to measure the thermal resistance of windows once installed in a building. There are many techniques for assessing window heat loss, ranging from simple measurements to infrared thermography and computer simulation. Perhaps the simplest method is to measure the outdoor temperature and the inside glass temperature at the centre of the window. The lower the window heat loss is the higher the glass temperature will be (Carpenter, 1991). Simple calculations can then be used to calculate the R-value of the window. The results of this type of measurement may not be entirely accurate. The on-site measurement of R-values of windows is not a procedure to be recommended, mainly because of the disturbance introduced by radiative

exchanges. Moreover, the R-value of windows depends greatly (and, for single-panel glazing's, exclusively) on the surface heat transfer coefficients, which are affected by meteorological factors, varying, in their turn, with time. For these reasons, the procedure presented above can 
lead to large errors, especially when the window is directly illuminated by sunlight (Fracastoro \& Lyberg, 1983). The difficulties of in-situ measurements are just one of the problems with full scale measurements.

One of the major drawbacks of full scale monitoring of buildings in use however, is the effect that occupancy patterns and habits can have on the overall energy performance. This can make direct comparisons between buildings or components difficult. It can also be difficult to correctly apportion the sources of savings. It can be uncertain whether the good performance can be attributed to occupant energy conservation, or to a particular retrofit technology such as secondary glazing. For these reasons, it is difficult to draw general conclusions from specific experiments (Moore, 1992).

In full scale unoccupied test buildings where all variables can be controlled and measured, the inherent disadvantages of occupied buildings can be overcome. However, the initial cost and subsequent costs associated with reconfiguration of windows still presents difficulties (Skates, 2006).

\subsubsection{Test Cells}

Test cells or buildings on the other hand are usually low mass to allow thermal mass reconfiguration, have a heat loss to collector ratio area similar to that of an actual passive building, have re-configurable solar aperture size, tilt and glazing and have controlled infiltration. Test cells are used to accomplish experimental objectives such as proof of concept demonstrations and comparative testing of components in matched test modules. They also act as direct physical analogues of actual buildings (Skates, 2006).

There are also test cells which have been standardised and used on a large scale such as the European PASSYS (Passive Solar Components and Systems Testing 1986 - 1992) project (Wouters, Vandaele, Voit, \& Fisch, 1993). These cells were created to develop reliable and affordable procedures for the testing of the thermal and solar characteristics of Passive Solar Components in a building system. The cells were developed to all have identical construction, infiltration, solar gain, mass properties and the same HVAC and monitoring devices. This 
resulted in a network of high quality and highly standardised test facilities, fully equipped with identical measurement and control devices and governed by the same quality standards (Wouters, Vandaele, Voit, \& Fisch, 1993).

\subsubsection{Test Boxes}

Test boxes are very similar to test cells although at a smaller scale. Their smaller size allows for lower construction costs. The smaller scale test boxes are used principally for comparative tests where convective heat flow is not a parameter. Test boxes are normally constructed of foam insulation with variable glazing, with a ratio of heat loss to collector area similar to that found in actual passive buildings (Skates, 2006).

\subsubsection{Laboratory Testing}

Testing the thermal transmittance of fenestration systems using laboratory equipment can allow for precise results. As discussed previously, In-situ measurement of fenestration systems can be difficult, it is thus advisable to make use of data from laboratory measurements or a theoretical analysis (Fracastoro \& Lyberg, 1983).

\subsubsection{Guarded Hot Box}

ASTM International have released two standards specific to testing fenestration systems in a guarded hot box. ASTM C1199-00: Standard Test Method for Measuring the Steady State Transmittance of Fenestration Systems Using Hot Box Methods (ASTM, 2000) and ASTM E1423-99: Standard Practice for Determining the Steady State Thermal Transmittance of Fenestration Systems (ASTM, 1999).

The International Organization for Standardization (ISO) have also released a standard for testing ISO 12567-1:2000 Thermal performance of windows and doors. Determination of thermal transmittance by hot box method. Complete windows and doors (ISO, 2000).

The BRANZ guarded hot box is able to test windows to the ASTM E1423 and ASTM C1199 combination with the test conditions of $21^{\circ} \mathrm{C}$ and $1 \mathrm{~m} / \mathrm{s}$ air velocity on the indoor face, and a 
parallel airflow of $3.4 \mathrm{~m} / \mathrm{s}$ and $-10^{\circ} \mathrm{C}$ to $10^{\circ} \mathrm{C}$ on the outdoor face. This meets the needs of the New Zealand window manufacturers by providing comparison between locally manufactured windows and at the same time providing a basis for comparison with tests from other countries (Cox-Smith, 1997).

One example of guarded hot box testing to measure retrofitted windows found the method to be promising (Desjarlais, Childs, \& Christian, 1998). The method employed was different to those prescribed by the standards mentioned above, as it used a specially modified guarded hot box allowing the measurement of both the thermal transmittance and air leakage of the windows. Consequently, two windows were measured and retrofitted with external storm windows and weatherisation.

\subsubsection{Computer Simulation}

\subsubsection{Window Simulation}

Another method that is used to determine the thermal transmittance of fenestration systems is to use computer programs that are specifically designed to model and then calculate the resistance of a window and frame. Many windows are performance tested by various organisations using thermal window monitoring programs such as Therm 5, Optics 5 and Window 5 (WERS, 2008b). These programs work together to produce whole window thermal transmittance values for fenestration systems. The programs are used by the National Fenestration Rating Council (NFRC) in the United States (NFRC, 2005), the Window Energy Rating Scheme (WERS) in Australia (WERS, 2008b) and in the New Zealand variant of WERS, the Window Efficiency Rating Scheme (Burgess \& Skates, 2001).

Optics 5 analyses the optical properties of glazing layers (LBNL, 2008). It can be used to create and modify glazing systems which are then used in both Window 5 and Therm 5 . There is also an International Glazing Database (IGDB) which contains the optical data for over 2800 glazing systems (LBNL, 2009). 
Therm can model two-dimensional heat-transfer effects in building components such as windows, walls, foundations, roofs, and doors; appliances; and other products where thermal bridges are of concern (Finlayson, Mitchell, \& Arasteh, 1998). It can be used to model and calculate the heat transfer through window frames. This data can then be exported to Window 5:

\footnotetext{
"Window is a publicly available PC compatible computer program developed by the Windows and Daylighting Group at LBNL for calculating total window thermal performance indices (i.e. R-values, solar heat gain coefficients, shading coefficients, and visible transmittances)." (Mitchell, Kohler, Arasteh, Carmody, Huizenga, \& Curcija, 2001)
}

Window is able to calculate a range of performance indices for a whole window of various sizes under different environmental conditions. It is able to import custom modelled glazings from Optics or the IGDB and import modelled frames from Therm. Both Window and Therm are based upon ISO 15099:2003 (Thermal performance of windows, doors and shading devices - detailed calculations). Together these programs allow for a whole window simulation to be calculated.

The use of computer simulation to calculate the performance of windows is becoming more popular with technological advances in computers, refinements to the simulation software and the growing popularity of performance rating systems.

\subsubsection{Full Scale Simulation}

Once the thermal transmittance of a window and its frame is known then the effect that it would have in a building can be calculated using thermal simulation software. This software allows the user to calculate the impact that windows are able to have on various aspects of a buildings performance such as temperature and energy use. A range of thermal simulation programs were assessed for use in this project. These programs were SUNREL (NREL, 2009), EnergyPlus (U.S. Department of Energy, 2009) and ALF (BRANZ, 2009a). 
SUNREL is an hourly building energy simulation program that aids in the design of small energy-efficient buildings where the loads are dominated by the dynamic interactions between the building's envelope, its environment, and its occupants (NREL, 2009).

EnergyPlus models heating, cooling, lighting, ventilating, and other energy flows as well as water consumption in buildings. It includes many innovative simulation capabilities such as time steps of less than an hour, modular systems and plant integrated with heat balance-based zone simulation, multizone air flow, thermal comfort, water use, natural ventilation, and photovoltaic systems (U.S. Department of Energy, 2009). Both SUNREL and EnergyPlus are complex programs, offering a large range of inputs to produce results that are as accurate as possible. They are capable of simulating a large range of building types, sizes and designs.

The Annual Loss Factor (ALF) tool is used to calculate the building performance index (BPI) - a measure of a building's thermal energy efficiency, which includes the building's insulation values for roof, walls and floor; window size, location, glazing type; floor area; location in the country; mass of building materials and other aspects. It uses these to calculate the theoretical amount of energy needed to heat the building per square metre (BRANZ, 2009a). While ALF offers far less input options when compared to other programs such as SUNREL and Energy Plus, it has been designed in New Zealand specifically for analysis of New Zealand homes. The results provided by ALF are also limited to annual analysis, rather than the hourly and sub-hourly time steps offered by SUNREL and Energy Plus respectively. While ALF does not offer many features provided by other programs, the simplicity makes it a very simple program to use and allows fast design of buildings and a large number of variations associated with New Zealand homes can quickly be explored.

\subsubsection{Calculations}

Various manual calculation methods are also commonly used. If the materials and their respective R-values are known, then these manual methods of calculation are a simple way of estimating the thermal resistance of a fenestration system, particularly due to the low thermal mass. There are standards available specific to window thermal transmittance calculations. These are BS EN ISO 10077-1:2000 (Thermal performance of windows, doors and shutters. Calculation of thermal 
transmittance. Simplified method), BS EN ISO 10077-2:2003 (Thermal performance of windows, doors and shutters. Calculation of thermal transmittance. Numerical method for frames) and ISO 15099:2003 (Thermal performance of windows, doors and shading devices - detailed calculations). ISO 10077 is widely used in Europe however it is inconsistent, simplified and inferior to ISO 15099.

\subsection{Summary}

In summary the literature review has shown that internationally there has been a modest amount of research into secondary glazing. As secondary glazing is not a new technology, the research has been conducted over a large period of time with research as early as the early 1970's (Godfrey, 1972) right through to today (Drumheller, Kohler, \& Minen, 2007). There has been a significant amount of research focusing on the thermal resistance of individual products, based on calculation and testing. However, as different test methods are used each time, results vary and it becomes difficult to draw direct comparisons. There is also very little research associated into the cost benefits of secondary glazing with only one recent piece of research focusing on the energy savings associated. Two types of secondary glazing have been assessed in New Zealand (Lloyd, Bishop, \& Callau, 2007) however the results were only a small part of a much larger project. 


\subsection{Test Methodology}

\subsection{Overview}

The following chapter describes the methodology employed for this research. It identifies aspects identified in the literature review where more research could be conducted to add to the established body of knowledge. The most appropriate methods to conduct a cost benefit analysis on secondary glazing were then analysed and are outlined. The chapter begins with the selection of an appropriate test method to achieve the aim of the research. An appropriate single glazed window was selected. The secondary glazing systems to be tested were then selected. From here a detailed explanation of the methodology is provided in chronological order. The process begins with the physical guarded hot box testing. This is followed by computer simulation of home heating energy consumption. The data from these simulations is then used for the final cost benefit calculations. Results from the processes discussed in the following sections are presented in Chapter 4.0, Results and Analysis.

\subsection{The Test Method}

The first step to beginning the test process was to select an appropriate test method. This section compares the merits and limitations of the various methods found in the literature review. The chapter discusses the suitability of these methods to explore the financial viability of secondary glazing as a retrofit option for typical New Zealand homes. The most suitable method for the purpose of this experiment was selected. Finally the types of secondary glazing to be tested and the type of primary window used in the testing were selected.

\subsubsection{Test Method Selection}

As stated in the literature review the potential test methods can be categorised by three main headings: full scale; test cell; and guarded hot box testing. 
Full scaled testing of an occupied house can be difficult due to the behaviour of the occupants. The measured temperature and energy variations, before and after the retrofit, would be too difficult to attribute to changes in the window insulation. This is due to variables such as occupant behaviour variations and environmental variations. While environmental variations can be monitored and accounted for, occupant behaviour requires too much time to monitor in detail. As the whole building envelope thermal resistance is being measured, small variations in energy consumption and temperature would not be able to be attributed to just the windows without a large margin of error. The large cost of a simulated occupancy or even an unoccupied full scale test means these options were not feasible for this project.

A more affordable option would be to construct two identical test cells or test boxes. These would be able to test either temperature or energy improvements of secondary glazing over a standard window. The window to wall ratio can be made similar to a typical building, allowing for fair reflections of potential improvements.

If more than one secondary glazing system was tested then more than two test cells would be required, greatly increasing the cost of the project. Alternatively, a before and after test method could be used, however there would be weather variations between the tests influencing the results. Detailed monitoring of the environmental variables could be conducted and then accounted for, however to do so in enough detail to measure minor temperature, energy or thermal resistance changes between similar secondary glazing systems would be too difficult.

Another method would be to physically measure the thermal resistance of the window. One method of measuring the thermal resistance of a fenestration system is by using a guarded hot box. This method is able to accurately provide thermal resistance measurements, however it would not document the temperature or energy benefits provided by installing secondary glazing.

In order to conduct a cost-benefit analysis the energy consumption needs to be known. Once detailed R-values for the various secondary glazing systems are known then it is possible to predict the change in energy consumption by using either calculations or computer simulation. 
The downside to Guarded Hot Box (GHB) testing is that the test specimen must be completely airtight. One advantage of secondary glazing is that it can dramatically reduce window air leakage, particularly in older homes where the timber windows have begun to deteriorate. Hot box testing cannot measure the solar gain or air leakage of a fenestration system. Section 4.4 of E1423 describes (ASTM, 1999):

"the thermal transmittance and conductance results obtained do not reflect performances expected from field installations since they do not account for solar radiation and air leakage effects. The thermal transmittance and conductance results were taken from specified laboratory conditions and should be used only for fenestration product comparisons and as input to thermal performance analyses that also include solar and air leakage effects."

To measure the effect of a reduced air leakage, the air leakage of the primary test specimen in the GHB would have to be measured followed by measurement of the same specimen with each different secondary glazed unit installed. This would add additional cost and complexities to the test process and would only reflect the improvement over that specific primary window. Due to this difficulty and the other variables associated with house infiltration, an infiltration test would not be feasible. Instead, an assumption of the worst case scenario, that the secondary glazing provides no additional improvement to airtightness would have to be used.

Solar gain cannot be measured in a GHB. Computer simulation of the heating energy consumption of a typical home can calculate the influence of solar gains, however the SHGC of the window needs to be known. Measuring the SHGC of the windows would require expensive equipment, assigning the window default SHGC coefficients from previous research, or simulating the SHGC of the window using known values for the glass and computer software.

Despite some of these limitations, the guarded hot box method was selected as the most suitable for this type of experiment. The accuracy of the R-value measurements is very important when comparing various secondary glazing methods as the differences between them could potentially be very small. The other two experiment techniques would take longer and involve much larger costs to build test cells or acquire a test house, whereas a GHB was available to use. 


\subsubsection{Window Selection}

To test the secondary glazing systems, a primary single glazed window needed to be selected. The window must be a fair reflection of what is currently in use in New Zealand. The window frame material needed to be the most commonly used material. A survey of existing New Zealand homes conducted in 2005 measured the proportion of different window types. These are displayed on the table below along with the findings of the same study conducted in 1999.

Table 3-1: Percentage of Window Types in a sample of New Zealand Homes (Clark, Jones, \& Page, 2005)

\begin{tabular}{|l|c|c|}
\hline Type & 1999 Survey & 2005 Survey \\
\hline Timber & $61 \%$ & $44 \%$ \\
\hline Aluminium (Powder Coated) & $9 \%$ & $26 \%$ \\
\hline Aluminium (Anodized) & $22 \%$ & $23 \%$ \\
\hline Timber/Aluminium Mixed & $7 \%$ & $7 \%$ \\
\hline Other & $1 \%$ & $0 \%$ \\
\hline
\end{tabular}

It is important to note that the survey classed anodized aluminium windows and powder coated aluminium windows as separate products. If these two materials are classed together as aluminium frames then they would make up the majority in the 2005 survey. The decrease in timber windows reflects the increased numbers of newer homes in the later survey. Homes built prior to the 1970 's decreased from $70 \%$ in the 1999 survey to $55 \%$, along with the number of older homes replacing some or all of their old timber windows with aluminium (Clark, Jones, \& Page, 2005). Homes built prior to the 1970's are often uninsulated as insulation was not required. Insulation became relied upon to meet the increased thermal performance requirements for new homes on the $1^{\text {st }}$ of April 1978, under NZS 4218P: 1977 Minimum Thermal Insulation Requirements for Residential Buildings. Due to this, pre-1970 homes would potentially benefit more from installing secondary glazing.

The percentage of heat lost through the window of an uninsulated house is smaller than from a partially or fully insulated house. This is because larger amounts of heat are lost through other parts of the building envelope such as the walls, roof and floor. Due to this there are often other 
retrofit alternatives targeting different aspects of the uninsulated building envelope that may be more cost effective than secondary glazing.

The survey also noted that aluminium windows were often in better condition than timber windows, but it was believed this was due to their age. On average timber windows were 64 years old and had an average condition of 3.5 out of 5 (Clark, Jones, \& Page, 2005). Anodised aluminium windows were an average age of 35 years old, and had an average condition of 4.0 while powder coated windows were only 23 years old on average and had the highest average condition of 4.4 (Clark, Jones, \& Page, 2005). Fixing secondary glazing to an aging, existing window which requires maintenance may result in future problems. The window would continue to deteriorate, potentially damaging the surrounding timber and possibly the secondary glazing. The performance of secondary glazing could also be reduced. While secondary glazing may help with the airtightness issues associated with older windows, deteriorating windows would be more suited to a complete retrofit with double glazing. With the superior condition of aluminium windows in the survey, the number installed in New Zealand homes that could be improved by secondary glazing would be larger.

Due to these reasons it was thought that a good condition, airtight timber frame window would not be representative of the windows within the majority of New Zealand homes. The additional thermal resistance of the airtight timber frame would also provide overly optimistic R-values for the secondary glazing systems. For these reasons an aluminium window frame was chosen.

The inability to measure a window with any air leakage in the GHB has resulted in the selection of a fixed window. While a common type of window such as a casement or double-hung window could be used, the openings would need to be completely sealed by a material as specified by ASTM E1423, removing any advantages of using these window types and potentially altering their thermal properties. 


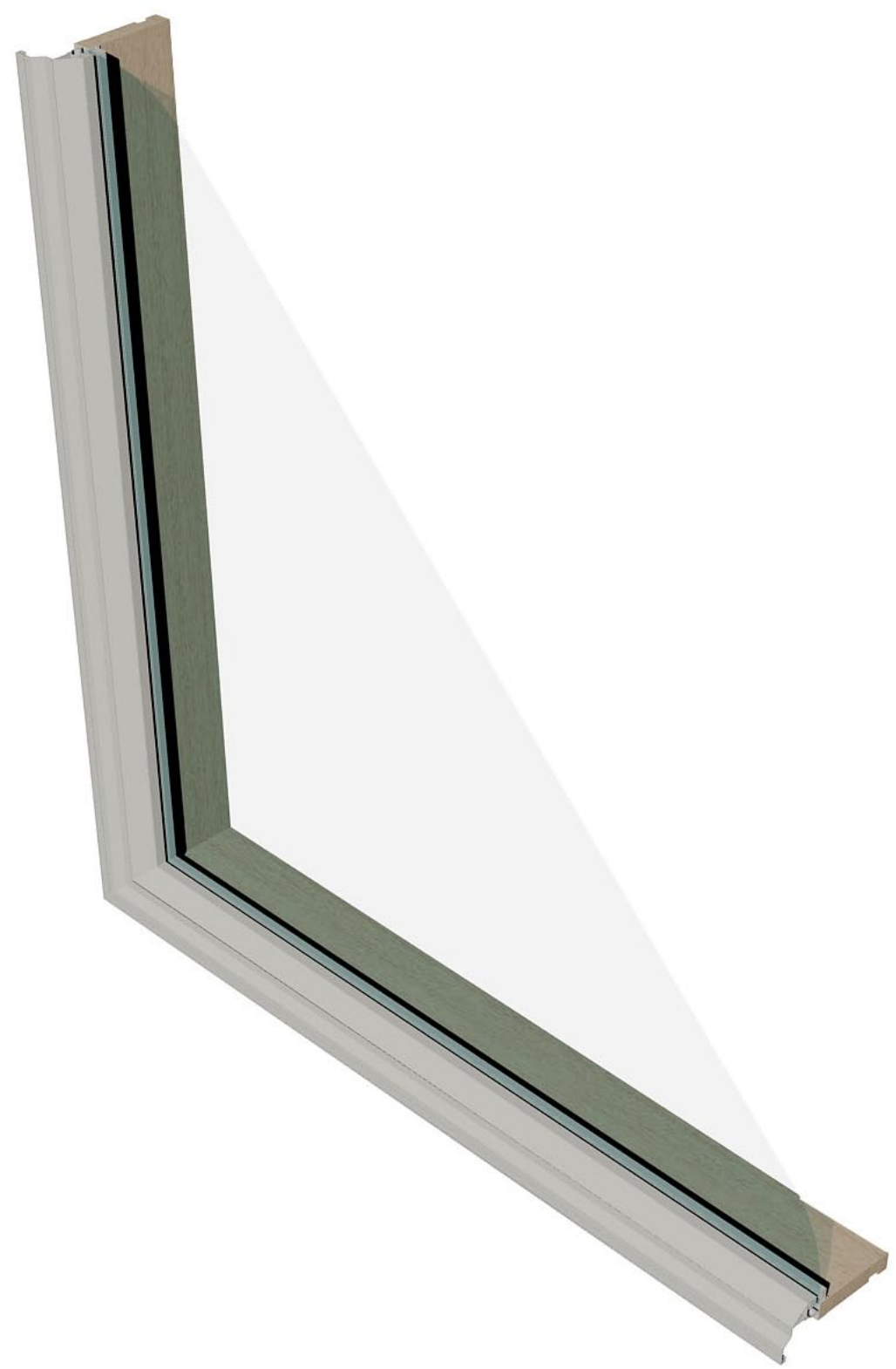

Figure 3-1: 3D Perspective of the Single Glazed Aluminium Window

\subsubsection{Secondary Glazing Selection}

To gain a fair assessment of cost benefits provided by secondary glazing, a variety of products were chosen to be tested. Once the initial setup was complete, it was much faster to conduct a multitude of tests, particularly so with secondary glazing which is a quick retrofit measure. Once the primary window was installed then the secondary glazing could be quickly added and removed from the window with only a limited set up time. 
A selection of four products which were identified in the literature review as the most commonly available, were used. A key difference between these products is the cost, with the products selected ranging from low cost temporary solutions to more expensive permanent inboard solutions.

The most basic and affordable solution to be tested was the thin plastic film window kit. While this simple DIY solution can be achieved in a variety of ways, a simple off the shelf kit manufactured for this particular reason was chosen. The kit consisted of a large clear, heat-shrink plastic sheet and a roll of double sided tape. These products are produced by a variety of manufacturers, however most are comprised of similar materials.

The second product was a $3 \mathrm{~mm}$ thick, magnetically attached acrylic sheet. This is a more permanent solution. It consists of an acrylic sheet fixed to the window using adhesive magnetic strips. While clear acrylic sheet could be purchased and installed using a DIY method such as screw fixing, a magnetic seal was chosen for the ability to easily remove and open the window at will, aesthetic appearance and the market availability. The chosen product was a professionally manufactured and installed product which increased the costs significantly, but ensured product quality.

The final product was a typical aluminium framed secondary glazing window. It consists of aluminium tracks installed inside the timber reveal of the window. These tracks house two sliding sash aluminium windows. The windows can be opened by sliding along the track to access the inter-pane space for cleaning and ventilation or they can be lifted out of the tracks outside of the heating season, and can be fitted with a variety of glazing panes. For this project two different types of glass were selected; typical clear float $5 \mathrm{~mm}$ glass and clear $5 \mathrm{~mm}$ float low-E glass. The products are very durable and designed to be a long term solution, however the cost to produce and install these windows can be high. The aluminium frame with clear glass has a similar pricing to the magnetically-attached acrylic sheet secondary glazing. Once tested, the two panes of clear glass were removed from the secondary glazing frames and replaced with the low-E glass. This glass increases the cost of the unit making it the most expensive of the chosen systems to test, however it is the most technically advanced solution. 


\subsection{Physical Testing}

\subsubsection{Guarded Hot Box Testing}

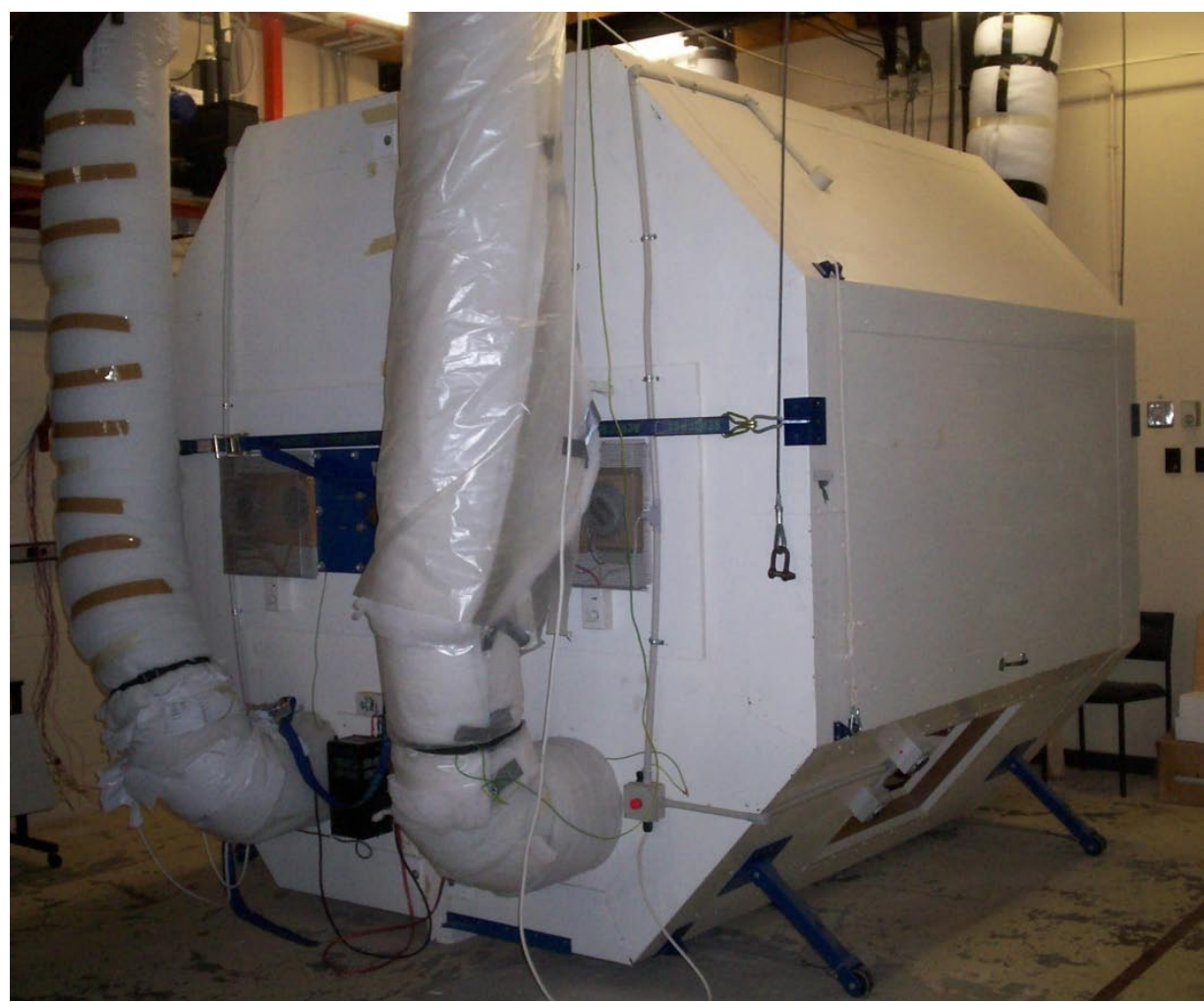

Figure 3-2: The BRANZ Guarded Hot Box

A guarded hot box measures the thermal resistance of products by creating temperature differences on each side of the box and measuring the flow of heat from one side to the other. The box itself consisted of two halves which could be wheeled apart. Each half also has a small door on the underside to allow access. The product was placed in between these two halves and each half was serviced by an individual heat pump. The GHB has an 'inside' or 'warm' side and an 'outside' or 'cool' side. The surface of the product which would typically face the exterior environment faces the cool side of the box.

The hot box measures the thermal resistance of a $1.2 \mathrm{~m} \times 1.2 \mathrm{~m}$ area covered by the heat metering box. It does this by measuring the temperatures on the cool side and the warm side of the box; the wattage used to sustain the set temperatures; and the air temperatures on each side of the window. The temperatures are measured using thermocouples positioned in a grid on the cool 
side and the thermocouples in the heat metering box on the warm side. All these measurements were monitored in real-time by a computer which records them at 1 minute intervals. They were entered into a program where the thermocouples being used in the experiment could be selected for recording while unused thermocouples were switched off. The program then averaged the temperature difference of the corresponding temperature thermocouples on each side of the box every minute giving the temperature difference $(\mathrm{dT})$. The power drawn by the heat pumps supplying the GHB was also measured every minute. As the measured area was that covered by the $1.44 \mathrm{~m}^{2}$ heat metering box, all the necessary values were known to calculate the thermal resistance. The $\mathrm{R}$-value formula to calculate the resistance from the variables measured by the hot box is described in Equation 3-1.

\section{Equation 3-1: Heat metering box R-value calculation}

$\mathrm{R}=\mathrm{A} * \cdot \mathrm{d} \mathrm{T} / \mathrm{W}$

Where:

$$
\begin{array}{ll}
\mathrm{A} & =\text { Measured Area }\left(\mathrm{m}^{2}\right) \\
\mathrm{dT} & =\text { Temperature Differential }\left({ }^{\circ} \mathrm{C}\right) \\
\mathrm{W} & =\text { Watts drawn by the GHB }(\mathrm{W}) \\
\mathrm{R} & =\text { R-Value }\left(\mathrm{m}^{2} \cdot \mathrm{K} / \mathrm{W}\right)
\end{array}
$$

Eg. The $1.44 \mathrm{~m}^{2}$ area monitored by the heat metering box was tested with a $10^{\circ} \mathrm{C}$ temperature difference between each side of the box. To maintain this differential the hot box requires a continuous heat supply of 50 Watts.

$$
\begin{aligned}
& \mathrm{R}=\mathrm{A} * \mathrm{dT} / \mathrm{W}= \\
& \mathrm{R}=1.44 * 10 / 50= \\
& \mathrm{R}=0.29 \mathrm{~m}^{2} \cdot \mathrm{K} / \mathrm{W}
\end{aligned}
$$

The computer was able to present all these results in real time graphs to allow the user to fully monitor all aspects of the GHB to ensure everything was running correctly. The following describes the process of setting up and conducting GHB tests on fenestration systems in detail. 


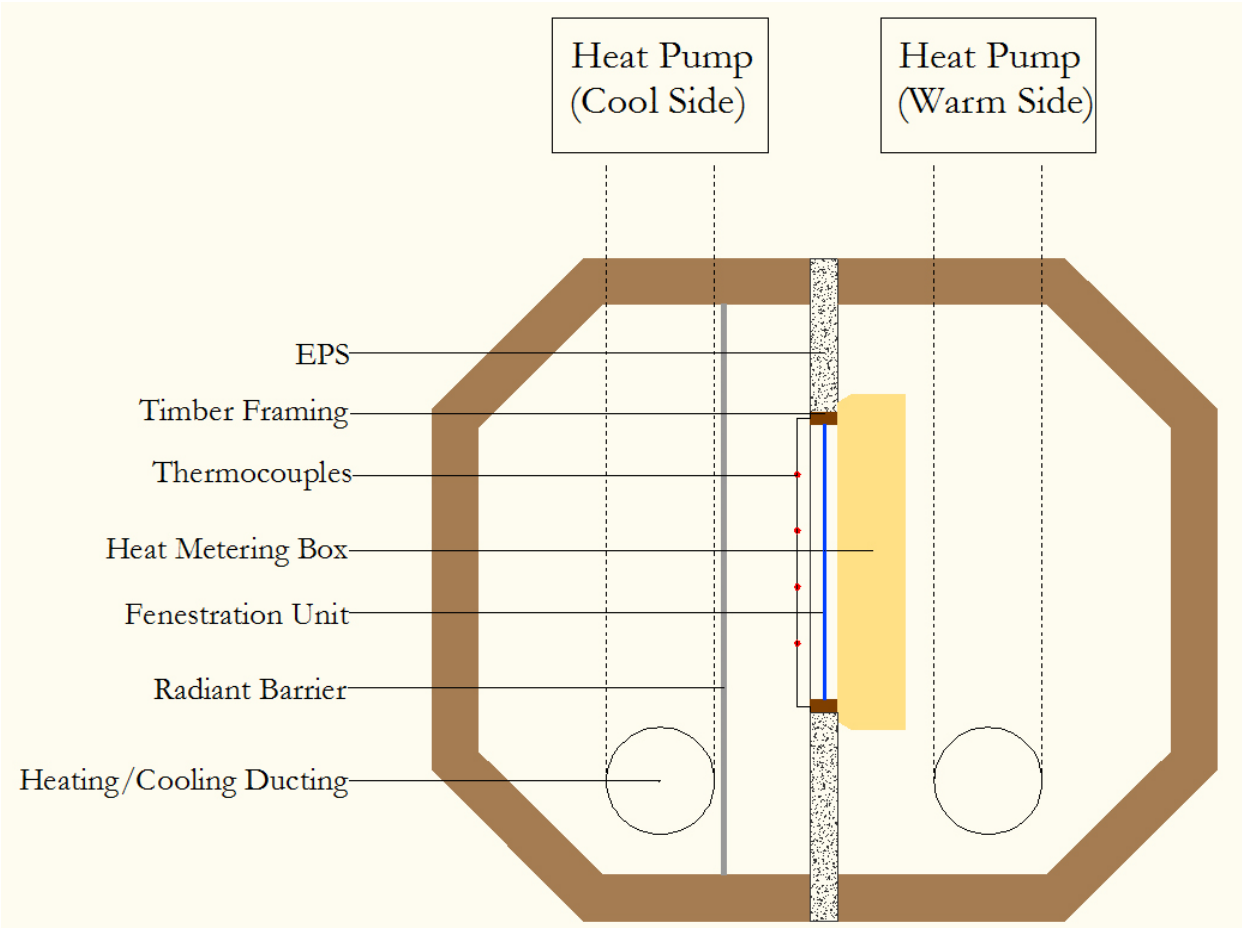

Figure 3-3: GHB Cross-section

The GHB used has a meter box on the warm side of the GHB. This meterbox was $1.2 \mathrm{~m} \times 1.2 \mathrm{~m}$. This allows the hot box to test fenestration systems up to $1.2 \mathrm{~m} \times 1.2 \mathrm{~m}$. Fenestration products larger than this are able to be tested, however a horizontal convection barrier needs to be used (Cox-Smith, 1997). The addition of this horizontal convection barrier means another calibration test is required to measure the influence it has on the results, which increases cost and time of the process. For this project a $1 \mathrm{~m} \times 1 \mathrm{~m}$ window was used and only required one initial calibration test.

Surrounding the window and separating the two sides of the hot box was the surround panel. This panel was comprised out of a timber frame made from $45 \mathrm{~mm}$ x $90 \mathrm{~mm}$ timber studs. Two studs run vertically from the bottom to the top of the hot box $1030 \mathrm{~mm}$ apart and were secured to the chamber. These form the vertical framing component of the window. The two horizontal members run between the two vertical members also at a $1030 \mathrm{~mm}$ spacing forming the lintels for the window. The result was a $1030 \mathrm{~mm} \times 1030 \mathrm{~mm}$ opening.

The open areas of this surround panel frame were filled in with expanded polystyrene (EPS). EPS was used because of its low thermal conductivity. This was in accordance with ATSM C 1199 - 00 which specifies a maximum thermal transmittance for the surround of $0.04 \mathrm{~W} / \mathrm{m} \cdot \mathrm{K}$ 
(ASTM, 2000). EPS with a density greater than $20 \mathrm{~kg} / \mathrm{m}^{3}$ that has been aged in the lab for over 90 days was used as recommended. The polystyrene used was $100 \mathrm{~mm}$ thick, the minimum thickness specified by ASTM C 1199 - 00. It was placed firmly against the timber frame to sit flush with the weather side of the surround panel. It was fixed securely in a plane parallel to the surround panel (ASTM, 1999) and then taped using non reflective masking tape at any connections to ensure there was no air leakage around the panel.
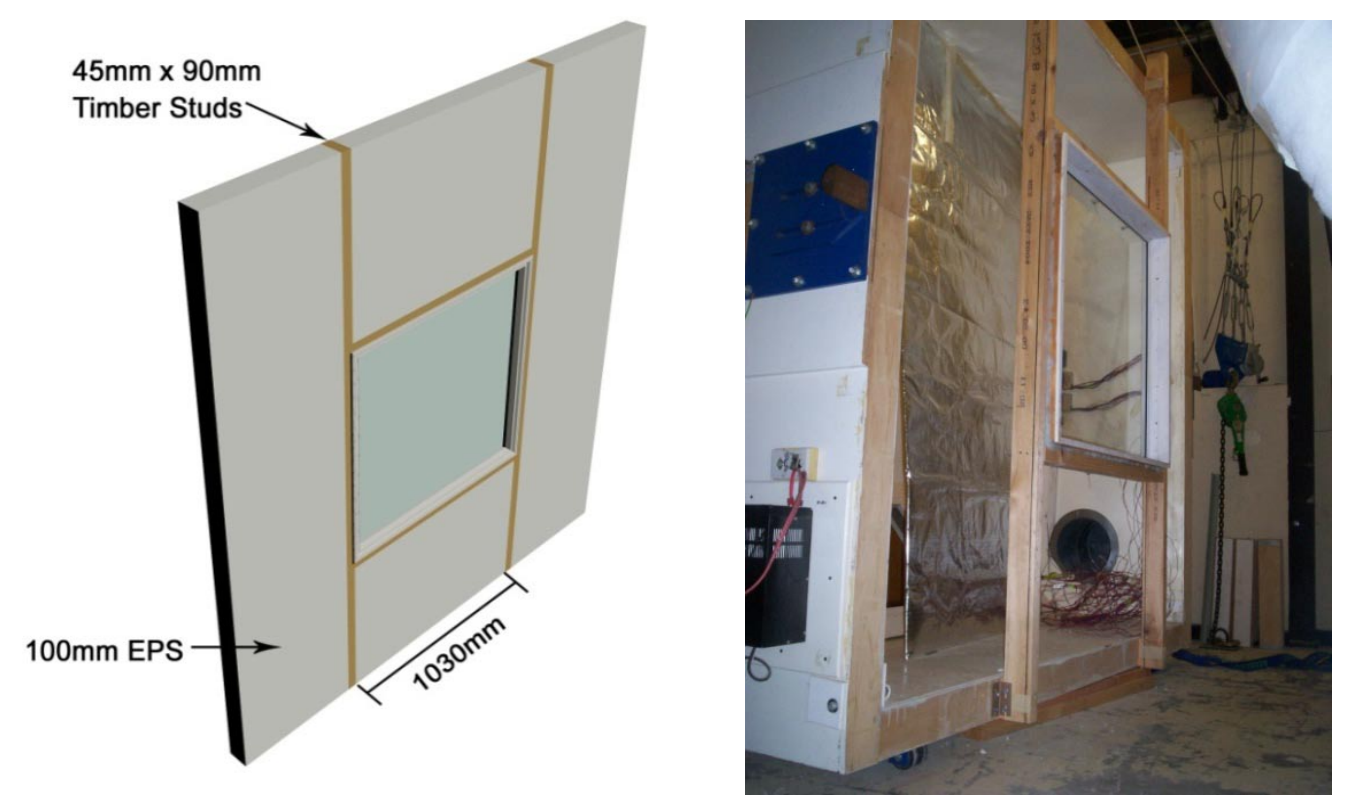

\section{Figure 3-4: Guarded Hot Box Surround Figure 3-5: Construction of the Surround}

Once the wall was in place then the window was positioned in the opening. $15 \mathrm{~mm}$ packers were used around the window to ensure it was positioned in the centre of the opening. As the thermal transmittance of the cavity between the window and the frame was not being tested, the space between the surround panel and the fenestration system was filled with material of similar thermal conductance to that of the surround panel (ASTM, 1999). As it was a small area it was packed with fibreglass insulation. The timber reveal was then firmly secured to the timber surround using screws.

Finally any potential areas of air leakage were sealed. This was done by sealing the edge of the aluminium frame to the timber stud of the surround using masking tape. Care was taken to ensure that there were no air leaks and that the tape did not cover more that $13 \mathrm{~mm}$ of the test specimen frame or edge as specified by Section 7.1.3 'Air Leakage' (ASTM, 1999). 


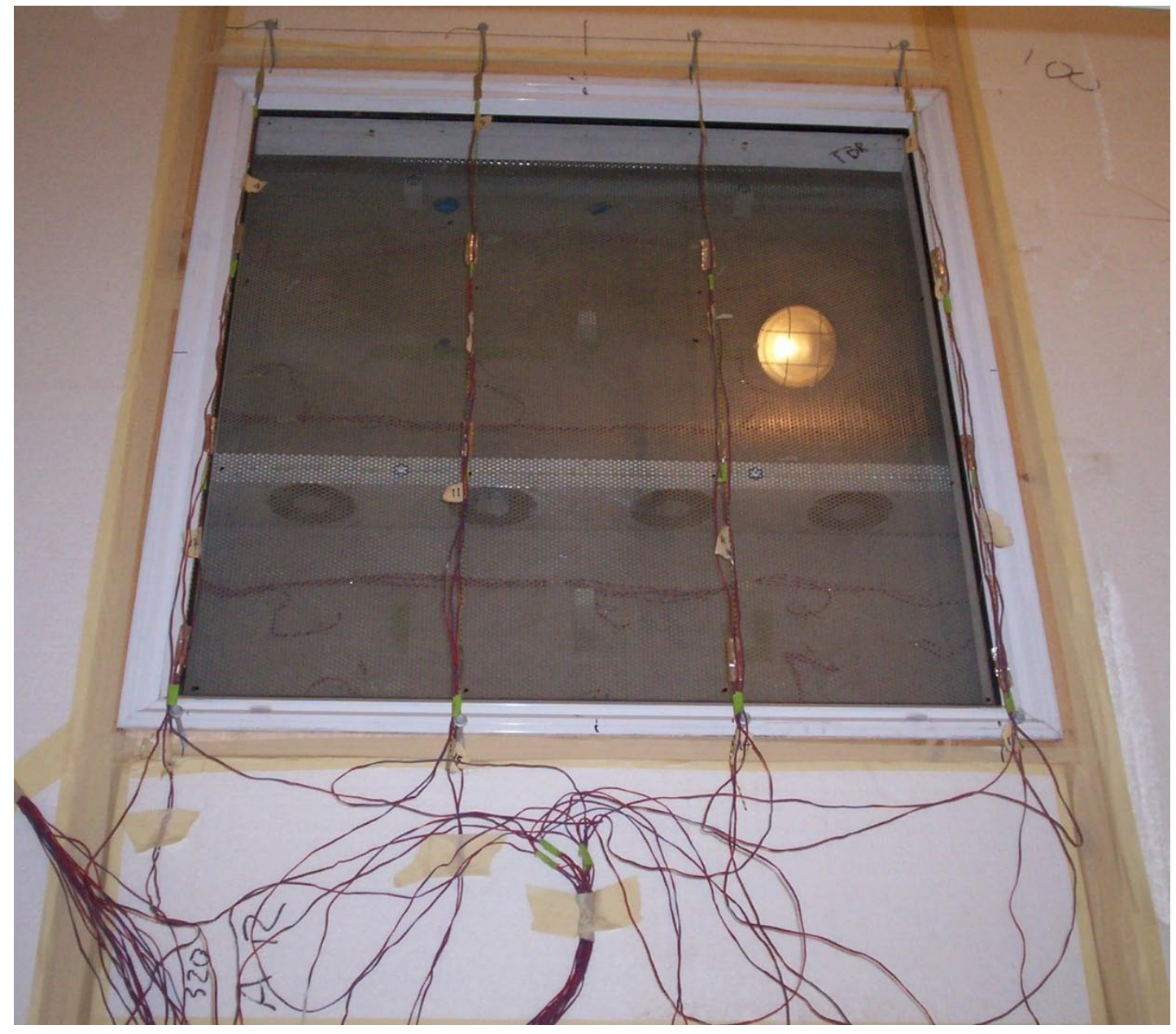

Figure 3-6: Thermocouple Positioning

Next the 16 temperature sensors were wired up on the cool side of the window. A 4 x 4 grid was drawn up for the temperature sensors on the window. 4 bolts at equal $300 \mathrm{~mm}$ spacing were screwed into the top lintel of the window and four bolts were fixed to the timber below the window. A vertical line of wire was firmly tied between the 4 top and bottom bolts approximately $100 \mathrm{~mm}$ from the surface of the window. The thermocouples were then mounted at equal $300 \mathrm{~mm}$ intervals along this wire. The result was a grid which aligned itself with the corresponding thermocouples in the heat metering box. Once all of this was complete, the warm half of the guarded hot box could be positioned firmly against the surround panel. The straps fixing the two sides of the GHB together were tightened firmly to make sure that there were no leaks between the surround panel and each side of the hot box. 


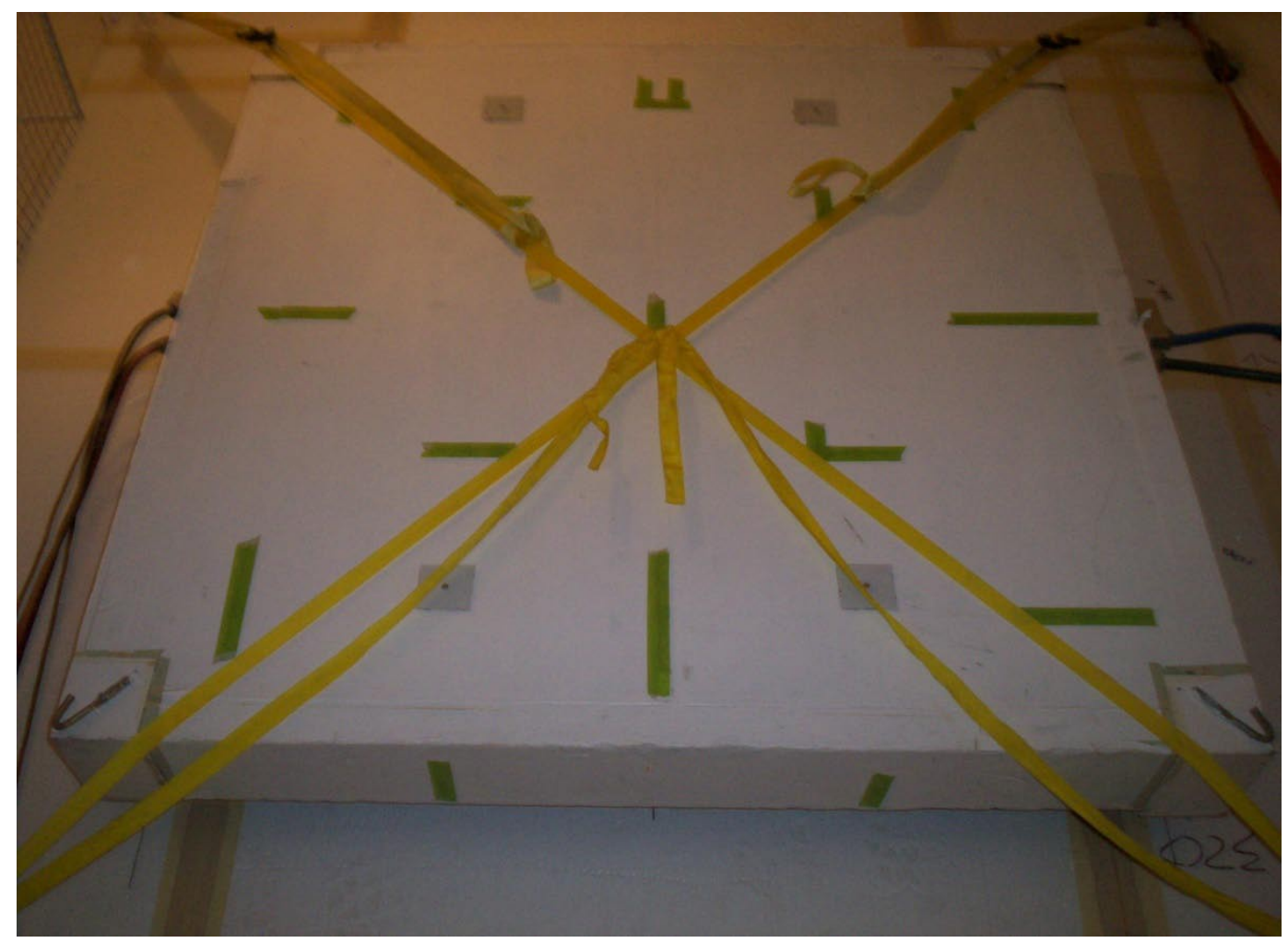

Figure 3-7: Heat Metering Box

The warm side of the guarded hot box contains the heat metering box. The next step was for the heat metering box to be positioned over the window. The heat metering box was centred over the window, covering an equal $100 \mathrm{~mm}$ of the surround on each side of the window. It was fixed firmly to the surround, with care taken to make sure that there were no air leaks between the heat metering box and the surround. The guarded hot box was now ready for operation. The environmental conditions on each side of the hot box then needed to be established.

Due to the low thermal resistance of the windows being tested, in particular the single glazed window, the hot box was unable to test the windows with a large variation in temperatures on each side. This was because of the large amount of energy which would be required to keep temperatures on each side stable. The energy required to keep each side at a stable temperature increases dramatically when the temperatures can easily transfer from one half of the GHB to the other through the window. Fourier's law states that the heat flow rate intensity from one side of the GHB to the other is equal to the product of the thermal conductivity of the window and the temperature gradient between each side of the window. Therefore the higher the conductivity of the window and the higher the temperature difference between each side of the 
GHB, the larger the heat conductivity through the window. The larger transfer of heat from one side of the GHB to the other could also produce increased temperature fluctuations which result in tests requiring a longer period of time to stabilise. The larger fluctuations could also result in reduced accuracy in the tests.

The $\mathrm{GHB}$ was not designed to run at temperatures of $21^{\circ} \mathrm{C}$ inside and $-18^{\circ} \mathrm{C}$ outside, the temperatures prescribed by NFRC 100-2001 for measuring the thermal resistance of windows (NFRC, 2004). The extreme of $-18^{\circ} \mathrm{C}$ on the weather side would not only gain a lot of heat from the warm side of the GHB but would also gain heat from the outside. The energy required to counter these heat gains and create a stable $-18^{\circ} \mathrm{C}$ would be extremely large and was much more than the heat pump servicing this side of the hot box would be able to provide. Likewise the indoor side of the hot box would also require large amounts of energy to remain at $21^{\circ} \mathrm{C}$ due to the amount of cool air transferred from the cold side of the box. To counter the inability of the hot box to sustain extreme temperatures, the guarded hot box needed to operate at the widest temperature difference that the heat pumps on either side could sustain. To do this the GHB was switched on with the single glazed window installed without any secondary glazing system. As the single glazed window was predicted to give the lowest thermal resistance it would require the narrowest temperature differential to operate in a stable manner.

Using temperatures significantly different to the outdoor conditions requires larger wattages to stabilise, reducing the possible temperature difference that could be achieved between each side, potentially limiting the accuracy of the results. Temperatures around $-18^{\circ} \mathrm{C}$ are seldom encountered in New Zealand; therefore the need to test at low temperatures was not as important. Due to these reasons it was decided that the results would be more accurate if the tests were conducted nearer the room temperature surrounding the GHB.

Initial testing was conducted at a $10^{\circ} \mathrm{C}$ temperature difference between each side of the box. The hot box was set to an inside temperature of $28^{\circ} \mathrm{C}$ and an outdoor temperature of $18^{\circ} \mathrm{C}$ on the cool side and switched on. After a period of time it was established that the temperature difference was too large for the GHB to effectively stabilise and produce reliable results within the testing timeframe. The temperature on the indoor side of the hot box could not remain at a constant $28^{\circ} \mathrm{C}$ due to heat lost through to the cool side of the $\mathrm{GHB}$ and to the outside 
environment. The temperature was then reduced by $3^{\circ} \mathrm{C}$ on the warm side of the box to $25^{\circ} \mathrm{C}$. It was found that the guarded hot box was able to quickly stabilise and produce reliable results with a $7^{\circ} \mathrm{C}$ temperature difference between the two sides. The difference in temperature from those used for NFRC calculations will produce convective differences. Radiative film coefficients depend slightly on surface temperature and will also be altered by the temperature differences. These factors could influence the final R-value calculations and possibly result in differences to R-values calculated using NFRC temperatures.

Due to the transparent nature of the test specimens being tested in the guarded hot box there was the potential for radiant heat transfer from the inside surface of the cool side of the GHB, through the window and onto the thermocouples inside the heat metering box. To reduce the influence of radiant heat transfer, the thermocouples had a low emissivity reflective aluminium coating, reducing the amount of radiated heat they received. While there will only be a very marginal temperature difference between the inside surface of the hot box and the hot box air temperature, it was important that any radiant heat transfer was prevented. This was to provide as accurate readings as possible due to the similar thermal transmittance of the various secondary glazing units.

A variety of methods to remove any radiant heat transfer were tested, including opaque polythene, opaque paper and a radiant shield. The polythene and paper were directly fixed to the visible glazed area of the window preventing the radiant transfer through the transparent glass. The shield was a $1.5 \mathrm{~m}$ wide vertical barrier running from the floor to the ceiling of the box approximately $400 \mathrm{~mm}$ back from the window. The radiant shield was chosen over the other two options for a variety of reasons. The low emissivity coating would prevent the majority of radiant heat transfer through the window. It was also able to be stepped back from the window itself meaning that there was no influence on the thermal transmittance of the window, which would have to be removed later by calculation with the other methods, and it did not interfere with the air movement across the window. 


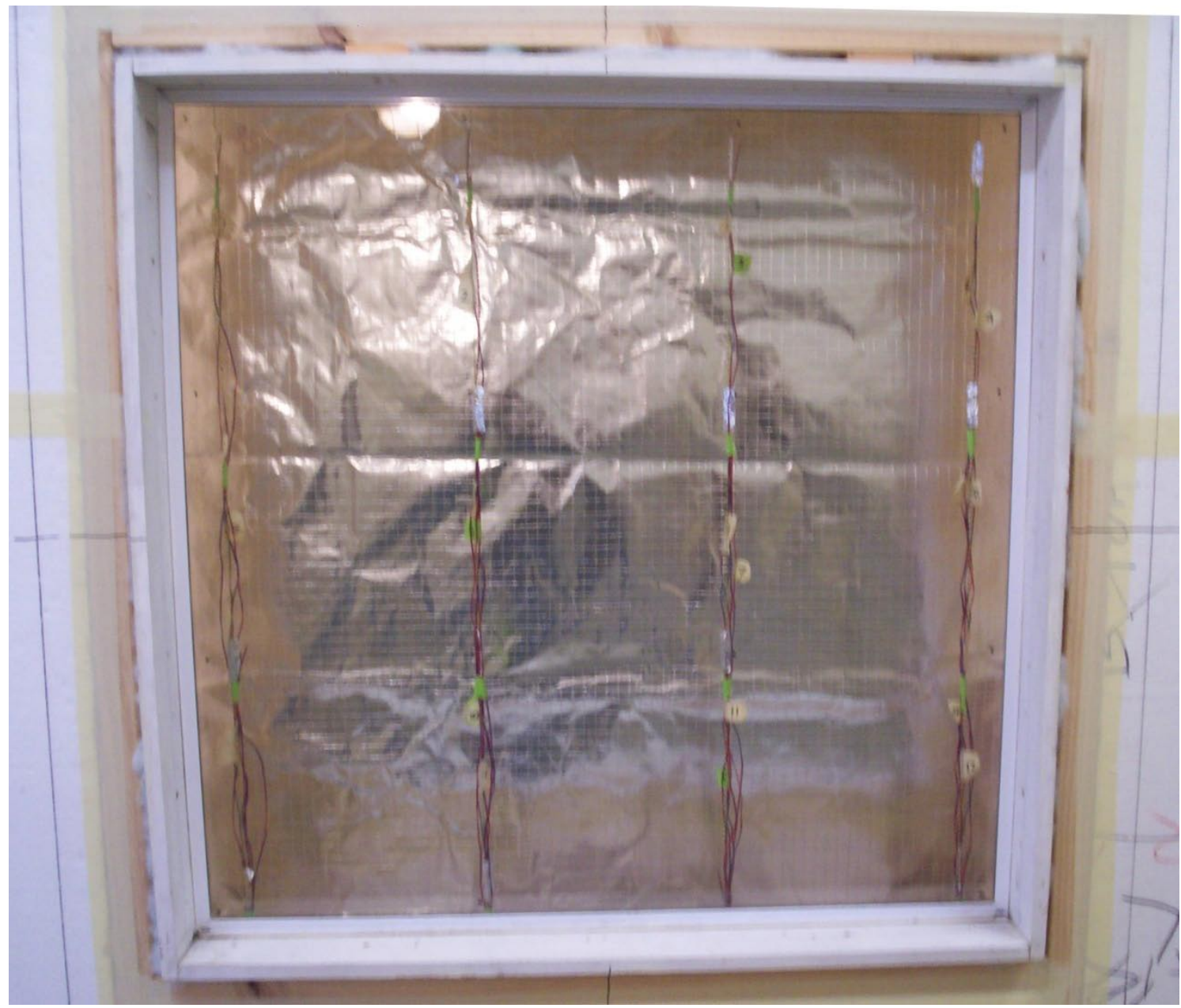

Figure 3-8: Aluminium Coated Radiant Heat Shield In Place

\subsubsection{Procedure}

A total of six tests were conducted for this research. They are as follows:

1. Aluminium Single Glazed Window

2. Aluminium Single Glazed Window with Magnetic Acrylic Secondary Glazing Installed

3. Aluminium Single Glazed Window with Thin Film Plastic Secondary Glazing Installed

4. Aluminium Single Glazed Window with Aluminium Framed Secondary Glazing Installed

5. Aluminium Single Glazed Window with Low-E Aluminium Secondary Glazing Installed

6. Aluminium Single Glazed Window with R-1.5 Polystyrene Installed in the Timber Reveal 
With the hot box set up the testing of the single glazed window could begin. The hot box was switched on and left over a period of time. Initial checks near the beginning of the experiment made sure that the appropriate thermocouples were responding and measuring correctly. The GHB was then left to stabilise. Once the large temperature swings which occur at the beginning of the test began to subside, the hot box was checked once again to ensure that the thermocouples were measuring correctly and that the temperatures were stabilising at the set points of $18^{\circ} \mathrm{C}$ on the cold side and $25^{\circ} \mathrm{C}$ on the warm side. If there were any problems then the appropriate changes could be made to resolve the issues and the test could be resumed. Once these checks were conducted and it was established that the GHB was running correctly then it was left overnight to run with stabilised temperatures to ensure an accurate result. It was only necessary to run the test until the temperatures in the GHB became stable. As the GHB temperatures fluctuate periodically longer test times could ensure accuracy. The single glazed window was tested for a period of just over 5 hours and was stable for more than 4 . The single glazed window experienced much smaller fluctuations than the secondary glazing tests. Due to this, the shortest secondary glazing test conducted was stable for over 14 hours. The results measured by the GHB are presented in Table 4-7. The next day the test was checked once again, if necessary, adjustments were made and the test was left to continue. If the GHB had been running at stable temperatures and was giving consistent $\mathrm{R}$-value results for at least 3 hours then the test could be stopped. The data collected by the computer was assembled into a spreadsheet, the GHB was switched off and opened up to prepare for the next test. 


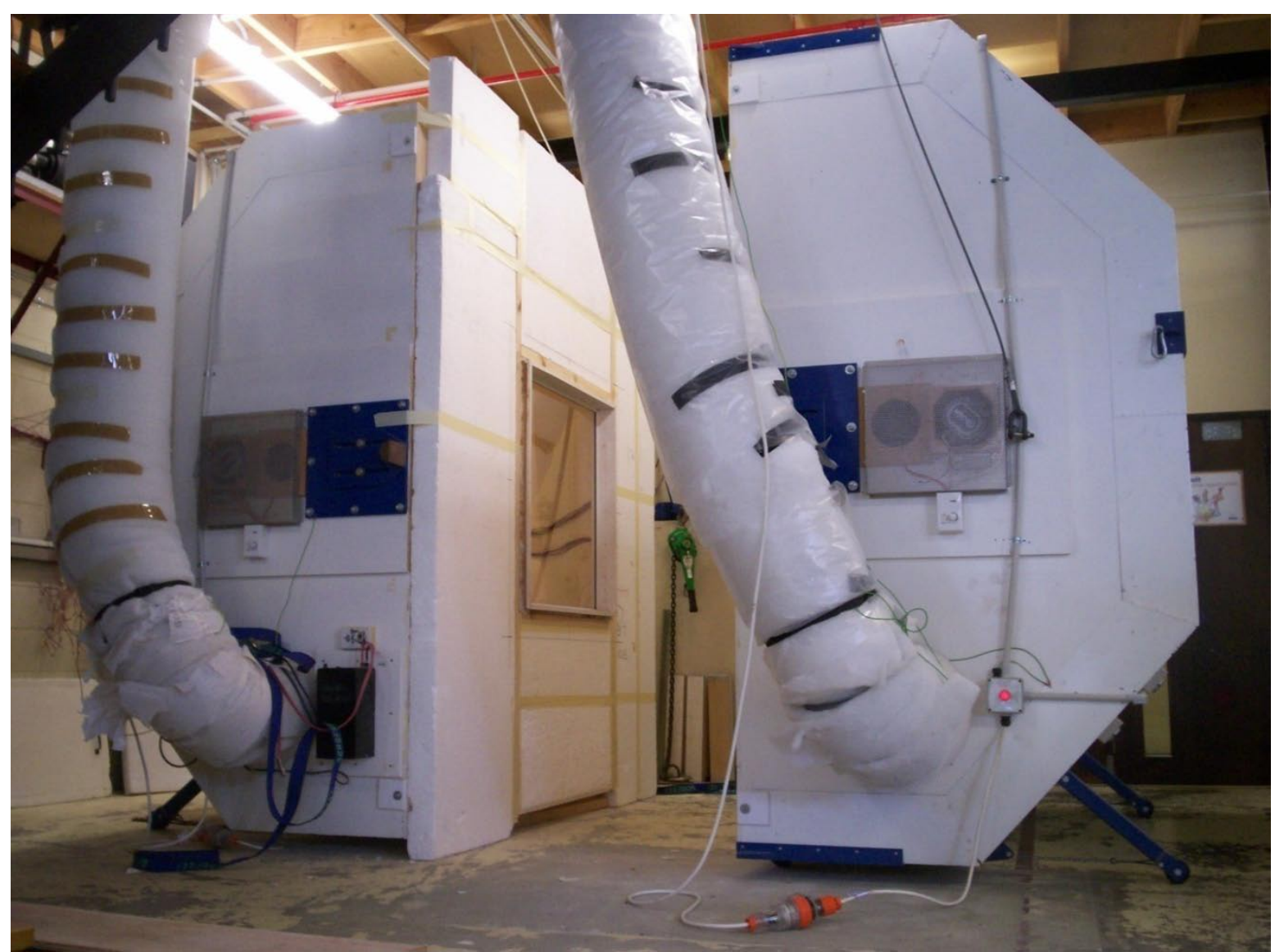

Figure 3-9: Hot Box Open with Single Glazed Sample in Position

The next test was the magnetically-attached acrylic sheet secondary glazing. A PVC block with the magnetic strip was fixed into place inside the timber reveal, $30 \mathrm{~mm}$ from the window. The block was placed there, as it is a similar distance to how the sheet would be mounted on a timber window. If the secondary glazing was being mounted for acoustic reasons then the PVC block would be mounted closer to the outside of the timber reveal. The acrylic panel with the magnetic PVC surround was then fixed to the PVC block on the window surround ensuring that there was a firm magnetic bond right around the window. The halves of the hot box were then closed firmly. The heat metering box was positioned over the window and the two small access doors were shut tight. The second test was then started. The procedure used was identical to that used for the single glazed window and was to be so for the remaining tests. Once the second test was completed and the GHB had been opened up, the magnetically-attached acrylic sheet secondary glazing could be removed to make way for the next test. 


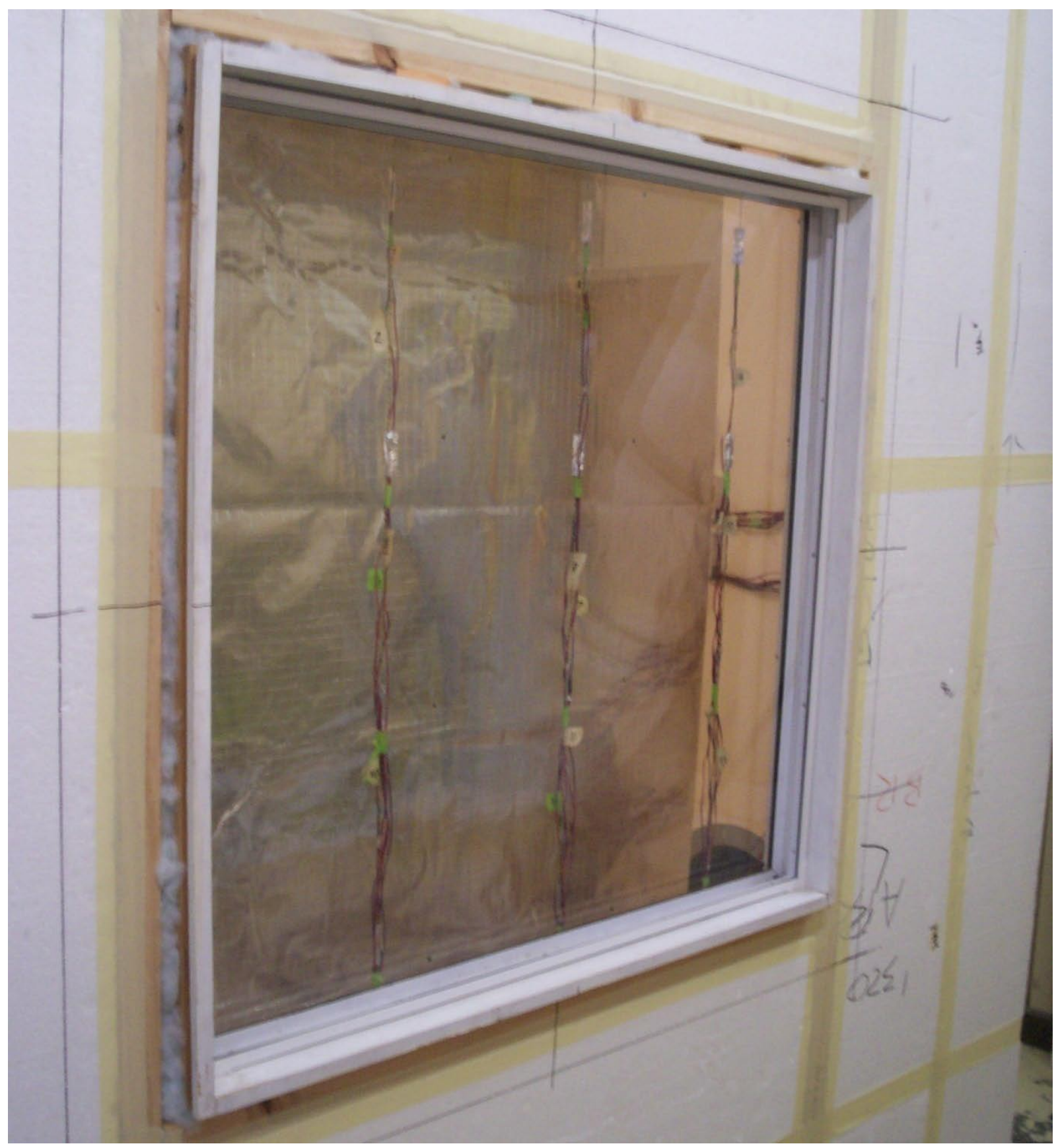

Figure 3-10: Magnetically-Attached Acrylic Sheet Positioned in Place

The third test involved installing the plastic film as secondary glazing, as per the manufacturers' instructions around the timber reveal of the window. The double sided tape was carefully positioned along the middle of the face of the timber reveal. Care was taken to ensure that the tape firmly adhered to the reveal of the window as the paint has begun to age. The plastic sheet was then cut to shape leaving a $25 \mathrm{~mm}$ overhang on each side. The second side of the double sided tape was then peeled and exposed and the polyethylene sheet was lightly fixed to it. The 
sheet was then released from different sides, stretched and then reattached. This process was continued until the creases were removed. Although the manufacturer recommends the use of a hairdryer, for this test a heat gun set to a low heat setting was then used to gently apply heat and shrink the polyethylene sheet. Beginning from the corner, the heat gun needed to be continuously moved and held at a $50 \mathrm{~mm}$ distance so it did not damage the sheet. This process was continued until there were no wrinkles and the sheet was firm. The double sided tape was then rechecked to make sure that it had not lifted off from the reveal or the sheet with the added tension and was pressed firmly once again, with the overhanging edges trimmed off. The GHB was then closed and the test started. At the end of the testing the double sided tape was carefully removed to prevent the aging paint from being lifted off the reveal.

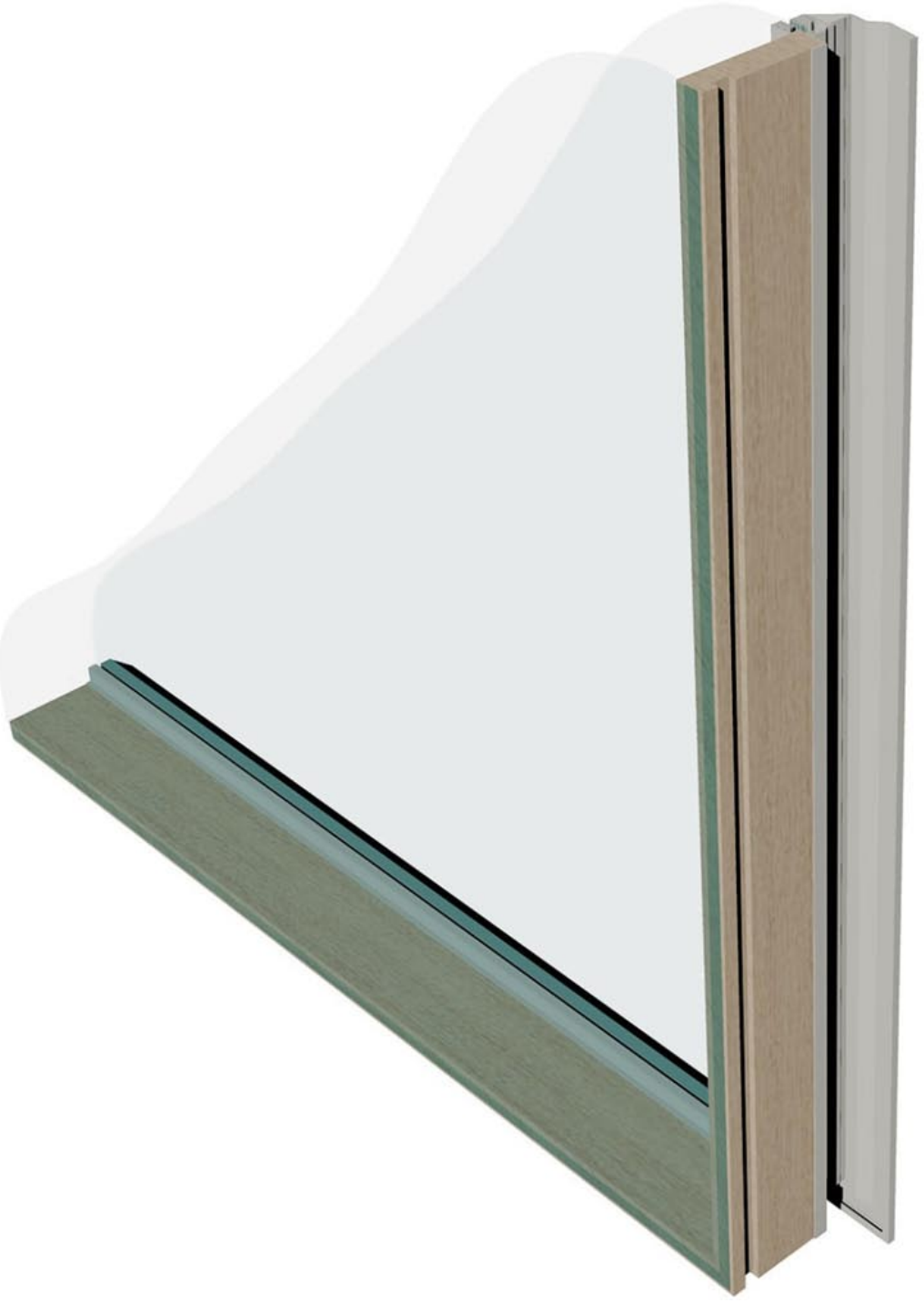

Figure 3-11: Perspective View of Thin Plastic Film Secondary Glazing 
The next test was on the aluminium framed, sliding-sash secondary glazing. The top and bottom tracks which had been cut to size by the manufacturer were firmly screwed into the reveal with the centre of the tracks approximately $45 \mathrm{~mm}$ from the existing glass. The aluminium rails were screwed to the side jamb, completing the framing. The two removable aluminium secondary glazed panes were then lifted into position in the tracks. They were slid into the closed position with care taken to ensure that the nylon brush pile draft strip that surrounds the panes was forming an air seal to prevent drafts into the cavity. The test was then started. Once the test was complete the two removable aluminium secondary glazed panes were lifted out and reglazed by the supplier with $6 \mathrm{~mm}$ low-E glass. They were then positioned back in the tracks as before with the low-E coating facing the cavity. The final secondary glazing test could then be started.

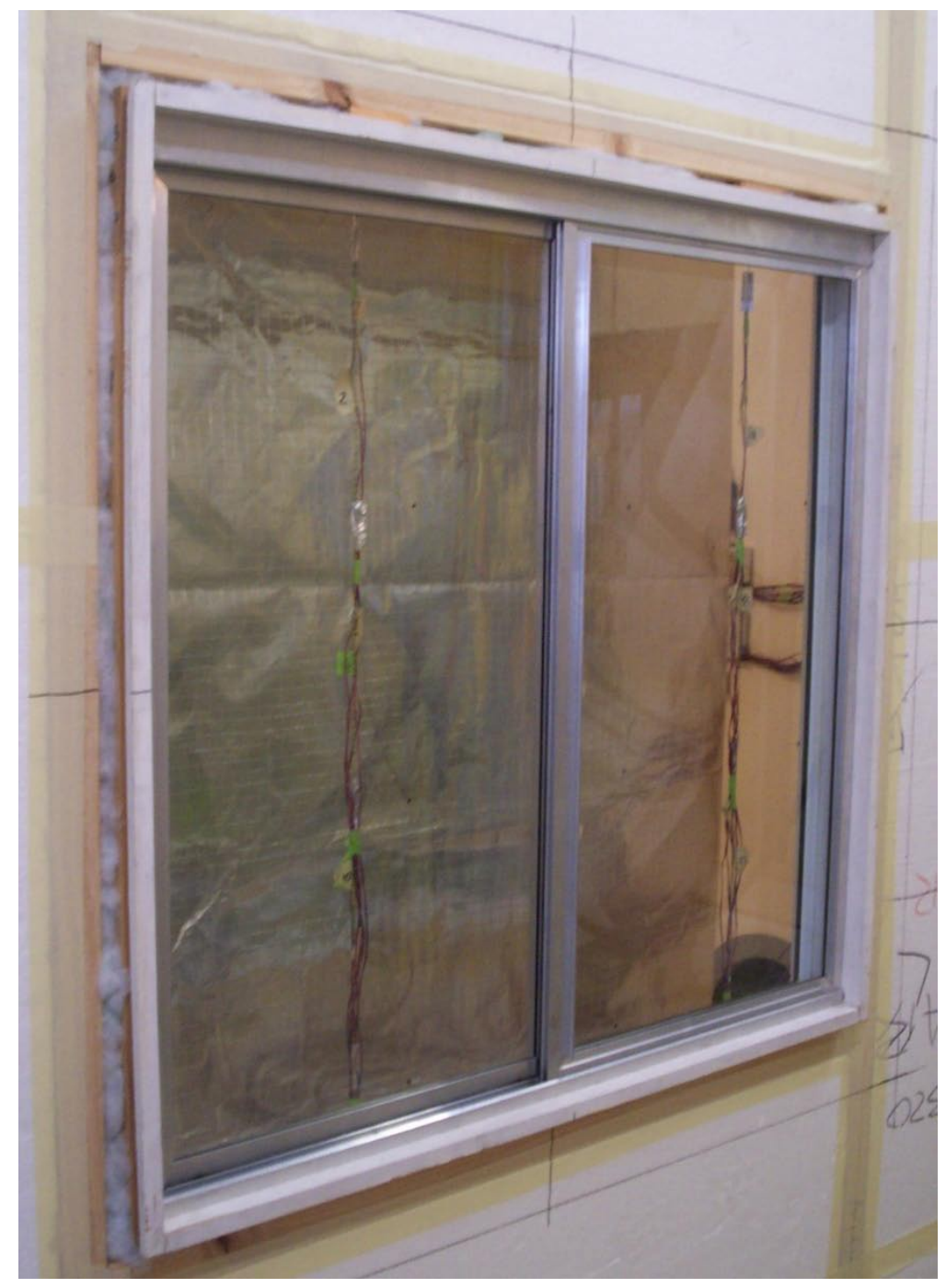

Figure 3-12: Aluminium Secondary Glazing 
As the heat metering box measured part of the surround panel as well as the test specimen, finally a calibration test was needed to quantify the thermal resistance of the surround. To do this a material with a known thermal resistance needed to be positioned in the window. For this experiment a sheet of EPS with a known R-value of $1.5 \mathrm{~m}^{2} \cdot \mathrm{K} / \mathrm{W}$ was used. The $1 \mathrm{~m} \times 1 \mathrm{~m}$ area now had a predicted thermal resistance. The results from this calibration test were used to help establish the uniform resistance of the $0.44 \mathrm{~m}^{2}$ panel surrounding the window.

With the data collected from the GHB testing, it then needed to be analysed. The measured results from all of the tests were then each analysed by an Excel macro where the R-value was calculated for every measured one minute interval of data from the testing. The data for each was assessed to find the point where the GHB output first stabilises. The data prior to this stabilisation was not required. From here on the measured R-value would only fluctuate very slightly above and below a constant value. This stable data was averaged to find the R-value of the tests including the window surround. The analysis of the GHB data as well as the results can be found in section 4.3.

The next step was to remove the influence of the surround panel from the GHB results. To do this the thermal resistance of the surround panel was calculated and subtracted using computer thermal simulation, providing the final whole window R-values. The computer thermal simulation process is described in detail in the following section.

\subsection{Computer Simulation}

This study used two different types of computer simulation.

\section{Window Thermal Transmittance Simulation}

2. Home Heating Energy Consumption Simulation

With the R-values from the GHB testing known, the next step was to calculate and remove the influence of the surround panel. As there were several different materials with various shapes and emissivities backing on to one another and facing the outside environment, the calculations 
become quite difficult. To simplify this process a thermal simulation program was used to conduct the calculations.

Once the thermal transmittance of the different secondary glazed windows was known then the potential energy savings were able to be calculated. Computer simulation of a home to calculate the heating energy savings provided by the various secondary glazing systems was used. The simulation program and test parameters needed to be identified and selected so the most suitable method to find the savings provided by secondary glazing in New Zealand could be implemented.

\subsubsection{LBNL Window 6 \& Therm 6}

The first simulations to be conducted were whole window thermal transmittance calculations. The chosen method to conduct these simulations was a combination of two separate programs, Window 6 (LBNL, 2009a) and Therm 6 (LBNL, 2009b), provided by Lawrence Berkley National Laboratory (LBNL).

The use of this thermal simulation software to calculate the resistance of the windows served multiple purposes. These programs were primarily selected to calculate and remove the influence of the surround panel, revealing the final whole window R-values measured by the guarded hot box. A total of four different computer simulations were used on each of the windows.

1. Pilot Thermal Simulation

2. Simulation in accordance with NZS 4218

3. Simulation to NFRC-100 Standards

4. Surround Panel Calculation and Removal

The following section provides a broad description of the modelling process and then the variables required for each specific simulation are outlined along with a discussion of why they were chosen and the implications the results may have. 
The first step was to model 5 glazing systems, one for the primary window and one for each of the four secondary glazing systems. This calculates the influence of the glazing used and the air gap separating the panes. The glazing systems which make up the primary window and the secondary glazing panes were modelled in Window 6. For each of these glazing systems Window 6 was able to provide results on the centre of glazing thermal transmittance, Solar Heat Gain Coefficient (SHGC), Visible Transmittance and Relative Heat Gain. These modelled glazing systems were required for the window frame simulation using Therm 6, which was the next step in the process. They will also be required again later in Window 6 for the whole window R-value calculation.

Computer-aided design (CAD) was used to produce the window structure, which was imported into Therm 6. To draw a complicated model in Therm 6, a CAD underlay was required to ensure the dimensions were correct. The various window profiles; sill, side jamb and top jamb for the primary window and for each of the secondary glazing systems fitted inside the primary window were modelled using AutoCAD (Autodesk, 2009) to produce sections. The two different aluminium secondary glazed windows also required an aluminium window divider to be modelled as well, completing the CAD underlays.

These CAD underlay sections were then traced over in Therm 6. The frame profile sections were drawn and each material and associated thermal transmittance was assigned appropriately. Any frame cavity areas were filled with the accepted NFRC 100-2001 frame cavity material. The appropriate glazing system for the section being modelled was then imported into Therm 6 from Window 6 and positioned in its place in the frame. Appropriate boundary conditions were assigned to all exterior surfaces as prescribed by the NFRC Simulation Manual (Mitchel, Kohler, \& Arasteh, 2006). Each section of every window setup, including the dividers on the aluminium windows, could then have its thermal transmittance calculated in Therm 6. Each model was also given the appropriate boundary conditions. A total of 64 frame cross sections were modelled and simulated. This was necessary to simulate the windows to each standard and model each cross section with and without the GHB surround. Examples of some of these models are provided in Appendix6.4B.1. The first of the following figures show the sill as modelled and the second gives a false colour display of the simulation results. The model shown represents the window only and has not modelled the surround 

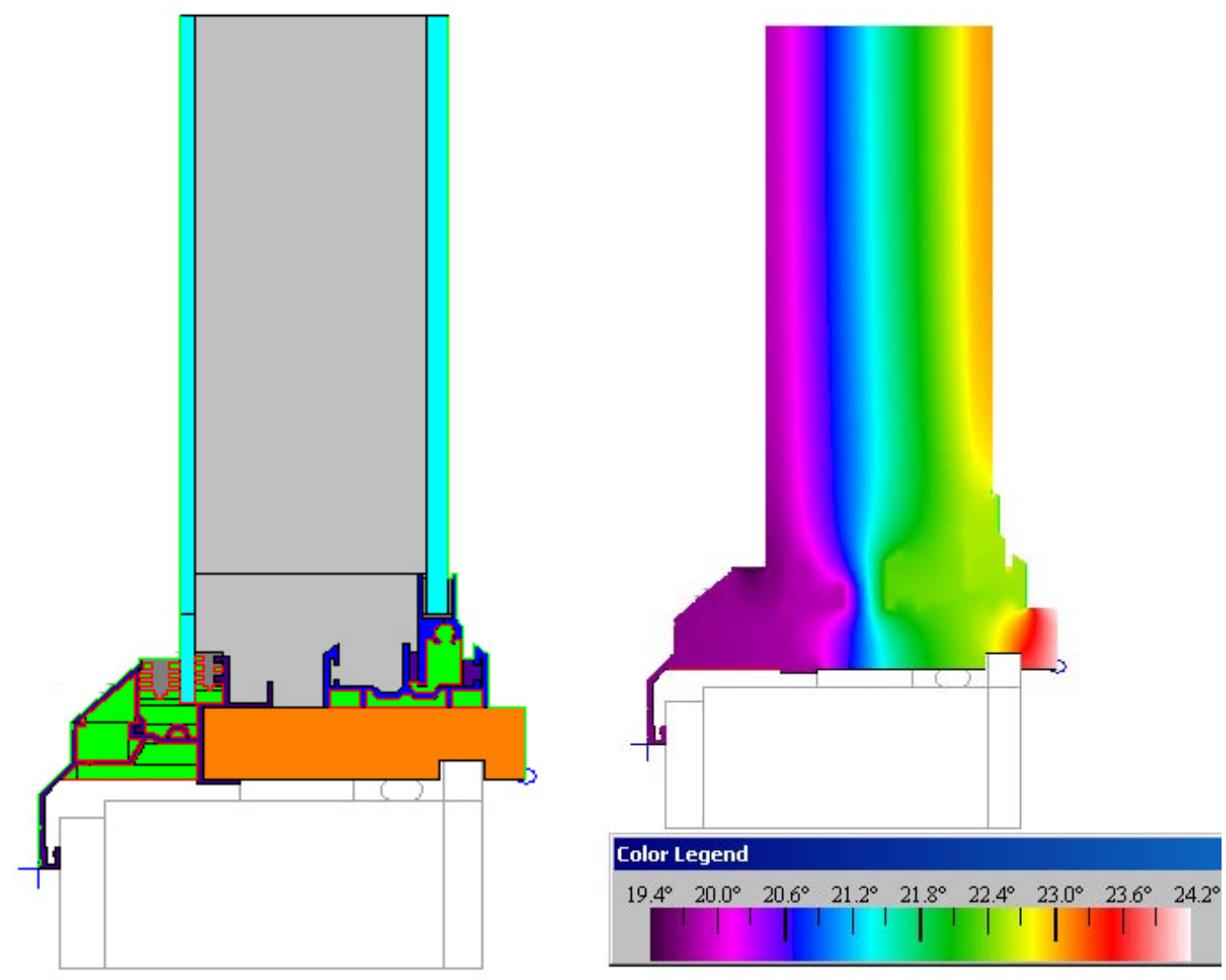

\section{Figure 3-13 \& Figure 3-14: Therm 6 Model of Aluminium Secondary Glazed Sill}

Once the frame R-values and properties were calculated in Therm 6 then it was possible to conduct a whole window simulation by importing the frame values into Window 6 . Here the frame R-values and the glazing unit were combined and a whole window R-value was calculated for the proportion of frame to glazing. A window was modelled with the appropriate glazing system which had been previously calculated in Window 6. Each of the frame components which had been calculated in Therm 6 (head, left and right jamb, sill and dividers if used) were imported into Window 6 and positioned appropriately around the glazing unit. Window 6 was then used to calculate the whole window $\mathrm{R}$-value using calculation methods prescribed by ISO 15099 (ISO, 2003) and NFRC 100 (NFRC, 2004).

\subsubsection{Comparison between GHB and Thermal Simulation Results}

The first series of simulations were originally calculated prior to the GHB test process as a pilot study. The model used NFRC indoor and outdoor boundary conditions in Therm 6 and NFRC 
environmental conditions in Window 6. The only deviation from the NFRC standard was that the window was modelled as a $1 \mathrm{~m} \times 1 \mathrm{~m}$ fixed frame window, the same dimensions as the window tested in the GHB.

The simulation essentially used the window proportions as tested in the GHB but simulated to NFRC 100 conditions (NFRC, 2004). The purpose of conducting this simulation was to allow direct comparisons between the computer simulation and the guarded hot box testing to be drawn. If the computer calculated results were similar to those measured in the guarded hot box then there would be evidence that the computer calculations are sufficient for finding thermal transmittance values for secondary glazing systems. This would support the assumption that future thermal transmittance calculations of secondary glazed fenestration systems would provide adequate results based on computer simulation.

The following simulations are very similar however they were simulated in accordance with specific standards. These simulations relative to the appropriate standards will show us how well the secondary glazing systems perform in relation to other windows simulated by these standards. If the performance calculated by these standards was significantly different to those measured in the hot box then they may not be suitable for determining the thermal performance of secondary glazing. This could be due to the differences between secondary glazed windows and the single and insulated glazing units the standards and programs are designed to calculate. Two different standards were used. They were NFRC 100-2004 and the Standard 'Window Rvalue Calculation Procedure' as used for NZS 4218:2009. The variables for each of the simulations are explained in the following sections.

\subsubsection{Simulation to NFRC-100 Standards}

The NFRC standard was chosen due to its widespread use. The National Fenestration Rating Council was established in 1989, developing and implementing a fenestration rating system. This system is voluntary however it has the largest database of whole window U-values; called the Certified Products Directory. The directory includes energy performance ratings for over 1.67 million product options from more than 500 manufacturers who have all chosen to participate (NFRC, 2009). While predominantly North American manufacturers are represented by the 
NFRC, such a widespread use of a singular simulation method is impressive. With so many products already modelled to NFRC-100 2004, this permits comparison of these secondary glazing systems with other products.

The Therm 6 models were modelled with the NFRC indoor and outdoor boundary conditions. The Window 6 model used the standard NFRC 100-2004 fixed window size convention of $1500 \mathrm{~mm} \times 1200 \mathrm{~mm}$ as specified (NFRC, 2004). The NFRC 100-2001 environmental conditions were specified under the environmental conditions tab of Window 6. This gave results in accordance with NFRC 100-2004.

\subsubsection{Simulation in accordance with NZS 4218}

This model used the same process used to produce the values listed in Tables C1 to C4 of Appendix C of NZS 4218 (NZS 4218, 2009). This process is based around NFRC 100 however there are some differences. The Window 6 model used the standard size used for modelling windows with this standard, which was a $1500 \mathrm{~mm}$ high $\times 1800 \mathrm{~mm}$ wide window (Burgess \& Skates, 2001) with a central mullion and one opening light. The aluminium frame was modelled in Therm 6 with a $19 \mathrm{~mm} \times 114 \mathrm{~mm}$ timber window liner, as prescribed by the standard calculation procedure (BRANZ, 2009b).

The results of this simulation will be useful to monitor how these systems would measure up to other windows simulated using New Zealand conventions. This will allow for the thermal performance of the secondary glazed windows to be compared to generic windows in a variety of frames. The R-values of the secondary glazed windows can be analysed against the R-values of comparable IGUs in aluminium frames, making it possible to evaluate the performance differences between retrofitting with double glazing and retrofitting with single glazing. Examples of windows simulated to these standards are the typical window R-values listed in Tables C1 to C4 of Appendix C of NZS 4218:2009 and the R-values of products on the market tested to these standards. 


\subsubsection{Surround Panel Calculation and Removal}

Once the R-value for each GHB measurement had been established, then the thermal resistance of the surround panel needed to be calculated and removed in order to find the R-value of just the test specimen. This was done by a combination of the LBNL software programs Therm 6 and Window 6 as well as using data from the calibration test.

The window was modelled as it was measured by the $1.2 \mathrm{~m} \times 1.2 \mathrm{~m}$ heat metering box. This meant that some of the surround needed to be modelled in Therm 6 . The opening was formed by timber studs measuring $90 \mathrm{~mm} \times 45 \mathrm{~mm}$ with $15 \mathrm{~mm}$ timber packers which were also modelled along with $40 \mathrm{~mm}$ of the surrounding expanded polystyrene wall.

For the simulation of the GHB testing to remove the influence of the surround panel, GHB specific boundary conditions were assigned in Therm 6 . These boundary conditions have the same indoor and outdoor temperatures as the GHB as well as similar convection coefficients.

The environment was engineered to match that created by the GHB by emulating the GHB boundary conditions in Therm 6 and the GHB environmental conditions in Window 6. The $1.2 \mathrm{~m} \times 1.2 \mathrm{~m}$ modelled whole window and GHB surround was simulated alone and with each secondary glazing unit installed in Window 6 to match the results found in the guarded hot box.

With the GHB tests emulated in the computer it was possible to repeat the calculations with the surround materials removed. The process above was repeated once again with identical boundary and environmental conditions. This time the sections modelled in Therm 6 do not have the surround panel modelled and the $1 \mathrm{~m}$ x $1 \mathrm{~m}$ windows could be simulated in Window 6 . Window 6 then calculates the final whole Window R-values, effectively calculating and removing the influence of the surround panel in the GHB tests. The results will provide a fair reflection of the performance improvements provided by the various secondary glazing systems. 


\subsubsection{House Model}

Once the whole window thermal resistance provided by each unit was known then it was necessary to calculate the energy savings provided. This was done by simulating typical New Zealand homes using the program ALF 3.1 (BRANZ, 2009a). ALF was chosen over other thermal simulation programs due to the programs ease of use for conducting simulations of typical New Zealand homes quickly in various New Zealand climate zones with typical New Zealand heating schedules. ALF has been created for use in New Zealand and is able to quickly provide energy reports as well as NZS 4218 calculations.

ALF was used to simulate the homes in four specific cities; these are presented on in Table 3-2 below. The climate zone for each city is defined by NZS 4218:2009.

Table 3-2: Chosen Climate Zones for ALF Simulation

\begin{tabular}{|c|c|c|c|}
\hline & City & Location & Climate Zone \\
\hline 1 & Auckland & Upper North Island & Zone 1 \\
\hline 2 & Wellington & Lower North Island & Zone 2 \\
\hline 3 & Christchurch & Upper South Island & Zone 3 \\
\hline 4 & Dunedin & Lower South Island & Zone 3 \\
\hline
\end{tabular}

Ten ordinary New Zealand homes were modelled in ALF. The homes were randomly selected middle income single and two-storied households from a range of designs, sizes and construction materials. The homes were all constructed prior to 1978 and as a result are generally uninsulated throughout with some of the homes receiving minor retrofits. The average window area for these homes was $40.5 \mathrm{~m}^{2}$, only $0.5 \mathrm{~m}^{2}$ more than the average home in 1996 (Burgess, 1998). The model houses had a variety of orientations with some having the majority of the glazing facing north to maximise solar gains while other houses were orientated towards the most attractive views. Modelling assumptions, detailed input data and final reports for each of these homes can be found in 0 . 
Table 3-3: House Sizes and Insulation Values

\begin{tabular}{|c|c|c|c|c|c|c|c|}
\hline House & $\begin{array}{l}\text { Floor } \\
\text { Area } \\
\left(\mathrm{m}^{2}\right)\end{array}$ & $\begin{array}{c}\text { Window } \\
\text { Area } \\
\left(\mathrm{m}^{2}\right)\end{array}$ & $\begin{array}{l}\text { Wall } \\
\text { Area } \\
\left(\mathrm{m}^{2}\right)\end{array}$ & $\begin{array}{l}\text { Window } \\
\text { to Wall } \\
(\%)\end{array}$ & $\begin{array}{c}\text { Floor } \\
\text { R-Value } \\
\left(\mathrm{m}^{2} \cdot \mathrm{K} / \mathrm{W}\right)\end{array}$ & $\begin{array}{c}\text { Wall } \\
\text { R-Value } \\
\left(\mathrm{m}^{2} \cdot \mathrm{K} / \mathrm{W}\right)\end{array}$ & $\begin{array}{c}\text { Roof } \\
\text { R-Value } \\
\left(\mathrm{m}^{2} \cdot \mathrm{K} / \mathrm{W}\right)\end{array}$ \\
\hline 1 & 171.2 & 38.8 & 165.2 & 23.5 & 0.73 & 0.70 & 1.36 \\
\hline 2 & 165.2 & 36.3 & 152.8 & 23.8 & 0.75 & 0.75 & 0.56 \\
\hline 3 & 189.7 & 46.7 & 167.0 & 28.0 & 0.78 & 0.70 & 0.50 \\
\hline 4 & 113.3 & 31.5 & 95.6 & 32.9 & 1.17 & 0.70 & 0.50 \\
\hline 5 & 142.0 & 32.8 & 110.4 & 29.7 & 1.12 & 1.23 & 0.50 \\
\hline 6 & 184.1 & 56.9 & 158.3 & 35.9 & 1.33 & 0.65 & 0.50 \\
\hline 7 & 253.7 & 50.6 & 159.8 & 31.7 & 1.05 & 0.69 & 1.61 \\
\hline 8 & 182.1 & 50.5 & 143.6 & 35.2 & 0.78 & 0.80 & 1.50 \\
\hline 9 & 120.7 & 24.1 & 140.8 & 17.1 & 0.94 & 0.80 & 1.61 \\
\hline 10 & 184.4 & 36.4 & 166.0 & 21.9 & 0.68 & 0.44 & 1.71 \\
\hline Mean & 170.6 & 40.5 & 146.0 & 27.7 & 0.93 & 0.75 & 1.04 \\
\hline
\end{tabular}

The homes were simulated using a typical NZ heating schedule of Morning (7am-9am) and Evening $(5 \mathrm{pm}-11 \mathrm{pm})$ heating. This schedule was chosen due to its frequent use in New Zealand energy analysis simulations. A house insulation cost benefit analysis conducted by BRANZ used two 12 month heating schedules, Morning (7am-9am) and Evening (5pm - 11pm) and All Day (7am - 11pm) (Page, 2006). Another study uses 24 hour heating and acknowledges while this is not likely in real situations it was used to calculate the BPI (Building Performance Index) (Pollard, 2005). For this research All Day and 24 hour heating schedules run the risk of overestimating the energy savings provided by secondary glazing. A morning and evening schedule was selected as the most likely to be encountered in the homes making it more suitable for a cost benefit analysis.

The heating level was set at $18^{\circ} \mathrm{C}$. This is the minimum temperature recommended for thermal comfort by the World Health Organisation (WHO, 2007) and was the closest set point in ALF to the average winter heating temperature of $17.3^{\circ} \mathrm{C}$ in homes built after 1978 as measured by the Household Energy End-use Project (HEEP) (Isaacs, Amitrano, Camilleri, Pollard, \& Stoecklein, 2002).

ALF calculates the heating season for the homes from the outdoor temperature data associated with the climate file. A comparison between the heating months determined by a small survey and the corresponding long-term average outdoor monthly temperatures gave the heating 
threshold for the program. The result was an outdoor average monthly threshold temperature of $11.5^{\circ} \mathrm{C}$ (Stoecklein \& Basset, 2000). This average monthly threshold temperature is applied to the four chosen climates described in Table 3-2 and ALF calculates the winter heating season. It is during this winter heating season that the home is heated to the heating set point of $18^{\circ} \mathrm{C}$ during the Morning $(7 \mathrm{am}-9 \mathrm{pm})$ and Evening $(5 \mathrm{pm}-11 \mathrm{pm})$ heating schedule. The winter heating season for each climate is presented in Table 3-4.

Table 3-4: Heating Seasons for each Climate

\begin{tabular}{|l|l|}
\hline Climate Zone & Winter Heating Season \\
\hline Auckland & June to August \\
\hline Wellington & May to September \\
\hline Christchurch & May to September \\
\hline Dunedin & May to October \\
\hline
\end{tabular}

Each of the ten homes was modelled 5 times, once with the primary windows installed and then four more times with each of the secondary glazing systems installed. This resulted in a total of 50 different models. These 50 models were each then simulated with the 4 different climates resulting in a total of 200 heating energy simulations.

Not all windows in the homes were able to be secondary glazed. Many of the homes contained glazing inset within doors, ranch slider doors, and conservatory style areas which, for the purposes of this study have not been secondary glazed. In the thermal models these windows retain the final whole window $\mathrm{R}$-value of the single glazed primary window for all four of the secondary glazing simulations as well as the initial single glazed simulation.

ALF has pre-programmed window thermal resistances which are selected from a drop down menu. Once the secondary glazing R-values were known they were then written into the ALF program files, enabling them to be selected from the drop down menu. These R-values were then matched up to a corresponding SHGC for the specific window. The program was able to then use these new window thermal resistance values and SHGC data to provide accurate thermal energy simulation results. 
SHGC is difficult to measure and subject to change depending on the glass used and the cleanliness of the window. There is also potential for the SHGC of plastic to decrease as the plastic deteriorates over time with UV damage. Due to these difficulties, default SHGC coefficients from Table 1 of BRANZ Bulletin 387 (BRANZ, 1999) were used assuming clear glass and an aluminium frame. As specified by the table, the SHGC of the primary aluminium window was 0.7 . The thin plastic film, magnetically-attached acrylic sheet and aluminium framed secondary glazing were all assumed to have equal SHGC's. The chosen SHGC for these products was 0.61 , the same as that of a typical clear 4-12-4 double glazed window. The SHGC of the low-E secondary glazing was assumed to match that of typical 4-12-4 low-E double glazed window which is 0.57 .

Once all 200 simulations had been calculated, the annual heating energy use from each simulation was compiled in a spreadsheet and then analysed to identify any trends or inconsistencies. Where necessary, further analysis of the results was possible within ALF to pinpoint where heat was being gained and lost through the building envelope and how the addition of the various secondary glazing systems influence this. Once this analysis was complete it was then possible to move on to the cost benefit equations for each of the secondary glazing systems.

\subsubsection{Cost Benefit Calculations}

Quotes were obtained from each of the manufacturers to secondary glaze two of the 10 homes. These two homes both have very similar glazing areas, varying by only $1.25 \mathrm{~m}^{2}$, however the home with the smaller glazing area has more windows resulting in a larger frame perimeter. Assuming the glazing and installation cost per $\$ / \mathrm{m}^{2}$ remains the same; the price variation between the two homes could be attributed to the additional framing and manufacturing to produce more windows. The two homes were chosen due to their large differences in area per window. When averaged, these two homes provide a reasonable reflection of the average window size across the sample. This allowed the quoted prices to be calculated for the remaining eight homes using a simple average cost per window, multiplied by the number of windows. These prices were used with the heating energy costs for each home to complete the final cost benefit calculation. 
With final energy consumptions for each home in the four climate zones in ALF it was then time to complete the cost benefit equations. It was assumed that the heating for the homes was provided by electricity. ALF only calculates the amount of heat which was necessary to achieve the specified heating schedule and level (Stoecklein \& Basset, 2000). It was assumed that the heating was equally distributed around the homes and that the electric heat source had an efficiency of $100 \%$. Therefore the cost to provide the required amount of heating energy was calculated by multiplying the current price of electricity $\$ / \mathrm{kWh}$ with the annual amount of energy required to heat the home for the standard single glazed option and for each of the four secondary glazing retrofits.

The electricity cost was determined from the schedule of domestic electricity prices provided by the Ministry of Economic Development (MED, 2009a). As energy costs vary depending on the location, region specific energy prices were used. These prices were generated using the New Zealand consumer average of $8000 \mathrm{kWh}$ per annum and include the "line charge" component, goods and services tax and any prompt-payment discounts offered by the retailer, so they represent the final cost to an average New Zealand domestic consumer who pays on time (MED, 2009b). The cost for each region is an ICP (Installation Control Point) weighted average retail charge. This value represents the average cost of electricity to a typical domestic consumer within the region for the $15^{\text {th }}$ of February 2009.

The cost calculation for the thin film secondary glazing required a different process. As the thin film is marketed as do-it-yourself, there are no installation costs. Therefore the costs could be calculated using the prices of the film alone. Kits specifically tailored towards window insulation are available or the appropriate film and adhesive could be purchased. This research found shrink film kits from two different manufacturers, 3M (Aneco, 2008) (NRL, 2008) (Sustainable Design, 2008) and Henkel (CEA, 2008b), available for purchase in New Zealand. For the purposes of this calculation, prices sourced from the same product which was tested were used. There were 3 sizes available and the most affordable store to purchase the kits from was selected. The prices used were (Sustainable Design, 2008): 


\section{Table 3-5: Thin Plastic Film Secondary Glazing Prices}

\begin{tabular}{|l|l|c|}
\hline Kit & Size $(\mathrm{mm})$ & Price $(\mathrm{NZD})$ \\
\hline Small & $2130 \times 1570$ & $\$ 19.00$ \\
\hline Large & $5330 \times 1570$ & $\$ 35.80$ \\
\hline Patio Door Kit & $2840 \times 2130$ & $\$ 29.80$ \\
\hline
\end{tabular}

The total price to secondary glaze the possible windows was calculated for each home from these costs. The windows were arranged so that there was as little unnecessary waste from the window film packs as possible, allowing for the lowest possible cost per $\mathrm{m}^{2}$ for each home. Due to this the homes primarily used the large pack with several windows being secondary glazed from the pack as it was the most cost efficient per $\mathrm{m}^{2}$. This would require sensible window selection from the homeowner installing the product and care to carefully cut out the appropriate shapes leaving only the $25 \mathrm{~mm}$ excess recommended on each side. The installer would also have to ensure that the film was not damaged during or after the installation. Using this technique the most affordable method of secondary glazing each home with the film was determined. Also included in the price for each home were the nationwide, flat rate shipping and handling charges of $\$ 20$.

It is only recommended to leave the film on the windows for one heating season. As the energy simulation used in ALF was for 12 months, the film was assumed to be left intact for 12 months. This will have little, if any; effect on the energy calculations as heating was only applied during the winter season described in Table 3-4. While the film could be left on after this period, there is a risk of deterioration so for the purpose of this research it was decided that it will be changed annually. Due to this the cost benefit calculation determines the annual saving made by installing the film. Rather than producing an expected payback period for the product, the result was the annual home heating energy cost savings for the year minus the cost of the window kits for that home.

The three remaining systems; magnetically-attached-acrylic, aluminium and aluminium low-E secondary glazing needed to have the payback period calculated. A simple payback calculation was chosen. The simple payback period was the number of years required for the annual heating energy savings to match the cost of purchasing and installing the units. The annual heating 
energy costs with the secondary glazing systems were subtracted from the annual heating energy costs for the single glazed window. This resulted in the total heating energy cost savings provided by installing the secondary glazing. The total purchase and installation costs of the secondary glazing options for each home were then divided by the annual energy savings to determine the simple payback period of each system in years. This was done for all of the various homes in each of the four climates. With the simple payback period known, it was possible to analyse this data and determine whether or not retrofitting with these secondary glazing units is a cost effective solution.

To allow comparison between the thin plastic film and the other secondary glazing systems, the cumulative lifetime costs were analysed over a period of 25 years. This analysis consisted of the capital cost of installing the system plus the heating energy costs over the 25 year period. The lifetime costs for the thin film plastic consist of the sum of the annual purchase costs and the annual heating energy costs over 25 years. It can then be determined if and when the three permanent secondary glazing systems become more financially viable than the thin plastic film secondary glazing. These comparisons are displayed in Figure 4-2: Lifetime Cumulative Secondary Glazing and Heating Costs from 0 - 25 Years.

\subsubsection{Ancillary Benefits}

Other benefits of the Secondary glazing will be discussed alongside the final Cost Benefit Results. This covers aspects not covered by the cost benefit calculation such as improved thermal comfort, increased acoustic insulation and decreased infiltration. Individual merits of each secondary glazing unit will also be discussed. These cover aspects such as ease of use, durability, maintenance, aesthetics and lifespan. 
A Cost Benefit Analysis of Secondary Glazing as a Retrofit Alternative for New Zealand Homes 


\subsection{Results and Analysis}

\section{$4.1 \quad$ Overview}

The following chapter describes the results found by this research. It begins with the results from the computer simulation of the windows to a variety of standards. This is followed by the raw data results conducted by the guarded hot box test. Following this the final whole window $\mathrm{R}$-values are presented. These results were then entered into home heating energy simulations which were used to determine the final cost benefit. The final cost benefit analysis is followed by a discussion on secondary glazing as a cost effective option when compared to other retrofit alternatives. The chapter then closes with a discussion on the other effects of secondary glazing and how these can relate to a cost benefit calculation.

\subsection{Window Thermal Simulation}

This section presents the results of whole window thermal resistance simulations, conducted using the programs Therm 6 and Window 6. There are three results presented in the following section, each containing a brief discussion. They are:

- Pilot thermal simulation for comparison with GHB results

- Simulation in accordance with NZS 4218 process

- Simulation to NFRC-100 Standards

The thermal simulation models will also be used later in section 4.3.3. The purpose of this was to calculate and remove the thermal resistance of the surround panel, providing the final whole window GHB results. 


\subsubsection{Pilot thermal simulations}

The first results presented are from the thermal simulations conducted using Window 6 and Therm 6 . These results were calculated prior to the guarded hot box testing to give an indication of the performance likely to be provided by each system. This allows comparison between calculated and measured results as well as comparison to other products simulated using the same standards.

The results of the whole window thermal resistance calculations are shown below. These results were calculated using the typical NFRC modelling standards for the window, frame and environment. The only difference is that the size of the window modelled was a $1 \mathrm{~m} \times 1 \mathrm{~m}$ fixed light window with an $84 \mathrm{~mm} \times 19 \mathrm{~mm}$ timber reveal and no horizontal or vertical dividers. This represents the windows modelled as they were tested in the guarded hot box but under NFRC conditions. Results of the window and secondary glazing systems modelled strictly to NFRC conditions are presented in Section 4.2.3.

Table 4-1: Pilot Thermal Resistance Simulation Results for Selected Secondary Glazing ${ }^{2}$

\begin{tabular}{|l|c|c|c|}
\hline Fenestration Unit & U-Value $\left(\mathbf{W} / \mathbf{m}^{\mathbf{2}} \cdot \mathbf{K}\right)$ & R-Value $\left(\mathbf{m}^{2} \cdot \mathbf{K} / \mathbf{W}\right)$ & Improvement \\
\hline Window & 6.1 & 0.16 & $\emptyset$ \\
\hline Magnetic Acrylic & 2.6 & 0.38 & $130 \%$ \\
\hline Thin Plastic Film & 2.7 & 0.37 & $120 \%$ \\
\hline Aluminium & 2.8 & 0.35 & $120 \%$ \\
\hline Aluminium Low-E & 2.0 & 0.51 & $210 \%$ \\
\hline
\end{tabular}

The results for the secondary glazing units show significant increases in thermal resistance with the best system (6mm clear, low-E aluminium frame) increasing the thermal resistance of the window by $210 \%$. The next best performing system was the magnetically-attached acrylic sheet unit. This received a better result due to the increased thermal resistance of plastics. The acrylic secondary glazing coupled with the plastic surrounding frame has a higher thermal resistance compared to the aluminium and clear glass of the aluminium framed secondary glazing.

\footnotetext{
${ }^{2} \mathrm{R}$-values presented in this chapter are for whole window results and are not centre of glass numbers.
} 
While the GHB testing was susceptible to air movement between the panes of glass, the Window 6 method assumes an airtight seal of the two panes. The sliding sash design of the aluminium low-E window means that it may be more susceptible to more air movement between the panes than that calculated in the Window 6 simulation.

These significant R-value improvements of the two glass secondary glazings over the single glazed window were possibly due to the nature of the air gap modelled in Window 6. In accordance with Section 8.4: 'Storm Windows' in the NFRC Simulation Manual (Mitchel, Kohler, \& Arasteh, 2006) the air gap assigned to the inter-pane space of the secondary glazing system was a standard 'air' fill just like one used between two panes when modelling an IGU in window 6 . In reality there may be more air circulation between the two panes of a secondary glazing unit due to the seal not being as airtight as one used in an IGU. The larger air gap is also more susceptible to natural convection of the air within the space. This would increase the heat flow across the space and lower the actual R-value of the window.

The key difference between modelling an IGU and modelling a secondary glazing system is the effectiveness of the air cavity between the two panes of glass. In reality secondary glazing systems may struggle to reach similar levels of airtightness as achieved by an IGU. Reasons for this could be the air infiltration of the primary window which the secondary glazing system has been fixed to, or infiltration through the surrounds of the inner, secondary glazing plane.

The results of the Window 6 simulations seem to be similar to those that were manually calculated or computer simulated in accordance with thermal calculation standards, but they seem to be much better than studies which have secondary glazing measured in test cells or houses. This may be a reflection that typical calculation assumptions may not be suitable for the calculation of secondary glazing R-values where the gap between the panes is greater than about $20 \mathrm{~mm}$. Should the hot box experiments find significantly lower R-values across the range of secondary glazing systems than these calculations, but not the single glazed window, then it would be fair to conclude that the thermal simulation method currently used may be too generous for secondary glazing. 


\subsubsection{NZS 4218}

The reason for using thermal simulation in this study was to provide final R-values from the physical testing by calculating and removing the influence of the surround panel used to house the window in the GHB. It also allows an analysis of the different results between the guarded hot box testing and thermal simulation techniques. The process used to calculate these differences in the previous section differs from other recommended thermal simulation methods.

These methods provide a standardised method for comparing the thermal resistance of whole window $\mathrm{R}$-values. Calculating the window $\mathrm{R}$-values in accordance with these guidelines allows for comparisons with the large databases of results from various products simulated under the same conditions. For the purpose of this research two different procedures were selected.

The first procedure was the same process used to produce the values listed in Tables C1 to C4 of Appendix C of NZS 4218:2009. It uses the Standard Window R-value Calculation Procedure (SCP) and is very similar to the NFRC method. The primary differences are that it uses the New Zealand conventions of a combination awning window, $1800 \mathrm{~mm}$ wide $\mathrm{x} 1500 \mathrm{~mm}$ high, with a central mullion, one opening light and a 19mm x 114mm timber reveal (BRANZ, 2009b). This simulation method was chosen due to the local significance. These results were produced to provide a comparison of results from this method of simulation and other forms of testing. To allow a fair comparison between these results and other windows in Appendix C of NZS 4218:2009, the secondary glazing units would need to be simulated on a typical New Zealand aluminium single glazed window. This single glazed window has an R-value of $0.15 \mathrm{~m}^{2} \cdot \mathrm{K} / \mathrm{W}$ (BRANZ, 1999), $0.02 \mathrm{~m}^{2} \cdot \mathrm{K} / \mathrm{W}$ lower than the calculated R-value of the actual window used. 
Table 4-2: Thermal Resistance Simulation to NZS 4218

\begin{tabular}{|l|c|c|c|}
\hline Fenestration Unit & U-Value $\left(\mathbf{W} / \mathbf{m}^{\mathbf{2}} \cdot \mathbf{K}\right)$ & R-Value $\left(\mathbf{m}^{2} \cdot \mathbf{K} / \mathbf{W}\right)$ & Improvement \\
\hline Window & 5.9 & 0.17 & $\emptyset$ \\
\hline Magnetic Acrylic & 2.6 & 0.38 & $130 \%$ \\
\hline Thin Plastic Film & 2.7 & 0.37 & $120 \%$ \\
\hline Aluminium & 2.8 & 0.36 & $110 \%$ \\
\hline Aluminium Low-E & 1.9 & 0.53 & $210 \%$ \\
\hline
\end{tabular}

\subsubsection{NFRC 100-2004}

There are only minor differences between the NFRC-100 and NZS 4218 prescribed methods for simulating windows. The NFRC-100 method allows for the simulation of a fixed framed window with no mullions and an $84 \mathrm{~mm} \times 19 \mathrm{~mm}$ timber reveal, similar to the window chosen for the GHB testing. The specified size for this type of window simulated in accordance with NFRC100 is $1500 \mathrm{~mm} \times 1200 \mathrm{~mm}$ (WERS, 2009).

Table 4-3: Thermal Resistance Simulation to NFRC 100-2004

\begin{tabular}{|l|c|c|c|}
\hline Fenestration Unit & U-Value $\left(\mathbf{W} / \mathbf{m}^{2} \cdot \mathbf{K}\right)$ & R-Value $\left.\mathbf{( m}^{2} \cdot \mathbf{K} / \mathbf{W}\right)$ & Improvement \\
\hline Window & 5.9 & 0.17 & $\emptyset$ \\
\hline Magnetic Acrylic & 2.6 & 0.38 & $130 \%$ \\
\hline Thin Plastic Film & 2.7 & 0.37 & $120 \%$ \\
\hline Aluminium & 2.8 & 0.36 & $110 \%$ \\
\hline Aluminium Low-E & 1.9 & 0.53 & $210 \%$ \\
\hline
\end{tabular}

As shown by these results the simulation methods for both the SCP and NFRC produce very similar R-values. The small calculated differences between the two simulation methods were too small to differentiate between the two methods due to simulation uncertainties. The slight differences in the simulation methods were primarily due to the different window size. As the key influences on a windows thermal resistance, such as materials and air gap sizes remain the same, the thermal resistance has remained rather similar. The differences between the two methods of modelling gave a small difference in $\mathrm{R}$-value, at most $0.005 \mathrm{~m}^{2} \cdot \mathrm{K} / \mathrm{W}$, which only equates to a difference of $1 \%$. This difference between the two was extremely small when 
modelling these systems and due to simulation uncertainties, it would be fair to say the difference between the two is negligible.

The difference between these and the first model, which followed the NFRC standards but with a smaller fixed window size of $1 \mathrm{~m} \times 1 \mathrm{~m}$ is slightly larger. The difference separating the different models is as large as $0.02 \mathrm{~m}^{2} \cdot \mathrm{K} / \mathrm{W}$. The smaller R-values of the primary model were due to the smaller size of the window. This was caused by the high conductivity of the window frame. The smaller window has a smaller proportion of glass in the centre of the window compared to the edge and therefore has a smaller R-value as the framing materials remained the same. While this may mean that testing these products installed on a $1 \mathrm{~m} \times 1 \mathrm{~m}$ window disadvantages them slightly compared to testing using these standards, the small difference this causes has very little effect on the final results.

\subsection{Guarded Hot Box}

With the guarded hot box testing complete, R-values needed to be produced from the raw data provided by the GHB. The guarded hot box testing was completed successfully. Collecting the data was a simple process whereby the data following each test was downloaded and entered into a spreadsheet. From here the stable data was selected and the R-values for each test were calculated.

\subsubsection{Guarded Hot Box Raw Data}

With the guarded hot box testing complete the raw data needs to be analysed and converted into R-values. The energy drawn by the guarded hot box and the temperature difference between each side of the box were measured by the hot box and recorded at one minute intervals. This data was collected and entered into a spreadsheet which uses these measurements along with the known measured area of the heat-metering box to calculate the R-value at each minute. The data was then analysed to determine how long into the testing it took the GHB to stabilise and then the stable data was averaged to produce the final $\mathrm{R}$-value of the window including the thermal surround. 


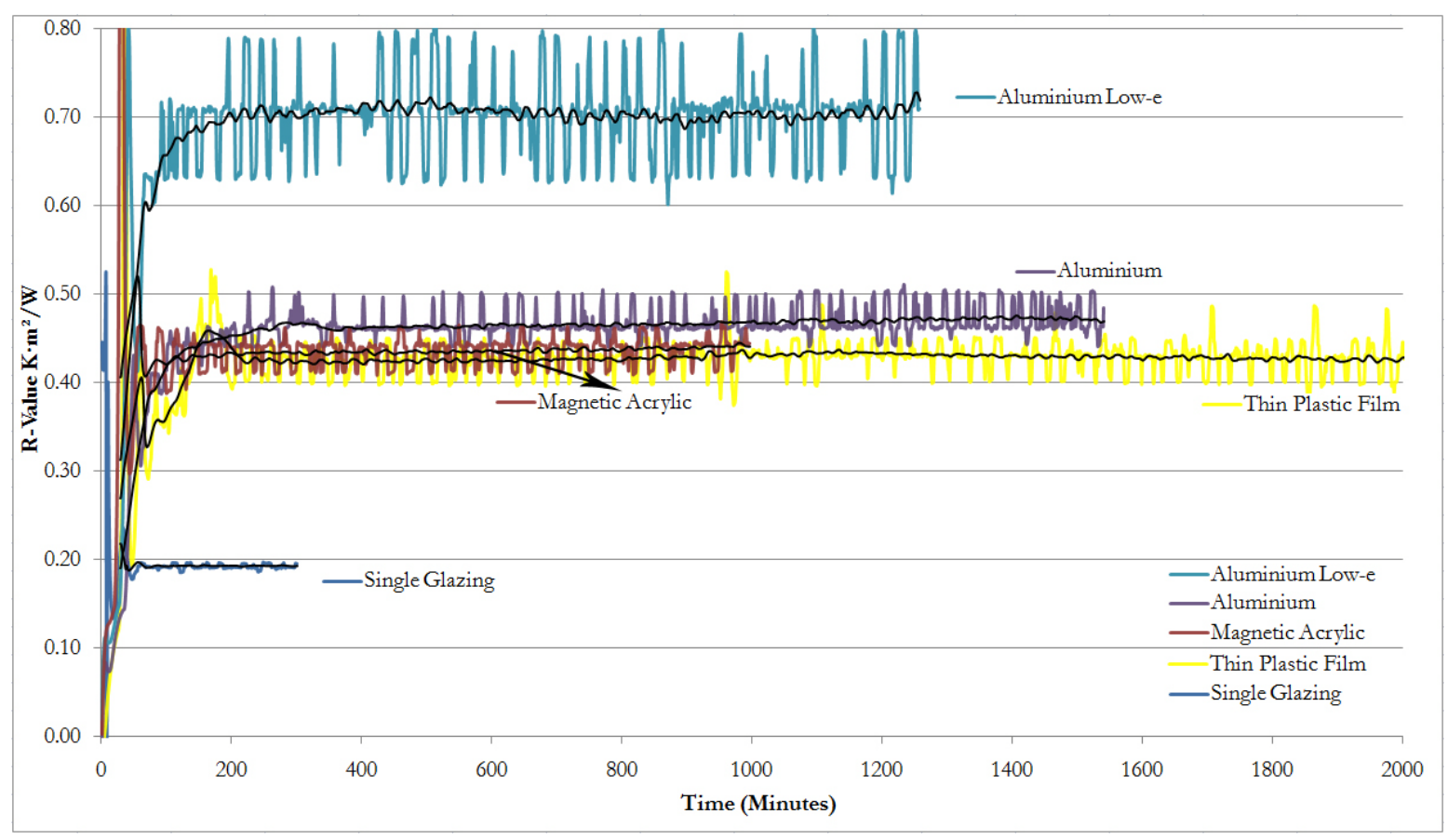

Figure 4-1: Guarded Hot Box Test Results

Figure 4-1 presents the R-values of the windows throughout the GHB test process. The black line represents the 60 minute floating average for each of the tests. A larger version of this graph can be found in Appendix A.

Table 4-4: Average, Stable Guarded Hot Box R-values (Including Surround)

\begin{tabular}{|l|c|}
\hline Window Type & Average Stable R-value $\left(\mathbf{m}^{2} \cdot \mathbf{K} / \mathbf{W}\right)$ \\
\hline Single Pane Window & 0.19 \\
\hline Magnetic Acrylic & 0.44 \\
\hline Thin Film Adhesive & 0.43 \\
\hline Aluminium & 0.47 \\
\hline Aluminium Low-E & 0.70 \\
\hline Single Pane Glazing with R-1.5 Insulation & 1.02 \\
\hline
\end{tabular}

The single pane window began the testing process with rather large fluctuations in the temperatures on each side of the box. This was due to the hot box having trouble stabilising the temperatures due the small amount of thermal resistance separating each side. By 50 minutes into the test the GHB had stabilised and the R-values at each interval only fluctuated between 
$0.18 \mathrm{~m}^{2} \cdot \mathrm{K} / \mathrm{W}$ and $0.20 \mathrm{~m}^{2} \cdot \mathrm{K} / \mathrm{W}$. This fluctuation remained constant right through to 300 minutes into the test giving a final R-value for the testing of $0.19 \mathrm{~m}^{2} \cdot \mathrm{K} / \mathrm{W}$.

The three secondary glazing tests all went smoothly. The magnetically-attached acrylic sheet test began with large fluctuations but quickly settled into stable periodic variations from 0.41 to 0.46 $\mathrm{m}^{2} \cdot \mathrm{K} / \mathrm{W}$. This resulted in the final $\mathrm{R}$-value of $0.44 \mathrm{~m}^{2} \cdot \mathrm{K} / \mathrm{W}$. The test of the thin film plastic secondary glazing also stabilised very quickly. The test was left on for 50 hours and remained oscillating between 0.40 and $0.45 \mathrm{~m}^{2} \cdot \mathrm{K} / \mathrm{W}$ for the duration of the test giving an average 0.43 $\mathrm{m}^{2} \cdot \mathrm{K} / \mathrm{W}$.

The aluminium secondary glazing took the longest amount of time, around 200 minutes, for the temperatures within the hot box to stabilise. Once the GHB temperatures equilibrated, the Rvalue measurements only varied between 0.44 and 0.50 for the entire remainder of the test. The small fluctuation of only $0.06 \mathrm{~m}^{2} \cdot \mathrm{K} / \mathrm{W}$ once the hot box temperatures had equilibrated suggests the longer time for the GHB temperatures to stabilise may not have been caused by a fault in the test such as air leakage. The final R-value of $0.47 \mathrm{~m}^{2} \cdot \mathrm{K} / \mathrm{W}$ for the aluminium secondary glazing was the highest of these three glazing systems.

The GHB test on the low-E secondary glazing experienced the largest fluctuations of the secondary glazing tests with the R-values typically fluctuating between 0.63 and $0.80 \mathrm{~m}^{2} \cdot \mathrm{K} / \mathrm{W}$ and on occasion drifting outside these values. Larger fluctuations were also common on the calibration test, which also had a high thermal resistance. The larger the thermal resistance of the specimen, the larger the fluctuations were. There could be many different reasons for these fluctuations such as the higher resistance of the specimen causing heat to be lost elsewhere, air movement within the cavity of the low-E secondary glazing or increased heat loss through the walls of the GHB. The fluctuations could also be caused by a combination of issues. It was possible that these fluctuations may have an influence on the accuracy of the tests however with the changes being stable and periodic, and the test lasting for 21 hours, an average of these values will provide a useable result.

The final test consisted of measuring the previous single pane window with a thin square of polystyrene with a known R-value of $1.5 \mathrm{~m}^{2} \cdot \mathrm{K} / \mathrm{W}$ inserted between the timber reveal. It was 
used as a calibration test to provide information useful in the process of calculating and removing the influence of the surround panel around the window. The test appeared to stabilise quickly with an R-value of $1.05 \mathrm{~m}^{2} \cdot \mathrm{K} / \mathrm{W}$ but then suddenly dropped mid test to level out at 1.00 $\mathrm{m}^{2} \cdot \mathrm{K} / \mathrm{W}$. The change in R-value during the experiment was caused by a climb in the wattage required. This could be due to a large temperature change outside the hot box, a small movement of the polystyrene in the test specimen or a very minor air leak. A difference of 0.05 $\mathrm{m}^{2} \cdot \mathrm{K} / \mathrm{W}$ is very minor, difficult to measure and would have very little influence. The temperature change happened midway through the test which lasted over 1000 minutes and despite the small fluctuation, remained stable throughout. As the true cause is not known the data will be averaged from both before and after the temperature change and the size of the uncertainty increased.

\subsubsection{Uncertainty Estimation, Precision and Bias}

The individual laboratory measurement uncertainty of the test method depends upon the test equipment and operating procedures, and upon the test conditions and specimen properties. For this reason, no simple quantitative statement can be made that will apply to all tests (ASTM, 2000). There are many factors that could have potentially influenced the uncertainty of the tests such as; the airtightness and heat transfer of the surround, the flanking losses occurring between the specimen and the surround, the metering box wall heat transfer and the heat transfer of the GHB chamber. The precision of the monitoring equipment, the GHB fans and the heat pumps supplying each side also affect the uncertainty.

There were also variables for each individual test which may have influenced the uncertainty such as; the resistance, emissivity and optical properties of each window, the airtightness of the GHB once closed and the external temperature variation.

Due to the difficulty of precisely measuring and or calculating the uncertainty for each test, the precision can be assumed from similar GHB fenestration tests where the precision has been quantified. Table 4-5 (Wise, 2002) presents the findings from 7 interlaboratory GHB comparisons conducted by the NFRC. The results presented are from calibrated air to air GHB testing to NFRC standards, a similar method to the one used in this study. 
Table 4-5: Results from 7 Interlaboratory Guarded Hot Box Comparisons

\begin{tabular}{|c|l|c|c|c|c|}
\hline \multicolumn{1}{|c|}{ Test Specimen } & \multicolumn{1}{|c|}{ Labs } & $\begin{array}{c}\mathbf{U}_{\text {ST }} \\
\left(\mathbf{W} / \mathbf{m}^{2} \cdot \mathbf{K}\right)\end{array}$ & $\begin{array}{c}\mathbf{U}_{\text {ST }} \mathbf{R} \\
\left(\mathbf{W} / \mathbf{m}^{\mathbf{2}} \cdot \mathbf{K}\right)\end{array}$ & $\begin{array}{c}\mathbf{U s}_{\mathbf{T}} \mathbf{R} \\
\mathbf{( \% )}\end{array}$ \\
\hline 1994 & Aluminium frame slider window & 9 & 3.80 & \pm 0.58 & 15.4 \\
\hline 1994 & Calibration transfer standard & 7 & 1.65 & \pm 0.34 & 20.3 \\
\hline 1995 & Vinyl frame double hung window & 8 & 2.09 & \pm 0.30 & 14.3 \\
\hline $1995 / 1996$ & Calibration transfer standard & 8 & 1.70 & \pm 0.20 & 12.7 \\
\hline 1996 & Aluminium clad wood frame fixed window & 8 & 1.43 & \pm 0.23 & 16.3 \\
\hline 1997 & Aluminium clad wood frame fixed window & 9 & 1.88 & \pm 0.23 & 12.3 \\
\hline 1998 & Aluminium clad wood frame fixed window & 9 & 1.79 & \pm 0.16 & 9.0 \\
\hline
\end{tabular}

$\mathrm{U}_{\mathrm{ST}}=$ average standardized thermal transmittance, $\mathrm{W} / \mathrm{m}^{2} \cdot \mathrm{K}$

$\mathrm{R}=$ reproducibility limit [for $95 \%$ confidence limits, 2.8 times the standard deviation], $\mathrm{W} / \mathrm{m}^{2} \cdot \mathrm{K}$

$\mathrm{R} \%=$ reproducibility limit percent [reproducibility limit divided by the mean], $\%$

The results presented on Table 4-5 show a large amount of variation between the various tested hot boxes. The reproducibility limit ranges from $9 \%$ to $20.3 \%$ and averages $14.3 \%$. Table $4-6$ presents the estimated uncertainty if a 14.3\% margin of error was applied to the whole window measured GHB results with the surround in place.

Table 4-6: Estimated Uncertainty for Measured GHB Results

\begin{tabular}{|l|c|l|}
\hline Window Type & $\begin{array}{c}\text { Average Stable } \\
\mathbf{R}-\mathbf{v a l u e} \\
\left(\mathbf{m}^{\mathbf{2}} \cdot \mathbf{K} / \mathbf{W}\right)\end{array}$ & $\begin{array}{c}\text { Estimated } \\
\text { Uncertainty } \\
\left(\mathbf{m}^{\mathbf{2}} \cdot \mathbf{K} / \mathbf{W}\right)\end{array}$ \\
\hline Single Pane Window & 0.19 & \pm 0.03 \\
\hline Magnetic Acrylic & 0.44 & \pm 0.06 \\
\hline Thin Film Adhesive & 0.43 & \pm 0.06 \\
\hline Aluminium & 0.47 & \pm 0.07 \\
\hline Aluminium Low-E & 0.7 & \pm 0.10 \\
\hline Single Pane Glazing with R-1.5 Insulation & 1.02 & \pm 0.15 \\
\hline
\end{tabular}

\subsubsection{R-Values}

Table 4-7 presents the R-values and $\mathrm{U}$-values from the guarded hot box testing. The improvement column gives an indication as to how much the secondary glazing units increase the performance of the window. 
Table 4-7: Guarded Hot Box Measurements including Surround Panel

\begin{tabular}{|l|c|c|c|}
\hline Fenestration Unit & U-Value $\left(\mathbf{W} / \mathbf{m}^{\mathbf{2}} \cdot \mathbf{K}\right)$ & R-Value $\left(\mathbf{m}^{2} \cdot \mathbf{K} / \mathbf{W}\right)$ & Improvement $\mathbf{( \% )}$ \\
\hline Window & 5.3 & $0.19 \pm 0.03$ & $\varnothing$ \\
\hline Magnetic Acrylic & 2.3 & $0.44 \pm 0.06$ & $130 \%$ \\
\hline Thin Plastic Film & 2.3 & $0.43 \pm 0.06$ & $130 \%$ \\
\hline Aluminium & 2.1 & $0.47 \pm 0.07$ & $150 \%$ \\
\hline Aluminium Low-E & 1.4 & $0.70 \pm 0.10$ & $270 \%$ \\
\hline Calibration & 1.0 & $1.02 \pm 0.15$ & $440 \%$ \\
\hline
\end{tabular}

These R-values are a measurement of the thermal resistance of the area enclosed by the heat metering box inside the guarded hot box. This covers the whole window including $100 \mathrm{~mm}$ of the surround panel on all four sides of the window as the heat-metering box was positioned with the window in the centre.

The low-E secondary glazing when attached to the window and measured with the surround panel produces an R-value of $0.70 \mathrm{~m}^{2} \cdot \mathrm{K} / \mathrm{W}$. The three other secondary glazing units all provide similar results to each other with a difference of just under $0.03 \mathrm{~m}^{2} \cdot \mathrm{K} / \mathrm{W}$ between them. A difference this small is very difficult to measure accurately in a GHB, therefore it was difficult to attribute the slight differences in thermal resistance to the products alone. With the uncertainty being twice as large as the difference between the three products, no difference between them can be determined. The small difference between the products despite large differences in design could be attributed to the fact that the majority of the improvement comes from the air gap provided by the secondary glazing with only a small amount of resistance being provided by the glazing itself (BRANZ, 1999). While there were variations in the size of the air gap which the various units tested provided they were all larger than $20 \mathrm{~mm}$. Once the cavity is larger than this, the size has a negligible influence on the R-value (see Figure 2-6) (Godfrey, 1972).

While the R-values for the window with the secondary glazing installed are high compared to similar measurements discussed within the literature review, they also included the $0.44 \mathrm{~m}^{2}$ of polystyrene surround measured by the heat metering box. Due to this, the R-value of the primary window and secondary glazing indicated in the table above were expected to be higher than the whole window R-values. 
The results from this testing already suggest that the addition of secondary glazing to the primary single glazed window yields significant improvements in the thermal resistance of the window. The results show significant improvements over the primary window, ranging from $130 \%$ to $270 \%$. These improvements were measured with the surround panel in place. The surround accounts for $0.44 \mathrm{~m}^{2}$ or $31 \%$ of the area measured by the heat metering box and the thermal resistance of this area remains the same throughout the tests. Therefore once the influence of the surround panel was removed then the improvements the secondary glazing units offer over the primary window could increase.

\subsubsection{Surround Panel Calculation and Removal}

To be able to accurately remove the thermal resistance of the surround panel from the R-values measured in the guarded hot box it was necessary to simulate the GHB tests using Therm 6 and Window 6. These programs can be used to simulate the whole window thermal resistance including the $100 \mathrm{~mm}$ of surround panel on each side of the window as measured by the $1.2 \mathrm{~m} \mathrm{x}$ $1.2 \mathrm{~m}$ heat metering box. The environmental conditions experienced in the guarded hot box are as follows.

Table 4-8: GHB Environmental Conditions

\begin{tabular}{|c|c|c|c|c|}
\hline \multicolumn{5}{|c|}{ Guarded Hot Box Environmental Conditions as Simulated in Window 6} \\
\hline & $\begin{array}{l}\text { U-Factor } \\
\text { Inside }\end{array}$ & $\begin{array}{l}\text { SHGC: } \\
\text { Inside }\end{array}$ & $\begin{array}{l}\text { U-factor } \\
\text { Outside }\end{array}$ & $\begin{array}{l}\text { SHGC: } \\
\text { Outside }\end{array}$ \\
\hline Inside/Outside Air Temp & 25 & 25 & 18 & 18 \\
\hline Direct Solar Radiation & & & & $0 \mathrm{~W} / \mathrm{m}^{2}$ \\
\hline \multicolumn{5}{|c|}{ Convection : Fixed Convection Coefficient } \\
\hline & $8.9 \mathrm{~W} / \mathrm{m}^{2} \cdot \mathrm{K}$ & $8.9 \mathrm{~W} / \mathrm{m}^{2} \cdot \mathrm{K}$ & $8.9 \mathrm{~W} / \mathrm{m}^{2} \cdot \mathrm{K}$ & $8.9 \mathrm{~W} / \mathrm{m}^{2} \cdot \mathrm{K}$ \\
\hline \multicolumn{5}{|l|}{ Radiation: ASHRAE/NFRC } \\
\hline Effective Room/Sky Temp & 25 & 25 & 18 & 18 \\
\hline Effective Room/Sky Emissivity & 0.9 & 0.9 & 0.9 & 0.9 \\
\hline
\end{tabular}

Using these values under the environment settings in Window 6 the following R-values were calculated. The intention of these results was to replicate the results found by the GHB testing. 
Table 4-9: Simulation Results using GHB Conditions

\begin{tabular}{|l|c|c|c|}
\hline Fenestration Unit & U-Value $\left(\mathbf{W} / \mathbf{m}^{\mathbf{2}} \cdot \mathbf{K}\right)$ & R-Value $\left(\mathbf{m}^{2} \cdot \mathbf{K} / \mathbf{W}\right)$ & Improvement $\mathbf{( \% )}$ \\
\hline Window & 5.3 & 0.19 & $\emptyset$ \\
\hline Magnetic Acrylic & 2.3 & 0.44 & $130 \%$ \\
\hline Thin Plastic Film & 2.4 & 0.41 & $120 \%$ \\
\hline Aluminium & 2.5 & 0.40 & $110 \%$ \\
\hline Aluminium Low-E & 1.6 & 0.62 & $220 \%$ \\
\hline
\end{tabular}

The table above presents the results of the computer simulations of the window with the thermal surround attached. Only the area of surround measured by the heat metering box needed to be modelled. With the GHB environment and the test specimens digitally recreated it was now possible to compare these results to the physical measurements. The table below presents a comparison between the measured and the calculated results.

Table 4-10: Comparison between Measured and Calculated Results

\begin{tabular}{|c|c|c|c|c|}
\hline & $\begin{array}{c}\text { GHB measured } \\
\text { R-value }\left(\mathrm{m}^{2} \cdot \mathrm{K} / \mathrm{W}\right)\end{array}$ & $\begin{array}{l}\text { Window Simulation } \\
\text { R-value }\left(\mathrm{m}^{2} \cdot \mathrm{K} / \mathrm{W}\right)\end{array}$ & $\begin{array}{c}\Delta \mathbf{R} \\
\left(\mathrm{m}^{2} \cdot \mathrm{K} / \mathrm{W}\right)\end{array}$ & $\%$ \\
\hline Window & 0.190 & 0.190 & $\varnothing$ & $\varnothing$ \\
\hline Magnetic Acrylic & 0.441 & 0.435 & 0.006 & $-1.4 \%$ \\
\hline Thin Plastic Film & 0.429 & 0.413 & 0.016 & $-3.7 \%$ \\
\hline Aluminium & 0.469 & 0.399 & 0.070 & $-14.9 \%$ \\
\hline Aluminium Low-E & 0.699 & 0.617 & 0.082 & $-11.7 \%$ \\
\hline
\end{tabular}

The R-values were within an acceptable tolerance of the original guarded hot box tests. The largest fluctuation in results occurred within the aluminium framed window containing $6 \mathrm{~mm}$ clear glass. While the simulated aluminium secondary glazed was almost $15 \%$ off from the guarded hot box test, it was still only $0.07 \mathrm{~m}^{2} \cdot \mathrm{K} / \mathrm{W}$ different to the measured window. The small $\mathrm{R}$-values associated with windows and the slight variation between the secondary glazing products is very difficult to measure using a guarded hot box. The average precision for GHB testing as presented in Table $4-5$ is $14.3 \%$. With only the aluminium-framed secondary glazing 
results falling just outside these reproducibility limits, the results can be accepted as appropriate for this research.

Due to the large amount of exposed aluminium surface area and the very low thermal resistance of the aluminium used in the aluminium framed secondary glazing, it would be expected that the window also has a lower thermal resistance than the other secondary glazing products. Potential reasons for the variation in the measured guarded hot box test could be small air leaks from the GHB to the outside air during the testing. While care was taken to make sure the GHB was closed correctly, there were no air leaks around the EPS surround and the heat metering box was positioned squarely over the centre of the window; there is still potential that any small variation may affect the results.

It should be noted that the method used to simulate the window frame in Window 6 was not able to fully recreate the surround. Cross-sections of the frame were modelled to simulate two dimensional heat transfer across the frame. While this was acceptable for the sill and head of the window, the timber framing running along the jambs continues from the bottom to the top of the GHB. This means there was slightly more timber than modelled. The simulation replaces $0.007 \mathrm{~m}^{2}$ of timber facing the heat-metering box with polystyrene. As the area was rather small and remains consistent on all simulations the influence of this on the final results was considered to be insignificant.

Both the aluminium secondary glazed units performed noticeably different from the simulation. With the other units performing relatively similar, the reason for this could be the very low surface emissivity of the aluminium framing. Under NFRC modelling rules bare aluminium has an emissivity of 0.2. The simulated guarded hot box conditions may not be ideal for the aluminium framing. It is also possible that there were slight temperature differences radiated from one side of the box to the other that were not prevented by the radiant heat shield. These would not be conducted through the aluminium frame as easily.

It is interesting to note that the clear glazed aluminium secondary glazing test took the longest period of time to stabilize and the low-E aluminium secondary glazing experienced the largest fluctuations during the guarded hot box tests. This may suggest that there were slight issues on 
these experiments which could have contributed to the larger variation between the calculated and the measured results. The variations only result in a small difference between the simulated and measured results. The size of the values is smaller than the GHB could be expected to accurately predict, as shown in Table 4-6.

Concerns that the use of the same air gap as was used to simulate airtight insulated glazing units may overestimate the performance of secondary glazing appear incorrect. The calculated and the measured results were very similar. The physically measured secondary glazing units all outperformed their comparable digital simulation model under similar conditions. The difference appears to be very minor and it appears that computer simulation of secondary glazing is a sufficient way of measuring the thermal resistance for these secondary glazed windows.

\subsection{Final Whole Window R-values}

Table 4-11: Final Results

\begin{tabular}{|c|c|c|c|}
\hline Fenestration Unit & U-Value $\left(W / \mathrm{m}^{2} \cdot \mathbf{K}\right)$ & R-Value $\left(\mathrm{m}^{2} \cdot \mathrm{K} / \mathrm{W}\right)$ & Improvement $(\%)$ \\
\hline Window & 6.9 & $0.15 \pm 0.02$ & $\varnothing$ \\
\hline Magnetic Acrylic & 2.8 & $0.36 \pm 0.05$ & $150 \%$ \\
\hline Thin Plastic Film & 2.9 & $0.35 \pm 0.05$ & $140 \%$ \\
\hline Aluminium & 3.0 & $0.34 \pm 0.05$ & $130 \%$ \\
\hline Aluminium Low-E & 1.8 & $0.57 \pm 0.08$ & $290 \%$ \\
\hline
\end{tabular}

The table above presents the final whole window R-values for both the primary single glazed window and for the window fitted with each of the four secondary glazing systems. These were the results measured by the GHB with the effects of the surround panel removed by calculation.

The R-value for the primary aluminium framed window was $0.15 \mathrm{~m}^{2} \cdot \mathrm{K} / \mathrm{W}$. This was within the experimental error for the typical R-value of an aluminium $4 \mathrm{~mm}$ clear single glazed window which is quoted as being typically around $0.15 \mathrm{~m}^{2} \cdot \mathrm{K} / \mathrm{W}$ (NZS 4218, 2009). 
The improvements over the original single glazed aluminium framed window are statistically significant. The R-value for the window more than doubled once a secondary glazing unit was attached. These are significant improvements for the windows. With the exception of the low-E coating the secondary glazing units all produce similar R-values when retrofitted on to the same window. This was expected as it is the air gap rather than the type of secondary glazing which provides the majority of the windows thermal resistance (BRANZ, 1999). While there were variations in the air gap size between the secondary glazing units, this would not have had a noticeable influence on the thermal transmission results of the tests. This was because all the cavities were larger than $20 \mathrm{~mm}$ wide; variations in spaces wider than this create very little difference in the R-value of the window (Godfrey, 1972).

The previously mentioned concern that the thermal simulation programs were possibly overestimating the resistance of the window does not seem to be true. Recreating the GHB environment in Window actually produced smaller thermal resistance values for the secondary glazed units.

Table 4-12: Comparison between $R$-values for all methods

\begin{tabular}{|l|l|l|l|l|}
\hline \multicolumn{1}{|c|}{ Test Method } & Pilot & NZS 4218 & NFRC 100 & GHB \\
\hline Fenestration Unit & $\begin{array}{l}\text { R-Value } \\
\left(\mathbf{m}^{2} \cdot \mathbf{K} / \mathbf{W}\right)\end{array}$ & $\begin{array}{l}\text { R-Value } \\
\left(\mathbf{m}^{2} \cdot \mathbf{K} / \mathbf{W}\right)\end{array}$ & $\begin{array}{l}\text { R-Value } \\
\left(\mathbf{m}^{2} \cdot \mathbf{K} / \mathbf{W}\right)\end{array}$ & $\begin{array}{l}\text { R-Value } \\
\left(\mathbf{m}^{2} \cdot \mathbf{K} / \mathbf{W}\right)\end{array}$ \\
\hline Window & 0.16 & 0.17 & 0.17 & 0.15 \\
\hline Magnetic Acrylic & 0.38 & 0.38 & 0.38 & 0.36 \\
\hline Thin Plastic Film & 0.37 & 0.37 & 0.37 & 0.35 \\
\hline Aluminium & 0.35 & 0.36 & 0.36 & 0.34 \\
\hline Aluminium Low-E & 0.51 & 0.53 & 0.53 & 0.57 \\
\hline
\end{tabular}

The final results only differ slightly from the thermal simulation methods using the NZS 4218 and NFRC standards, and are all within the experimental error. The final R-values for all GHB tests, with the exception of the low-E glazed secondary glazing, did perform slightly below the values predicted by thermal simulation. The earlier prediction that this may be due to the way that the air gap is calculated in the simulation, which is no different to the air gap used by double glazing, cannot be true as the single glazed window R-value was also measured to be smaller. The 
final measured results were all approximately $0.02 \mathrm{~m}^{2} \cdot \mathrm{K} / \mathrm{W}$ smaller than those calculated by the thermal simulation software. Only the low-E secondary glazing shows an improvement over the simulated results by $0.04 \mathrm{~m}^{2} \cdot \mathrm{K} / \mathrm{W}$. The results were all only very slightly different to those simulated to the standards, falling within the experimental error, and therefore cannot be differentiated.

The small differences were most probably due to the different size and environmental conventions used by the standards. When these size and environmental conditions used in the GHB testing were adopted for the simulation, the results become slightly lower than those found by the physical testing. Thermal simulation of secondary glazing was able to produce fair and accurate results. GHB testing is more expensive. As thermal simulation does not appear to significantly over or underestimate the performance of secondary glazing systems its use in future calculations of secondary glazing systems would be sufficient.

In many cases these results were better than others previously measured and calculated for various secondary glazing units. Magnetically-attached acrylic sheet secondary glazing performed rather closely to other claims and findings documented in the literature review. New Zealand manufacturer MagicSeal calculated their product to have an R-value of $0.37 \mathrm{~m}^{2} \cdot \mathrm{K} / \mathrm{W}$ (MagicSeal, 2007). This R-value was manually calculated using a method similar to that prescribed by NZS: 4214 (MagicSeal, n.d.). WERS simulations found Magnetite able to produce R-values as high as $0.37 \mathrm{~m}^{2} \cdot \mathrm{K} / \mathrm{W}$ with a timber window or $0.22 \mathrm{~m}^{2} \cdot \mathrm{K} / \mathrm{W}$ when installed over an aluminium window (WERS, 2008c). The final GHB measured magnetically-attached acrylic sheet R-value of $0.36 \pm$ $0.05 \mathrm{~m}^{2} \cdot \mathrm{K} / \mathrm{W}$ was similar to the WERS result when using a timber framed window. The $150 \%$ improvement measured in the GHB testing however was much larger than the improvements found by the WERS simulations. WERS simulation found attaching Magnetite provided an 18\% improvement over the WERS single glazed aluminium window $\left(0.18 \mathrm{~m}^{2} \cdot \mathrm{K} / \mathrm{W}\right)$ and a $41 \%$ improvement over the WERS single glazed timber window $\left(0.22 \mathrm{~m}^{2} \cdot \mathrm{K} / \mathrm{W}\right)$ (Magnetite, 2006). With the GHB results producing an $\mathrm{R}$-value $0.1 \mathrm{~m}^{2} \cdot \mathrm{K} / \mathrm{W}$ higher than what was calculated for a timber window, rather than aluminium, with a similar secondary glazing system attached the simulation result does seem high for the product. Some reasons for this large improvement could be the lower thermal resistance of the primary window and the use of PVC spacers to 
provide a larger air gap than what would be achieved by just affixing magnetic strips to the aluminium frame.

Thin film secondary glazing had been claimed by a manufacturer to improve the R-value of a window by $90 \%(3 \mathrm{M}, 2006)$. The testing found the product to go further than this and improve the R-value of the window by $140 \%$. This improvement was more than found by another New Zealand study which determined the R-value of the windows with plastic film to be 0.24 $\mathrm{m}^{2} \cdot \mathrm{K} / \mathrm{W}$. This was only a $33 \%$ improvement over the windows original $\mathrm{R}$-value which was measured to be $0.16 \mathrm{~m}^{2} \cdot \mathrm{K} / \mathrm{W}$ (Lloyd \& Callau, 2006).

The results from the GHB testing should be considered a best case scenario, as it was tested in laboratory conditions; both the window and each of the secondary glazing systems had been installed extremely carefully to make sure that there were no air leaks or imperfections and had only just been installed with no time left for any deterioration. The product was also installed over an aluminium window with little thermal resistance allowing for a large potential for improvement. Despite these facts the improvement of 140\% remains a significant improvement over the primary window.

The aluminium framed secondary glazing provided the least resistance of the secondary glazing systems. This was primarily due to the large amount of aluminium framing. Aluminium was used for the tracks and sash of the sliding-sash design. Despite this the performance was still very similar to the two previous solutions. A difference of less than $0.02 \mathrm{~m}^{2} \cdot \mathrm{K} / \mathrm{W}$ is very difficult to measure accurately and would provide little difference in the total amount of heating energy saved. Calculated R-values for aluminium framed secondary glazed products ranged from 0.34 to $0.38 \mathrm{~m}^{2} \cdot \mathrm{K} / \mathrm{W}$ (Selectaglaze, 2008a). These R-values were just slightly higher than the results found by the guarded hot box physical testing, but fell within the experimental uncertainty.

The low-E glazing gave a particularly impressive performance providing a 290\% improvement over the primary window. The large performance advantages of low-E secondary glazing over standard secondary glazing have been highlighted in a previous study which found the payback period was half that of standard secondary glazing (Drumheller, Kohler, \& Minen, 2007). The final result of $0.57 \pm 0.08 \mathrm{~m}^{2} \cdot \mathrm{K} / \mathrm{W}$ was just slightly higher and within the experimental error of 
the results of manually calculated R-values found by the CWCT. These results were between 0.51 $-0.56 \mathrm{~m}^{2} \cdot \mathrm{K} / \mathrm{W}$ for similar low-E secondary glazing units (Selectaglaze, 2008a). A test cell study on low-E secondary glazing found it to have an R-value of only $0.42 \mathrm{~m}^{2} \cdot \mathrm{K} / \mathrm{W}$ when used in conjunction with a $0.23 \mathrm{~m}^{2} \cdot \mathrm{K} / \mathrm{W}$ primary window (Klems, 2003). It is important to note that a low-E coating is not constant among various glass products and the properties of low-E windows can vary dramatically between different products. The emissivity can vary on the window and is typically influenced by various factors such as climate, cost and tint and the surface of glass which receives the low-E coating can also vary giving different results (NFRC, 2004). Glazing emissivities are tabulated in the IGDB.

The final R-value results were also impressive when compared to R-values for typical double glazed units. One reason for this could be the larger air gap provided by secondary glazing when compared to double glazing as the air gap provides the majority of the insulation in an IGU (BRANZ, 1999). A detailed discussion comparing secondary glazing and IGU's can be found in section 5.1.

With such large improvements in R-values, particularly for low-E secondary glazing there is potential for secondary glazing retrofits to produce significant reductions in annual heating energy consumption.

\subsection{Home Heating Energy Simulation}

This section covers the results found by simulating ten typical New Zealand homes using the ALF software. Each home was simulated within four climate zones. In all four climate zones, each of the homes was simulated using the five results from the final whole window R-values. Note that only windows capable of being fitted with secondary glazing were modelled as having it. The whole window R-values and Solar Heat-gain Coefficients used in ALF are presented in Table 4-13. The results from each of the 200 simulations were analysed and are displayed in the following sections. 
Table 4-13: Values Used in ALF Simulation

\begin{tabular}{|l|c|c|}
\hline Fenestration Unit & R-Value $\left(\mathrm{m}^{2} \cdot \mathbf{K} / \mathrm{W}\right)$ & SHGC \\
\hline Primary Window & 0.15 & 0.70 \\
\hline Magnetic Acrylic & 0.36 & 0.61 \\
\hline Thin Plastic Film & 0.35 & 0.61 \\
\hline Aluminium & 0.34 & 0.61 \\
\hline Aluminium Low-E & 0.57 & 0.57 \\
\hline
\end{tabular}

\subsubsection{Primary Window}

With the R-values of the primary window and the primary window with each of the four secondary glazing units attached known it was now possible to simulate the impact these retrofit solutions have on home heating energy.

First the existing energy use for all 10 homes was established. Details of these homes can be found in section 3.4.2. This was done by taking the 10 models and fitting them with windows that have an R-value of $0.15 \mathrm{~m}^{2} \cdot \mathrm{K} / \mathrm{W}$ to match the $\mathrm{GHB}$ measured R-value of the primary single glazed aluminium window. Each of the homes was simulated in the four chosen climates and the kilowatt hours to heat the home to the specified schedule was calculated. 
Table 4-14: Primary Window Simulated Heating Energy Results

\begin{tabular}{|l|r|r|r|r|}
\hline House & Auckland (kWh) & Wellington $\mathbf{( k W h )}$ & Christchurch $\mathbf{( k W h )}$ & Dunedin (kWh) \\
\hline $\mathbf{1}$ & 5230 & 11141 & 13031 & 15035 \\
\hline $\mathbf{2}$ & 5422 & 11486 & 13543 & 15701 \\
\hline $\mathbf{3}$ & 6715 & 14050 & 16603 & 19244 \\
\hline $\mathbf{4}$ & 3996 & 8462 & 10051 & 11651 \\
\hline $\mathbf{5}$ & 4413 & 9542 & 11274 & 13050 \\
\hline $\mathbf{6}$ & 6361 & 13102 & 15891 & 18319 \\
\hline $\mathbf{7}$ & 5227 & 11638 & 13949 & 16088 \\
\hline $\mathbf{8}$ & 3988 & 9004 & 10588 & 12151 \\
\hline $\mathbf{9}$ & 3140 & 6709 & 8137 & 9455 \\
\hline $\mathbf{1 0}$ & 6114 & 12925 & 15179 & 17589 \\
\hline Average & $\mathbf{5 0 6 1}$ & $\mathbf{1 0 8 0 6}$ & $\mathbf{1 2 8 2 5}$ & $\mathbf{1 4 8 2 8}$ \\
\hline
\end{tabular}

Table 4-14 shows the energy used by each home when fitted with single glazing. There is a significant difference in energy use for the various climates. The average energy use in Dunedin was almost three times larger than that of Auckland. This was due to the amount of time Auckland spends near or above the heating setpoint and the shorter winter heating season. It is important to note that the construction of the homes remained the same for simulations in the various climates. As the majority of the homes lack additional thermal insulation, with a few only having insulation in small areas, they have difficulty keeping the heat in during the cold Dunedin winters.

Of the homes, House 9 had the lowest heating energy consumption; this was due to the dwelling having the second smallest floor area of the sample and the smallest glazing area. House 3, which loses a lot of heat through the floor, has the second largest floor area and a thin skillion roof, had the largest energy consumption. House 4 has the largest heating energy consumption per square metre of floor area. This was due to the house being uninsulated with the exception of light ceiling insulation in one room. House 7 has the lowest energy consumption per square metre. 
Table 4-15: Average HEEP annual space heating energy consumption (Isaacs, et al., 2006)

\begin{tabular}{|l|r|r|r|c|}
\hline \multicolumn{1}{|c|}{ Location } & HEEP (All Fuels) & Alf Simulation & Difference & \% Difference \\
\hline Auckland & 3190 & 5061 & 1871 & 63 \\
\hline Wellington & 2630 & 10806 & 8176 & 24 \\
\hline Christchurch & 3010 & 12825 & 9815 & 23 \\
\hline Dunedin & 6810 & 14828 & 8018 & 46 \\
\hline Overall & 3820 & 10880 & 7060 & 35 \\
\hline
\end{tabular}

The ALF average heating energy consumption results shown in Table 4-14 are much larger than those measured in the HEEP survey of New Zealand houses. In Dunedin, Christchurch and Wellington, the simulated heating energy consumption was closer to the average whole house total energy consumption found by HEEP (Isaacs, et al., 2006). The heating schedule used in the ALF simulations was for morning (7am-9pm) and evening $(5 \mathrm{pm}-11 \mathrm{pm})$ heating with the heating setpoint of $18^{\circ} \mathrm{C}$. The homes were simulated to heat to $18^{\circ} \mathrm{C}$ between these hours during the heating season described in Table 3-4.

Research has shown that New Zealand houses often struggle to reach acceptable temperatures during the winter time (French, Camilleri, Isaacs, \& Pollard, 2007) with HEEP finding the average winter living room heating temperature to be $17.3^{\circ} \mathrm{C}$ (Isaacs, Amitrano, Camilleri, Pollard, \& Stoecklein, 2002), $0.7^{\circ} \mathrm{C}$ cooler than the setpoint used in the simulations. The living rooms were typically the warmest room in the HEEP survey. The simulations heated all areas of the home to $18^{\circ} \mathrm{C}$ to gain an insight to the influence of secondary glazing on the whole home. While many people will also heat bedrooms during winter months much of the home will go unheated which was one reason for the large differences between the simulations.

The simulated homes were all uninsulated houses built before 1978 with little, if any, additional insulation. Post-1970's houses represent approximately 30\% of New Zealand houses (Clark, Jones, \& Page, 2005). HEEP found that post-1978 houses were $1{ }^{\circ} \mathrm{C}$ warmer on average (Isaacs, Amitrano, Camilleri, French, Pollard, \& Stoecklein, 2003). The lack of insulation in these simulated homes results in more heating energy required to keep them warm, particularly in the colder climates. 
Table 4-16: Single Glazed Home Heat Losses

\begin{tabular}{|l|c|c|c|c|c|c|}
\hline House & Floor Loss & Wall Loss & Window Loss & Roof Loss & Air Leakage & Warm-up \\
\hline $\mathbf{1}$ & $9.2 \%$ & $16.4 \%$ & $22.0 \%$ & $5.8 \%$ & $10.6 \%$ & $36.1 \%$ \\
\hline $\mathbf{2}$ & $8.1 \%$ & $14.5 \%$ & $17.2 \%$ & $14.1 \%$ & $10.6 \%$ & $35.5 \%$ \\
\hline $\mathbf{3}$ & $9.3 \%$ & $14.0 \%$ & $18.3 \%$ & $14.3 \%$ & $10.1 \%$ & $33.9 \%$ \\
\hline $\mathbf{4}$ & $7.4 \%$ & $12.8 \%$ & $19.7 \%$ & $19.5 \%$ & $8.3 \%$ & $32.3 \%$ \\
\hline $\mathbf{5}$ & $9.1 \%$ & $7.2 \%$ & $17.4 \%$ & $23.3 \%$ & $8.9 \%$ & $34.2 \%$ \\
\hline $\mathbf{6}$ & $6.6 \%$ & $13.9 \%$ & $25.9 \%$ & $16.9 \%$ & $4.8 \%$ & $32.0 \%$ \\
\hline $\mathbf{7}$ & $7.5 \%$ & $13.6 \%$ & $19.9 \%$ & $6.0 \%$ & $7.8 \%$ & $45.3 \%$ \\
\hline $\mathbf{8}$ & $8.7 \%$ & $13.1 \%$ & $24.5 \%$ & $5.9 \%$ & $7.8 \%$ & $40.0 \%$ \\
\hline $\mathbf{9}$ & $6.6 \%$ & $20.2 \%$ & $18.5 \%$ & $5.2 \%$ & $7.3 \%$ & $42.1 \%$ \\
\hline $\mathbf{1 0}$ & $8.8 \%$ & $23.8 \%$ & $15.4 \%$ & $4.8 \%$ & $11.7 \%$ & $35.5 \%$ \\
\hline Average & $8.1 \%$ & $14.9 \%$ & $19.9 \%$ & $11.6 \%$ & $8.8 \%$ & $36.7 \%$ \\
\hline
\end{tabular}

Table 4-16 presents where and what proportion of heat was lost through each element of the building envelope. The table represents proportional heat-loss data calculated during the simulation of the 10 houses. The homes were simulated using single glazing $\mathrm{R}$-values for the windows and the Wellington climate. Maximum and minimum values by component are represented by red and blue shaded cells. As the cells represent proportion of heat lost through each element, a building which loses a large proportion of heat through one particular element will often lose proportionally little through some of the others.

House 6 has the largest proportion of heat lost through the windows. This house has the largest window area as well as the largest window to floor ratio. House 6 was also the most airtight of the modelled homes, so may not have lost much heat through ventilation. House 10 has the smallest proportion of heat lost through the windows. This was due to the house having the smallest glazing to floor ratio. House 10 was also very draughty and has walls with very low Rvalues, reducing the proportion of heat lost through the windows, although not the absolute amount of heat. 


\subsubsection{Magnetically-Attached Acrylic Sheet}

The house models were then modified to represent a retrofit with magnetically-attached acrylic sheet secondary glazing. The $\mathrm{R}$-value of the windows was adjusted to match the thermal resistance of the measured combination of the primary single glazed window with the secondary glazing attached. The GHB measured whole window R-value for this combination was 0.36 $\mathrm{m}^{2} \cdot \mathrm{K} / \mathrm{W}$. Windows that could not accommodate secondary glazing such as ranch slider doors retain the single glazed $\mathrm{R}$-value of $0.15 \mathrm{~m}^{2} \cdot \mathrm{K} / \mathrm{W}$.

Table 4-17: Magnetic Acrylic Simulated Heating Energy Results

\begin{tabular}{|l|cc|cc|cc|cc|}
\hline \multirow{2}{*}{ House } & \multicolumn{2}{|c|}{ Auckland } & \multicolumn{2}{c|}{ Wellington } & \multicolumn{2}{c|}{ Christchurch } & \multicolumn{2}{c|}{ Dunedin } \\
\cline { 2 - 9 } & $\mathbf{( k W h )}$ & Reduction & $\mathbf{( k W h )}$ & Reduction & $\mathbf{( k W h )}$ & Reduction & (kWh) & Reduction \\
\hline $\mathbf{1}$ & 4265 & $19 \%$ & 9323 & $16 \%$ & 10814 & $17 \%$ & 12449 & $17 \%$ \\
\hline $\mathbf{2}$ & 4753 & $12 \%$ & 10207 & $11 \%$ & 11988 & $12 \%$ & 13889 & $12 \%$ \\
\hline $\mathbf{3}$ & 5852 & $13 \%$ & 12410 & $12 \%$ & 14608 & $12 \%$ & 16918 & $12 \%$ \\
\hline $\mathbf{4}$ & 3344 & $16 \%$ & 7224 & $15 \%$ & 8543 & $15 \%$ & 9892 & $15 \%$ \\
\hline $\mathbf{5}$ & 3841 & $13 \%$ & 8456 & $11 \%$ & 9952 & $12 \%$ & 11510 & $12 \%$ \\
\hline $\mathbf{6}$ & 5412 & $15 \%$ & 11302 & $14 \%$ & 13699 & $14 \%$ & 15761 & $14 \%$ \\
\hline $\mathbf{7}$ & 4335 & $17 \%$ & 9933 & $15 \%$ & 11880 & $15 \%$ & 13673 & $15 \%$ \\
\hline $\mathbf{8}$ & 3233 & $19 \%$ & 7572 & $16 \%$ & 8839 & $17 \%$ & 10107 & $17 \%$ \\
\hline $\mathbf{9}$ & 2692 & $14 \%$ & 5850 & $13 \%$ & 7095 & $13 \%$ & 8239 & $13 \%$ \\
\hline $\mathbf{1 0}$ & 5376 & $12 \%$ & 11518 & $11 \%$ & 13470 & $11 \%$ & 15597 & $11 \%$ \\
\hline Mean & $\mathbf{4 3 1 0}$ & $\mathbf{1 5 \%}$ & $\mathbf{9 3 8 0}$ & $\mathbf{1 3 \%}$ & $\mathbf{1 1 0 8 9}$ & $\mathbf{1 4 \%}$ & $\mathbf{1 2 8 0 4}$ & $\mathbf{1 4 \%}$ \\
\hline
\end{tabular}

House 10 has the smallest heating reduction percentage. This was primarily due to House 10 having the smallest Glazing to Floor ratio. This means the increased resistance provided by the secondary glazing only has a small influence on the thermal resistance of the entire envelope of the building.

House 1 had the largest reductions in the heating energy once secondary glazing was installed. The house has the third largest heat loss through the windows. Unlike the two homes which have larger heat losses through the windows, House 6 and House 8, the house was able to receive secondary glazing to the majority of its windows. In Auckland, House 8 has the largest reductions. This was due to the warmer climate having a larger ratio of gains to losses through the windows. The lower percentage of secondary glazed windows within this home has a smaller 
effect due to the orientation of these windows. The single glazed windows were able to achieve more solar gains through the windows due to the smaller SHGC when compared to the secondary glazing equivalent. The proportion of heat loss to the outside was also smaller due to the increased outdoor temperature.

House 6 experiences the largest percentage of heat loss through the windows with $26 \%$ of the heat lost through the single glazed windows. This was due to House 6 having the largest glazing area of all the homes. Some of the glazing comes from doors, including one large glazed ranch slider and a conservatory. As these windows do not receive secondary glazing in this project they remain single glazed for the simulations. House 6 has the smallest percentage of secondary glazing installed within the home with only $58 \%$ of the windows within the home receiving secondary glazing. This results in the relatively small reduction in heating energy of around 14\%.

Table 4-18: Secondary Glazed Home Heat Losses

\begin{tabular}{|l|l|l|l|l|l|l|}
\hline House & $\begin{array}{l}\text { Floor } \\
\text { Loss: }\end{array}$ & $\begin{array}{l}\text { Wall } \\
\text { Loss: }\end{array}$ & $\begin{array}{l}\text { Window } \\
\text { Loss: }\end{array}$ & $\begin{array}{l}\text { Roof } \\
\text { Loss: }\end{array}$ & $\begin{array}{l}\text { Air } \\
\text { Leakage: }\end{array}$ & $\begin{array}{l}\text { Warm- } \\
\text { up }\end{array}$ \\
\hline $\mathbf{1}$ & $10.4 \%$ & $18.6 \%$ & $11.2 \%$ & $6.6 \%$ & $12.0 \%$ & $41.1 \%$ \\
\hline $\mathbf{2}$ & $8.9 \%$ & $15.9 \%$ & $8.8 \%$ & $15.6 \%$ & $11.7 \%$ & $39.1 \%$ \\
\hline $\mathbf{3}$ & $10.3 \%$ & $15.5 \%$ & $9.7 \%$ & $15.8 \%$ & $11.2 \%$ & $37.5 \%$ \\
\hline $\mathbf{4}$ & $8.4 \%$ & $14.5 \%$ & $9.3 \%$ & $22.1 \%$ & $9.4 \%$ & $36.4 \%$ \\
\hline $\mathbf{5}$ & $9.9 \%$ & $7.8 \%$ & $9.6 \%$ & $25.5 \%$ & $9.7 \%$ & $37.5 \%$ \\
\hline $\mathbf{6}$ & $7.3 \%$ & $15.4 \%$ & $17.8 \%$ & $18.7 \%$ & $5.3 \%$ & $35.5 \%$ \\
\hline $\mathbf{7}$ & $8.4 \%$ & $15.0 \%$ & $11.1 \%$ & $6.6 \%$ & $8.7 \%$ & $50.2 \%$ \\
\hline $\mathbf{8}$ & $9.6 \%$ & $14.5 \%$ & $16.3 \%$ & $6.5 \%$ & $8.7 \%$ & $44.3 \%$ \\
\hline $\mathbf{9}$ & $7.4 \%$ & $22.4 \%$ & $9.7 \%$ & $5.7 \%$ & $8.1 \%$ & $46.7 \%$ \\
\hline $\mathbf{1 0}$ & $9.6 \%$ & $26.1 \%$ & $7.1 \%$ & $5.3 \%$ & $12.9 \%$ & $39.0 \%$ \\
\hline Average & $9.0 \%$ & $16.6 \%$ & $11.0 \%$ & $12.8 \%$ & $9.8 \%$ & $40.7 \%$ \\
\hline
\end{tabular}

This table presents the heat-loss percentages calculated in ALF for each home for a Wellington location once the magnetically-attached acrylic sheet secondary glazing was installed. On average the heat lost through the windows drops by $9 \%$. The largest reduction in heat lost through windows was $10.8 \%$ for House 1 while the smallest was $7.8 \%$ for House 5 . House 6 continues to experience the largest percentage of heat lost through the windows. This was due to having the

Nick Smith 
largest window to floor ratio and the largest window area. House 6 also had the smallest proportion of windows receiving secondary glazing with only $59 \%$ of the windows being able to be secondary glazed. Despite this the secondary glazing was still capable of producing a reduction in heat lost through the windows of $8.1 \%$

\subsubsection{Thin Plastic Film}

The modelling was then conducted for the thin film plastic secondary glazing. The SHGC remains at the same value of 0.61 however the $\mathrm{R}$-value will now be changed from $0.36 \mathrm{~m}^{2} \cdot \mathrm{K} / \mathrm{W}$ to $0.35 \mathrm{~m}^{2} \cdot \mathrm{K} / \mathrm{W}$, as provided by the thin plastic film adhesive secondary glazing.

Table 4-19: Thin Film Simulated Heating Energy Results

\begin{tabular}{|l|c|c|c|c|c|c|cc|}
\hline \multirow{2}{*}{ House } & \multicolumn{2}{|c|}{ Auckland } & \multicolumn{2}{c|}{ Wellington } & \multicolumn{2}{c|}{ Christchurch } & \multicolumn{2}{c|}{ Dunedin } \\
\cline { 2 - 9 } & $\mathbf{( k W h )}$ & Reduction & $\mathbf{( k W h )}$ & Reduction & $\mathbf{( k W h )}$ & Reduction & $\mathbf{( k W h )}$ & Reduction \\
\hline $\mathbf{1}$ & 4289 & $18 \%$ & 9366 & $16 \%$ & 10867 & $17 \%$ & 12511 & $17 \%$ \\
\hline $\mathbf{2}$ & 4770 & $12 \%$ & 10237 & $11 \%$ & 12025 & $11 \%$ & 13933 & $11 \%$ \\
\hline $\mathbf{3}$ & 5873 & $13 \%$ & 12448 & $11 \%$ & 14655 & $12 \%$ & 16973 & $12 \%$ \\
\hline $\mathbf{4}$ & 3360 & $16 \%$ & 7254 & $14 \%$ & 8579 & $15 \%$ & 9935 & $15 \%$ \\
\hline $\mathbf{5}$ & 3856 & $13 \%$ & 8483 & $11 \%$ & 9985 & $11 \%$ & 11548 & $12 \%$ \\
\hline $\mathbf{6}$ & 5435 & $15 \%$ & 11345 & $13 \%$ & 13415 & $16 \%$ & 15822 & $14 \%$ \\
\hline $\mathbf{7}$ & 4359 & $17 \%$ & 9977 & $14 \%$ & 11933 & $15 \%$ & 13735 & $15 \%$ \\
\hline $\mathbf{8}$ & 3252 & $19 \%$ & 7608 & $16 \%$ & 8882 & $16 \%$ & 10158 & $16 \%$ \\
\hline $\mathbf{9}$ & 2703 & $14 \%$ & 5871 & $13 \%$ & 7120 & $13 \%$ & 8269 & $13 \%$ \\
\hline $\mathbf{1 0}$ & 5394 & $12 \%$ & 11551 & $11 \%$ & 13511 & $11 \%$ & 15645 & $11 \%$ \\
\hline Mean & $\mathbf{4 3 2 9}$ & $\mathbf{1 5 \%}$ & $\mathbf{9 4 1 4}$ & $\mathbf{1 3 \%}$ & $\mathbf{1 1 0 9 7}$ & $\mathbf{1 4 \%}$ & $\mathbf{1 2 8 5 3}$ & $\mathbf{1 3 \%}$ \\
\hline
\end{tabular}

As expected the small decrease in $\mathrm{R}$-value has resulted in slightly higher energy consumption across the range of homes, although this is within experimental error of the GHB measurements. Aside from this difference the results were very similar to the previous magnetically-attached acrylic sheet results. This could create rather interesting results as the thin plastic film is a very basic affordable option. Despite the temporary nature of the product it may prove to be a very cost effective retrofit solution for these homes. 


\subsubsection{Clear Glazed Aluminium Secondary Glazing}

Table 4-20: Aluminium Simulated Heating Energy Results

\begin{tabular}{|l|c|c|c|c|c|c|cc|}
\hline \multirow{2}{*}{ House } & \multicolumn{2}{|c|}{ Auckland } & \multicolumn{2}{c|}{ Wellington } & \multicolumn{2}{c|}{ Christchurch } & \multicolumn{2}{c|}{ Dunedin } \\
\cline { 2 - 9 } & $\mathbf{( k W h )}$ & Reduction & $\mathbf{( k W h )}$ & Reduction & $\mathbf{( k W h )}$ & Reduction & $\mathbf{( k W h )}$ & Reduction \\
\hline $\mathbf{1}$ & 4314 & $18 \%$ & 9412 & $16 \%$ & 10923 & $16 \%$ & 12577 & $16 \%$ \\
\hline $\mathbf{2}$ & 4788 & $12 \%$ & 10270 & $11 \%$ & 12065 & $11 \%$ & 13979 & $11 \%$ \\
\hline $\mathbf{3}$ & 5896 & $12 \%$ & 12489 & $11 \%$ & 14705 & $11 \%$ & 17031 & $12 \%$ \\
\hline $\mathbf{4}$ & 3378 & $16 \%$ & 7285 & $14 \%$ & 8617 & $14 \%$ & 9980 & $14 \%$ \\
\hline $\mathbf{5}$ & 3871 & $12 \%$ & 8511 & $11 \%$ & 10020 & $11 \%$ & 11589 & $11 \%$ \\
\hline $\mathbf{6}$ & 5460 & $14 \%$ & 11390 & $13 \%$ & 13807 & $13 \%$ & 15887 & $13 \%$ \\
\hline $\mathbf{7}$ & 4384 & $16 \%$ & 10023 & $14 \%$ & 11990 & $14 \%$ & 13802 & $14 \%$ \\
\hline $\mathbf{8}$ & 3272 & $18 \%$ & 7645 & $15 \%$ & 8929 & $16 \%$ & 10212 & $16 \%$ \\
\hline $\mathbf{9}$ & 2716 & $14 \%$ & 5893 & $12 \%$ & 7147 & $12 \%$ & 8300 & $12 \%$ \\
\hline $\mathbf{1 0}$ & 5413 & $12 \%$ & 11587 & $10 \%$ & 13554 & $11 \%$ & 15696 & $11 \%$ \\
\hline $\boldsymbol{M e a n}$ & $\mathbf{4 3 4 9}$ & $\mathbf{1 4 \%}$ & $\mathbf{9 4 5 1}$ & $\mathbf{1 3} \%$ & $\mathbf{1 1 1 7 6}$ & $\mathbf{1 3 \%}$ & $\mathbf{1 2 9 0 5}$ & $\mathbf{1 3 \%}$ \\
\hline
\end{tabular}

Once again the small decrease in the R-value of the secondary glazing has resulted in slightly higher energy consumption when compared to the two previous secondary glazing solutions. These differences in energy consumption are very minimal, falling within the experimental error, and should not be used to compare these three products. Margins of error in the hot box testing, window deterioration such as fading and damage, SHGC, Cleanliness and ease of cleaning could all have small influences on these windows making direct comparison between the three product's energy savings in real world applications very difficult to draw direct conclusions from. Due to the very similar results between these three products their suitability for installation would depend more on window type, aesthetic preference, durability, price and ease of installation and use. 


\subsubsection{Low-E Glazed Aluminium Secondary Glazing}

Table 4-21: Low-E Aluminium Simulated Heating Energy Results

\begin{tabular}{|l|c|c|c|c|c|c|cc|}
\hline \multirow{2}{*}{ House } & \multicolumn{2}{|c|}{ Auckland } & \multicolumn{2}{c|}{ Wellington } & \multicolumn{2}{c|}{ Christchurch } & \multicolumn{2}{c|}{ Dunedin } \\
\cline { 2 - 9 } & $\mathbf{( k W h )}$ & Reduction & $\mathbf{( k W h )}$ & Reduction & $\mathbf{( k W h )}$ & Reduction & $\mathbf{( k W h )}$ & Reduction \\
\hline $\mathbf{1}$ & 4045 & $23 \%$ & 8896 & $20 \%$ & 10298 & $21 \%$ & 11850 & $21 \%$ \\
\hline $\mathbf{2}$ & 4607 & $15 \%$ & 9913 & $14 \%$ & 11633 & $14 \%$ & 13477 & $14 \%$ \\
\hline $\mathbf{3}$ & 5655 & $16 \%$ & 12022 & $14 \%$ & 14139 & $15 \%$ & 16373 & $15 \%$ \\
\hline $\mathbf{4}$ & 3198 & $20 \%$ & 6936 & $18 \%$ & 8195 & $19 \%$ & 9488 & $19 \%$ \\
\hline $\mathbf{5}$ & 3718 & $16 \%$ & 8213 & $14 \%$ & 9658 & $14 \%$ & 11169 & $14 \%$ \\
\hline $\mathbf{6}$ & 5182 & $19 \%$ & 10878 & $17 \%$ & 13186 & $17 \%$ & 15164 & $17 \%$ \\
\hline $\mathbf{7}$ & 4153 & $21 \%$ & 9564 & $18 \%$ & 11436 & $18 \%$ & 13156 & $18 \%$ \\
\hline $\mathbf{8}$ & 3067 & $23 \%$ & 7248 & $20 \%$ & 8445 & $20 \%$ & 9648 & $21 \%$ \\
\hline $\mathbf{9}$ & 2595 & $17 \%$ & 5653 & $16 \%$ & 6858 & $16 \%$ & 7962 & $16 \%$ \\
\hline $\mathbf{1 0}$ & 5211 & $15 \%$ & 11191 & $13 \%$ & 13076 & $14 \%$ & 15140 & $14 \%$ \\
\hline Mean & $\mathbf{4 1 4 3}$ & $\mathbf{1 8 \%}$ & $\mathbf{9 0 5 1}$ & $\mathbf{1 6 \%}$ & $\mathbf{1 0 6 9 2}$ & $\mathbf{1 7 \%}$ & $\mathbf{1 2 3 4 3}$ & $\mathbf{1 7 \%}$ \\
\hline
\end{tabular}

With a $290 \%$ improvement over the original single glazed window, it would be expected that using the low-E window would significantly reduce the heating load of the home. A similar study which compared low-E secondary glazing and clear secondary glazing in a cold climate found that there was a $13 \%$ reduction in heating costs using clear glass while using low-E glazing resulted in a 21\% reduction (Drumheller, Kohler, \& Minen, 2007). However this study was conducted in Chicago, Illinois where the winters are much colder than those found in New Zealand. The lowest monthly average minimum temperature in Chicago is $-8^{\circ} \mathrm{C}(\mathrm{BBC}, 2009 \mathrm{a})$, $11^{\circ} \mathrm{C}$ colder than the monthly average minimum of $3^{\circ} \mathrm{C}$ for Dunedin (BBC, 2009b). In Chicago the lower SHGC of the low-E window may not have as large an impact on the window performance dependent upon solar gains. The houses in Chicago were better insulated than the typical New Zealand house models used in the simulations. This would accentuate the secondary glazing improvements in the Chicago climate.

The reductions in space conditioning energy use using the low-E glass were much lower than those found in the study in Chicago where the reduced solar heat gain co-efficient of the low-E glass resulted in less solar heat gain inside the homes, particularly during the winter months where the low angle of the sun can provide useful heat. 
As with the other secondary glazing products House 1 has the highest proportional energy savings. With the low-E secondary glazing installed this becomes the largest percentage reduction averaging a $21 \%$ reduction in the overall heating energy of the dwelling. This maximum is similar to the $21 \%$ reduction low-E storm windows provided in Chicago (Drumheller, Kohler, \& Minen, 2007).

\subsection{Cost Benefit Results}

With the energy consumption for the 10 homes now simulated for all the window options and climates it was now time to complete all the cost benefit calculations. To do this the cost of installing the windows needs to be calculated. The cost of using thin plastic film was taken using prices from the Sustainable Design website (Sustainable Design, 2008). These prices were then used to find the most affordable way to secondary glaze the windows for each of the 10 homes. This was done by organising the windows of each home to efficiently use the most affordable thin film window kit with minimal waste.

For the other secondary glazing systems, quotes were requested from manufacturers of the product. The two homes used to request quotes for were House 2 and House 8. The table below outlines the window width, window height, window perimeter, window area and the number of windows able to be secondary glazed. A detailed description of each window for every home is documented in the simulation outputs in 0 .

Table 4-22: Size Details of Quoted Home Windows

\begin{tabular}{|c|c|c|c|c|c|}
\hline $\begin{array}{c}\text { House } \\
\text { Windows }\end{array}$ & $\begin{array}{c}\text { Total Width } \\
(\mathrm{m})\end{array}$ & $\begin{array}{c}\text { Total Height } \\
(\mathrm{m})\end{array}$ & $\begin{array}{c}\text { Total } \\
\text { Perimeter }(\mathrm{m})\end{array}$ & $\begin{array}{c}\text { Total Area } \\
(\mathrm{m} 2)\end{array}$ \\
\hline 2 & 20 & 29.8 & 23.2 & 105.8 & 33.3 \\
\hline 8 & 18 & 26.6 & 23.8 & 100.9 & 34.6 \\
\hline
\end{tabular}

From here the price per window could be averaged to provide rough estimates for the remaining homes. The quotes for these homes are outlined in Table 4-23. 


\section{Table 4-23: Manufacturing and Installation Cost Quotes}

\begin{tabular}{|l|l|l|}
\hline Product & House 2 & House 8 \\
\hline Magnetic Acrylic & $\$ 7,058.00$ & $\$ 7,057.00$ \\
\hline Aluminium & $\$ 7,751.00$ & $\$ 6,534.00$ \\
\hline Aluminium Low-E & $\$ 8,729.00$ & $\$ 7,512.00$ \\
\hline
\end{tabular}

Disregarding the windows that cannot be secondary glazed; the two homes have very similar window area, with House 2 having $33.3 \mathrm{~m}^{2}$ and House 8 having $34.6 \mathrm{~m}^{2}$. While House 8 has almost $1.3 \mathrm{~m}^{2}$ more window area than House 2, it only has 18 windows while House 2 has 20 windows. The smaller average window area of House 2 requires a larger amount of framing with $5 \mathrm{~m}$ more perimeter around the windows than House 8 , despite the smaller window area. This increases the cost to manufacture the windows as it requires more framing material and work. There were also two more windows to install, increasing the installation time. Due to these factors House 2 was more expensive to retrofit than House 8 despite the $1.3 \mathrm{~m}^{2}$ less window area to cover with the secondary glazing.

It is interesting to note that there was only $\$ 1$ difference in cost between each of the two homes to retrofit them with magnetically-attached acrylic sheet secondary glazing. This was different to the aluminium framed secondary glazing where House 2 costs $\$ 1217$ more than House 8 to secondary glaze. The price difference between these two homes remained the same when low-E secondary glazing was used. As the price difference does not change between low-E or clear glass the added cost could be attributed to the extra windows and additional labour. The difference between the costs of the two homes was larger for the aluminium windows than for the magnetically-attached acrylic sheet. The reason for this could be the additional materials this would require. The additional windows require a larger perimeter of framing. This means more aluminium extrusions for the tracks that the windows sit in as well as more framing extrusions for each of the two windows which sit within the tracks. The magnetically-attached acrylic sheet secondary glazing only requires slightly more PVC and magnetic strips.

These quotes were current at the time of this research. For the purpose of this study it was assumed that the systems could be fully financed by the occupants or paid for using interest free loans. As there is no New Zealand specific research, the value added to a home by installing the systems was not assessed. Payback periods will potentially require a period of time larger than 
possible life expectancies of the window. The secondary glazing costs will not factor in maintenance or replacement costs as there is no research into the lifespan and durability of these products in New Zealand.

\subsubsection{Magnetically-Attached Acrylic Sheet}

Table 4-24: Magnetically-Attached Acrylic Sheet Energy Savings (\$/yr)

\begin{tabular}{|c|c|c|c|c|c|}
\hline & Capital & Auckland & Wellington & Christchurch & Dunedin \\
\cline { 3 - 6 } House & Cost & $@ 22.88 \mathrm{c} / \mathrm{kWh}$ & $@ 22.85 \mathrm{c} / \mathrm{kWh}$ & $@ 21.43 \mathrm{c} / \mathrm{kWh}$ & $@ 21.95 \mathrm{c} / \mathrm{kWh}$ \\
\hline $\mathbf{1}$ & $\$ 5,587$ & $\$ 221$ & $\$ 415$ & $\$ 475$ & $\$ 568$ \\
\hline 2 & $\$ 7,058$ & $\$ 153$ & $\$ 292$ & $\$ 333$ & $\$ 398$ \\
\hline $\mathbf{3}$ & $\$ 8,195$ & $\$ 197$ & $\$ 375$ & $\$ 428$ & $\$ 511$ \\
\hline $\mathbf{4}$ & $\$ 8,195$ & $\$ 149$ & $\$ 283$ & $\$ 323$ & $\$ 386$ \\
\hline $\mathbf{5}$ & $\$ 5,960$ & $\$ 131$ & $\$ 248$ & $\$ 283$ & $\$ 338$ \\
\hline $\mathbf{6}$ & $\$ 5,960$ & $\$ 217$ & $\$ 411$ & $\$ 470$ & $\$ 561$ \\
\hline $\mathbf{7}$ & $\$ 8,195$ & $\$ 204$ & $\$ 390$ & $\$ 443$ & $\$ 530$ \\
\hline $\boldsymbol{8}$ & $\$ 7,057$ & $\$ 173$ & $\$ 327$ & $\$ 375$ & $\$ 449$ \\
\hline $\mathbf{9}$ & $\$ 4,097$ & $\$ 103$ & $\$ 196$ & $\$ 223$ & $\$ 267$ \\
\hline $\mathbf{1 0}$ & $\$ 6,332$ & $\$ 169$ & $\$ 322$ & $\$ 366$ & $\$ 437$ \\
\hline Mean & $\$ 6,663$ & $\$ 172$ & $\$ 326$ & $\$ 376$ & $\$ 438$ \\
\hline
\end{tabular}

Table 4-25: Magnetically-Attached Acrylic Sheet Payback Period

\begin{tabular}{|c|c|c|c|c|c|}
\hline House & $\begin{array}{c}\text { Capital } \\
\text { Cost }\end{array}$ & $\begin{array}{c}\text { Auckland } \\
\text { (Years) }\end{array}$ & $\begin{array}{c}\text { Wellington } \\
\text { (Years) }\end{array}$ & $\begin{array}{c}\text { Christchurch } \\
\text { (Years) }\end{array}$ & $\begin{array}{c}\text { Dunedin } \\
\text { (Years) }\end{array}$ \\
\hline $\mathbf{1}$ & $\$ 5,587$ & 25.3 & 13.5 & 11.8 & 9.8 \\
\hline $\mathbf{2}$ & $\$ 7,058$ & 46.1 & 24.2 & 21.2 & 17.8 \\
\hline $\mathbf{3}$ & $\$ 8,195$ & 41.5 & 21.9 & 19.2 & 16.1 \\
\hline $\mathbf{4}$ & $\$ 8,195$ & 54.9 & 29.0 & 25.4 & 21.2 \\
\hline $\mathbf{5}$ & $\$ 5,960$ & 45.5 & 24.0 & 21.0 & 17.6 \\
\hline $\mathbf{6}$ & $\$ 5,960$ & 27.5 & 14.5 & 12.7 & 10.6 \\
\hline $\mathbf{7}$ & $\$ 8,195$ & 40.2 & 21.0 & 18.5 & 15.5 \\
\hline $\boldsymbol{8}$ & $\$ 7,057$ & 40.9 & 21.6 & 18.8 & 15.7 \\
\hline $\mathbf{9}$ & $\$ 4,097$ & 40.0 & 20.9 & 18.4 & 15.4 \\
\hline $\mathbf{1 0}$ & $\$ 6,332$ & 37.5 & 19.7 & 17.3 & 14.5 \\
\hline Mean & $\$ \mathbf{6 , 6 6 3}$ & $\mathbf{3 9 . 9}$ & $\mathbf{2 1 . 0}$ & $\mathbf{1 8 . 4}$ & $\mathbf{1 5 . 4}$ \\
\hline
\end{tabular}


The average simple payback period for this product ranged from between 40 years for Auckland down to only 15 years in Dunedin. A 40 year payback is a significant amount of time to seek a return on an investment of around $\$ 6600$. It is important to note that this study did not measure the life expectancy of the product, nor was any research found on this. There was no evidence to suggest that the product would not last for more than 40 years, however it should be noted that acrylic sheets are subject to scratching from wear and tear and have been known to cloud over from long term exposure to UV radiation. With well formulated material and good design acrylic glazing can have a service life of 20 or more years (BRANZ, 1994). To seek a return within 20 years the product would generally have to be retrofitted into homes within the South Island. While there were some homes simulated from the Wellington region which fall into this category, there were also a few homes within the South Island which wouldn't see a return within this time. The product in these cooler climates appears to have the ability to pay itself off within the estimated lifespan. An average home in Dunedin would achieve this in approximately $75 \%$ of the 20 years. Despite this economic benefit consumers may not find the promise of a 1520 year payback a feasible return time.

\subsubsection{Thin Film Plastic}

The thin film plastic secondary glazing required a different method to calculate the payback. As it is assumed that the film is disposed of and then replaced once a year, the payback occurs annually. With this product the cost to purchase the kits was subtracted from the annual heating energy savings. If the cost of installing the kits was larger than the annual heating energy savings, the kit could not be financially viable without an increase in electricity prices or a decrease in the cost of the kits.

The costs to install the thin film secondary glazing varied from house to house, depending on the window shapes, sizes and quantities. As the cost depends upon how efficiently the pre-sized sheets could cover all the windows there were no specific areas of windows or window sizes which result in a lower cost per square metre. Rather it depends on how efficiently the combination of windows could be made to utilise the pre-sized kits. 
Table 4-26: Adhesive Plastic Secondary Glazing Costs

\begin{tabular}{|c|c|c|c|c|c|c|c|}
\hline House & $\operatorname{Area}\left(\mathrm{m}^{2}\right)$ & Cost (\$) & $\$ / \mathrm{m}^{2}$ & House & $\operatorname{Area}\left(\mathrm{m}^{2}\right)$ & Cost (\$) & $\$ / \mathrm{m}^{2}$ \\
\hline$\# 1$ & 36.3 & 218.00 & 6.01 & $\# 6$ & 33.3 & 252.60 & 7.59 \\
\hline$\# 2$ & 33.3 & 269.60 & 8.09 & $\# 7$ & 43.1 & 318.20 & 7.39 \\
\hline$\# 3$ & 41.9 & 270.60 & 6.45 & $\# 8$ & 34.6 & 247.80 & 7.17 \\
\hline$\# 4$ & 31.5 & 306.40 & 9.73 & $\# 9$ & 21.8 & 157.20 & 7.20 \\
\hline$\# 5$ & 28.0 & 193.00 & 6.90 & $\# 10$ & 36.4 & 234.80 & 6.44 \\
\hline \multicolumn{5}{|c|}{ AVERAGE } & 34.0 & 246.80 & 7.30 \\
\hline
\end{tabular}

For the 10 homes, the average cost was $\$ 7.40 / \mathrm{m}^{2}$ for the kits including delivery. The lowest cost was $\$ 6.01 / \mathrm{m}^{2}$ for House 1 which was also the home with the largest energy savings from secondary glazing installation. The highest price was $\$ 9.73 / \mathrm{m}^{2}$ for House 4 , a house which consisted of many windows just slightly too large to place side by side on a sheet with the suggested $25 \mathrm{~mm}$ clearance around the window area.

The cost benefit equation was calculated using the average cost of electricity to a typical domestic consumer within the region for the $15^{\text {th }}$ of February 2009 and using the cheapest available prices for the tested kit (Sustainable Design, 2008) including courier costs. Variations in electricity costs and the price paid for the kitset could result in findings different from those presented below.

Table 4-27: Annual Thin Film Returns for Energy Savings

\begin{tabular}{|l|r|r|r|r|}
\hline House & \multicolumn{1}{|c|}{ Auckland } & Wellington & Christchurch & \multicolumn{1}{l|}{ Dunedin } \\
\hline $\mathbf{1}$ & $-\$ 3$ & $\$ 188$ & $\$ 246$ & $\$ 336$ \\
\hline $\mathbf{2}$ & $-\$ 120$ & $\$ 16$ & $\$ 56$ & $\$ 118$ \\
\hline $\mathbf{3}$ & $-\$ 78$ & $\$ 95$ & $\$ 147$ & $\$ 228$ \\
\hline $\mathbf{4}$ & $-\$ 161$ & $-\$ 30$ & $\$ 9$ & $\$ 70$ \\
\hline $\mathbf{5}$ & $-\$ 66$ & $\$ 49$ & $\$ 83$ & $\$ 137$ \\
\hline $\mathbf{6}$ & $-\$ 41$ & $\$ 149$ & $\$ 278$ & $\$ 295$ \\
\hline $\mathbf{7}$ & $-\$ 120$ & $\$ 61$ & $\$ 114$ & $\$ 198$ \\
\hline $\mathbf{8}$ & $-\$ 79$ & $\$ 71$ & $\$ 118$ & $\$ 190$ \\
\hline $\mathbf{9}$ & $-\$ 57$ & $\$ 34$ & $\$ 61$ & $\$ 103$ \\
\hline $\mathbf{1 0}$ & $-\$ 70$ & $\$ 79$ & $\$ 123$ & $\$ 192$ \\
\hline Average & $-\$ 79$ & $\$ 71$ & $\$ 123$ & $\$ 187$ \\
\hline
\end{tabular}


The thin film secondary glazing kits cost efficiency was region specific. In Auckland where the heating energy need was the lowest out of the four chosen locations, the cost to purchase the secondary glazing kits was higher than the energy savings for all ten homes, with an average annual loss of $\$ 79.45$. With House 1 , where the energy savings by installing secondary glazing were the largest of the modelled homes in Auckland, there was only a $\$ 2.70$ loss.

The temporary nature of the thin plastic film secondary glazing means that the cost effectiveness was assessed on an annual basis. Determining the viability solely on cost efficiency, simulated to the conditions used in this research, it is fair to conclude that it is not economically feasible to use this type of secondary glazing in Auckland. For cooler climates such as Wellington, Christchurch and Dunedin it is an economically viable product provided that the labour cost to install the product is zero-rated. In Wellington all homes, with the exception of House 4, saw a return on the annual investment of this type of product. House 4 has the largest cost per $\mathrm{m}^{2}$ for the thin film plastic sheets due to the window sizes. While the simulated Wellington homes produced positive returns, on average they were relatively small. As there are some drawbacks to the use of this type of secondary glazing, the homeowner may not find it worthwhile unless the film can be retained for more than a single year, whereas someone looking to increase the insulation of their windows for comfort or condensation control with an affordable short term solution may find these small savings an added bonus.

While there were annual savings to be made in cooler climates, there are also disadvantages associated with this type of system. The DIY nature of the system requires a significant amount of time to retrofit a home. This process must be carried out once a year and could cause significant inconvenience for the person installing it. The system also prevents the opening of windows which could make the home difficult to ventilate. The final downside is the durability of the product. Care must be taken to ensure the adhesive does not lose contact with the surround and that the plastic doesn't become damaged. This could be difficult in households with cats or small children.

The other benefits that are associated with installing secondary glazing must also be considered. These include the increased thermal comfort both from increased air temperature and an increase in radiant temperature from the windows, increased air tightness reducing drafts and 
infiltration, reduced condensation on the windows and a reduction in external noise. Depending on the negative impact some of these factors have on occupants within the dwelling, the ancillary improvements the system may be able to provide could make it worthwhile.

The significant annual cost savings that thin film secondary glazing was able to provide to homes within the South Island climates, Dunedin especially, make it an attractive option for retrofitting the windows. Wellington would need consideration from the occupant because the limitations and install time may offset the small savings. In Auckland the system provides no cost benefit and due to the installation requirements, is not recommended.

While the inability to open windows if the film is installed over the entire window, fragile material and temporary design of the secondary glazing fails to compete with the other systems simulated it was able to provide annual returns. This rapid payback would be suitable for someone who is only seeking a short term solution. Examples of this could be tenants of a rental property, an owner who is looking to replace the windows before other secondary glazing systems would be able to provide a return on the initial investment or someone with future plans to sell the home. The product could also be used as a trial for homeowners contemplating a permanent secondary glazing system.

\subsubsection{Standard Aluminium-framed Secondary Glazing}

Table 4-28: Aluminium-framed Secondary Glazing Energy Savings

\begin{tabular}{|c|c|c|c|c|c|}
\hline & Capital & Auckland & Wellington & Christchurch & Dunedin \\
\cline { 3 - 6 } House & Cost & $@ 22.88 \mathrm{c} / \mathrm{kWh}$ & $@ 22.85 \mathrm{c} / \mathrm{kWh}$ & $@ 21.43 \mathrm{c} / \mathrm{kWh}$ & $@ 21.95 \mathrm{c} / \mathrm{kWh}$ \\
\hline $\mathbf{1}$ & $\$ 5,629$ & $\$ 210$ & $\$ 395$ & $\$ 452$ & $\$ 540$ \\
\hline $\mathbf{2}$ & $\$ 7,751$ & $\$ 149$ & $\$ 278$ & $\$ 317$ & $\$ 378$ \\
\hline $\mathbf{3}$ & $\$ 8,256$ & $\$ 187$ & $\$ 357$ & $\$ 407$ & $\$ 486$ \\
\hline $\mathbf{4}$ & $\$ 8,256$ & $\$ 141$ & $\$ 269$ & $\$ 307$ & $\$ 367$ \\
\hline $\mathbf{5}$ & $\$ 6,004$ & $\$ 124$ & $\$ 236$ & $\$ 269$ & $\$ 321$ \\
\hline $\mathbf{6}$ & $\$ 6,004$ & $\$ 206$ & $\$ 391$ & $\$ 447$ & $\$ 534$ \\
\hline $\mathbf{7}$ & $\$ 8,256$ & $\$ 193$ & $\$ 369$ & $\$ 420$ & $\$ 502$ \\
\hline $\boldsymbol{8}$ & $\$ 6,534$ & $\$ 164$ & $\$ 311$ & $\$ 356$ & $\$ 426$ \\
\hline $\mathbf{9}$ & $\$ 4,128$ & $\$ 97$ & $\$ 186$ & $\$ 212$ & $\$ 254$ \\
\hline $\mathbf{1 0}$ & $\$ 6,380$ & $\$ 160$ & $\$ 306$ & $\$ 348$ & $\$ 416$ \\
\hline Mean & $\$ 6,720$ & $\$ 163$ & $\$ 310$ & $\$ 357$ & $\$ 416$ \\
\hline
\end{tabular}


Table 4-29: Aluminium-framed Secondary Glazing Payback Period

\begin{tabular}{|c|c|c|c|c|c|}
\hline House & $\begin{array}{c}\text { Capital } \\
\text { Cost }\end{array}$ & $\begin{array}{c}\text { Auckland } \\
\text { (Years) }\end{array}$ & $\begin{array}{c}\text { Wellington } \\
\text { (Years) }\end{array}$ & $\begin{array}{c}\text { Christchurch } \\
\text { (Years) }\end{array}$ & $\begin{array}{c}\text { Dunedin } \\
\text { (Years) }\end{array}$ \\
\hline $\mathbf{1}$ & $\$ 5,629$ & 26.9 & 14.3 & 12.5 & 10.4 \\
\hline $\mathbf{2}$ & $\$ 7,751$ & 53.4 & 27.9 & 24.5 & 20.5 \\
\hline $\mathbf{3}$ & $\$ 8,256$ & 44.1 & 23.2 & 20.3 & 17.0 \\
\hline $\mathbf{4}$ & $\$ 8,256$ & 58.4 & 30.7 & 26.9 & 22.5 \\
\hline $\mathbf{5}$ & $\$ 6,004$ & 48.4 & 25.5 & 22.3 & 18.7 \\
\hline $\mathbf{6}$ & $\$ 6,004$ & 29.1 & 15.4 & 13.4 & 11.3 \\
\hline $\mathbf{7}$ & $\$ 8,256$ & 42.8 & 22.4 & 19.7 & 16.5 \\
\hline $\boldsymbol{8}$ & $\$ 6,534$ & 39.9 & 21.0 & 18.4 & 15.4 \\
\hline $\mathbf{9}$ & $\$ 4,128$ & 42.6 & 22.1 & 19.5 & 16.3 \\
\hline $\mathbf{1 0}$ & $\$ 6,380$ & 39.8 & 20.9 & 18.3 & 15.4 \\
\hline Mean & $\$ \mathbf{6 , 7 2 0}$ & $\mathbf{4 2 . 5}$ & $\mathbf{2 2 . 3}$ & $\mathbf{1 9 . 6}$ & $\mathbf{1 6 . 4}$ \\
\hline
\end{tabular}

The aluminium secondary glazing on average cost $1 \%$ more than the magnetically-attached acrylic sheet windows and was measured to have approximately $6 \%$ more thermal resistance. Due to these differences the payback period was inevitably going to be larger than the magnetically-attached acrylic sheet windows. These small differences in thermal resistance and price result in an average payback period approximately 1 year longer in a cool climate such as Dunedin through to 2.5 years longer in a warmer climate such as Auckland. The differences between the two systems were very small and are only a general representation of the payback period.

While the magnetically-attached acrylic sheet unit does manage to outperform the aluminium framed glass secondary glazing, the difference between the two is within the experimental and simulation error. It would be sensible to choose a unit based on durability, aesthetic and functional preference rather than purely economic reasons when the payback period is so similar. These choices would ultimately be down to the individual consumer. For example one consumer may prefer the slim profile and the aesthetic of the magnetically-attached acrylic sheet while another may find the sliding sash function and durability of an aluminium framed unit outweighs the very small performance difference. 


\subsubsection{Low-E Aluminium-framed Secondary Glazing}

Table 4-30: Low-E Aluminium-framed Secondary Glazing Energy Savings

\begin{tabular}{|c|c|c|c|c|c|}
\hline & Capital & Auckland & Wellington & Christchurch & Dunedin \\
\cline { 3 - 6 } House & Cost & $@ 22.88 \mathrm{c} / \mathrm{kWh}$ & $@ 22.85 \mathrm{c} / \mathrm{kWh}$ & $@ 21.43 \mathrm{c} / \mathrm{kWh}$ & $@ 21.95 \mathrm{c} / \mathrm{kWh}$ \\
\hline $\mathbf{1}$ & $\$ 6,403$ & $\$ 271$ & $\$ 513$ & $\$ 586$ & $\$ 699$ \\
\hline $\mathbf{2}$ & $\$ 8,729$ & $\$ 186$ & $\$ 359$ & $\$ 409$ & $\$ 488$ \\
\hline $\mathbf{3}$ & $\$ 9,392$ & $\$ 243$ & $\$ 463$ & $\$ 528$ & $\$ 630$ \\
\hline $\mathbf{4}$ & $\$ 9,392$ & $\$ 183$ & $\$ 349$ & $\$ 398$ & $\$ 475$ \\
\hline $\mathbf{5}$ & $\$ 6,830$ & $\$ 159$ & $\$ 304$ & $\$ 346$ & $\$ 413$ \\
\hline $\mathbf{6}$ & $\$ 6,830$ & $\$ 270$ & $\$ 508$ & $\$ 580$ & $\$ 693$ \\
\hline $\mathbf{7}$ & $\$ 9,392$ & $\$ 246$ & $\$ 474$ & $\$ 539$ & $\$ 644$ \\
\hline $\boldsymbol{8}$ & $\$ 7,512$ & $\$ 211$ & $\$ 401$ & $\$ 459$ & $\$ 549$ \\
\hline $\mathbf{9}$ & $\$ 4,696$ & $\$ 125$ & $\$ 241$ & $\$ 274$ & $\$ 328$ \\
\hline $\mathbf{1 0}$ & $\$ 7,257$ & $\$ 207$ & $\$ 396$ & $\$ 451$ & $\$ 538$ \\
\hline Mean & $\$ 7,765$ & $\$ 210$ & $\$ 401$ & $\$ 461$ & $\$ 538$ \\
\hline
\end{tabular}

Table 4-31: Low-E Aluminium-framed Secondary Glazing Payback Period

\begin{tabular}{|c|c|c|c|c|c|}
\hline House & $\begin{array}{c}\text { Capital } \\
\text { Cost }\end{array}$ & $\begin{array}{c}\text { Auckland } \\
\text { (Years) }\end{array}$ & $\begin{array}{c}\text { Wellington } \\
\text { (Years) }\end{array}$ & $\begin{array}{c}\text { Christchurch } \\
\text { (Years) }\end{array}$ & $\begin{array}{c}\text { Dunedin } \\
\text { (Years) }\end{array}$ \\
\hline $\mathbf{1}$ & $\$ 6,403$ & 23.6 & 12.5 & 10.9 & 9.2 \\
\hline $\mathbf{2}$ & $\$ 8,729$ & 46.8 & 24.3 & 21.3 & 17.9 \\
\hline $\mathbf{3}$ & $\$ 9,392$ & 38.7 & 20.3 & 17.8 & 14.9 \\
\hline $\mathbf{4}$ & $\$ 9,392$ & 51.4 & 26.9 & 23.6 & 19.8 \\
\hline $\mathbf{5}$ & $\$ 6,830$ & 43.0 & 22.5 & 19.7 & 16.5 \\
\hline $\mathbf{6}$ & $\$ 6,830$ & 25.3 & 13.4 & 11.8 & 9.9 \\
\hline $\mathbf{7}$ & $\$ 9,392$ & 38.2 & 19.8 & 17.4 & 14.6 \\
\hline $\boldsymbol{8}$ & $\$ 7,512$ & 35.7 & 18.7 & 16.4 & 13.7 \\
\hline $\mathbf{9}$ & $\$ 4,696$ & 37.7 & 19.5 & 17.1 & 14.3 \\
\hline $\mathbf{1 0}$ & $\$ 7,257$ & 35.1 & 18.3 & 16.1 & 13.5 \\
\hline Mean & $\$ \mathbf{\$ 7 , 6 4 3}$ & $\mathbf{3 7 . 6}$ & $\mathbf{1 9 . 6}$ & $\mathbf{1 7 . 2}$ & $\mathbf{1 4 . 4}$ \\
\hline
\end{tabular}

Use of the low-E secondary glazing resulted in the shortest average payback period of the three permanent secondary glazing systems. It was able to produce these positive results in all four 
climates in which the products were simulated. Despite having the largest cost to manufacture and install, the significant energy savings provided by the low-E secondary glazing were enough to result in the largest savings.

The average expected payback period in Auckland, like with the other units was still rather high. The average for the other three climates; Wellington, Christchurch and Dunedin, was below 20 years. This was below what would be the life expectancy of aluminium framed windows. Provided the low-E coating was not heavily scratched or damaged with chemicals then it would remain effective throughout its life. The average payback period for homes simulated within Dunedin was below 15 years. This was a significant reduction in the payback period over other units. For a slightly larger capital investment this system was able to give the fastest rate of return. Due to the significant increase in performance the system was still capable of a shorter payback period than the other systems simulated, even when the energy consumption was lower, such as in the warmer Auckland climate.

\subsection{Lifetime Costs}

The simple payback period of the various secondary glazing systems presents the amount of years it would take for the heating energy savings to become larger than the initial cost of the system when compared to just the single glazing. As the thin film plastic secondary glazing needs replacing each year, the payback was calculated by subtracting the cost of the product from the annual heating energy savings. To provide a more detailed comparison between the products as well as the initial single glazed windows a graph of the lifetime costs has been created. As with the previous data analysis the systems were assumed to have equal costs throughout the country. The cost of energy varies regionally and is treated as being consistent over the years, with no attempt being made to estimate future energy price variations. The cost of the thin film secondary glazing was also assumed to be consistent over the years. The graph presents the results over 25 years. Aside from the thin film secondary glazing, replacement costs of the units during this timeframe have not been included. 


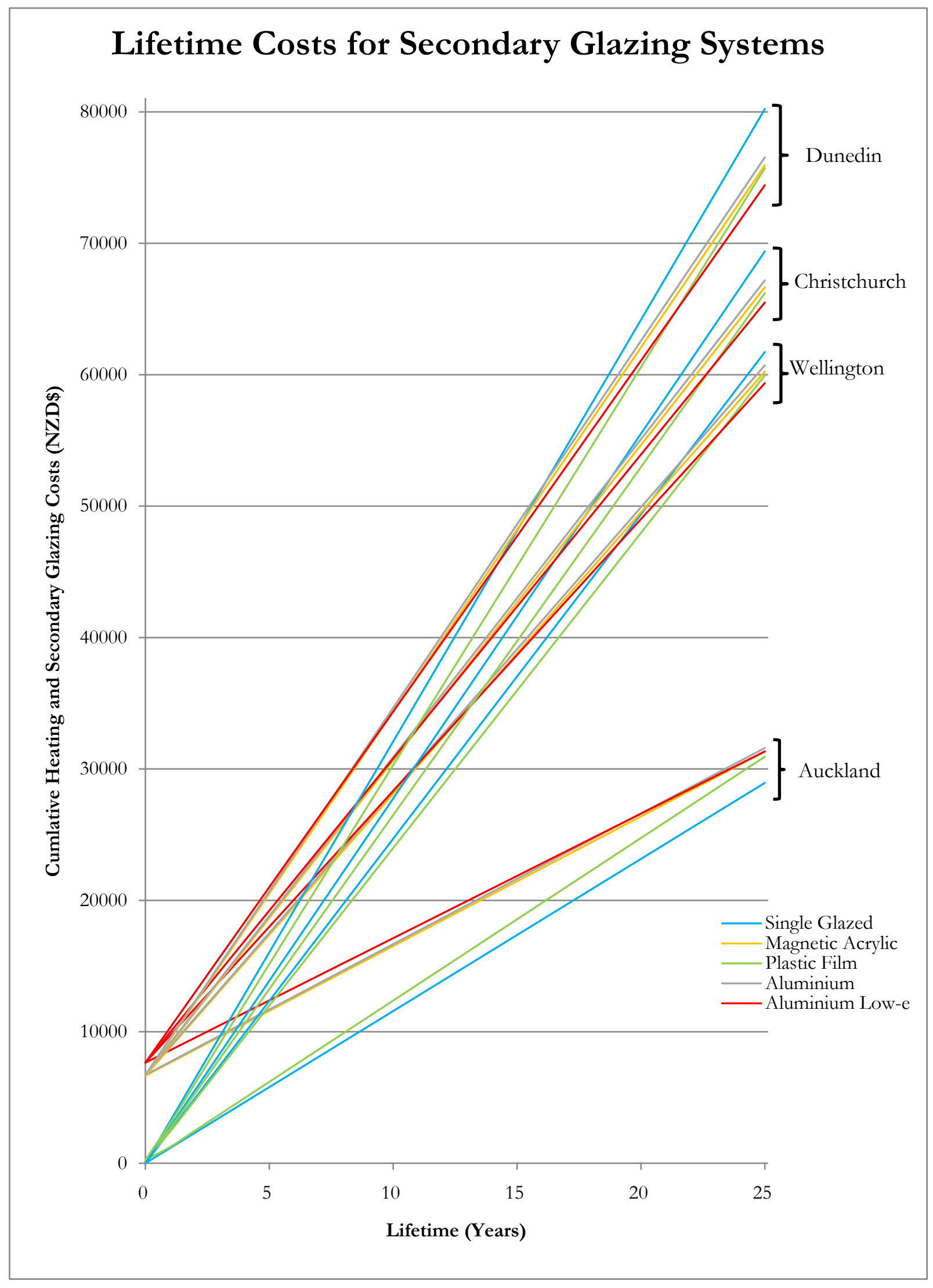

Figure 4-2: Lifetime Cumulative Secondary Glazing and Heating Costs from 0 - 25 Years 
Figure 4-2 presents the cumulative secondary glazing and heating energy costs over 25 years in all four climates. The initial costs are presented at $x=0$ and the gradient of the lines represent the annual costs. Systems such as the magnetically-attached acrylic sheet and the two aluminium secondary glazing's begin further up the graph due to their initial manufacturing and installation costs. The initial purchase cost of the thin plastic film secondary glazing was added to the energy consumption costs at the beginning of each year. Due to this small additional cost the product begins only slightly above the single glazing which has no initial cost. It then continues with a steeper gradient than the other secondary glazing systems despite having a similar R-value due to the annual purchasing costs.

Over 25 years the difference in heating energy depending on climate becomes clearly visible, especially in Auckland where the warmer climate results in significantly reduced energy consumption when compared to the other three climates. The Auckland graph also shows the inability of secondary glazing to pay itself off in the 25 years. As the thin plastic film secondary glazing purchase cost exceeds the annual energy savings the gradient was much steeper than that of the secondary glazing.

The thin film plastic secondary glazing does prove to be a worthwhile short term investment in the South Island. It takes around 21 to 23 years for the low-E secondary glazing to save more money than the thin plastic film in the three cooler climates. The thin film plastic secondary glazing actually outperforms the other two secondary glazing systems during the 25 year period. During this time however it would need to be attached to the windows annually. The collective, uncosted, labour required over this period would be very large.

The thin plastic film was a better short term solution in the cooler South Island climates. There are a few scenarios where this may be useful. A temporary solution for windows which are approaching the need for replacement is one possibility. Here installing more permanent secondary glazing would not be cost effective as the windows could require replacement prior to the system recouping initial purchase costs. It may be an option for rented dwellings where tenants often move. This could be problematic however as the system has the potential to remove damaged paint from reveals when removed. 
In Wellington, while the use of thin plastic secondary glazing produces cost savings, they were only very small. As there would be a reasonable amount of labour involved each year and the result could leave windows within the home inoperable during the winter, it would be hard to justify the use of this type of product in this climate, unless the system could be used for more than one heating season.

Due to the initial installation costs and R-values being very similar, the magnetically-attached acrylic sheet and aluminium secondary glazing systems produce a near identical lifetime cost in all climates. As the magnetically-attached acrylic sheet was slightly cheaper and has a slightly higher R-value the lifetime cost of the product was lower. The performance of the two products was near identical however and after allowing for a small margin of error, differentiation between the two is not possible. Ultimately the choice between the products would be down to other aspects rather than the thermal performance.

Over 25 years the low-E aluminium secondary glazing produces the best result of all the systems in the three cooler climates. Despite the higher initial cost it out performed all the other secondary glazing solutions in the 25 year period. It was able to surpass both the aluminium and the magnetically-attached acrylic sheet secondary glazing in 10 years time in a Dunedin climate, 12 years in a Christchurch climate and 14 years in a Wellington climate. This was approximately 5 years before the products were able to recuperate their initial costs in energy savings when compared to secondary glazing. Due to these savings, low-E aluminium framed secondary glazing was the most cost-effective secondary glazing solution.

The magnetically-attached acrylic sheet secondary glazing offers differences in appearance and function over the aluminium low-E secondary glazing which may influence a consumer's decision. The clear glass aluminium secondary glazing however offers very little advantage. The primary advantages to a consumer are a lower initial cost and a slightly different colour and tint in the window. While these may appeal to a consumer, low-E glazing performs better and is more cost-effective.

With small differences between the systems, much of the choice would depend on the household. This study used a strict morning and evening heating schedule with an $18^{\circ} \mathrm{C}$ setpoint 
and evenly distributed electric heating at $100 \%$ efficiency. This is not representative of many households and therefore the small savings would rely heavily on how the home is heated.

\subsection{Climate Zone Discussion}

The four chosen climates all produce rather different results. Each climate was selected due to these variations in temperature. It is important to note however that there are only 3 climate zones used in the New Zealand Building Code Clause H1. These climate zones are:

Zone 1: Districts north of Franklin and Thames-Coromandel Districts inclusive

Zone 2: North Island districts south of Franklin and Thames-Coromandel Districts (excluding Central Plateau)

Zone 3: South Island and North Island Central Plateau

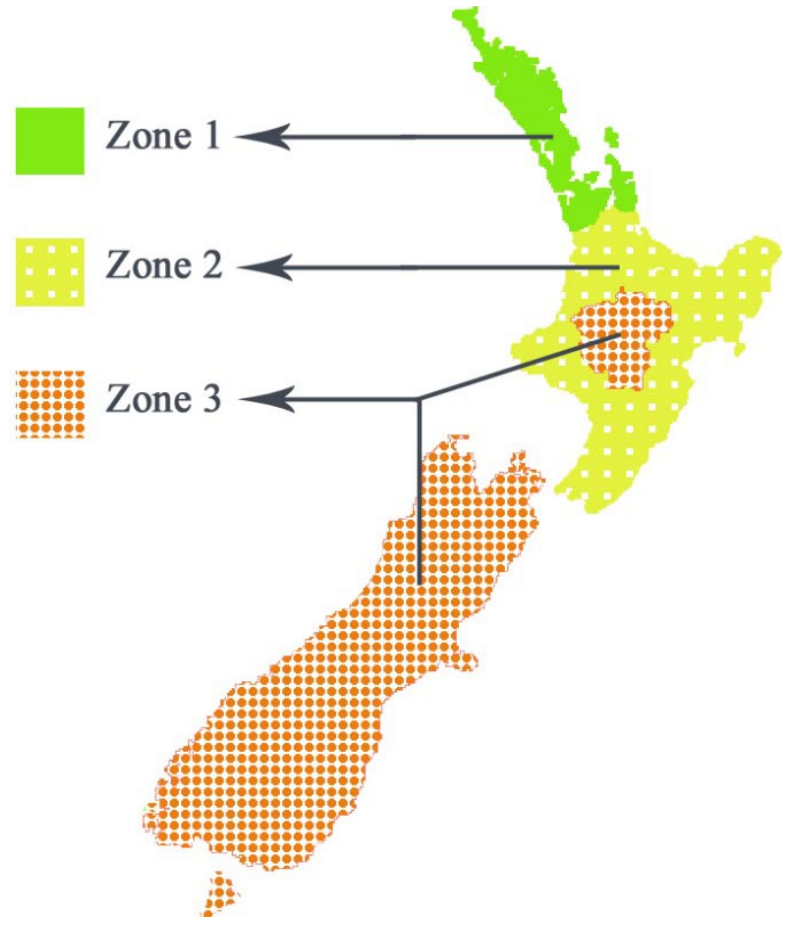

Figure 4-3: Map of Climate Zones (NZS 4218, 2009)

Of the Climate Zones used within the simulations, the Auckland results would fall within Climate Zone 1; Wellington would be Zone 2 while Christchurch and Dunedin would be Zone 3. It is important to note that while these cities fall within the specific climate zone, their climate 
is not necessarily representative of the entire zone. The recommendations for these secondary glazing systems could be broken down into the 3 climate zones.

For the three permanent secondary glazing solutions, the average payback periods were all below 20 years when used in Christchurch and Dunedin. Secondary glazing is a cost effective retrofit solution for homes in Climate Zone 3.The average payback for the Wellington homes was around 20 years. This is still an effective retrofit solution for homes however the larger payback period may be becoming too large for people concerned primarily with financial return from retrofits. Secondary glazing is a cost effective solution for increasing window insulation values in the Wellington region. As the payback for Wellington is relatively low there is potential for secondary glazing to be cost effective for many, if not all other areas in climate zone 2.

The Auckland simulations resulted in payback periods of approximately 40 years. This is a long period of time, almost twice the payback of the Wellington region and there are other retrofit alternatives which could prove more effective. There is a large chance of deterioration over 40 years, particularly with the primary window which would not be new when the secondary glazing was installed. For homes within Climate Zone 1, secondary glazing is not a cost effective solution. While homeowners in climate zone 1 may find the ancillary benefits of secondary glazing justify the initial cost, as a financially motivated retrofit, secondary glazing would not be recommended. 
A Cost Benefit Analysis of Secondary Glazing as a Retrofit Alternative for New Zealand Homes 


\subsection{Further Discussion}

\section{$5.1 \quad$ Overview}

This chapter uses the findings from the results and analysis chapters and discusses the significance of these findings. The findings are used to compare and assess secondary glazing to other retrofit alternatives. There is also discussion on how these findings relate to other properties of secondary glazing. The section ends with discussion on how non-quantifiable benefits of secondary glazing may influence a cost benefit analysis.

\subsection{Secondary or Double Glazing - A Retrofit Comparison}

A secondary purpose of this work was to assess the cost benefits of secondary glazing as a retrofit alternative to installing double glazing. The performance comparisons are simple to make based on the window R-values. The following table presents the final whole window R-values from the secondary glazing measurements and compares these with base case R-values for double glazing as well as calculated R-values from some manufactured products. The method used to calculate both the Standard window R-values (BRANZ, 2009b) and the manufacturers R-values (Metroglass, 2008) was computer thermal simulation.

The secondary glazing results are the final whole window R-values. The secondary glazing values were calculated for a $1000 \mathrm{~mm}$ x $1000 \mathrm{~mm}$ fixed window while the double glazed windows were calculated using a $1500 \mathrm{~mm} \times 1800 \mathrm{~mm}$ window with a central mullion and one opening light. For a fair comparison between these secondary and double glazing R-values the secondary glazing R-values from Table 4-2 were calculated using a very similar method as the double glazing R-values. The method from Table 4-2 calculates the R-values for single and secondary glazing to be $0.02 \mathrm{~m}^{2} \cdot \mathrm{K} / \mathrm{W}$ higher than those below while the low-E secondary glazing value was $0.04 \mathrm{~m}^{2} \cdot \mathrm{K} / \mathrm{W}$ lower than the value presented in Table $5-1$. 
Table 5-1: Window System R-values

\begin{tabular}{|c|c|c|}
\hline Measured R-Values & $\begin{array}{l}\text { Centre of Glazing } \\
\text { R-Value }\left(\mathrm{m}^{2} \cdot \mathrm{K} / \mathrm{W}\right)\end{array}$ & $\begin{array}{c}\text { Whole Window } \\
\text { R-Value }\left(\mathrm{m}^{2} \cdot \mathrm{K} / \mathrm{W}\right)\end{array}$ \\
\hline Window & 0.17 & 0.15 \\
\hline Magnetic Acrylic & 0.37 & 0.36 \\
\hline Thin Plastic Film & 0.36 & 0.35 \\
\hline Aluminium & 0.36 & 0.34 \\
\hline Aluminium Low-E & 0.56 & 0.57 \\
\hline \multicolumn{3}{|c|}{$\begin{array}{l}\text { Standard Aluminium Framed } \\
\text { Window R-values (calculated) }\end{array}$} \\
\hline Single & 0.17 & 0.15 \\
\hline Double 4-12-4 & 0.37 & 0.26 \\
\hline Double Low-E 4-12-4 & 0.53 & 0.31 \\
\hline
\end{tabular}

As shown by the table above, the secondary glazed windows perform comparably well against values for double glazing. While the measured single glazed window performance was the same as a standard single glazed window the secondary glazed units outperformed standard values for double glazing. On average the secondary glazed windows outperformed a standard 4-12-4 IGU by $0.09 \mathrm{~m}^{2} \cdot \mathrm{K} / \mathrm{W}$. This results in a $35 \%$ improvement when compared to a standard double glazed window. The low-E secondary glazing was even more impressive with an $84 \%$ or 0.25 $\mathrm{m}^{2} \cdot \mathrm{K} / \mathrm{W}$ improvement over the standard low-E IGU.

The secondary glazing $\mathrm{R}$-values are very large but require some explanation when used as a direct comparison. The standard window R-values are only a base case representation of a basic IGU installed in a typical aluminium extrusion. These windows are $1800 \times 1500 \mathrm{~mm}$ in size and have a central mullion and one opening light, leaving more framing for heat to be lost through, compared to the $1000 \mathrm{~mm}$ square windows tested in the GHB. This framing remains a weak point even when double glazing is used. A performance benefit to secondary glazing is the air gap also separates the aluminium framing of a window. With a double glazed unit the aluminium sash surrounding the glass is a thermally weak point in the window. The aluminium is highly conductive and, unless a thermally broken frame is used, provides a direct link from the outside

3 (NZS 4218, 2009) Appendix C 
to the inside environment. With a secondary glazed window this part of the sash separates the outside environment from the cavity rather than the indoor environment. The standard window R-value results also only feature a $12 \mathrm{~mm}$ cavity between the panes of glass. The cavity size in all of the tested secondary glazed units exceeds $20 \mathrm{~mm}$, the optimum cavity width for thermal performance in typical New Zealand climates as shown by Figure 2-6: Effect of cavity Width on R-Value.

Double glazing outperforms single glazing due to the ability to form an airtight seal of the cavity. This is difficult to achieve with secondary glazing. To minimise condensation between the secondary glazing and the main window, the cavity typically needs to be ventilated to the outside unless the internal panes are able to be removed for cleaning. As the GHB testing requires an airtight seal and the systems tested were removable, with the exception of the thin plastic film which is only temporary, this was not done for the physical testing. The two small drainage holes located at the sill of the fixed light aluminium window were taped over in accordance with Section 7.1.3 'Air Leakage' of ASTM E 1423 (ASTM, 1999). With these holes open there is a chance that more convection within the cavity would have lowered the thermal resistance of the secondary glazing.

Each of the secondary glazed windows provides a similar performance when retrofitted to a typical aluminium primary window as comparable double glazed windows. This shows that replacing single glazed windows with double glazing is not the only measure that can achieve a good level of window thermal performance. Secondary glazing can also be significantly cheaper. 
Table 5-2: Installation Cost and R-value of Various Glazing Systems.

\begin{tabular}{|c|c|c|c|c|c|}
\hline $\begin{array}{l}\text { Measured } \\
\text { R-values }\end{array}$ & $\begin{array}{l}\text { R-Value } \\
\left(\mathrm{m}^{2} \cdot \mathrm{K} / \mathrm{W}\right)\end{array}$ & Cost & & & \\
\hline Window & 0.15 & House 2 & House 8 & & Average \\
\hline Magnetic Acrylic & 0.36 & $\$ 7,058$ & $\$ 7,057$ & & $\$ 7,058$ \\
\hline Thin Plastic Film & 0.35 & $\$ 270$ & $\$ 248$ & & $\$ 259$ \\
\hline Aluminium & 0.34 & $\$ 7,751$ & $\$ 6,534$ & & $\$ 7,143$ \\
\hline Aluminium Low-E & 0.57 & $\$ 8,729$ & $\$ 7,512$ & & $\$ 8,121$ \\
\hline $\begin{array}{l}\text { Standard Window } \\
\text { R-values }^{4,5}\end{array}$ & & Auckland & Wellington & Christchurch & Average \\
\hline Single & 0.15 & $\$ 7,768$ & $\$ 8,292$ & $\$ 8,379$ & $\$ 8,146$ \\
\hline Double & 0.26 & $\$ 11,037$ & $\$ 12,787$ & $\$ 10,528$ & $\$ 11,451$ \\
\hline Double Low-E & 0.31 & $\$ 13,766$ & $\$ 16,593$ & $\$ 12,237$ & $\$ 14,199$ \\
\hline
\end{tabular}

The table above provides examples of the capital cost for secondary glazing systems as well as the capital cost of double glazed units. The cost for the double glazing has been taken from a cost benefit study assessing the financial advantages of initially constructing a house with double glazing. Unlike the secondary glazing costs these prices were for the windows only and do not include installation. The prices were for the purchase of double glazing to be installed in the NatHERS model house - a $170 \mathrm{~m}^{2}$ house with $34 \mathrm{~m}^{2}$ of glazing (Burgess, 2007). As the cost of double glazing varies for different regions depending on the uptake and availability, prices were taken from each of the climate zones. To simplify the comparison to the secondary glazing values these have been averaged.

The cost for the secondary glazing was taken from manufacturers quotes for two of the homes. House 2 was $165 \mathrm{~m}^{2}$ with $33.3 \mathrm{~m}^{2}$ of secondary glazing installed. House 8 was $182 \mathrm{~m}^{2}$ with $34.6 \mathrm{~m}^{2}$ of secondary glazing area. The average of these two homes would be a house that would have a very similar floor area and a near identical window area as the house used in the NatHERS

\footnotetext{
${ }^{4}$ Cost is capital cost only and does not account for labour and installation costs. Costs have been adjusted to match the consumer price index inflation from Q4 2005 - Q1 2008 of 6.6\%. (RBNZ, 2009)

5 Prices for double glazing are originally from: (Burgess, Economic Analysis of Window Insulation Requirements an Update, DC1076, 2007)
} 
model. For this research the quoted installation and cost prices for secondary glazing were assumed to be identical throughout the country.

As displayed by Table 5-2 there is a large difference in cost between secondary and double glazing. The secondary glazing capital costs presented on the previous table are only between 57 $-62 \%$ of the average cost of double glazing. Not only is the double glazing more expensive but it also does not include the prices for labour or installation. The prices for secondary glazing cover these costs. It is difficult to estimate the labour and installation costs of a double glazed retrofit. Cladding can need to be replaced and painted, access to multi-level dwellings may require a scaffold and due to weather tightness reasons a building consent may be required, further adding to the price (Burgess, 2008). The result is an expense much larger than that of secondary glazing for a similar performance.

Some existing window sashes can be simply retrofitted with double glazed units. Many timber windows can be easily modified to fit IGUs however these still require the double glazing to be purchased and considerable labour to modify the sash to accommodate the larger unit. If this is the situation, it is recommended that a quote is obtained and the options are assessed by the homeowner. It is also possible to retrofit double glazing into some existing aluminium sashes.

A recent cost-benefit analysis compared the cost effectiveness of retrofitting secondary glazing and the cost effectiveness of retrofitting double glazing into an existing aluminium frame (Page, 2009). The study determined that the cost benefit ratio of aluminium framed secondary glazing was slightly better than that of retrofitting double glazing into an existing aluminium frame. The study priced retrofitting double glazing into an existing aluminium frame to be slightly more expensive than retrofitting secondary glazing. Secondary cost $\$ 3432$ while retrofitting double glazing cost $\$ 3718$. Retrofitting double glazing into a timber frame was assumed to cost 1.5 times that of aluminium. The thermal resistance of each fenestration retrofit was not mentioned in the report.

The addition of secondary glazing requires windows which are in good condition. The units could be added to windows of a poorer condition and potentially offer improvements to the condition of the window and reduce deterioration, these windows would eventually require 
replacing. If this happens early into the life of the secondary glazing there will not have been enough time for the energy savings and ancillary benefits to have offset the capital costs. This study assumes the windows have been well maintained over the years and that there is no additional cost to fix window defects prior to installing secondary glazing. This approach is not necessarily appropriate for much of the single glazed housing stock.

In the 2005 BRANZ House Condition Survey, windows were found to have a condition rating of 3.8 out of 5 . Of the windows surveyed $11 \%$ were ranked in the categories serious or poor (Clark, Jones, \& Page, 2005). Windows within in these categories require significant amounts of money to repair and maintain, requiring some of the highest costs to remedy the defects in the survey. The cost to repair the windows and install secondary glazing would become very large. In this scenario replacing the windows with IGUs becomes a more cost effective option.

The study also identified windows as among the most critical components for repair as they can deteriorate quickly after reaching a moderate condition (rating of 3) (Clark, Jones, \& Page, 2005). With an average rating of 3.8 out of 5 many of the windows in the study would require some minor maintenance to bring them up to a reasonable standard before secondary glazing could be installed. In a comparison these costs would increase the payback period of secondary glazing. A retrofit where double glazing replaced the windows would not require these maintenance costs. Retrofitting double glazing into the existing windows may also solve some of these issues. It is important to note that in many situations the conditions of various windows in an individual home will vary. Ultimately a decision choosing between these options would need to be made on a case by case basis.

\subsection{Secondary Glazing as a Retrofit Alternative}

For the systems to be considered as a seriously viable retrofit alternative they must be able to outperform or offer advantages over other retrofit alternatives. For many consumers in New Zealand the economic benefits of the various retrofit options would be important. This study has not compared secondary glazing with other retrofit options. This section discusses other 
research into the cost benefit of other retrofit options and how secondary glazing may perform in comparison.

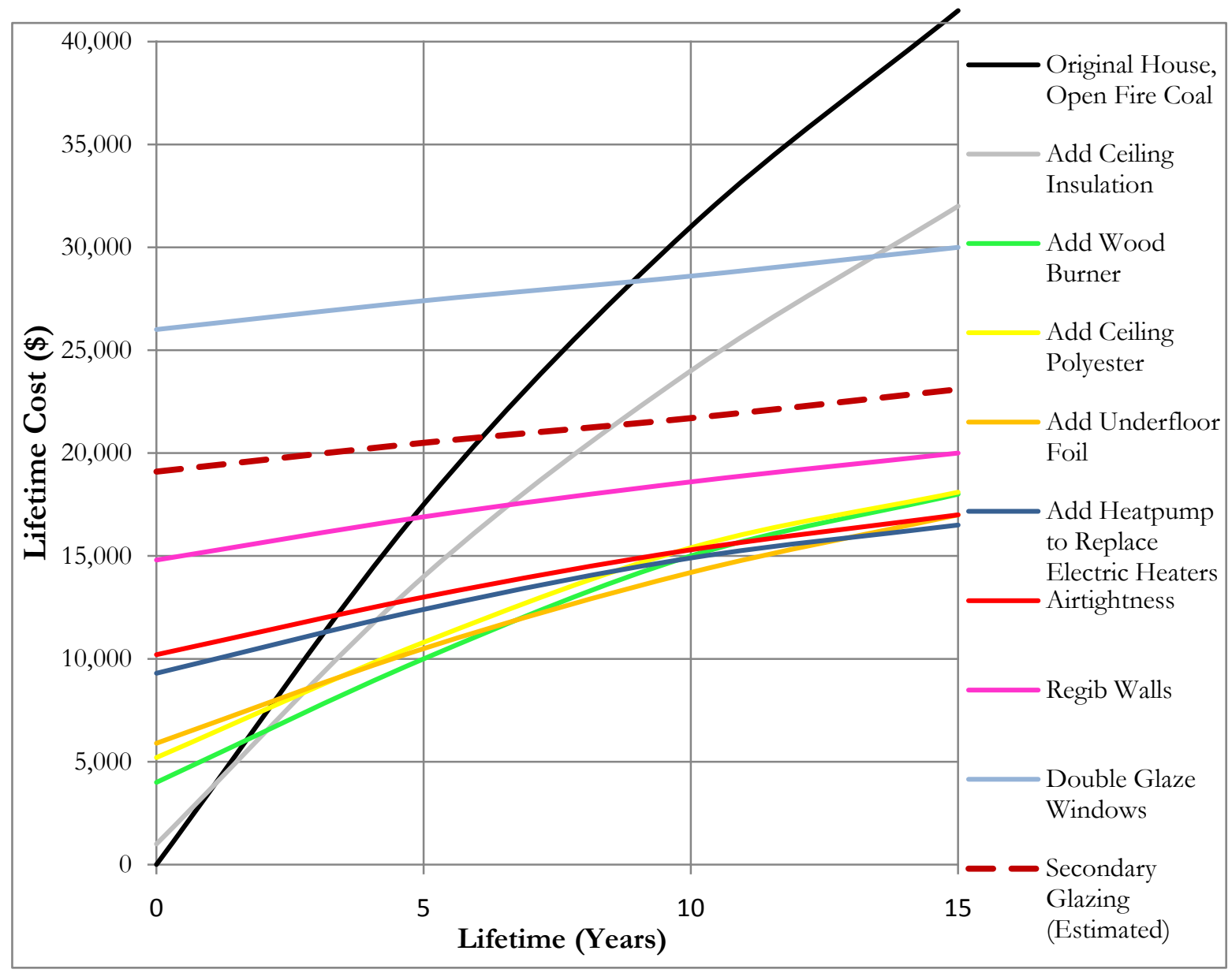

Figure 5-1: Initial and Discounted Recurrent Costs from 0 - 15 years (Lloyd, Bishop, \& Callau, 2007)

The graph above presents the lifetime costs for various upgrade options. These were determined by a retrofit study of a state house in Dunedin. This graph documents a full retrofit of a house from the first retrofit of adding ceiling insulation through to the final retrofit of double glazing. The dashed line (added to the original results) represents the estimated lifetime costs of secondary glazing, using the data from this research, should it have been used rather than double glazing. For the purpose of this comparison, the dashed line assumes identical discounted heating costs to that provided by double glazing. For this to occur, the resistance provided by secondary glazing the existing windows would have to be identical to that of the double glazing. 
The initial cost of approximately $\$ 11,000$ to double glaze the home is the most expensive of the retrofit options. It is also rather ineffective, providing only small savings over the 15 years despite the large initial cost. Ceiling insulation costs much less and provides much larger savings. The house was rather small with a floor area of $68 \mathrm{~m}^{2}$ and 11 timber windows with an external window area of $18 \mathrm{~m}^{2}$ (Lloyd \& Callau, 2006). This was the same amount of windows and a slightly smaller window area as House 9 which was the second smallest house and had the smallest window area in this research. By working out the cost per window from the secondary glazing quotes it was estimated that a home like this would cost approximately $\$ 4,100$ for magnetically-attached acrylic sheet installed through to $\$ 4,700$ for low-E secondary glazing. The performance of the secondary glazing would be more comparable to the gradient of the line formed by the double glazing option.

The price of the secondary glazing is comparable to replacing electric heaters with a heat pump, adding a wood burner or regibbing the walls. Using the initial cost of $\$ 4,700$ and assuming a similar savings gradient over the 15 years as that of the double glazing, if secondary glazing were placed on the previous chart it would provide similar savings to regibbing the walls or replacing electric heaters with a heat pump. Aside from airtigtness, which would also benefit from secondary glazing, the other retrofit options presented on the graph appear to be more financially viable in a typical uninsulated New Zealand home.

A cost benefit study of solar hot-water heating systems found them to have a payback of around 12 years without the need for a cylinder replacement to approximately 17 years for flat panel systems and 19 years for evacuated tube systems with replacement of the cylinder (Stoecklein, 2005). The study assumed a life expectancy of these systems varied from around 20 years for flat panel systems and 15 years for evacuated tube systems. Generally these systems performed in a similar manner nationwide, unlike secondary glazing which tended to perform best in the South Island. As retrofit alternatives there are many different factors between the two options which can make them difficult to compare. As a purely financial retrofit, secondary glazing is only a better option in cooler climates if the cylinder needs replacing.

When compared to other retrofit options for an uninsulated home, secondary glazing may produce a longer payback period. As a financially motivated retrofit option, it would be difficult 
to recommend secondary glazing. To draw comprehensive conclusions, a direct comparison of the payback periods for a variety of products would need to be conducted. Properties of the envelope of the dwelling as well as what needed to be achieved would have too larger influence to broadly recommend secondary glazing over other retrofit alternatives. As secondary glazing is able to perform well, there may be situations where its use would be more beneficial than other retrofit alternatives. In situations where more affordable options such as floor and ceiling insulation have been installed or are not possible, secondary glazing should be considered. This section shows that secondary glazing has the potential to provide significant savings but may not be financially competitive with other technologies. Potential future research could provide a direct comparison of the cost benefit of a variety of retrofit technologies when compared to secondary glazing.

\subsection{Ancillary Benefits of Secondary Glazing}

The purpose of this study was to assess the cost benefit secondary glazing could provide homeowners when retrofitted into existing single glazed windows. The previous sections within this report analyse the effectiveness of secondary glazing on a purely financial basis. This method was able to find the shortest payback period for the consumer, enabling the product to be compared to other potential retrofit options. This 'value for money' approach ignores many other potential non-energy benefits that secondary glazing is able to provide. These advantages have been labelled ancillary benefits and are discussed in this section.

\subsubsection{Airtightness}

The addition of secondary glazing to primary windows could reduce the air leakage of a home. A study looking at modelling heat loss within houses found air leakage responsible for around 6 $9 \%$ of the heat loss in an uninsulated house through to $10-17 \%$ in a fully insulated house (Pollard, 2005). The amount of air leakage lost through the windows depends on the age, type and condition of the window with older timber windows resulting in the most leakage. One study found that taping all the opening joints on timber windows resulted in a 30\% improvement to the airtightness of the house (Bassett, 1996). A well sealed secondary glazing unit could provide a similar effect. A recent study conducted in the United States found that on average, 
storm windows reduced the air leakage of the houses by 7\% (Drumheller, Kohler, \& Minen, 2007).

The addition of secondary glazing has the ability to significantly reduce the infiltration of older style timber windows. This could provide further energy savings on top of those already calculated by this study. It should be noted that while the reduction of air leakage may be large if the primary window was poorly sealed, the unit may not perform as well as indicated by the testing due to more ventilation within the cavity. This would reduce the thermal resistance provided by the cavity when compared to a still air space.

Care must be taken if secondary glazing were to be added to a more modern airtight home. To add further sealing to a modern airtight home could result in problems from increased condensation, reduced indoor air quality and high internal moisture levels because of the lack of ventilation (BRANZ, 1993). This would be made worse if the secondary glazing was not easily removable from the window preventing the use of windows that were once operable.

\subsubsection{Acoustic}

As discussed in the literature review, acoustic performance is a key advantage to secondary glazing. Secondary glazing is able to produce an air gap much wider than that produced by an IGU, resulting in improved acoustic insulation over a wide range of frequencies (BRE, 1993). Dwellings near noise sources such as busy roads, bars etc would stand to benefit from improved noise reduction through the window. Acoustic benefits are difficult to assess on a large scale as they are often isolated problems. They depend on the volume of the noise, the time the noise occurs and occupant's perception of the noise. One New Zealand study (Stoecklein, Zhao, Christie, \& Skumatz, 2005) has attempted to quantify the benefits of improved acoustic insulation of IGUs; the results are presented in Table 5-3.

\subsubsection{Comfort}

With windows typically being the thermal weak spot in the building envelope they may also be the coldest element in a room. Not only does this serve to reduce the mean radiant temperature 
but it can also result in radiant asymmetry. These have an influence on a person's perceived comfort and if large enough, can leave them dissatisfied with the environment despite having a satisfactory air temperature.

By increasing the thermal resistance of the windows with secondary glazing the internal air temperature of the home will increase provided the occupant's behaviour remains the same. As this study calculated the heating energy reduction provided by secondary glazing in homes with an $18^{\circ} \mathrm{C}$ morning and evening heating schedule, both pre- and post-retrofit homes experience the same temperature. While there would be temperature benefits outside the times of the schedule these are times where the occupants are assumed to be away or in bed. The additional heat retention provided by the secondary glazing outside of heating hours would also be reflected in the energy results. What the results cannot calculate is the influence of radiant temperature sources on the occupants comfort.

Increasing the resistance of the windows by adding another pane of glazing in either the form of double glazing or secondary glazing increases the surface temperature of the innermost pane of glass. Figure 5-2 \& 3 show the internal surface temperature of the pane of glass for both a single and a double glazed window with R-values of 0.18 and $0.33 \mathrm{~m}^{2} \cdot \mathrm{K} / \mathrm{W}$ respectively. Each graph displays the results for two different conditions during a cold winter's day where the external temperature is $0^{\circ} \mathrm{C}$. The green line represents an unheated room with an internal temperature of $12^{\circ} \mathrm{C}$ while the red line represents a room heated to $20^{\circ} \mathrm{C}$.

As shown by a comparison of the two graphs the inclusion of a second pane of glass increases the surface temperature of the internal pane. The surface temperature of the double glazing is approximately $4^{\circ} \mathrm{C}$ higher than that of the single glazing in an unheated room while it is just over $6^{\circ} \mathrm{C}$ higher in the room heated to $20^{\circ} \mathrm{C}$. This increase would reduce the radiant discomfort of an occupant within the room. The increased surface temperature would also reduce downdrafts caused by the comparatively cooler temperature of the window. The decrease or removal of these downdrafts would further improve an occupants thermal comfort. 

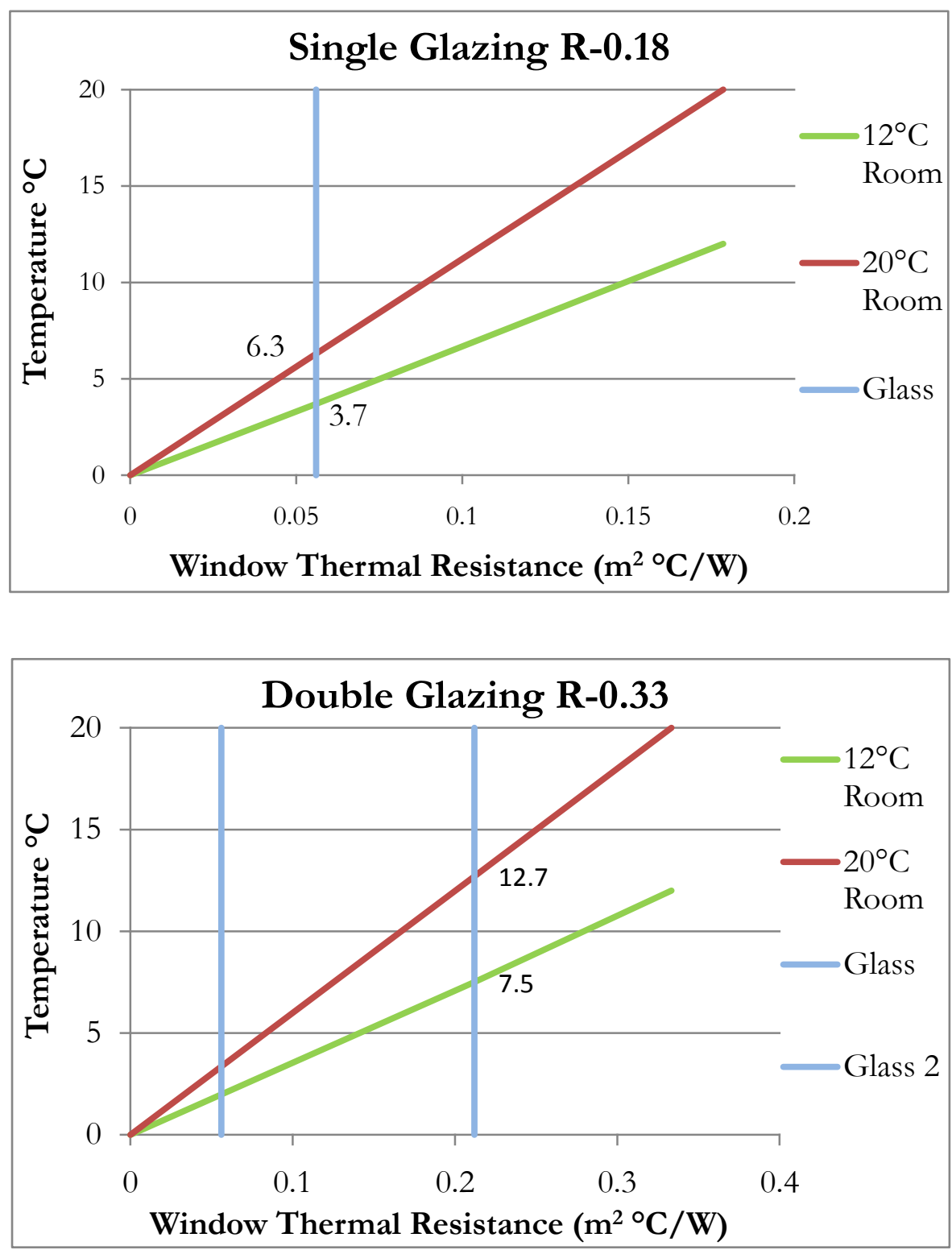

Figure 5-2 (above) and Figure 5-3: The effect of a second pane on internal window temperature (Godfrey, 1972).

\subsubsection{Condensation}

Not only does the increased surface temperature of the window result in a more pleasant environment but it can also reduce the occurrence of condensation. As air temperature increases the air is able to hold more moisture. Condensation occurs when the air temperature drops to or below the dew point, the temperature at which the water vapour condenses into water. In buildings this occurs when warm moist air comes into contact with a cold surface such as a window (BRANZ, 1998). 
In the two scenarios represented in Figure 5-2 (above) and Figure 5-3: The effect of a second pane on internal window temperature. The dew point in the air needs to be $4-6^{\circ} \mathrm{C}$ higher for condensation to form on the double glazed window when compared to the single glazed window. Simple dew point calculations could be used to calculate the relative humidity $(\mathrm{RH})$ required in each scenario for condensation to occur. Examples of these calculations are presented in section 2.3.3.3, Condensation Performance.

Figure 5-2 (above) and Figure 5-3: The effect of a second pane on internal window temperature. represent two very cold winter scenarios where condensation is very likely. For the first scenario the house is unheated resulting in a $12^{\circ}$ indoor temperature with a $0.18 \mathrm{~m}^{2} \cdot \mathrm{K} / \mathrm{W}$ single glazed window. The internal surface of the glass is $3.7^{\circ} \mathrm{C}$. For condensation to form on the glass the relative humidity would only need to be $59 \%$ or higher. If this is replaced with double glazing with an R-value of $0.33 \mathrm{~m}^{2} \cdot \mathrm{K} / \mathrm{W}$ then the surface temperature of the glass would rise to $7.5^{\circ} \mathrm{C}$, requiring an $\mathrm{RH}$ of $78 \%$ or above for condensation to form. Should the room be heated to $20^{\circ} \mathrm{C}$ then condensation forming on the glass pane is more likely due to the increased air temperatures being able to hold more water vapour and only a small increase in surface temperature of the window. In this situation condensation would form on the single glazed window unless the RH was below $32 \%$. If double glazing was installed however the humidity would need to be $64 \%$ or higher. A second pane of glass in the form of double or secondary glazing would result in much less likelihood of condensation appearing on the window.

The effect of reduced condensation on windows can result in a longer lifespan for the window due to less water damage. Increasing the lifespan of the primary window is another financial incentive for the homeowner if condensation related damage is a problem. Condensation pooling at the bottom of the window can also be a problem resulting in mould. This can cause health issues such as respiratory problems. These health issues are discussed in the following section.

It is important to note that as the cavity of secondary glazing is not airtight there is potential for condensation to form between the panes. This could also result in damage to the window. If the secondary glazing is permanently fixed to the window it is recommended that the cavity is vented to the outside air. If operable secondary glazing experiences problems with condensation the 
pane can be opened up and cleaned, to prevent the likelihood of this occurring the secondary glazing could be fixed on a cold, dry morning when there is little water vapour in the air. Another option to reduce this problem could be the use of a desiccant within the cavity space.

\subsubsection{Health}

There is also potential for secondary glazing to provide health benefits to the occupants due to the increased thermal resistance of the windows. The installation of secondary glazing is able to provide increased air temperature, increased radiant temperature from the windows and decreased condensation on the windows, resulting in less mould and allergens. There is also however, potential for the secondary glazing to increase dampness within the home due to increased airtightness. This is particularly a problem with inoperable secondary glazed windows which restrict the opening of windows.

One New Zealand study (Chapman et al., 2004) has quantified the cost savings provided by good health as a result of better living environments. These cost savings arise from fewer GP visits, fewer hospital admissions, fewer days off work and fewer days off school. The study looked at the benefits of installing insulation in houses and the influence that this would have on both energy use and reduced health costs. It found that the annual energy savings provided by insulation was $\$ 1060$ while the health related savings totalled $\$ 2050$ (Chapman, HowdenChapman, \& O'Dea, 2004). The health related savings nearly doubled the savings from reduced energy consumption.

It is unknown whether the changes provided by secondary glazing would be enough to produce any health related benefits like those found with the previously mentioned insulation packages but there is a possibility. Much of this possibility would depend on the condition of the dwelling and how it is used by the occupant. Inoperable secondary glazing or secondary glazing left sealed by the owner could potentially increase the water vapour within the dwelling, resulting in detrimental health effects. Used sensibly however, the secondary glazing could improve conditions within a dwelling enough to produce positive health effects and as a result, financial savings from reduced healthcare and days off work. 


\subsection{Quantifying Non Energy Benefits}

The primary reason that these ancillary benefits have not been analysed in the previous section is because they can be difficult to quantify in economic terms. Assessing the total effectiveness of secondary glazing on a cost-benefit analysis alone essentially assumes a cost for these ancillary benefits as well, which incidentally is $\$ 0$.

This study will only discuss these ancillary benefits and will not attempt to quantify them in economic terms. There have been other studies which have analysed and prescribed $\$$ values to these added benefits of retrofit technologies, called non-energy benefits (NEBs). The BRANZ Zero and Low Energy House Project (ZALEH) is the first project to quantify NEBs in New Zealand. The project used a number of carefully designed questionnaires to interview the occupants of a variety of low energy houses about how much they value NEBs such as comfort, health and appearance.

Table 5-3: Annual NEB values by technology and NEB type in New Zealand dollars (Stoecklein, Zhao, Christie, \& Skumatz, 2005)

\begin{tabular}{|c|c|c|c|c|c|c|c|c|c|c|}
\hline & 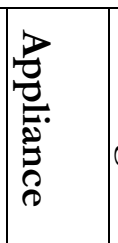 & 是 & 㞼 & 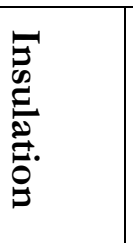 & $\begin{array}{l}0 \\
0 \\
0 \\
0 \\
0 \\
0 \\
0 \\
0 \\
0.0 \\
0 \\
0\end{array}$ & $\frac{0}{\stackrel{0}{9}}$ & 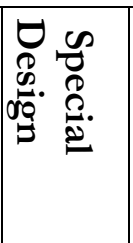 & 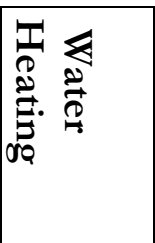 & 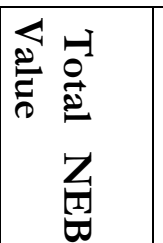 & 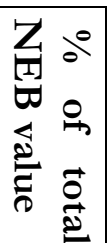 \\
\hline Appearance & $\$ 12$ & $\$ 82$ & $\$ 69$ & $\$ 301$ & $-\$ 69$ & $\$ 440$ & $\$ 952$ & $\$ 3$ & $\$ 1,379$ & F\% \\
\hline Bill Control & $\$ 11$ & $\$ 134$ & $\$ 58$ & $\$ 292$ & & $\$ 0$ & $\$ 0$ & $\$ 205$ & $\$ 795$ & $4 \%$ \\
\hline Comfort & $\$ 2$ & $\$ 1,080$ & $\$ 695$ & $\$ 1,895$ & $\$ 31$ & $\$ 60$ & $\$ 1,707$ & $\$ 763$ & $\$ 5,574$ & $28 \%$ \\
\hline Environmental & $\$ 161$ & $\$ 248$ & $\$ 382$ & $\$ 432$ & & $\$ 1,600$ & $\$ 633$ & $\$ 1,291$ & $\$ 4,227$ & $22 \%$ \\
\hline Features & $-\$ 3$ & $\$ 55$ & $\$ 48$ & $\$ 4$ & $-\$ 129$ & $\$ 60$ & $\$ 0$ & $-\$ 2$ & $\$ 61$ & $0 \%$ \\
\hline Health & $\$ 0$ & $\$ 150$ & $\$ 175$ & $\$ 322$ & $\$ 100$ & $\$ 0$ & $\$ 0$ & $\$ 58$ & $\$ 653$ & $3 \%$ \\
\hline Maintenance & $\$ 28$ & $\$ 418$ & $-\$ 28$ & $\$ 262$ & & $\$ 220$ & $\$ 0$ & $-\$ 131$ & $\$ 232$ & $1 \%$ \\
\hline Moving & $\$ 0$ & $\$ 264$ & $\$ 407$ & $\$ 1,640$ & $\$ 510$ & $\$ 714$ & $\$ 1,802$ & $\$ 295$ & $\$ 4,307$ & $22 \%$ \\
\hline Noise & $\$ 35$ & $\$ 702$ & $\$ 3$ & $\$ 368$ & $-\$ 83$ & $\$ 0$ & $\$ 0$ & $-\$ 17$ & $\$ 925$ & $5 \%$ \\
\hline Notices & $\$ 0$ & $\$ 0$ & $\$ 0$ & $\$ 0$ & $\$ 0$ & $\$ 0$ & $\$ 0$ & $\$ 0$ & $\$ 0$ & $0 \%$ \\
\hline Cost & $-\$ 44$ & $-\$ 366$ & $-\$ 154$ & $-\$ 612$ & & $-\$ 441$ & $\$ 0$ & $-\$ 361$ & $-\$ 3,340$ & $-11 \%$ \\
\hline All Other & $\$ 66$ & $\$ 120$ & $-\$ 120$ & $\$ 244$ & $-\$ 331$ & $\$ 0$ & $\$ 0$ & $\$ 93$ & $-\$ 187$ & $-1 \%$ \\
\hline Sum & $\$ 269$ & $\$ 2,888$ & $\$ 1,537$ & $\$ 4,660$ & $\$ 349$ & $\$ 2,653$ & $\$ 5,094$ & $\$ 2,198$ & $\$ 19,648$ & $100 \%$ \\
\hline $\begin{array}{l}\% \text { of houses } \\
\text { with the } \\
\text { measure }\end{array}$ & $61 \%$ & $91 \%$ & $91 \%$ & $83 \%$ & $35 \%$ & $22 \%$ & $96 \%$ & $96 \%$ & $100 \%$ & \\
\hline $\begin{array}{l}\% \text { NEBs for } \\
\text { technology }\end{array}$ & $1 \%$ & $15 \%$ & $8 \%$ & $24 \%$ & $2 \%$ & $14 \%$ & $26 \%$ & $11 \%$ & $100 \%$ & \\
\hline
\end{tabular}


As the questions asked the participants to rate the value of the individual categories, the sum of these values tends to lead to an overestimation for the technology. To balance this, the survey included a question asking the occupant to rate the overall benefit of all technologies. The ZALEH survey reported the overall value to be $\$ 2,750$ on average per house. The frequency rated total of the individual benefits from Table 5-3 is $\$ 15,765$. Using the ratio between these two values has been used to downscale the individual technology benefits. For the glazing technology means that the total benefit is $\$ 2,888 *(\$ 2,750 / \$ 15,765)=\$ 504$ per year (Burgess, 2007).

As the performance of secondary glazing was similar to that of double glazing it could be assumed that the annual NEB value is similar to the $\$ 504$ provided by double glazing. There would be comparative differences between some of the categories, for example secondary glazing may score better in the cost and noise category while not as good in the appearance category. Due to these differences, the NEB value for double glazing cannot be attributed directly to secondary glazing. It is worth noting that the annual NEB value for double glazing is quite often larger than many of the secondary glazing energy savings which range from $\$ 162$ in Auckland to $\$ 538$ for Low-E secondary glazing in Dunedin. If a NEB value was able to be assessed and implemented into the cost benefit for secondary glazing the payback period could be significantly reduced. 


\subsection{Conclusions and Recommendations}

\subsection{Overview}

The primary purpose of this research was to produce a cost benefit analysis of a variety of secondary glazing systems in typical homes throughout the country. To achieve this some secondary aims needed to be met. The thermal resistance of a typical single glazed window needed to be measured. This single glazed window was then retrofitted with each of the secondary glazing units and the individual R-values for these products were measured. This research aimed to produce accurate R-values for a selection of secondary glazing systems using both physical laboratory testing and computer simulation. The R-values were to provide a comparison between secondary and double glazing as well as the information required to simulate typical home heating energy consumption.

Computer simulation was used to remove the influence of the surround panel from the guarded hot box measurements. This required a detailed computer model of the window. This also allowed for the study to analyse the differences between thermal simulation and physical testing. The purpose of this was to determine whether computer simulation was a sufficient form of determining the thermal resistance of windows with secondary glazing. It also allows for comparisons to be drawn against other windows simulated in accordance with standards.

Once the final whole Window R-values were known they were then used in a thermal energy simulation to determine the annual energy savings produced by retrofitting these into a variety of typical New Zealand homes. The energy cost was then analysed and compared to the price of the secondary glazing. This information was sufficient to determine the cost benefit analysis of a variety of secondary glazing systems in typical homes throughout the country.

This chapter presents the conclusions drawn from this body of research. From these conclusions, recommendations for the use of secondary glazing in New Zealand as well as other recommendations related to the research are prescribed. From here recommendations for future

Nick Smith 
research into secondary glazing in New Zealand are discussed. These include aspects not covered by the scope of this research as well as further questions posed from the findings of this project.

\subsection{Conclusions}

\subsubsection{R-Values}

The measured R-values of the secondary glazing units indicated significant improvements over the single glazed window. The low-E secondary glazing produced a significant R-value of $0.57 \pm$ $0.08 \mathrm{~m}^{2} \cdot \mathrm{K} / \mathrm{W}$. The remaining three secondary glazing units all resulted in similar $\mathrm{R}$-values ranging from $0.34 \pm 0.05 \mathrm{~m}^{2} \cdot \mathrm{K} / \mathrm{W}$ to $0.36 \pm 0.05 \mathrm{~m}^{2} \cdot \mathrm{K} / \mathrm{W}$. The slight differences between them were caused by the different framing and glazing materials used. A key finding was the significant improvement these systems were able to provide over the existing single glazed window. Attaching secondary glazing increased the windows R-value from $130 \%$ through to $290 \%$ of the performance of the single glazed, fixed aluminium window.

The thermal resistance of each secondary glazing system were similar to those of comparable double glazed units with a $12 \mathrm{~mm}$ cavity. The large improvements were attributed to the larger cavity secondary glazing provides. Each unit created a cavity larger than $20 \mathrm{~mm}$ which separated both the pane of glass and the aluminium window frame from the interior surface.

When fixed to a timber frame the increase in performance may not be as large, however the whole window R-values would be larger. This is because the timber frame loses less heat than an aluminium frame so the comparative benefits provided by a secondary glazing retrofit would be smaller.

\subsubsection{Cost Benefit}

Low-E aluminium framed secondary glazing provided the shortest payback of all the systems tested. This shorter payback period was applicable for all the homes tested using each of the four climates. The additional energy savings provided outweighed the higher initial capital investment in all climates. 
Secondary glazing is not a cost effective retrofit alternative within the Auckland region. As a result, it would not be a cost effective retrofit option for homes located anywhere within climate zone 1. Wellington, Christchurch and Dunedin all provided much shorter payback periods than simulations run using the Auckland climate. Wellington averaged a payback period of 20 to 22 years depending on the system. When used in a Wellington climate, low-E secondary glazing produces a mean payback of just below 20 years.

Christchurch and Dunedin were both capable of producing much faster returns. Both climates were able to provide a mean payback period of less than 20 years for all systems. Low-E secondary glazing produced a mean payback just below 14 years when used in Dunedin. For homes located within climate zone 3 , secondary glazing is a cost effective retrofit alternative.

As thin film secondary glazing restricts the opening of operable windows and requires the homeowner to install it themselves, it may not be a suitable solution for many homes. As it is a seasonal product it requires replacement annually. This also means that it is able to provide annual returns, making it suitable for short term solutions. The low cost of thin plastic film secondary glazing allows it to provide an annual payback in homes within climate zone 3 . In Wellington it was able to provide small returns in all but one of the simulated homes. In Wellington, returns were only small and as it is a DIY system that requires time to install it may not be suitable for many homeowners. In Auckland the energy savings did not outweigh the cost of purchasing the materials for any of the homes simulated.

\subsubsection{As a retrofit alternative}

As a retrofit alternative to double glazing, secondary glazing performs very well. The cost of secondary glazing purchased and installed is much cheaper than the purchase cost alone for double glazing, between $57-62 \%$ of the price. Only in situations where existing sashes allow for affordable installation of double glazing should it be considered. This study found that the performance difference between double glazing and properly installed secondary glazing units to be minimal. 
Provided existing single glazed windows are in a good condition and do not need to be replaced in the near future, secondary glazing is a cost effective retrofit alternative to double glazing. As the condition of windows in some older single glazed homes is poor, a final decision on a suitable window retrofit option would need to be made on a case by case basis depending on the level of maintenance required on the existing windows.

When compared to other retrofit alternatives secondary glazing has the potential to provide comparable payback periods. As a purely financial retrofit option in uninsulated homes there are other retrofit options that should be conducted prior to considering secondary glazing. Should these options be unavailable or completed then secondary glazing is recommended.

\subsection{Recommendations}

The use of secondary glazing as a retrofit alternative is recommended for typical New Zealand homes located within climate zone 3. The use of secondary glazing on windows of homes located in climate zone 2 is encouraged. Homes within climate zone 1 were not likely to see a return on their initial investment, therefore the installation of secondary glazing for financial reasons within this area is not advised.

Of the available secondary glazing solutions, low-E aluminium framed secondary glazing provides the best results across the board. If a secondary glazing retrofit was being considered, this research suggests low-E secondary glazing is used. In a situation where a short term solution is required, a thin adhesive film style secondary glazing is recommended for homes within climate zone 3.

The use of secondary glazing is not recommended for homes which show signs of window deterioration. Windows that are beginning to deteriorate either require a total replacement or the appropriate maintenance prior to the fitting of secondary glazing.

In uninsulated homes other more affordable retrofit options such as ceiling and floor insulation should be explored as options prior to secondary glazing. It should be noted that the non- 
financial benefits of secondary glazing may have greater value to house occupants than the energy cost savings.

\subsection{Future Research}

Some findings of this research have posed further questions about the performance of secondary glazing and how it relates to that of other retrofit technologies. To answer these questions there is a need to examine aspects of secondary glazing not covered by the scope of this research.

The measured thermal resistance of the four tested secondary glazing systems is now known. These results now add to the existing body of research into the thermal resistance of retrofit technologies. A detailed computer simulated cost benefit study would allow a fair and direct comparison of secondary glazing and a variety of retrofit technologies. These energy saving comparisons along with cost and installation prices would be able to determine just how cost effective secondary glazing is in comparison to other retrofit options.

The durability of secondary glazing systems under New Zealand conditions should be assessed. These could be used to provide a greater knowledge of recurring costs in a lifecycle cost assessment of the systems. It could also be paired with an analysis of typical window conditions within New Zealand homes, the amount of life these various single glazed systems have left before requiring replacing and the influence that secondary glazing has on the life expectancy of single glazing.

A better understanding of the total embodied energy of a secondary glazing retrofit would also add to the body of knowledge. The embodied energy used to harvest materials; manufacture, deliver, install and dispose of various secondary glazing systems could be calculated. These could then be offset by the energy savings depending on the source and the renewability of the heating energy. These calculations would need to be New Zealand specific.

Finally there is the influence these systems would have on the airtightness of a typical New Zealand single glazed home. Air leakage is a primary source of energy loss through the envelope 
of a home and older single glazed windows are a primary source of this leakage. The ability of secondary glazing to provide an additional seal to these windows could result in a decrease in infiltration and the heating energy savings from this could be calculated.

As the secondary glazing is a permanent solution, with the exception of the thin plastic film products, there is a good chance the property it is installed in will change ownership during the lifetime of the product. Despite the relatively low costs of secondary glazing there is a chance that the product may generate more interest in a property and possibly increase the resale value. There would be a large number of variables affecting these factors making it difficult to determine the influence of secondary glazing alone, any research able to offer some insight into the effect it may have, would be useful. 


\section{Bibliography}

3M. (2006). 3M Interior Window Kits. Retrieved May 21, 2008, from 3M Canada:

http://www3.3m.com/catalog/ca/en001/home_leisure/-

/node_GS7P6B2C5Nbe/root_GST1T4S9TCgv/vroot_GSHCV1ZFXKge/gvel_XWM5R22X3

Vgl/theme_ca_en_homeleisure_3_0/command_AbcPageHandler/output_html

Aneco. (2008). Energy Saving. Retrieved September 6, 2008, from Aneco Sustainability Solutions: http://omins.co.nz/aneco/category/5/energy-saving/

Anink, D., Boonstra, C., \& Mak, J. (1996). Handbook of Sustainable Building. Earthscan.

Anonymous. (2008, February). Low-e Storm Windows. Energy Design Update, 28 (2), pp. 11-12.

ASTM. (2000). ASTM C 1199 - 00: Standard Test Method for Measuring the Steady State Thermal

Transmittance of Fenestration Systems Using Hot Box Methods. ASTM International.

ASTM. (1999). ASTM E 1423-99: Standard Practice for Determining the Steady State Thermal

Transmittance of Fenestration Systems. ASTM International.

Autodesk. (2009). AutoCAD. Retrieved October 11, 2009, from Autodesk: http://southapac.autodesk.com/adsk/servlet/index?id=12306190\&siteID $=1157326$

Baird, G. (1997). The Energy Embodied in Building Materials - Updated New Zealand Coefficients and their Significance. IPENZ Transactions, 24 (No. 1/CE).

Bassett, M. R. (1996). Conference Paper 27, A Practical Study of Retrofit Airtightening Old Houses for Energy Efficiency. BRANZ Ltd. 
BBC. (2009a). BBC Weather Centre, Chicago. Retrieved March 26, 2009, from BBC:

http://www.bbc.co.uk/weather/world/city_guides/results.shtml?tt=TT001200 26/03/09

BBC. (2009b). BBC Weather Centre, Dunedin. Retrieved March 26, 2009, from BBC:

http://www.bbc.co.uk/weather/world/city_guides/results.shtml?tt=TT003120 26/03/09

Bennett, J. M., \& Burgess, J. C. (2006). TE180 Multi-Paned Windows. Beacon Pathways.

BRANZ. (2002). Bulletin 427: Improving Thermal Insulation. BRANZ Ltd.

BRANZ. (2007). Aluminium. Retrieved May 26, 2008, from Level:

http://www.level.org.nz/fileadmin/downloads/Materials/LevelMAluminium.pdf

BRANZ. (2009a). Annual Loss Factor (ALF) Tool. Retrieved September 19, 2009, from BRANZ: http://www.branz.co.nz/alf

BRANZ. (1994). Appraisal Certificate No. 296: Magnetite Inside Insulating Window System. Judgeford: BRANZ Ltd.

BRANZ. (1998). Appraisal Certificate No. 370: Magicseal Magnetic Thermal Insulating Windows and Magicseal Magnetic Insect Screens. Judgeford: BRANZ Ltd.

BRANZ. (1993). Bulletin 312: Reducing Heat Loss Through Windows. BRANZ Ltd.

BRANZ. (1994). Bulletin 322: Glazing Plastics 1 - Characteristics and Durability. BRANZ Ltd.

BRANZ. (1998). Bulletin 367: Condensation. BRANZ Ltd.

BRANZ. (1999). Bulletin 387: Double Glazing. BRANZ Ltd.

BRANZ. (2001). Bulletin 421: Windows - Films and Coatings. BRANZ Ltd. 
BRANZ. (2005). Bulletin 463: Aluminium Windows and E2/ AS1. BRANZ Ltd.

BRANZ. (2006). Bulletin 471: Insulating Glazing Units. BRANZ Ltd.

BRANZ. (2006). Bulletin 474: WERS - Window Efficiency Rating System. BRANZ Ltd.

BRANZ. (2009). Bulletin 507: Timber Windows - Retrofit Glazing Options for Thermal Improvement. BRANZ Ltd.

BRANZ. (2007). Bulliten 481: Timber Windows. BRANZ Ltd.

BRANZ. (2002). EC0567: Surveys of Insulating window Systems in the New Zealand Residential Construction Sector. Judgeford: BRANZ Ltd.

BRANZ. (2008). Glass. Retrieved May 8, 2008, from Level: http://www.level.org.nz/fileadmin/downloads/Materials/LevelMGlass.pdf

BRANZ. (2009b, August). Standard Window 'R-value' Calculation Procedure (SCP). Retrieved 11 26, 2009, from BRANZ: http://www.branz.co.nz/cms_show_download.php?id=1152

BRE. (1993, February). Double Glazing for Heat and Sound Insulation. Building Research Establishment Digest, 379.

Building Act. (2008, March 15). Building Act 2004, Schedule 1 s41(1)(b) N.Z.

Building Amendment Act. (2009). Building Amendment Act 2009. Wellington: Department of Building and Housing.

Burch, D. M., \& Hunt, C. M. (1978). Retrofitting an Existing Wood-Frame Residence to Reduce its Heating and Cooling Energy Requirements. ASHRAE Transactions, 84, pp. 176-185. 
Burgess, J. C. (1998). Conference Paper 58,Surveys of Insulated Glazing Use in New Zealand Housing, as an Energy Efficiency Micro-Indicator 1994 -1998. BRANZ Ltd.

Burgess, J. C. (2007). Economic Analysis of Window Insulation Requirements - an Update, DC1076. Judgeford: BRANZ Ltd.

Burgess, J. C. (2008, April/May). Retrofitting Double Glazing, John Burgess. Build, 105, pp. 3637.

Burgess, J. C., \& Skates, H. (2001). A New Zealand Window Efficiency Rating System. BRANZ Conference Paper 94: International Conference on Building Envelope Systems and Technology, Ottawa, Canada, June 26-29.

Burton, S. (2001). Energy Efficient Office Refurbishment. London: James \& James.

Cameron, T. A. (1985, May). A Nested Logit Model of Energy Conservation Activity by Owners of Existing Single Family Dwellings. The Review of Economics and Statistics, 67 (2).

Camm, F. J. (1959, December). The Practical Householder. Newnes .

Carpenter, S. (1991, January 01). In-situ measurement of window performance. ASHRAE Journal, 33:1, pp. 14-18.

CAT. (2007). Glazing Over. Machynlleth: Centre for Alternative Technology.

CEA. (2008a). Order Online. Retrieved May 27, 2008, from Community Energy Action: http://www.cea.co.nz/order-online

CEA. (2008b). Retail Shop. Retrieved May 27, 2008, from Community Energy Action: http://www.cea.co.nz/retail-shop/\#Window\%20kit 
Chapman, R., Howden-Chapman, P., \& O'Dea, D. (2004). A Cost-benefit Evaluation of Housing Insulation: Results from the New Zealand "Housing Insulation \& Health" Study. Wellington: University of Otago.

Chapman, R., Howden-Chapman, P., O'Dea, D., Viggers, H., \& Kennedy, M. (2009).

Retrofitting houses with insulation: a cost-benefit analysis of a randomised community trial. Journal of Epidemiology and Community Health , 63, pp. 271-277.

Childerstone, C. (1982, Apri). Acoustic Insulation Through Secondary Double Glazing. Noise and Vibration Control Worldwide, 13 (3), pp. 115-116.

Chudley, R., \& Greeno, R. (2006). Building Construction Handbook: Incorporating Current Building and Construction Regulations. Butterworth-Heinemann.

Clark, S. J., Jones, M., \& Page, I. C. (2005). Study Report No. 142, New Zealand 2005 House Condition Survey. BRANZ Ltd.

Cooper, R., \& Buckland, J. (1985). A Practical Guide to Alterations and Improvements. UK: Routledge.

Cox-Smith, I. (1997, February). Proposed method for measuring the thermal properties of windows in the new BRANZ guarded hotbox. Proceedings of the IPENZ annual conference , 2 (95), pp. 94-99.

Dang, H. (2007). New Zealand Energy Data File. Wellington: Ministry of Economic Development.

DBH. (2007). Complience Document for the New Zealand Building Code Clause H1 Energy Efficiency Third Edition. Department of Building and Housing. October 31st: Department of Building and Housing.

Desjarlais, A. O., Childs, K. W., \& Christian, J. E. (1998). To Storm or Not to Storm: Measurement Method to Quantify Impact of Exterior Envelope Airtightness on Energy Usage 
Prior to Construction. ORNL Conference - Thermal Envelopes VII/Fenestration and Energy Costs Practices. Clearwater: ASHRAE.

Drumheller, S. C., Kohler, C., \& Minen, S. (2007). Field Evaluation of Low-e Storm Windows. Buildings X. ASHRAE.

EEA. (2008, January 11). Share of renewable electricity in gross electricity consumption (\%) 1990-2004 and 2010 indicative targets. Retrieved May 12, 2008, from European Environment Agency: http://dataservice.eea.europa.eu/atlas/viewdata/viewpub.asp?id=2631

EECA. (2007). Home Energy Rating Scheme. Retrieved December 17, 2008, from Energy Efficiency and Conservation Authority: http://www.eeca.govt.nz/residential/home-energy-ratingscheme/indexnew.html

EERE. (2008, August 13). A Consumer's Guide to Energy Efficiency and Renewable Energy. Retrieved November 16, 2008, from Energy Savers:

http://www.energysavers.gov/your_home/windows_doors_skylights/index.cfm/mytopic=1349 0 ?print

Elmahdy, A. H. (1992). Heat Transmission and R-value of Fenestration Systems Using IRC Hot Box: Procedure and Uncertainty Analysis. ASHRAE Transactions (98), pp. 630-637.

Elmahdy, A. H., \& Haddad, K. (2000). Experimental procedure and uncertainty analysis of a guarded hotbox method to Determine the Thermal Transmission Coefficient of Skylights and Sloped Glazing. ASHRAE Transactions (106), pp. 601-613.

Energy Savings Trust. (2006b). CE184 Practical Refurbishment of Solid-Walled Houses. London: Energy Savings Trust.

Energy Savings Trust. (2006a). CE66 Windows for New and Existing Housing. London: Energy Savings Trust. 
Environment Canterbury. (2008). Doors \& Windows. Retrieved June 12, 2008, from Environment Canterbury:

http://www.ecan.govt.nz/Our+Environment/Energy/YourHome/homeimprovement/doorswindows.htm

Finlayson, E., Mitchell, R., \& Arasteh, D. (1998). Therm 2.0: Program Description. Lawrence Berkeley National Laboratory.

Fisher. (2008, July 31). Personal Quote, Fisher Windows and Doors. (N. Smith, Interviewer) Flynn, C. F. (1940). Patent No. 2205353.

Fossdal, S. (1996). Windows in Existing Norwegian Buildings in a Sustainable Perspective. Life cycle assessment of new windows supplied with inner frames. BRE Sustainable Use of Materials conference. Gartson.

Fracastoro, G. V., \& Lyberg, M. D. (1983). Guiding Principles Concerning Design of Experiments, Instrumentation, and Measuring Techniques, Annex III. Stockholm: International Energy Agency.

French, L. J., Camilleri, M. J., Isaacs, N. P., \& Pollard, A. R. (2007). Temperatures and Heating Energy in New Zealand Houses from a Nationally Representative Study-HEEP. Energy and Buildings, 39.

Godfrey, J. A. (1972). Double Glazing and Double Windows. Building Research Station Digest (140).

Gorgolewski, M. (1995). Optimising Renovation Strategies for Energy Conservation in Housing. Building and Enuironment, 30 (4), pp. 583-589.

Howard, N. P., Burgess, J., \& Lim, C. (2007). Comparative Service Life Assessment of Window Systems. Judgeford: BRANZ Ltd. 
Howden-Chapman, P., Crane, J., Matheson, A., Viggers, H., Cunningham, M., Blakely, T., et al. (2005). Retrofitting houses with insulation to reduce health inequalities: Aims and methods of a clustered, randomised community-based trial. Social Science \& Medicine (61), pp. 2600-2610.

Isaacs, N. P., Camilleri, M., French, L., Pollard, A., Saville-Smith, K., Fraser, R., et al. (2006). Energy Use in New Zealand Households: Report on the Year 10 Analysis for the Household Energy End-use Project (HEEP). Branz Study Report 155. Judgeford: BRANZ Ltd.

Isaacs, N. (2007, October/November). Thermal Insulation. Build, pp. 110-111.

Isaacs, N., Amitrano, L., Camilleri, M., French, L., Pollard, A., \& Stoecklein, A. (2003). Energy Use in New Zealand Households: Report on the Year 7 Analysis for the Household Energy End-use Project (HEEP). Bran₹ Study Report 122. Judgeford: BRANZ Ltd.

Isaacs, N., Amitrano, L., Camilleri, M., French, L., Pollard, A., Saville-Smith, K., et al. (2004). Energy Use in New Zealand Households: Report on the Year 8 Analysis for the Household Energy End-use Project (HEEP). Judgeford: BRANZ Ltd.

Isaacs, N., Amitrano, L., Camilleri, M., French, L., Pollard, A., Saville-Smith, K., et al. (2005). Energy Use in New Zealand Households: Report on the Year 9 Analysis for the Household Energy End-use Project (HEEP). Judgeford: BRANZ Ltd.

Isaacs, N., Amitrano, L., Camilleri, M., Pollard, A., \& Stoecklein, A. (2002). Energy Use in New Zealand Households, Report on the Year 6 Analysis for the Household Energy End-use Project (HEEP), Study Report 115. BRANZ Ltd: Judgeford.

ISO. (2000). BS EN ISO 12567-1: Thermal performance of windows and doors - Determination of thermal transmittance by hot box method - Complete windows and doors. The International Organization for Standardization. 
ISO. (2003). ISO 15099:2003, Thermal performance of windows, doors and shading devices - Detailed calculations. International Organization for Standardization.

Klems, J. H. (2003). Measured Winter Performance of Storm Windows. ASHRAE Transactions Career and Technical Education, 109, pp. 847-854.

Krigger, J., \& Dorsi, C. (2004). Residential Energy: Cost Savings and Comfort for Existing Buildings. Saturn Resource Management, Inc.

LBNL. (2009, August 21). International Glazing Database. Retrieved September 17, 2009, from http://windows.lbl.gov/materials/igdb/

LBNL. (2008). Software Tools. Retrieved August 12, 2008, from Windows \& Daylighting: http://windows.lbl.gov/software/default.htm

LBNL. (2009b, August). Therm 6 Research Version. Retrieved September 19, 2009, from LBNL Window \& Daylighting Software: http://windows.lbl.gov/software/therm/6/

LBNL. (2009a, August). Window 6 Research Version. Retrieved September 19, 2009, from LBNL Window \& Daylighting Software: http://windows.lbl.gov/software/window/6/

Lilly, J. G. (2004, February). Recent Advances in Acoustical Glazing. Sound and Vibration .

Lloyd, B., \& Callau, M. (2006). Monitoring of Energy Efficiency Upgrades in State Houses in Southern New Zealand. Dunedin: University of Otago.

Lloyd, B., Bishop, T., \& Callau, M. (2007). Retrofit Alternatives for State Houses in Cold Regions of New Zealand. Dunedin: University of Otago.

Llyon, C. G. (1957). Patent No. 2780846. United States of America. 
Longstreth, M., Coveney, A. R., \& Bowers, J. S. (1984, June). Conservation Characteristics Among Determinants of Residential Property Value. Journal of Consumer Research , 1, p. 564.

Maclean, J. H., \& Scott, J. S. (1993). The Penguin Dictionary of Building (4th ed.). Penguin.

MagicSeal. (n.d.). Calculation of Thermal Resistance For MagicSeal Secondary Glazing. MagicSeal.

MagicSeal. (2007). MagicSeal Secondary Double Glaring for Thermal and Acoustic Insulation of Existing Windows. MagicSeal.

Magnetite. (2006). Energy Efficiency. Retrieved April 24, 2008, from Magnetite: http://www.magnetite.com.au/page.asp?pID=235

Mattinson, B., DePaola, R., \& Arasteh, D. (2002, July/August). What Should I Do About My Windows? Home Energy, pp. 24-31.

McBride, S. (2002). Windows and Doors: Expert Advice from Start to Finish. Taunton Press.

MED. (2009a, March). Domestic Electricity Prices Available Up To 15 February 2009. Retrieved April 12, 2009, from Ministry of Economic Development: http://www.med.govt.nz/upload/68395/QSDEP.pdf

MED. (2009b). Quarterly Survey of Domestic Electricity Prices: Updated to 15 Febuary 2009. Retrieved March 24, 2009, from Ministry of Economic Development: http://www.med.govt.nz/templates/MultipageDocumentTOC 39087.aspx

Metroglass. (2008). Metroglass, Catalogue and Reference Guide 6th Ed. Retrieved July 8, 2008, from Metro Glasstech: http://www.metroglasstech.co.nz/120.aspx

Miller, M. R., \& Baker, G. E. (2004). Carpentry \& Construction. McGraw-Hill Professional. 
Mitchel, R., Kohler, C., \& Arasteh, D. (2006). Therm 5.2/Window 5.2 NFRC Simulation Manual. Lawrence Berkeley National Laboratories.

Mitchell, R., Kohler, C., Arasteh, D., Carmody, J., Huizenga, C., \& Curcija, D. (2001). WINDOW 5: Program Description, A PC Program for Analyzing the Thermal Performance of Fenestration Products. Lawrence Berkeley National Laboratory.

Moore, F. (1992). Test Modules. In J. D. Balcomb, Passive Solar Buildings. MIT Press.

NFRC. (2009). Frequently Asked Questions. Retrieved May 27, 2009, from National Fenestration

Rating Council: http://www.nfrc.org/faqs.aspx?path=sitebuilt

NFRC. (2004). NFRC 100-2004: Procedure for Determining Fenestration Product U-Factors. Greenbelt: National Fenestration Rating Council.

NFRC. (2005). Software. Retrieved August 28, 2008, from National Fenestration Rating Council: NFRC, http://www.nfrc.org/software.aspx

NGS. (2007). Durability - Windows. Retrieved October 28, 2009, from Greenspec - National Green Specification: http://www.greenspec.co.uk/html/durability/windows.html

Nippon. (2008). Nippon Sheet Glass Spacia. Retrieved October 28, 2009, from http://www.nsgspacia.co.jp

Norfolk County Council. (2007). Making Old Buildings Energy Efficient. Norwich: Norfolk County Counci.

NRC. (1988). Window Performance and New Technology, Proceedings of Building Science Insight '88.

Ottawa: National Research Council of Canada, Institute for Research in Construction. 
NREL. (2009, January 2). NREL: Buildings Research - SUNREL Energy Simulation Software.

Retrieved September 19, 2009, from National Renewable Energy Laboratory:

http://www.nrel.gov/buildings/sunrel/

NRL. (2008). Window Warmers and $V$-seal. Retrieved September 6, 2008, from Negawatt

Resources Ltd: http://www.nrl.co.nz/main.php?page=1304

NZS 4214. (2006). NZS 4214:2006 Methods of Determining the Total Thermal Resistance of Parts of Buildings. Standards New Zealand.

NZS 4218. (2009). NZS 4218:2009, Thermal Insulation - Housing and Small Buildings. Standards New Zealand.

Page, I. (2009). Cost benefits of sustainable bousing retrofits. Report TE106/19: Beacon Pathway Ltd.

Page, I. (2006). QC 5048: NZBC Clause H1 Review House Insulation Cost Benefit Analysis. BRANZ Ltd.

Pollard, A. (2005). EC0939: Modelling Heat Loss in Retrofitted Houses. BRANZ Ltd.

Quach, S., Culp, T. D., \& de Vries, R. (2003). Surface treatment \& modification: The forgotten market. International Glass Review (2), pp. 91-92.

Quirouette, R. L. (1980). Building Practice Note: Insulated Window Shutters. Ottawa: National Research Council of Canada.

Rayment, R., \& Morgan, K. (1985). Energy Savings From Secondary Windows. Building Services Engineering Research \& Technology, 6 (3), pp. 95-102.

RBNZ. (2009). New Zealand Inflation Calculator. Retrieved October 21, 2009, from Reserve Bank of New Zealand: http://www.rbnz.govt.nz/statistics/0135595.html 
Richardson, B. A. (2001). Defects and Deterioration in Buildings 2nd Edition. Cornwall: Spon Press.

Richardson, B. A. (1980). Remedial Treatment of Buildings. Landcaster: The Construction Press.

Schultz, J. M., Jensen, K. I., \& Kristiansen, F. H. (2005, November). Super Insulating Aerogel Glazing. Solar Energy Materials and Solar Cells , 89 (2-3), pp. 275-285.

Selectaglaze. (2008b). Security. Retrieved March 3, 2008, from Selectaglaze: http:/ /www.selectaglaze.co.uk/security.php

Selectaglaze. (2008a). Thermal Testing and Results. Retrieved April 9, 2008, from Selectaglaze: http://sg2.net-commerce-solutions.co.uk/energy/thermal_testing_and_results.php

Skates, H. (2006). The Design and Development of an Integrated Solar Collector and Thermal Energy Storage Window System for Lightweight Construction. Victoria University of Wellington.

Smarter homes. (2008, March 10). Double Glazing and Glass Options. Retrieved April 17, 2006, from Smarter Homes: http://www.smarterhomes.org.nz/design/glazing/double-glazing-glassoptions/

Smith, J. (2008). Implementation of a Building Sustainability Rating Tool: A Survey of the New Zealand Building Industry. Victoria University of Wellington.

Statistics New Zealand. (2006, September). Hot Off the Press - New Zealand Energy Statistics. Retrieved May 12, 2008, from Statistics New Zealand: http://www.stats.govt.nz/ /media/statistics/browse $\% 20$ for $\% 20$ stats/nzenergystatistics/previo us-releases/nz-energy-statistics-jun06qtr-hotp.aspx

Stoecklein, A. (2005). Cost Benefit Analysis for Solar Hot Water Heating Systems. EC1112. Judgeford: BRANZ Ltd. 
Stoecklein, A., \& Basset, M. (2000). ALF 3: The Annual Loss Factor Method, 3rd Edition - Heater Efficiency. BRANZ Ltd.

Stoecklein, A., Zhao, Y., Christie, L., \& Skumatz, L. (2005). The value of Low Energy Technologies for Occupant and Landlord. Branz Conference Paper No. 112. Judgeford: BRANZ Ltd.

Sustainable Design. (2008). Window Insulators. Retrieved July 15, 2008, from Sustainable Design: http://www.sustainabledesign.co.nz/store/index.php?main_page=index\&cPath=69

The Window Man. (2008). Secondary Glazing. Retrieved March 18, 2008, from http://www.thewindowman.co.uk/secondary.htm

Thermosash. (n.d.). Thermosash Secondary Double Glazing for Heat \& Sound Control. Thermosash.

Thompson, S. J. (1983). Site Practice Series: Glaring. Essex: Construction Press.

Turner, D. P. (1971). Windows and Environment. Pilkington Brothers Ltd.

Turrell, C. (2000, July/August). Storm Windows Save Energy. Retrieved February 5, 2009, from Home Energy Online: http://homeenergy.org/archive/hem.dis.anl.gov/eehem/00/000711.html

U.S. Department of Energy. (2009, September 11). EnergyPlus Energy Simulation Software. Retrieved September 19, 2009, from U.S. Department of Energy:

http://apps1.eere.energy.gov/buildings/energyplus/

VUW. (1999). Embodied Energy Coefficients. Retrieved May 8, 2008, from Victoria University of Wellington: http://www.victoria.ac.nz/cbpr/documents/pdfs/ee-coefficients.pdf

Wedd, K. (2002). The Victorian Society book of The Victorian house. London: Aurum. 
WERS. (2008c, May 16). 2008 WERS Certified Products Directory - NFRC. Retrieved 24 June, 2008, from Window Energy Rating Scheme:

http://www.wers.net/documents/Magnetite_Aus_NON_NFRC.pdf

WERS. (2008b). Custom Ratings. Retrieved April 24, 2008, from Window Energy Rating Scheme: http://www.wers.net/how-wers-works/custom-ratings

WERS. (2009). Extract from NFRC 100-2004 Table 4-3. Retrieved March 7, 2009, from Window Energy Rating Scheme: http://www.wers.net/documents/rating_sizes.pdf

WERS. (2008a). Window Energy Rating Scheme. Retrieved June 5th, 2008, from http://www.wers.net/faqs\#shgc

WHO. (2007). Housing, Energy and Thermal Comfort, A review of ten countries within the WHO European Region. World Health Organisation Europe.

WINDOW 5: Program Description, A PC Program for Analyzing the Thermal Performance of.

Wise, D. J. (2002). An Assesment of InterLaboratory Repeatability in FenestrationEnergy Ratings: 2001 NFRC InterLaboratory Test Round Robin. In D. L. McElroy, J. F. Kimpflen, R. S. Graves, \& D. C. Wysocki, Insulation materials, testing, and applications, Volume 4. ASTM International.

Woolley, T., \& Kimmins, S. (2000). Green Building Handbook: A Guide to Building Products and Their Impact on the Environment (Vol. 2). Taylor \& Francis.

Wouters, P., Vandaele, L., Voit, P., \& Fisch, N. (1993). Use of Outdoor Test Cells for Thermal and Solar Building Research within the PASSYS Project. Building and Environment, 28 (2), pp. $107-113$. 
A Cost Benefit Analysis of Secondary Glazing as a Retrofit Alternative for New Zealand Homes 


\section{Additional References}

Anink, D., Boonstra, C., \& Mak, J. (1996). Handbook of Sustainable Building. Earthscan.

BRANZ. (1994). Appraisal Certificate No. 296: Magnetite Inside Insulating Window System. Judgeford: BRANZ Ltd.

BRANZ. (1998). Appraisal Certificate No. 370: Magicseal Magnetic Thermal Insulating Windows and Magicseal Magnetic Insect Screens. Judgeford: BRANZ Ltd.

BRANZ. (2005). Bulletin 463: Aluminium Windows and E2/ AS1. BRANZ Ltd.

BRANZ. (2006). Bulletin 474: WERS - Window Efficiency Rating System. BRANZ Ltd.

BRANZ. (2009). Bulletin 507: Timber Windows - Retrofit Glazing Options for Thermal Improvement. BRANZ Ltd.

Building Amendment Act. (2009). Building Amendment Act 2009. Wellington: Department of Building and Housing.

Burton, S. (2001). Energy Efficient Office Refurbishment. London: James \& James.

Cameron, T. A. (1985, May). A Nested Logit Model of Energy Conservation Activity by Owners of Existing Single Family Dwellings. The Review of Economics and Statistics, 67 (2). 
Chapman, R., Howden-Chapman, P., O'Dea, D., Viggers, H., \& Kennedy, M. (2009).

Retrofitting houses with insulation: a cost-benefit analysis of a randomised community trial. Journal of Epidemiology and Community Health , 63, pp. 271-277.

Chudley, R., \& Greeno, R. (2006). Building Construction Handbook: Incorporating Current Building and Construction Regulations. Butterworth-Heinemann.

Dang, H. (2007). New Zealand Energy Data File. Wellington: Ministry of Economic Development.

EERE. (2008, August 13). A Consumer's Guide to Energy Efficiency and Renewable Energy. Retrieved November 16, 2008, from Energy Savers:

http://www.energysavers.gov/your_home/windows_doors_skylights/index.cfm/mytopic=1349 0?print

Elmahdy, A. H. (1992). Heat Transmission and R-value of Fenestration Systems Using IRC Hot Box: Procedure and Uncertainty Analysis. ASHRAE Transactions (98), pp. 630-637.

Elmahdy, A. H., \& Haddad, K. (2000). Experimental procedure and uncertainty analysis of a guarded hotbox method to Determine the Thermal Transmission Coefficient of Skylights and Sloped Glazing. ASHRAE Transactions (106), pp. 601-613.

Gorgolewski, M. (1995). Optimising Renovation Strategies for Energy Conservation in Housing. Building and Enuironment, 30 (4), pp. 583-589.

Howard, N. P., Burgess, J., \& Lim, C. (2007). Comparative Service Life Assessment of Window Systems. Judgeford: BRANZ Ltd. 
Howden-Chapman, P., Crane, J., Matheson, A., Viggers, H., Cunningham, M., Blakely, T., et al. (2005). Retrofitting houses with insulation to reduce health inequalities: Aims and methods of a clustered, randomised community-based trial. Social Science \& Medicine (61), pp. 2600-2610.

Isaacs, N. (2007, October/November). Thermal Insulation. Build, pp. 110-111.

Isaacs, N., Amitrano, L., Camilleri, M., French, L., Pollard, A., Saville-Smith, K., et al. (2004). Energy Use in New Zealand Households: Report on the Year 8 Analysis for the Household Energy End-use Project (HEEP). Judgeford: BRANZ Ltd.

Isaacs, N., Amitrano, L., Camilleri, M., French, L., Pollard, A., Saville-Smith, K., et al. (2005). Energy Use in New Zealand Households: Report on the Year 9 Analysis for the Household Energy End-use Project (HEEP). Judgeford: BRANZ Ltd.

Krigger, J., \& Dorsi, C. (2004). Residential Energy: Cost Savings and Comfort for Existing Buildings. Saturn Resource Management, Inc.

Longstreth, M., Coveney, A. R., \& Bowers, J. S. (1984, June). Conservation Characteristics Among Determinants of Residential Property Value. Journal of Consumer Research , 1, p. 564.

McBride, S. (2002). Windows and Doors: Expert Advice from Start to Finish. Taunton Press.

Miller, M. R., \& Baker, G. E. (2004). Carpentry \& Construction. McGraw-Hill Professional.

NZS 4214. (2006). NZS 4214:2006 Methods of Determining the Total Thermal Resistance of Parts of Buildings. Standards New Zealand. 
Quach, S., Culp, T. D., \& de Vries, R. (2003). Surface treatment \& modification: The forgotten market. International Glass Review (2), pp. 91-92.

Richardson, B. A. (1980). Remedial Treatment of Buildings. Landcaster: The Construction Press.

Smarter homes. (2008, March 10). Double Glazing and Glass Options. Retrieved April 17, 2006, from Smarter Homes: http://www.smarterhomes.org.nz/design/glazing/double-glazing-glassoptions/

Smith, J. (2008). Implementation of a Building Sustainability Rating Tool: A Survey of the New Zealand Building Industry. Victoria University of Wellington.

Thompson, S. J. (1983). Site Practice Series: Glaring. Essex: Construction Press.

Wedd, K. (2002). The Victorian Society book of The Victorian house. London: Aurum. 


\section{Appendices}

\section{Appendix A Guarded Hotbox Testing}

\section{A.1 Photos}

This section is a photo documentation of the GHB test process using images that are not displayed in the body of this thesis.

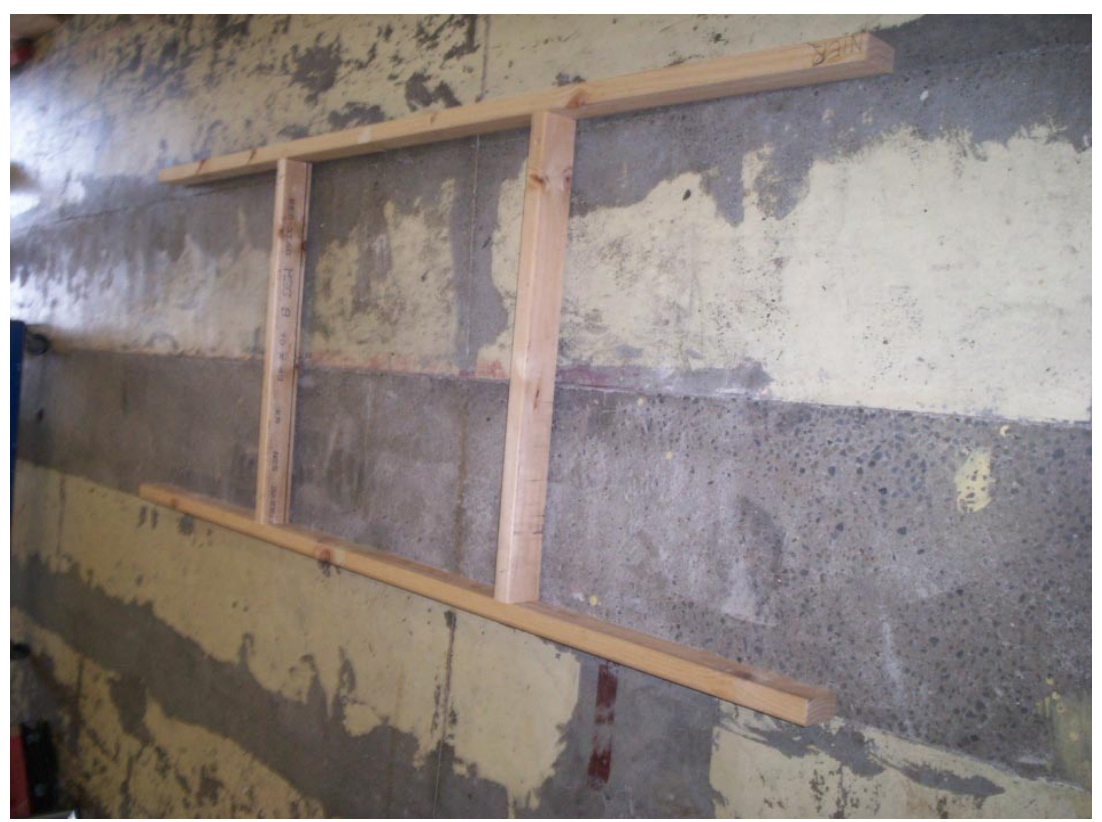

Figure A-1: Timber framing for the window 


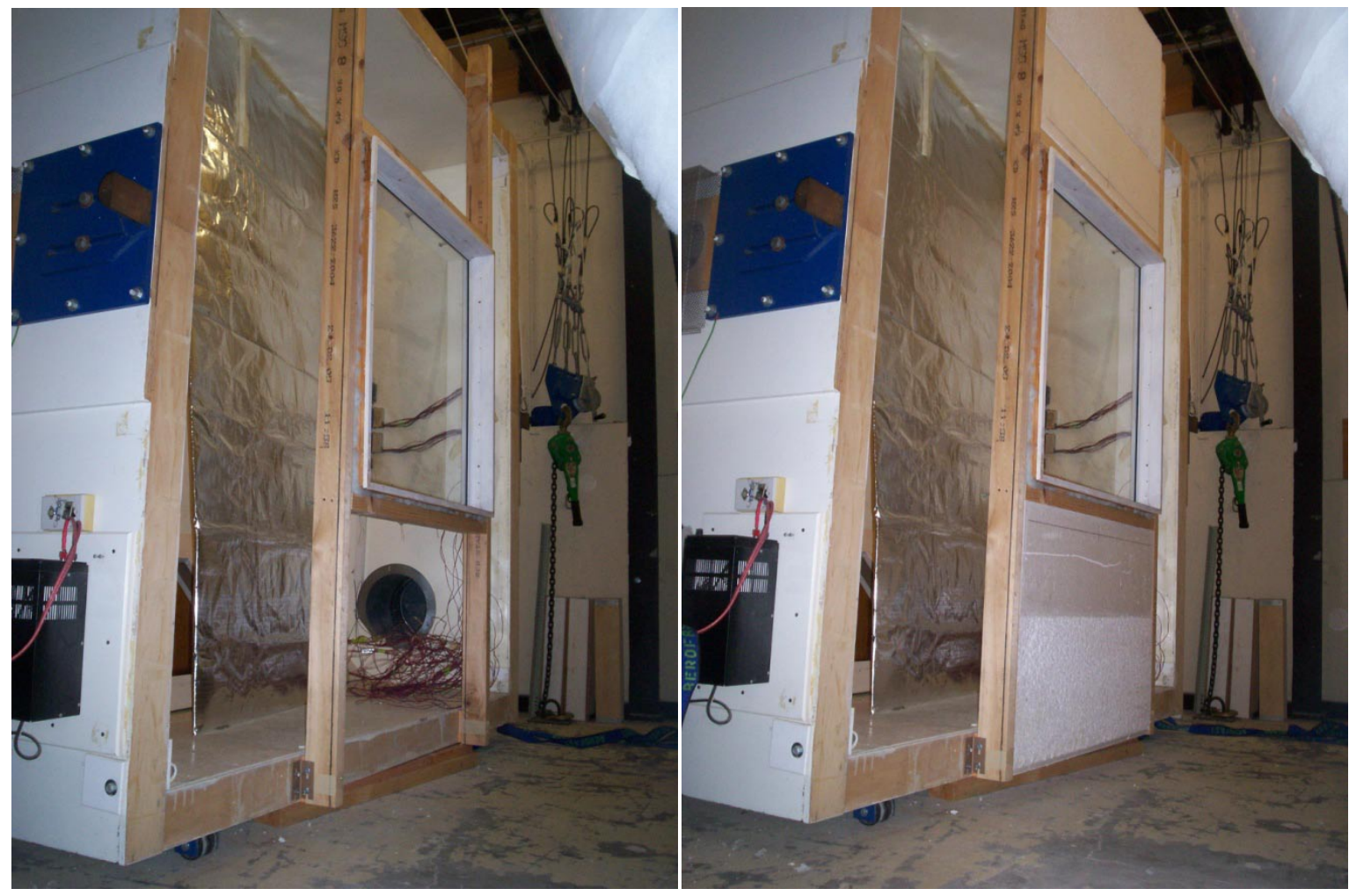

Figure A-2 \& Figure A-3 Assembly of the GHB surround

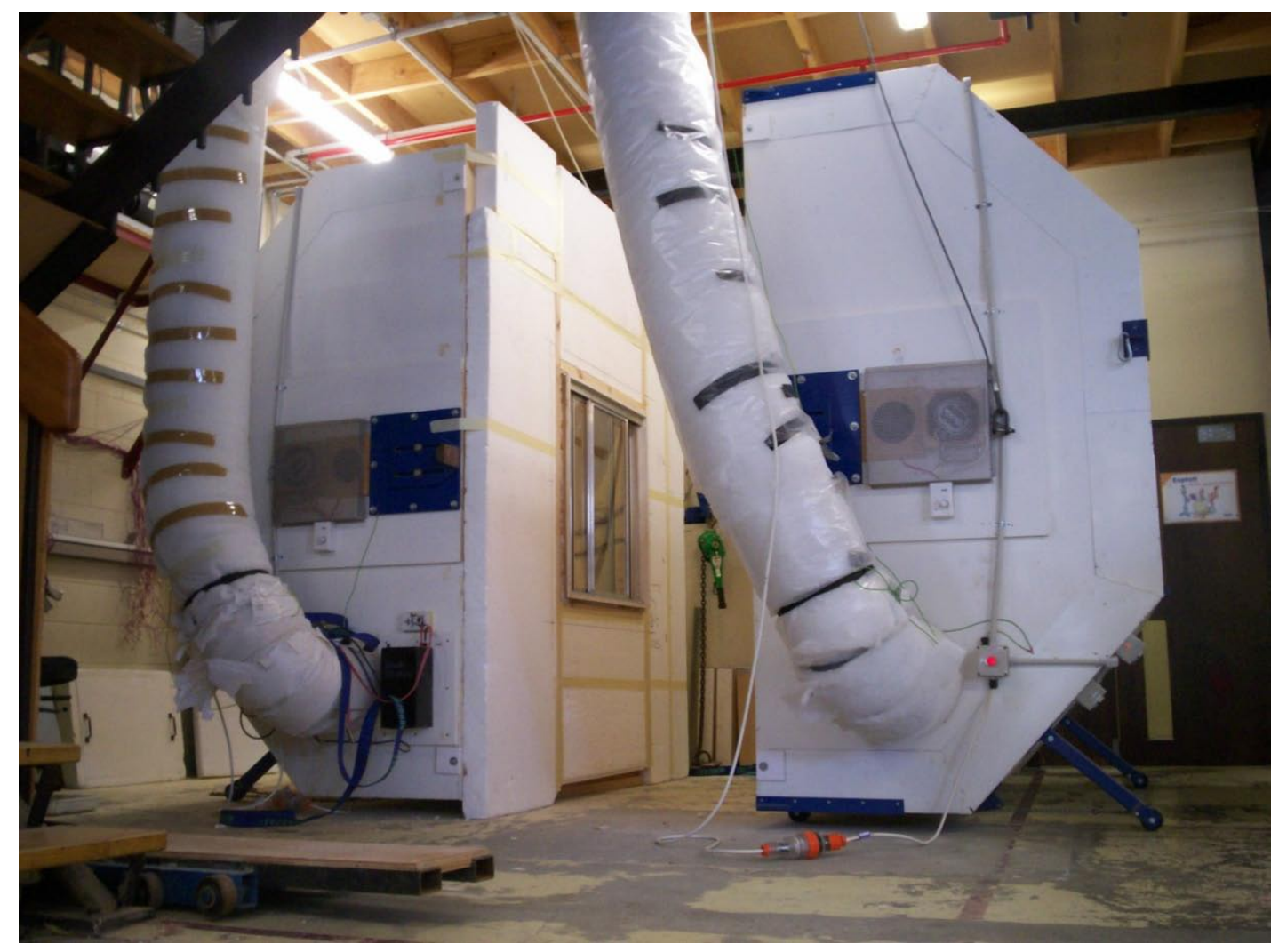

Figure A-4: GHB open with surround constructed 


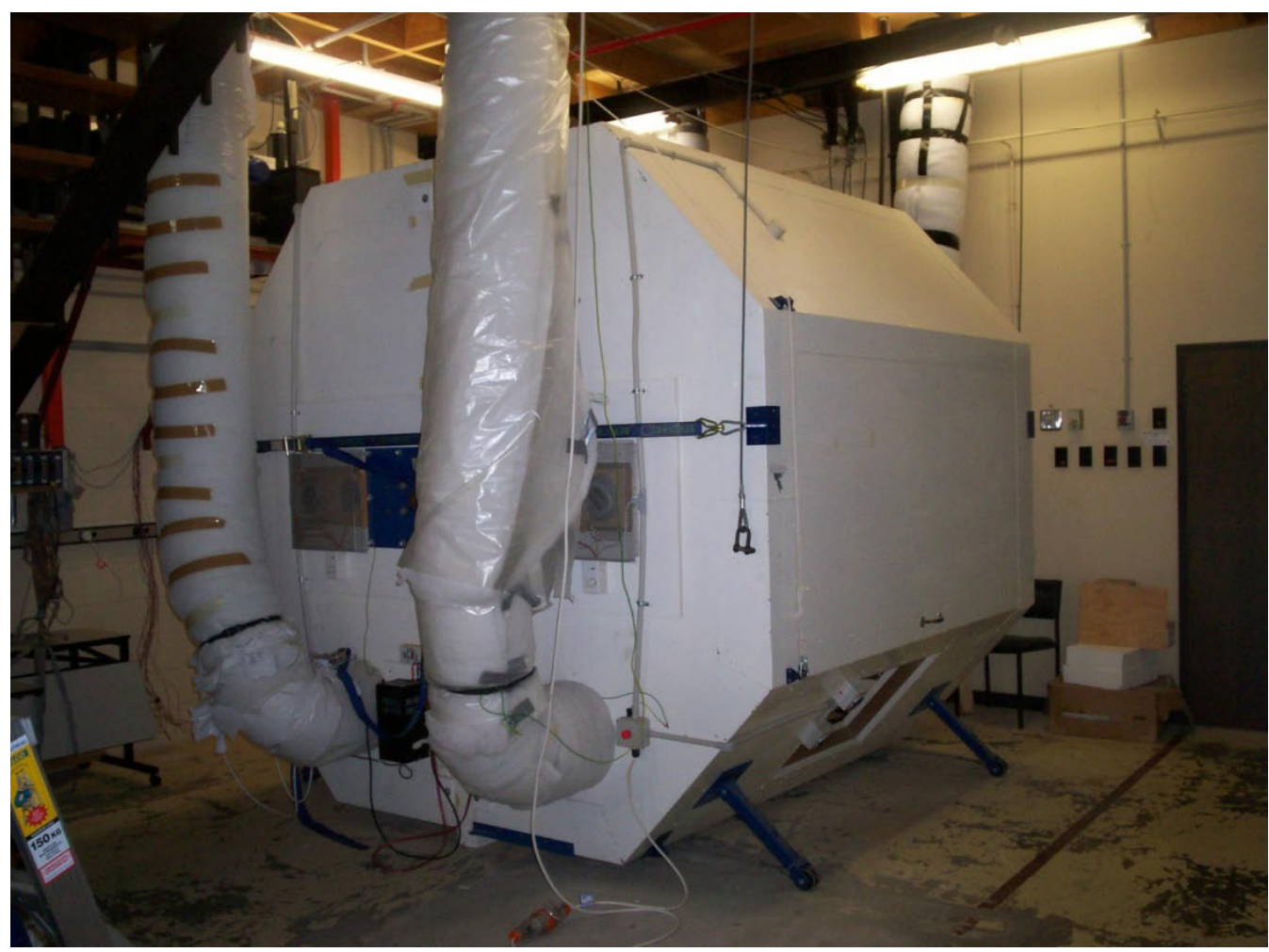

Figure A-5: GHB closed with surround in between

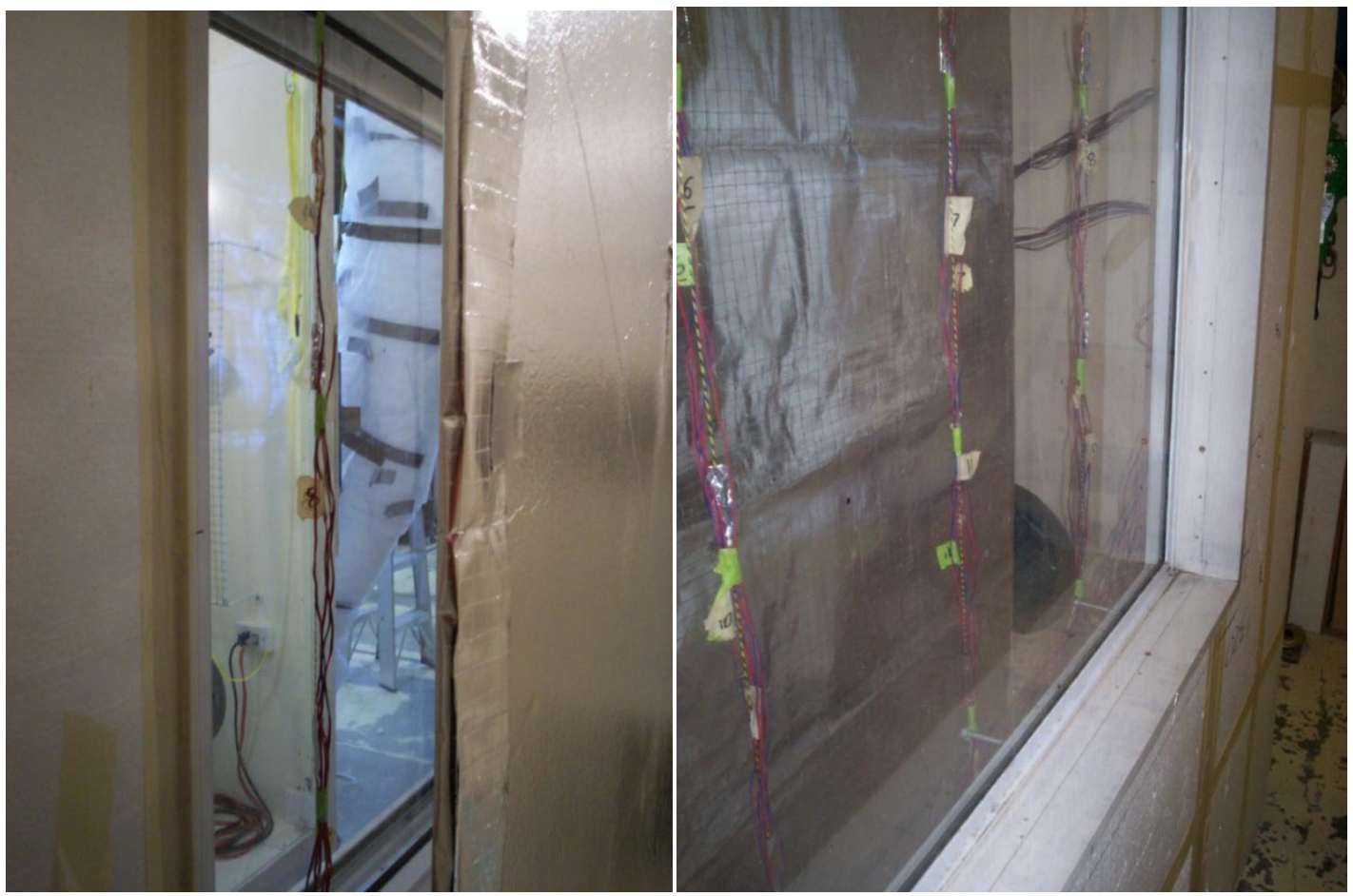

Figure A-6 \& Figure A-7: Thermocouples positioned between the radiant shield and the window installed in the surround 


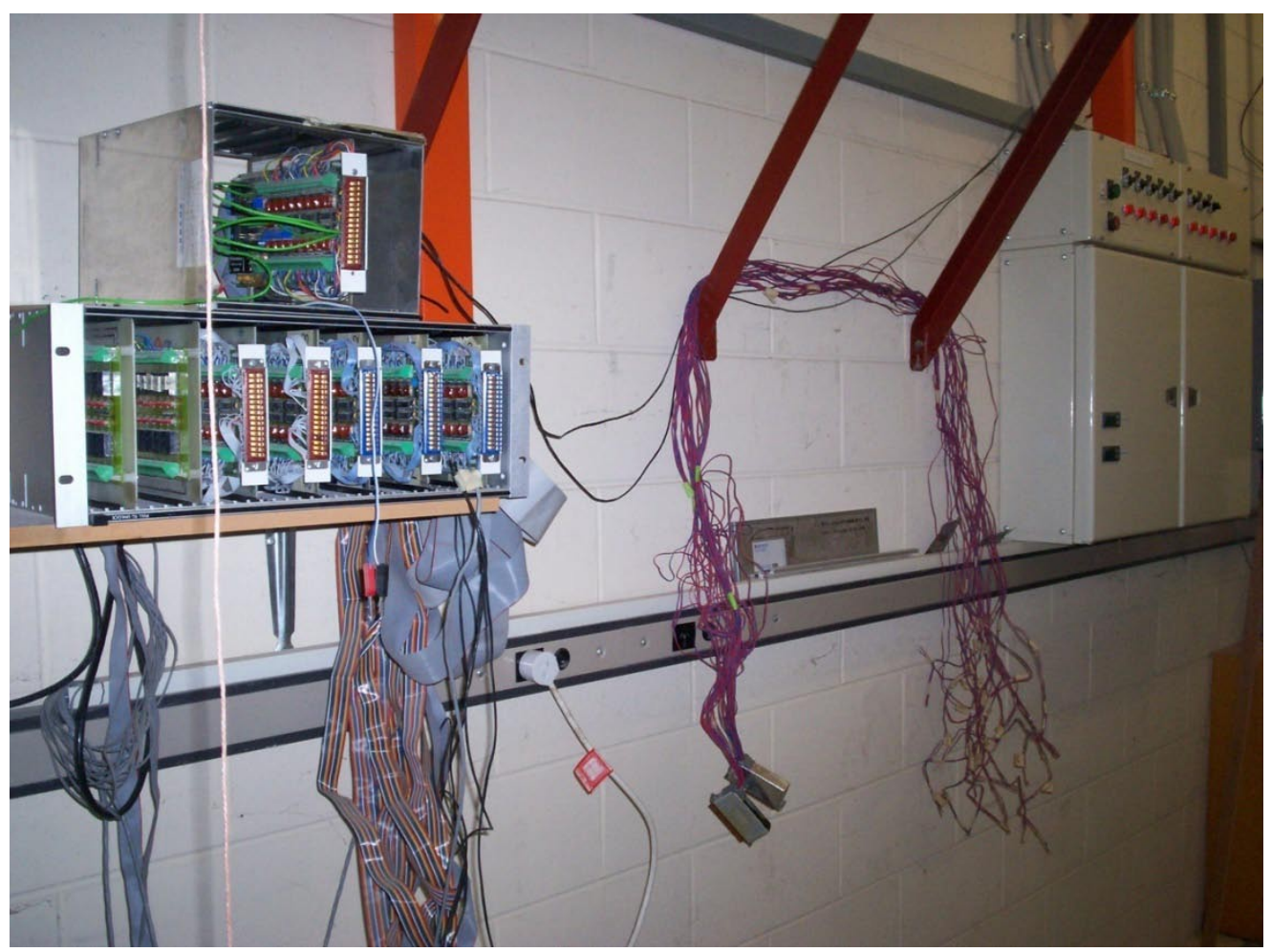

Figure A-8: Data logging and operating equipment

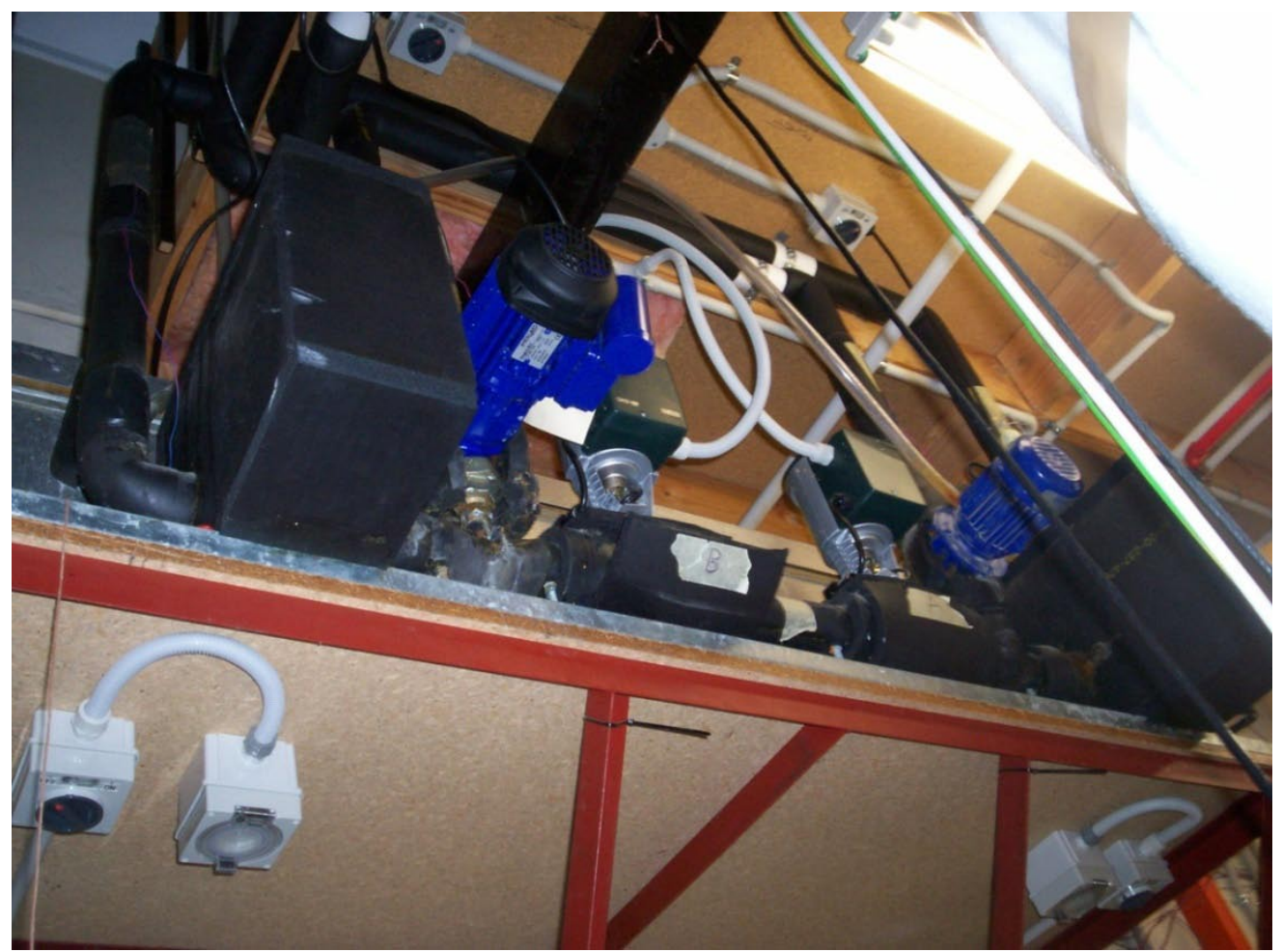

Figure A-9: The heat pumps which service each chamber 


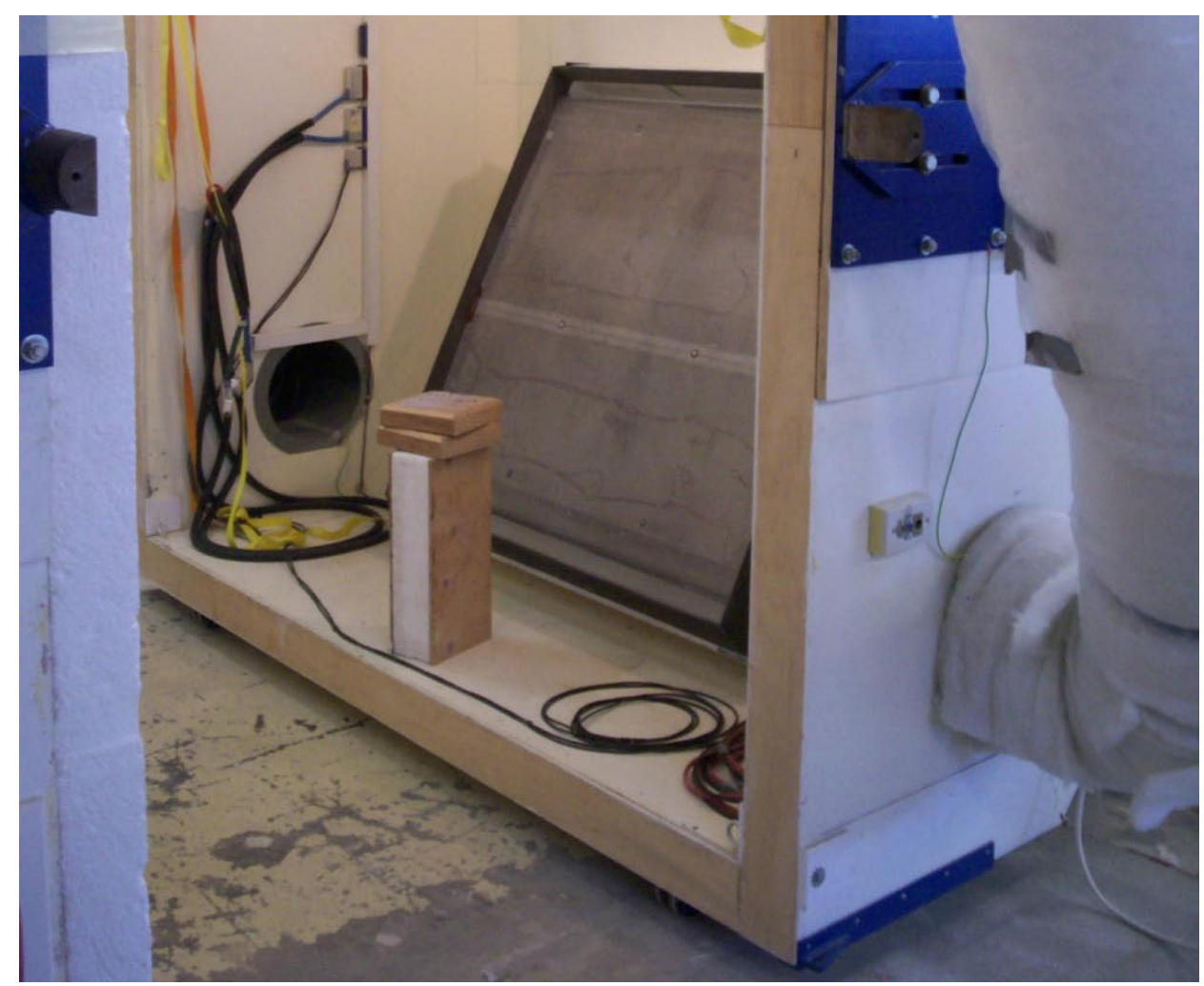

Figure A-10: Inside of the chamber showing the heat metering box

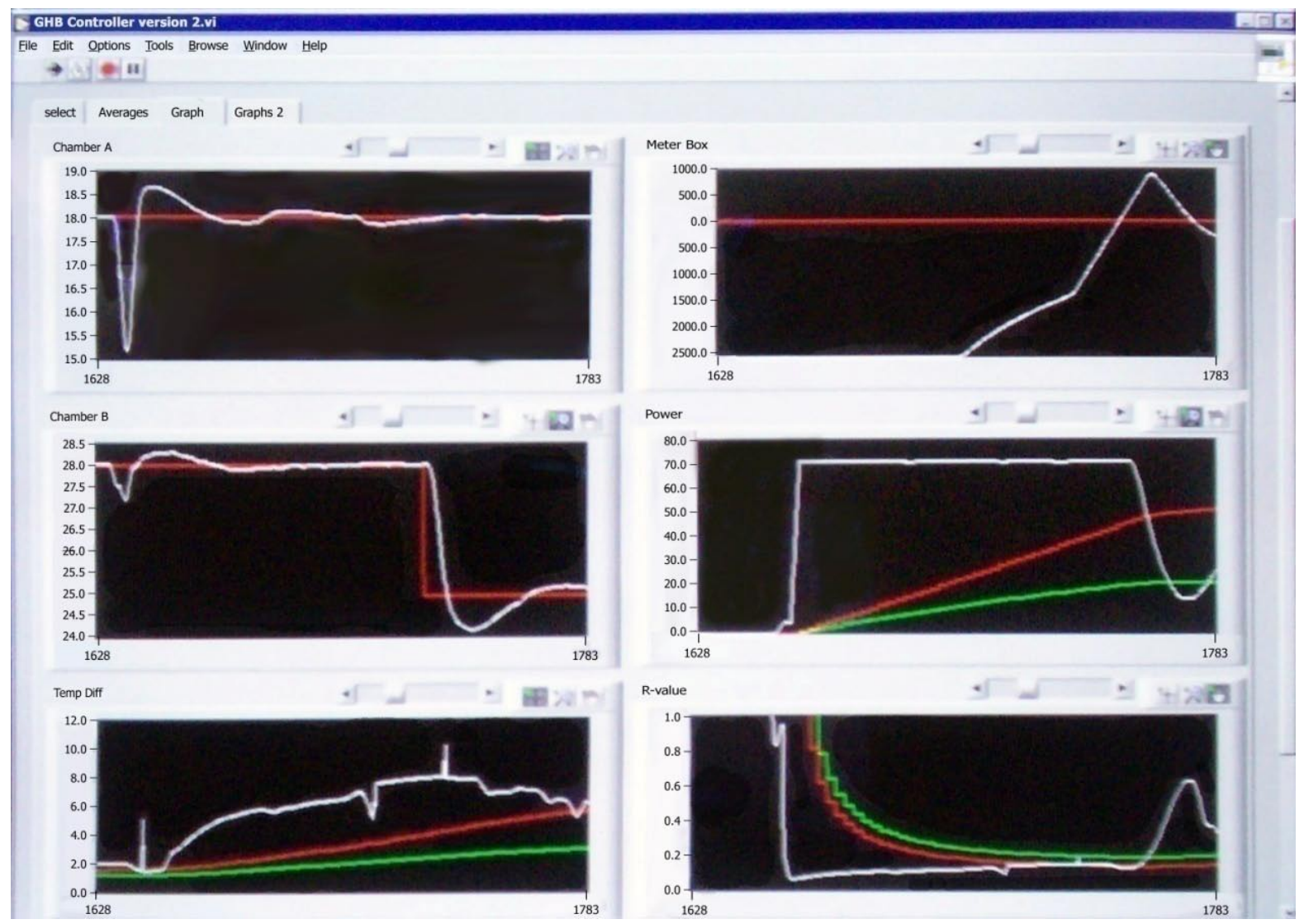

Figure A-11 Real-time GHB Measurements 


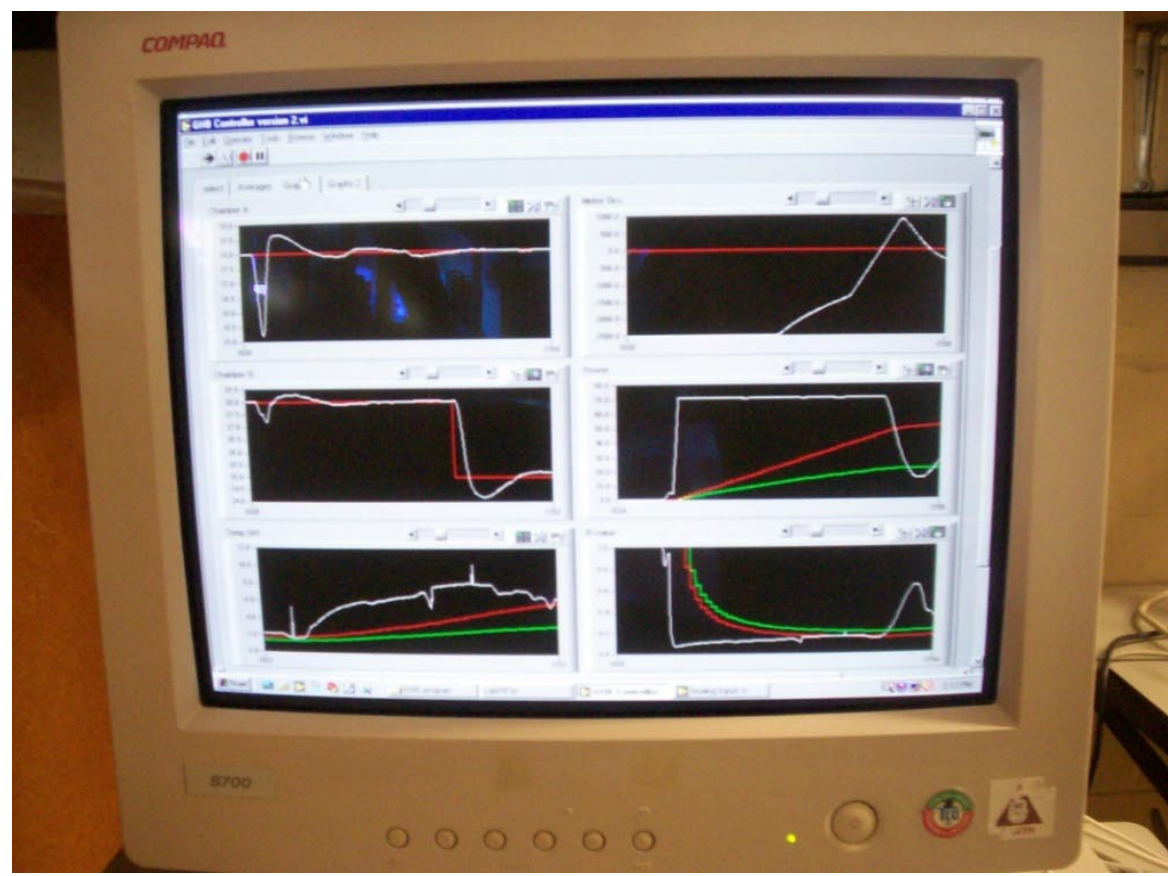

Figure A-12: Real time data logging

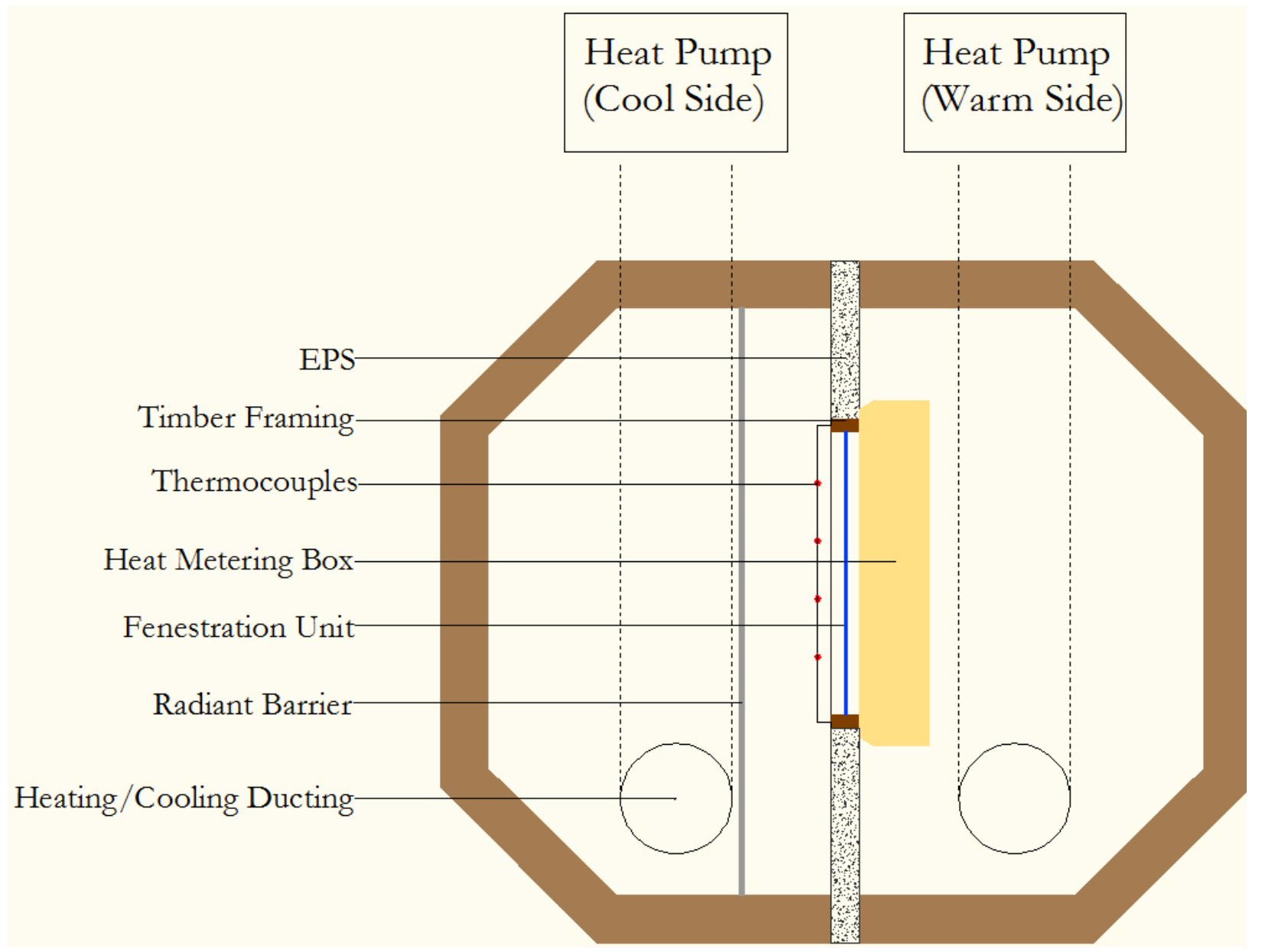

Figure A-13: Larger GHB cross-section 


\section{A.2 Window Images}

\section{A.2.1 Window}
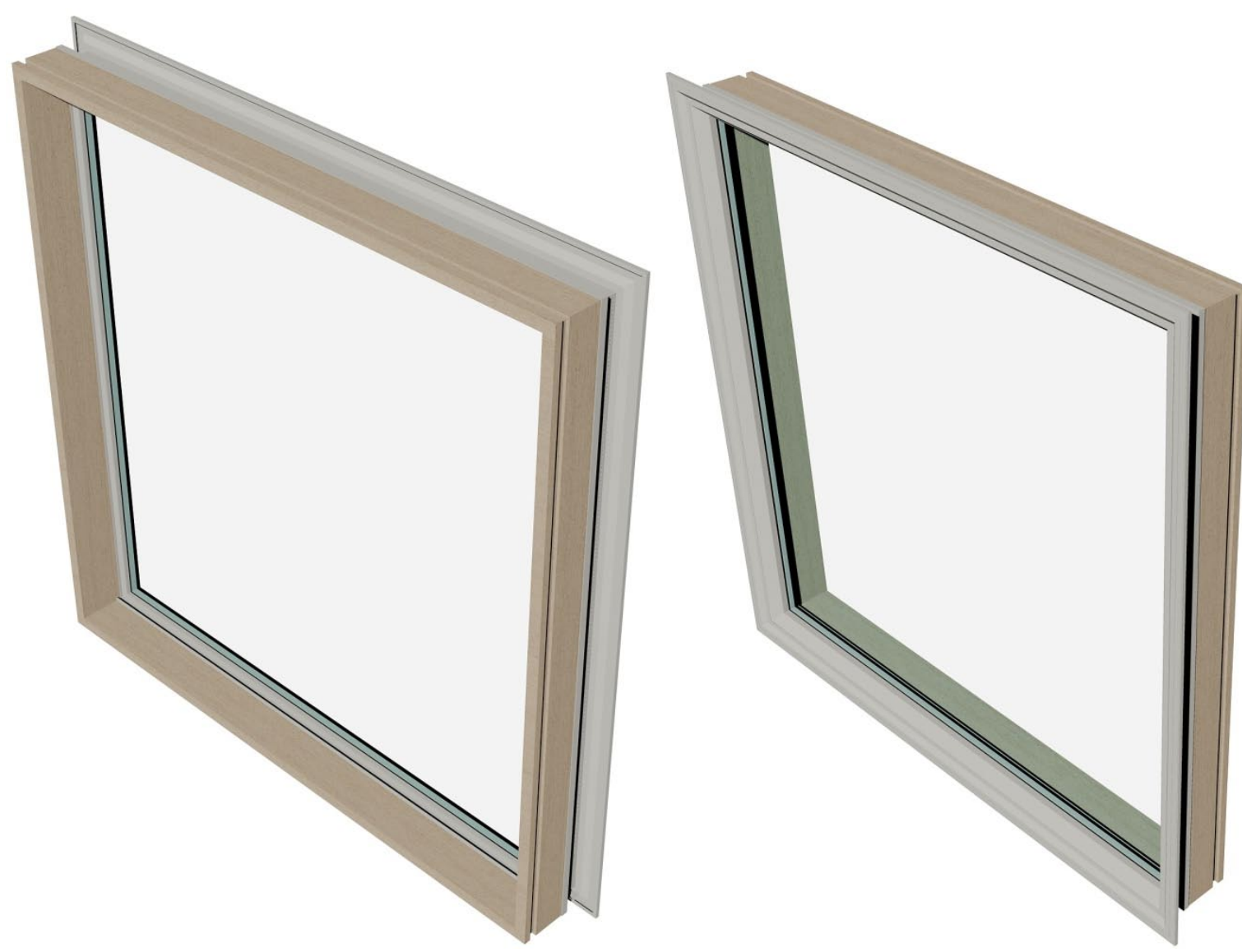

Figure A-14 \& Figure A-15: The primary aluminium single glazed window

\section{A.2.2 Magnetically-Attached Acrylic Sheet}

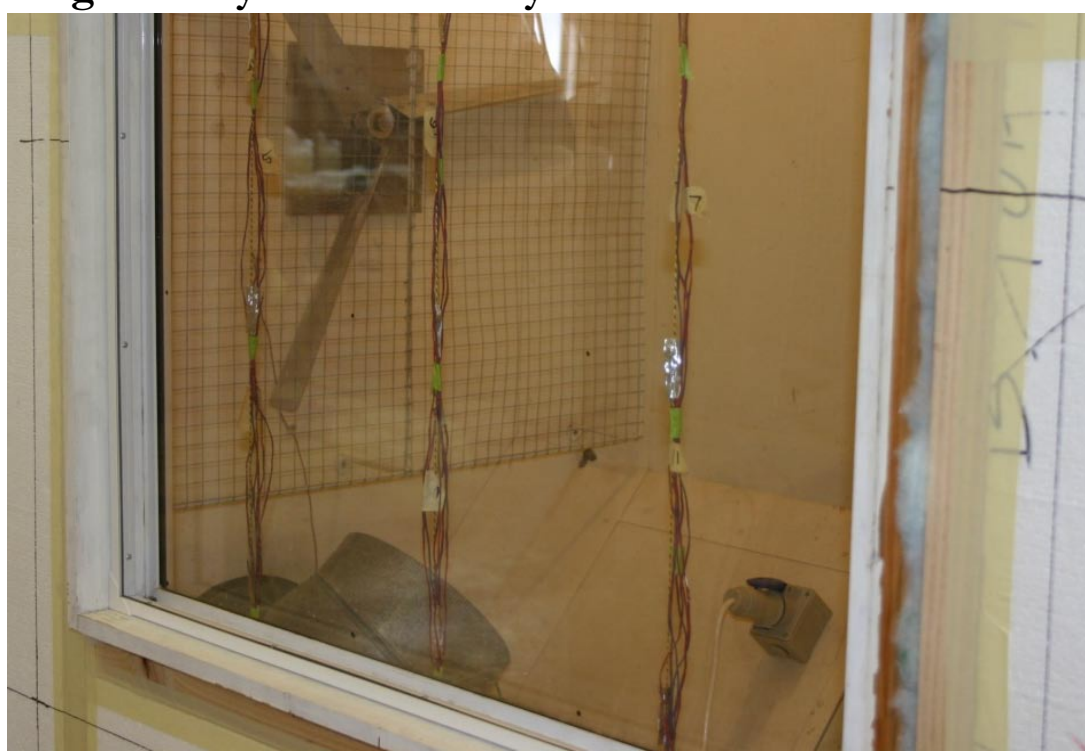

Figure A-16: The magnetic fixed acrylic secondary glazing 


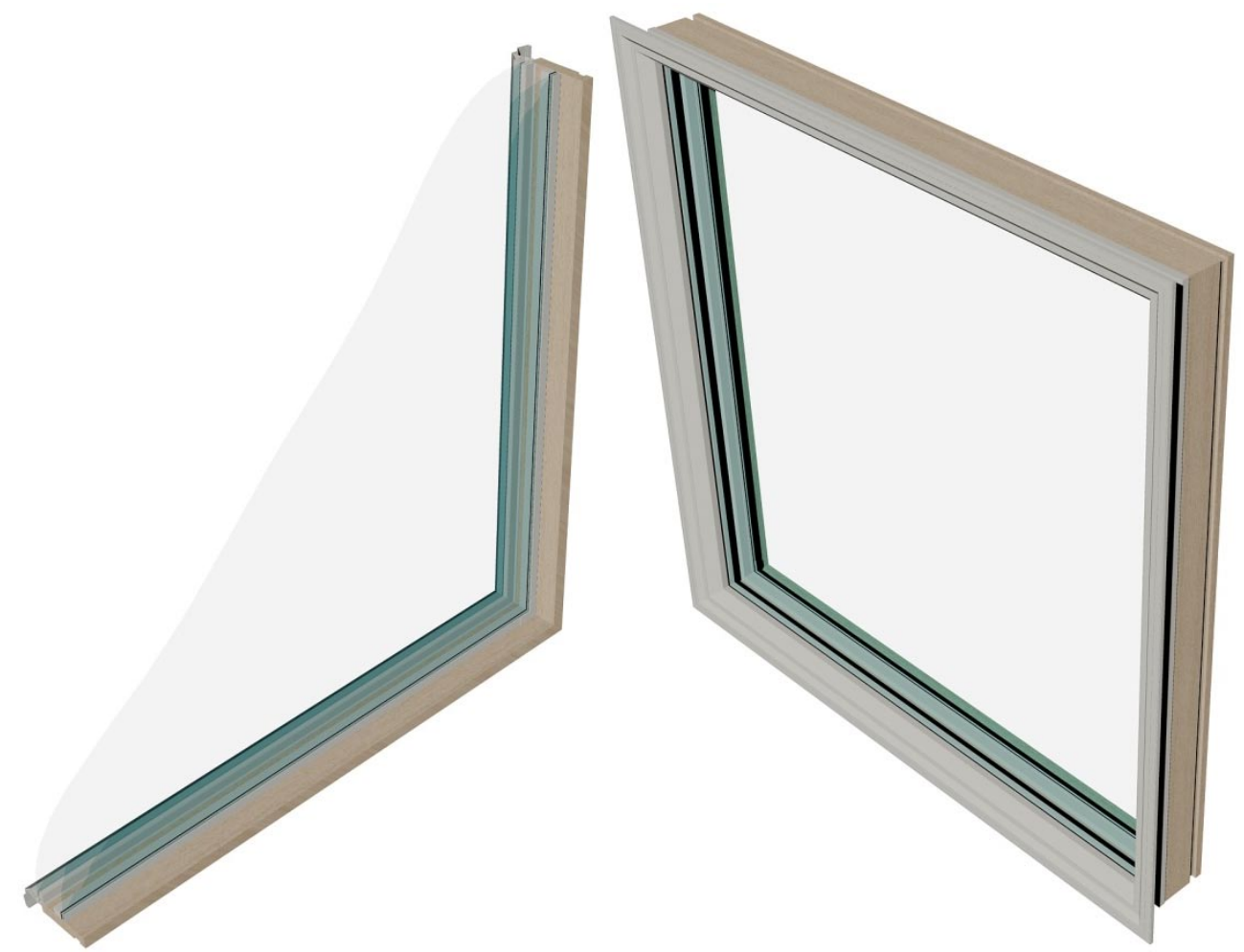

Figure A-17, A-18, A-19 \& A-20: Magnetic attached acrylic secondary glazing
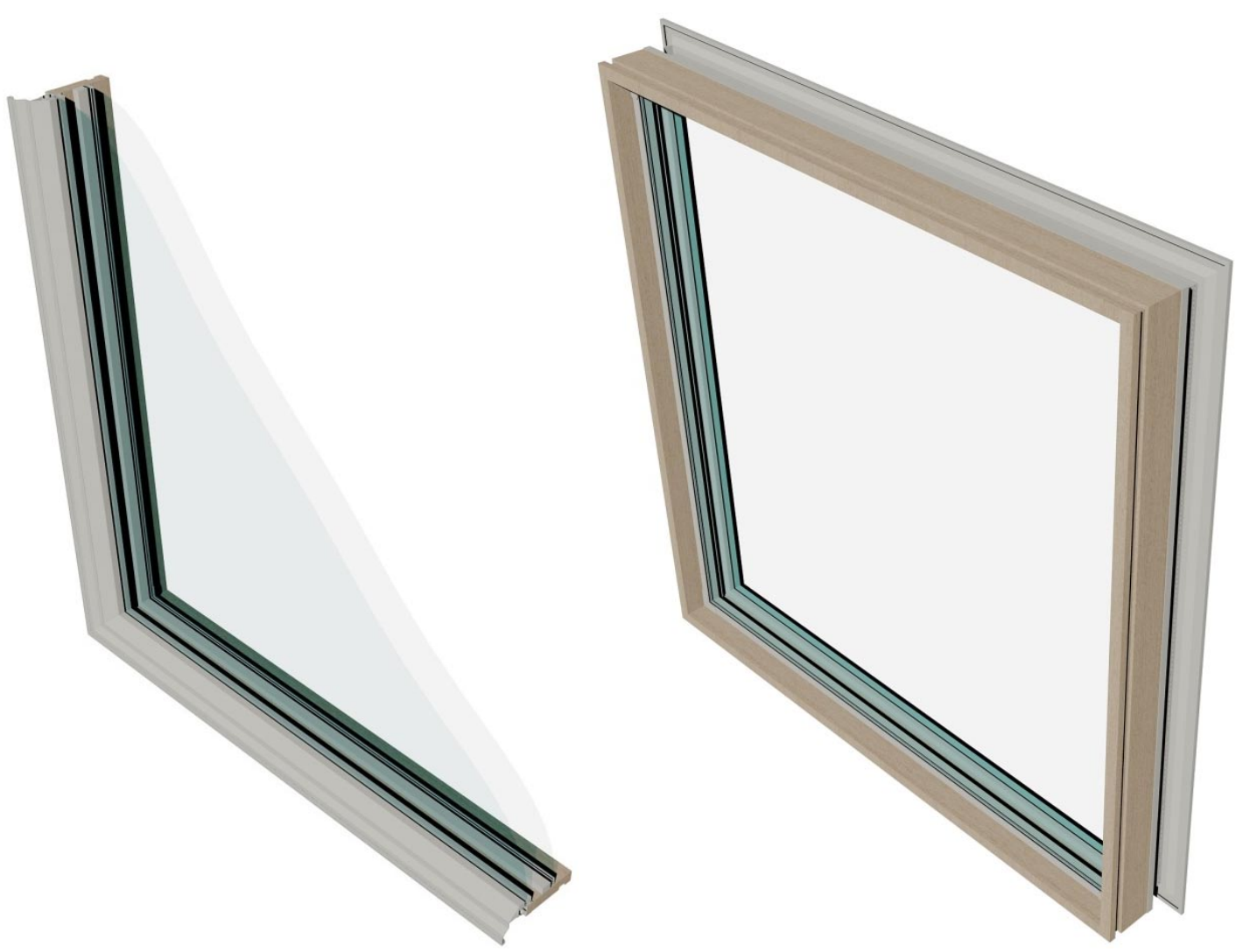


\section{A.2.3 Thin Plastic Film}

Note the near transparency when positioned over the window, leaving the original aesthetic of the window. Film is visible around the edges where it overhangs the double sided tape.
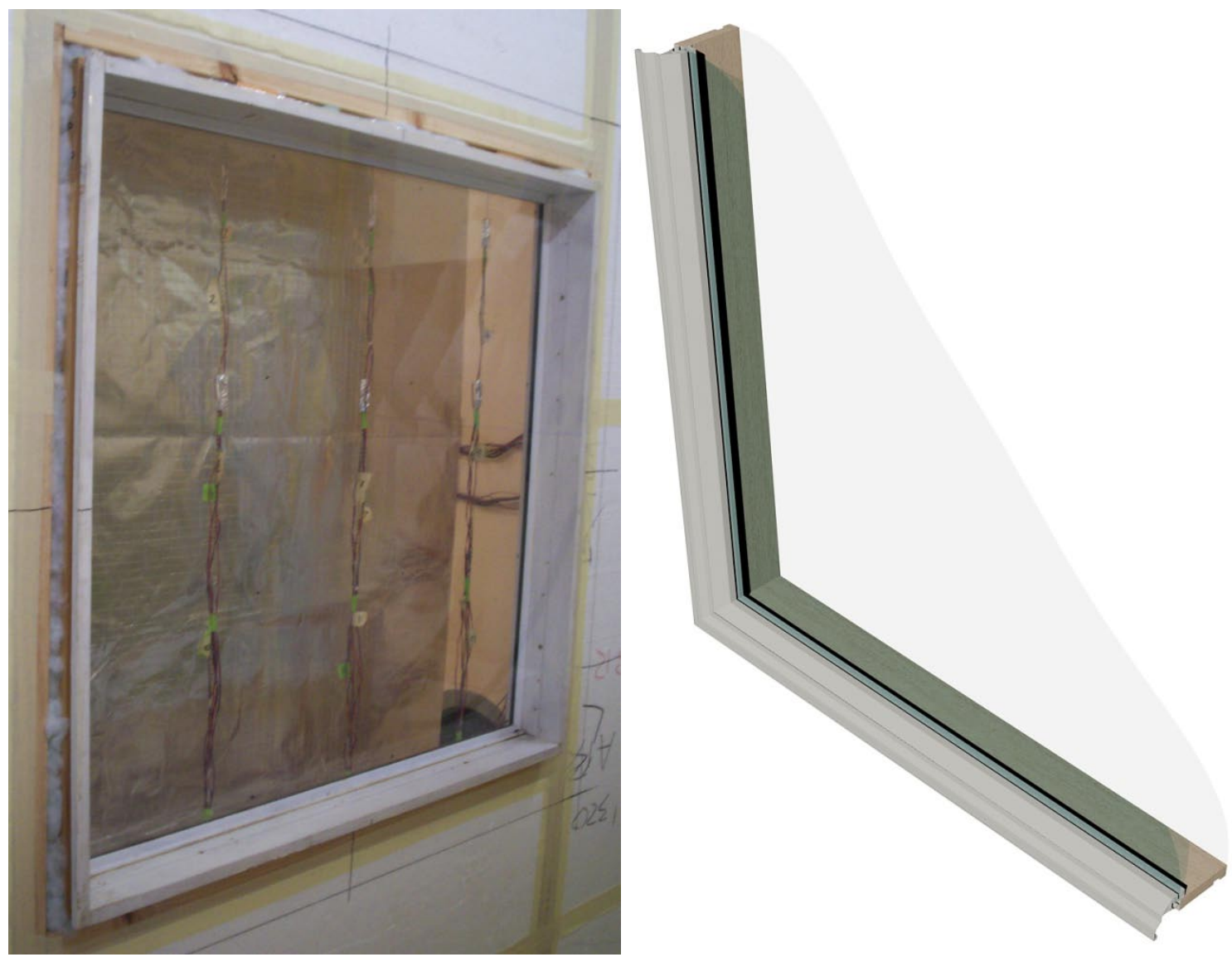

Figure A-21 \& A-22: Thin plastic film secondary glazing 


\section{A.2.4 Aluminium \& Low-E Aluminium}
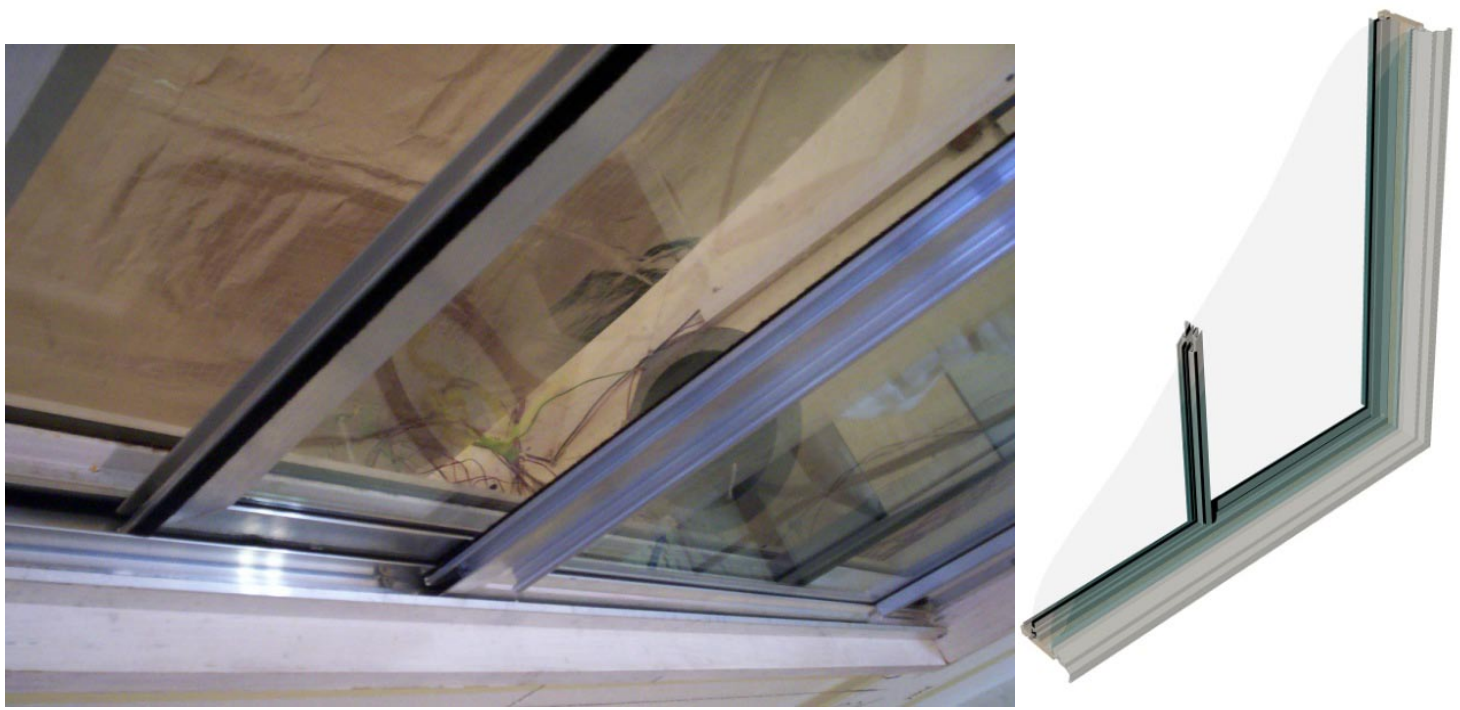

Figure A-23 \& A-24: Aluminium framed secondary glazing close-up
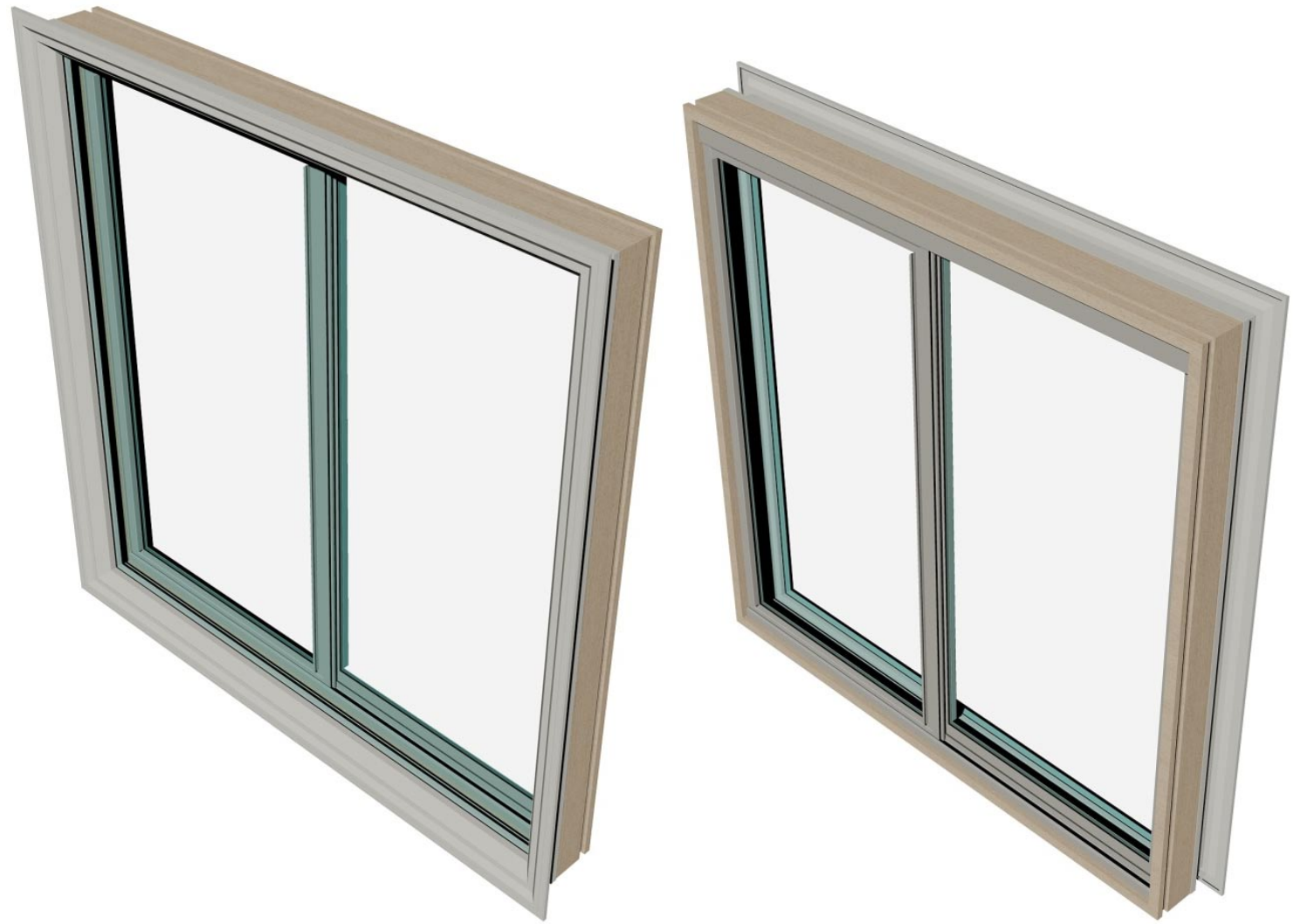

Figure A-25 \& A-26: Aluminium framed secondary glazing front and back 


\section{A.3 Example of GHB outputs.}

The following table is a portion of the data taken from the single glazed window test. It should be noted that the values have been reduced from 3 decimal places in the interest of space. The cells in blue represent the measurements from the active thermocouples; inactive thermocouples have been left out.

Table A-1: Sample of the GHB test output from the single glazed window test.

\begin{tabular}{|c|c|c|c|c|c|c|c|c|c|c|c|c|c|c|c|c|c|c|c|c|c|c|c|c|c|c|c|c|c|c|c|c|c|}
\hline & 16.83 & 14.39 & 3.40 & -5.91 & 48.81 & 6.55 & 0.20 & 18.2 & 17.8 & 25.3 & 24.7 & 6.6 & 6.8 & 6.6 & 6.8 & 6.7 & 6.9 & 6.8 & 6.5 & 6.5 & 6.2 & 6.5 & 6.7 & 6.6 & 6.5 & 6.8 & 6.5 & 6.4 & 6.3 & 6.5 & 6.5 & 6.2 & 6.3 \\
\hline Date-Time & Tjunct & volts & current & uV & watts & dT & $\mathrm{R}$ & Tair-retn A & Tair-sup A & Tair-sup B & Tair-retn B & B1 & B2 & B3 & B4 & B5 & B6 & B8 & B9 & B11 & B15 & C2 & C3 & C5 & C6 & C7 & C8 & C10 & C11 & C12 & C13 & C14 & C15 \\
\hline 22/10/2008 11:01 & 16.80 & 14.38 & 3.45 & -4.12 & 49.59 & 6.58 & 0.19 & 18.2 & 17.9 & 25.3 & 24.7 & 6.6 & 6.8 & 6.6 & 6.8 & 6.6 & 6.9 & 6.8 & 6.5 & 6.5 & 6.2 & 6.6 & 6.7 & 6.7 & 6.6 & 6.8 & 6.6 & 6.4 & 6.4 & 6.5 & 6.6 & 6.2 & 6.3 \\
\hline 22/10/2008 11:02 & 16.80 & 14.38 & 3.44 & -4.83 & 49.42 & 6.58 & 0.19 & 18.2 & 17.9 & 25.3 & 24.8 & 6.6 & 6.8 & 6.6 & 6.7 & 6.7 & 6.9 & 6.8 & 6.5 & 6.5 & 6.2 & 6.5 & 6.7 & 6.7 & 6.6 & 6.8 & 6.6 & 6.4 & 6.4 & 6.5 & 6.6 & 6.3 & 6.3 \\
\hline 22/10/2008 11:03 & 16.80 & 14.38 & 3.45 & 2.19 & 49.57 & 6.58 & 0.19 & 18.2 & 17.9 & 25.2 & 24.7 & 6.6 & 6.8 & 6.6 & 6.7 & 6.7 & 6.9 & 6.8 & 6.5 & 6.5 & 6.2 & 6.6 & 6.7 & 6.7 & 6.6 & 6.8 & 6.6 & 6.4 & 6.4 & 6.5 & 6.6 & 6.3 & 6.3 \\
\hline $22 / 10 / 2008$ 11:04 & 16.80 & 14.38 & 3.45 & 7.11 & 49.58 & 6.58 & 0.19 & 18.2 & 17.9 & 25.3 & 24.7 & 6.6 & 6.8 & 6.6 & 6.7 & 6.7 & 6.9 & 6.8 & 6.5 & 6.5 & 6.2 & 6.6 & 6.7 & 6.6 & 6.6 & 6.8 & 6.6 & 6.4 & 6.4 & 6.5 & 6.6 & 6.2 & 6.3 \\
\hline $22 / 10 / 2008$ 11:05 & 16.80 & 14.38 & 3.41 & 15.55 & 49.09 & 6.59 & 0.19 & 18.2 & 17.8 & 25.2 & 24.7 & 6.6 & 6.8 & 6.6 & 6.8 & 6.7 & 6.9 & 6.8 & 6.5 & 6.5 & 6.2 & 6.6 & 6.7 & 6.7 & 6.6 & 6.8 & 6.6 & 6.4 & 6.4 & 6.5 & 6.6 & 6.3 & 6.3 \\
\hline 22/10/2008 11:06 & 16.80 & 14.39 & 3.35 & 14.50 & 48.19 & 6.58 & 0.20 & 18.2 & 17.9 & 25.2 & 24.7 & 6.6 & 6.8 & 6.6 & 6.7 & 6.7 & 6.9 & 6.8 & 6.5 & 6.5 & 6.2 & 6.6 & 6.7 & 6.6 & 6.6 & 6.8 & 6.6 & 6.4 & 6.4 & 6.5 & 6.6 & 6.3 & 6.3 \\
\hline 22/10/2008 11:07 & 16.80 & 14.39 & 3.36 & 11.46 & 48.30 & 6.58 & 0.20 & 18.2 & 17.9 & 25.2 & 24.7 & 6.6 & 6.8 & 6.6 & 6.7 & 6.7 & 6.8 & 6.8 & 6.5 & 6.5 & 6.2 & 6.6 & 6.7 & 6.7 & 6.6 & 6.8 & 6.6 & 6.4 & 6.4 & 6.5 & 6.6 & 6.3 & 6.3 \\
\hline $22 / 10 / 2008$ 11:08 & 16.80 & 14.39 & 3.35 & 8.03 & 48.13 & 6.58 & 0.20 & 18.2 & 17.8 & 25.2 & 24.7 & 6.6 & 6.8 & 6.6 & 6.7 & 6.7 & 6.9 & 6.8 & 6.5 & 6.5 & 6.2 & 6.6 & 6.7 & 6.7 & 6.6 & 6.8 & 6.6 & 6.4 & 6.4 & 6.5 & 6.6 & 6.3 & 6.3 \\
\hline $22 / 10 / 200811: 09$ & 16.80 & 14.39 & 3.36 & 6.18 & 48.29 & 6.58 & 0.20 & 18.1 & 17.8 & 25.2 & 24.7 & 6.6 & 6.8 & 6.6 & 6.7 & 6.7 & 6.9 & 6.8 & 6.5 & 6.5 & 6.2 & 6.6 & 6.7 & 6.7 & 6.6 & 6.8 & 6.6 & 6.4 & 6.4 & 6.5 & 6.6 & 6.2 & 6.3 \\
\hline 22/10/2008 11:10 & 16.80 & 14.40 & 3.35 & 3.42 & 48.21 & 6.58 & 0.20 & 18.2 & 17.8 & 25.3 & 24.7 & 6.6 & 6.8 & 6.6 & 6.7 & 6.7 & 6.9 & 6.8 & 6.5 & 6.5 & 6.2 & 6.5 & 6.7 & 6.7 & 6.6 & 6.8 & 6.6 & 6.4 & 6.4 & 6.5 & 6.6 & 6.3 & 6.3 \\
\hline $22 / 10 / 2008$ 11:11 & 16.80 & 14.36 & 3.35 & -1.19 & 48.14 & 6.58 & 0.20 & 18.2 & 17.8 & 25.2 & 24.7 & 6.6 & 6.8 & 6.6 & 6.7 & 6.7 & 6.9 & 6.8 & 6.5 & 6.5 & 6.2 & 6.6 & 6.7 & 6.7 & 6.6 & 6.8 & 6.6 & 6.4 & 6.4 & 6.5 & 6.6 & 6.2 & 6.3 \\
\hline $22 / 10 / 2008$ 11:12 & 16.80 & 14.39 & 3.35 & -3.63 & 48.26 & 6.58 & 0.20 & 18.2 & 17.8 & 25.3 & 24.7 & 6.6 & 6.8 & 6.6 & 6.7 & 6.7 & 6.9 & 6.8 & 6.5 & 6.5 & 6.2 & 6.6 & 6.7 & 6.7 & 6.6 & 6.8 & 6.6 & 6.4 & 6.4 & 6.5 & 6.6 & 6.3 & 6.3 \\
\hline $22 / 10 / 200811: 13$ & 16.80 & 14.40 & 3.35 & -9.09 & 48.25 & 6.58 & 0.20 & 18.2 & 17.8 & 25.3 & 24.7 & 6.6 & 6.8 & 6.6 & 6.7 & 6.7 & 6.9 & 6.8 & 6.5 & 6.5 & 6.2 & 6.6 & 6.7 & 6.7 & 6.6 & 6.8 & 6.6 & 6.4 & 6.4 & 6.5 & 6.6 & 6.2 & 6.3 \\
\hline $22 / 10 / 200811: 14$ & 16.80 & 14.38 & 3.41 & -17.49 & 49.08 & 6.57 & 0.19 & 18.2 & 17.8 & 25.3 & 24.8 & 6.6 & 6.8 & 6.6 & 6.7 & 6.7 & 6.9 & 6.8 & 6.5 & 6.5 & 6.2 & 6.6 & 6.7 & 6.7 & 6.6 & 6.8 & 6.6 & 6.4 & 6.4 & 6.5 & 6.6 & 6.2 & 6.3 \\
\hline $22 / 10 / 2008$ 11:15 & 16.80 & 14.38 & 3.45 & -19.30 & 49.55 & 6.57 & 0.19 & 18.2 & 17.8 & 25.3 & 24.7 & 6.6 & 6.8 & 6.6 & 6.7 & 6.7 & 6.9 & 6.8 & 6.5 & 6.5 & 6.2 & 6.6 & 6.7 & 6.7 & 6.6 & 6.8 & 6.5 & 6.4 & 6.4 & 6.5 & 6.6 & 6.2 & 6.3 \\
\hline $22 / 10 / 2008$ 11:16 & 16.80 & 14.38 & 3.45 & -23.20 & 49.58 & 6.58 & 0.19 & 18.2 & 17.8 & 25.3 & 24.7 & 6.6 & 6.8 & 6.6 & 6.7 & 6.6 & 6.9 & 6.8 & 6.5 & 6.5 & 6.2 & 6.5 & 6.7 & 6.7 & 6.6 & 6.8 & 6.6 & 6.4 & 6.4 & 6.5 & 6.6 & 6.3 & 6.3 \\
\hline $22 / 10 / 2008$ 11:17 & 16.81 & 14.37 & 3.45 & $|-27.37|$ & 49.63 & 6.58 & 0.19 & 18.2 & 17.8 & 25.3 & 24.7 & 6.6 & 6.8 & 6.6 & 6.7 & 6.7 & 6.9 & 6.8 & 6.5 & 6.5 & 6.2 & 6.6 & 6.7 & 6.7 & 6.6 & 6.8 & 6.6 & 6.4 & 6.4 & 6.5 & 6.6 & 6.3 & 6.3 \\
\hline
\end{tabular}




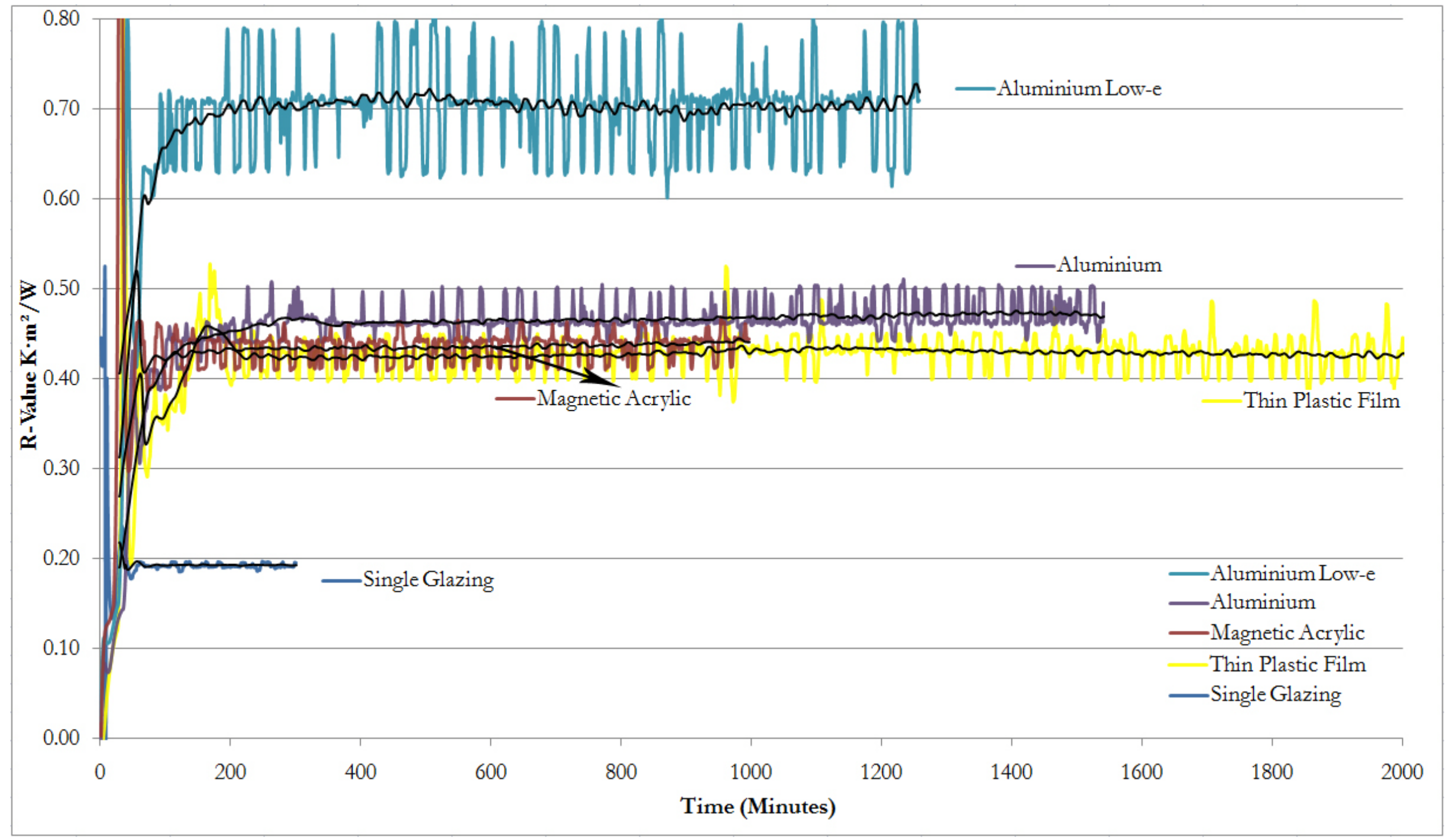

Figure A-27: Enlarged version of Figure 4-1: Guarded Hot Box Test Results 


\section{Appendix B Thermal Modelling}

\section{B.1Therm 6}

This section presents the sections modelled in Therm 6 for each window. The window sill and heads are presented as the jambs are identical to the head. In the case of the aluminium secondary glazing the jamb is different so a section is shown, as is the mullion. The Low-E secondary glazing sections are visually no different and as such; do not need to be presented.

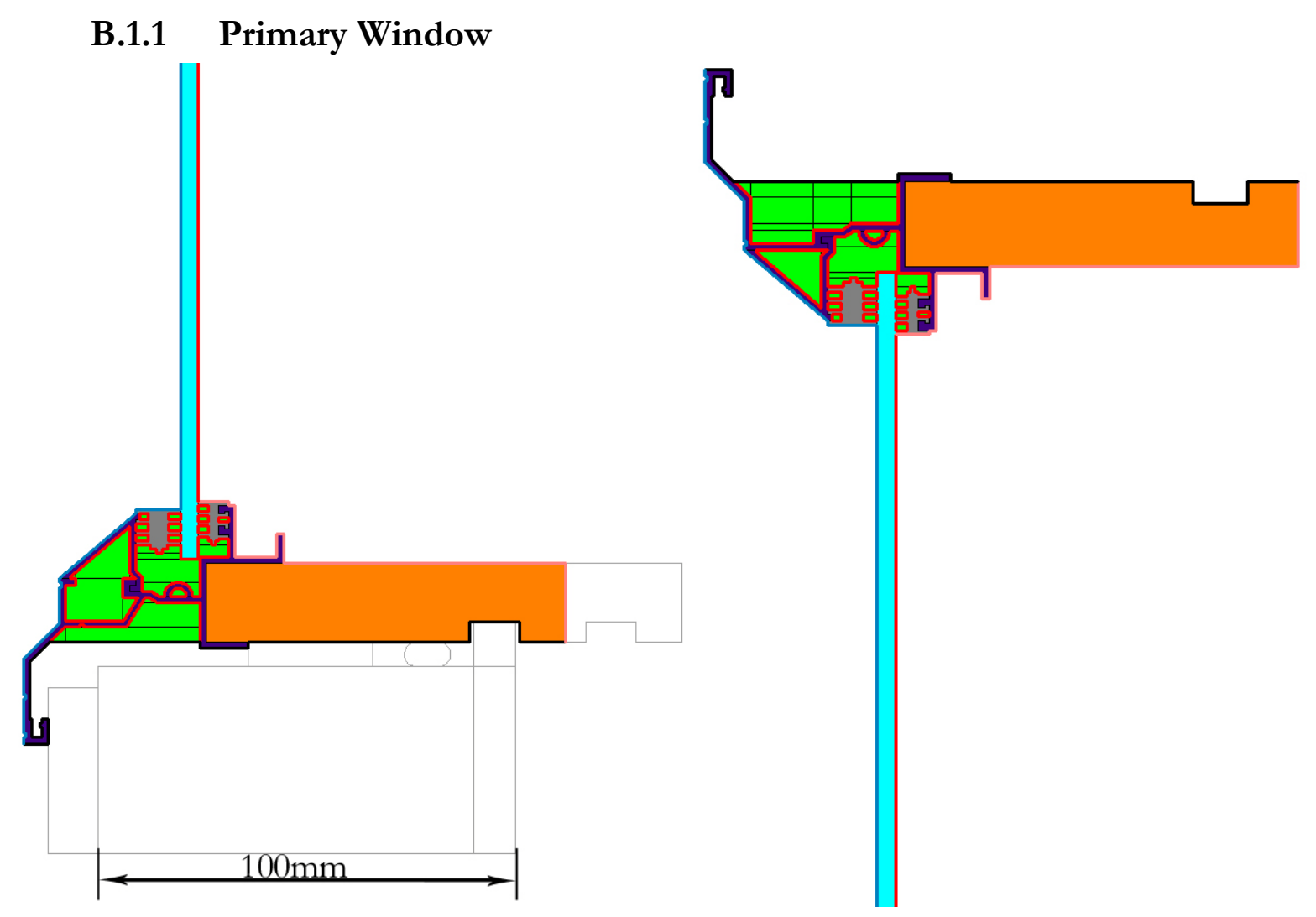

Figure B-28\& B-29: Primary Window Sill and Head Sections 


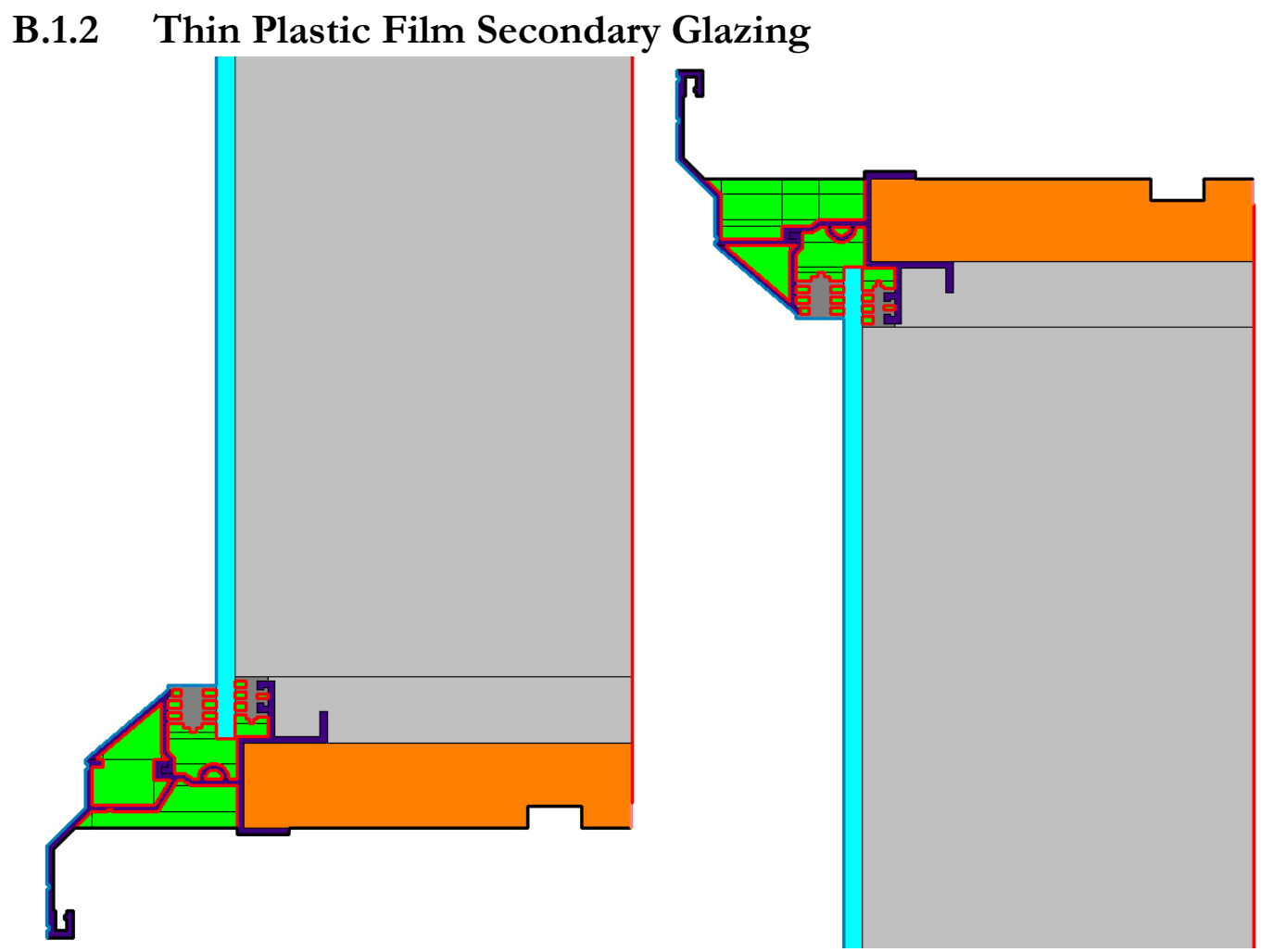

Figure B-30 \& B-31: Thin Plastic Film Sill and Head Sections

\section{B.1.3 Magnetic Attached Acrylic Secondary Glazing}
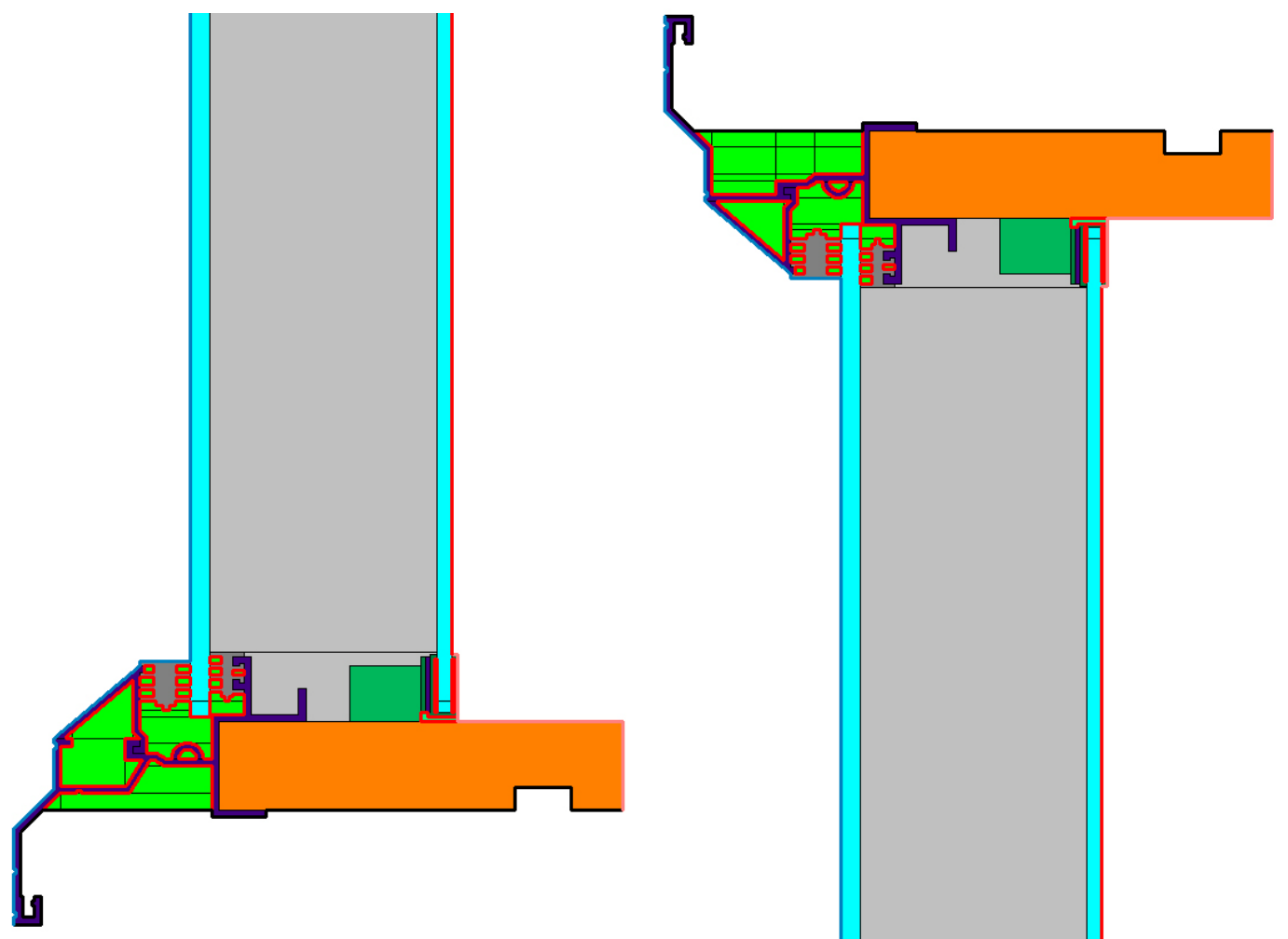

Figure B-32\& B-33: Magnetic Acrylic Sill and Head Sections 
B.1.4 Aluminium Framed and Low-E Secondary Glazing
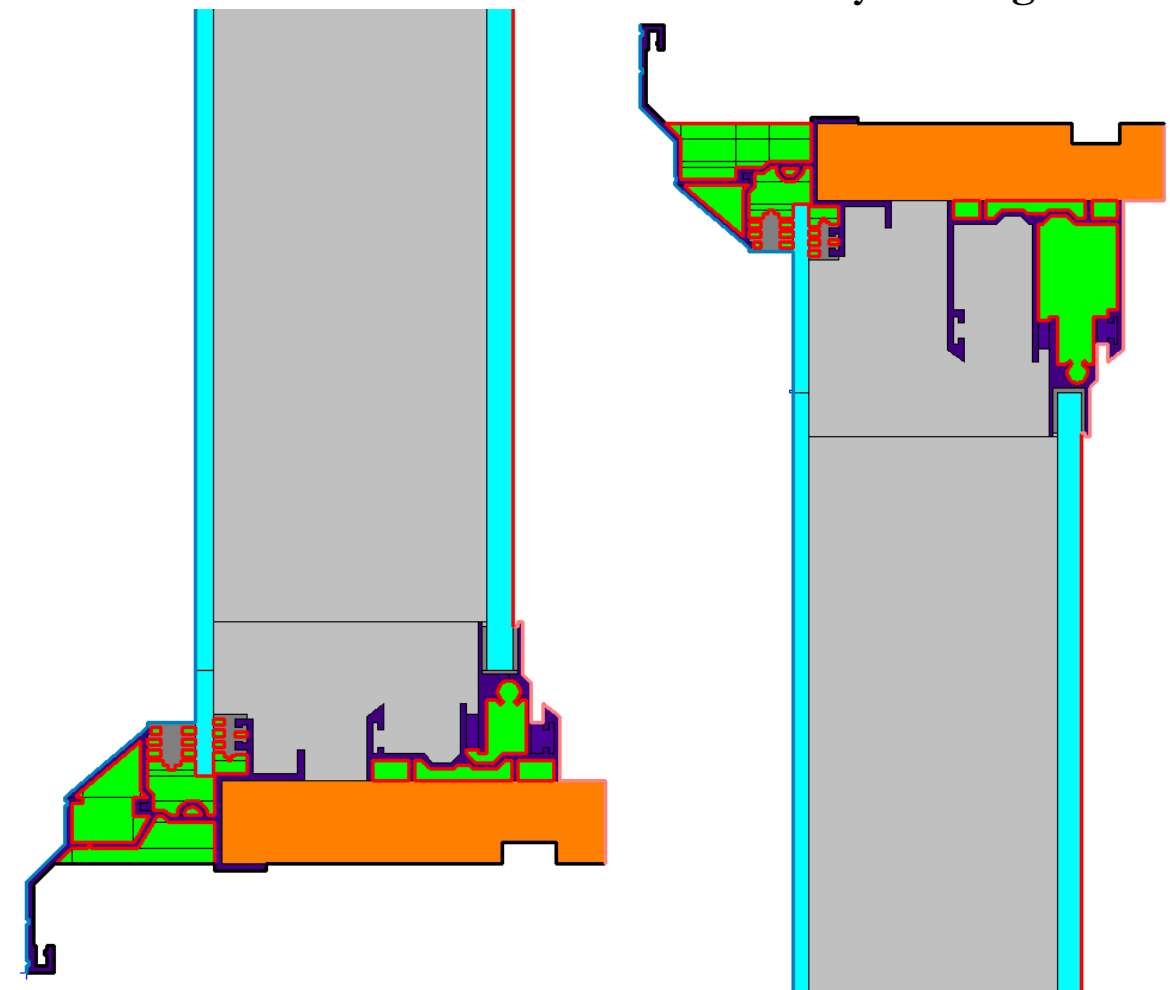

Figure B-34 \& B-35: Aluminium Secondary Glazing Sill and Head Sections
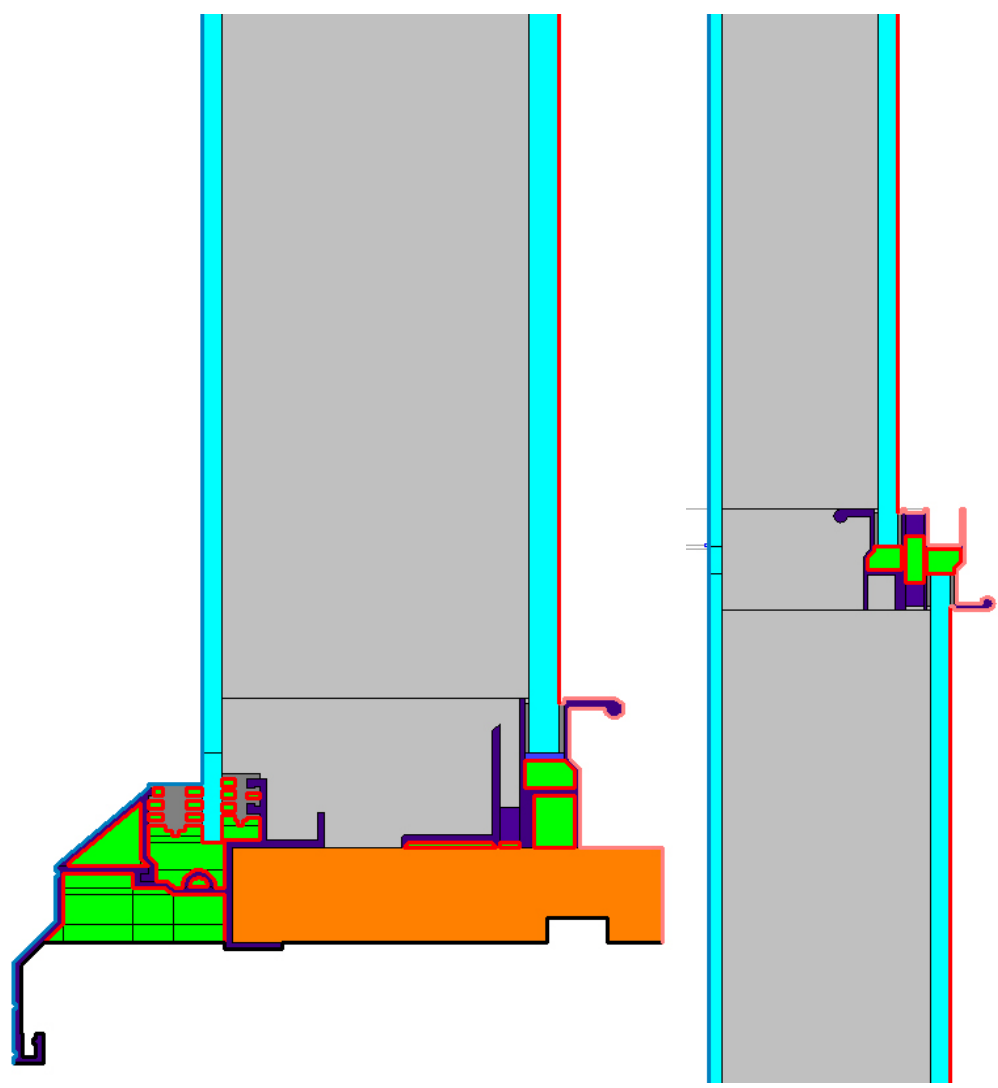

Figure B-36 \& B-37: Aluminium Secondary Glazing Jamb and Mullion Section 


\section{B.2 Window 6}

This section provides technical data on the glass properties and glazing systems that were used in the whole window thermal simulation.

\section{B.2.1 Glass Properties}

This table presents the properties of the glass panes used in the final calculation where the influence of the GHB surround was calculated and removed.

Table B-2: Glass Properties used in Window 6

\begin{tabular}{|c|c|c|c|c|c|c|c|c|c|c|c|c|c|}
\hline \multirow[b]{4}{*}{ Window Used In } & \multirow[b]{2}{*}{ Thickness } & \multicolumn{4}{|c|}{ Solar } & \multicolumn{4}{|c|}{ Visible } & \multicolumn{3}{|c|}{ IR } & \multirow[t]{3}{*}{ Conductivity } \\
\hline & & \multicolumn{2}{|c|}{ Trans } & \multicolumn{2}{|c|}{ Reflect } & Trans & Trans & Reflect & Reflect & Trans & Emis & Emis & \\
\hline & & Front & Back & Front & Back & Front & Back & Front & Back & & Front & Front & \\
\hline & $(\mathrm{mm})$ & Tsol & Tsol2 & Rsol & Rsol2 & Tvis & Tvis2 & Rvis & Rvis2 & Tir & Emis1 & Emis2 & \\
\hline (All) & 4 & 0.721 & 0.721 & 0.098 & 0.098 & 0.892 & 0.892 & 0.104 & 0.104 & 0 & 0.84 & 0.84 & 1 \\
\hline (Magnetic) & 3 & 0.771 & 0.771 & 0.095 & 0.095 & 0.83 & 0.83 & 0.83 & 0.83 & 0 & 0.84 & 0.84 & 0.19 \\
\hline (Plastic Film) & 0.2 & 0.771 & 0.771 & 0.095 & 0.095 & 0.83 & 0.83 & 0.83 & 0.83 & 0 & 0.84 & 0.84 & 0.4 \\
\hline (Aluminium) & 6 & 0.817 & 0.817 & 0.082 & 0.082 & 0.896 & 0.896 & 0.084 & 0.084 & 0 & 0.84 & 0.84 & 1 \\
\hline (Low-E) & 6 & 0.434 & 0.434 & 0.268 & 0.314 & 0.748 & 0.748 & 0.05 & 0.039 & 0 & 0.84 & 0.025 & 1 \\
\hline
\end{tabular}




\section{B.2.2 Glazing Systems}

This table presents the centre of glass results for each of the five glazing systems.

Table B-3: COG results for glazing systems

\begin{tabular}{|c|c|c|c|c|c|c|c|c|c|}
\hline Window Used In & \multicolumn{3}{|c|}{ Thickness } & Ufactor & $\mathrm{SC}$ & SHGC & Rel Ht. Gain & Tvis & Keff \\
\hline & Glass 1 & Airgap & Glass 2 & $\mathrm{~W} / \mathrm{m} 2-\mathrm{K}$ & & & $\mathrm{W} / \mathrm{m} 2$ & & $\mathrm{~W} / \mathrm{m}-\mathrm{K}$ \\
\hline (Single) & $4 \mathrm{~mm}$ & & & 5.878 & 0.89 & 0.775 & 603 & 0.892 & $\mathrm{~N} / \mathrm{A}$ \\
\hline (Magnetic) & $4 \mathrm{~mm}$ & $48.5 \mathrm{~mm}$ & $3 \mathrm{~mm}$ & 2.686 & 0.748 & 0.651 & 492 & 0.747 & 0.2665 \\
\hline (Plastic Film) & $4 \mathrm{~mm}$ & $88.1 \mathrm{~mm}$ & $0.2 \mathrm{~mm}$ & 2.815 & 0.751 & 0.653 & 495 & 0.747 & 0.4882 \\
\hline (Aluminium) & $4 \mathrm{~mm}$ & $61.4 \mathrm{~mm}$ & $6 \mathrm{~mm}$ & 2.767 & 0.778 & 0.677 & 512 & 0.806 & 0.3394 \\
\hline (Low-E) & $4 \mathrm{~mm}$ & $61.4 \mathrm{~mm}$ & $6 \mathrm{~mm}$ & 1.775 & 0.571 & 0.497 & 370 & 0.67 & 0.1617 \\
\hline
\end{tabular}


A Cost Benefit Analysis of Secondary Glazing as a Retrofit Alternative for New Zealand Homes

Nick Smith 


\section{Appendix C Home Heating Energy Simulation: ALF}

This section presents the report output file from each of the 10 'typical New Zealand homes' modelled using the simulation software ALF. This report documents all the details and assumptions for each of the homes as well as the results.

The reports present the homes modelled using the magnetically-attached acrylic sheet secondary glazing. This allows the reader to distinguish between the windows which can be secondary glazed and those that cannot, such as ranch slider doors etc. The windows which can be secondary glazed have the R-value of $0.36 \mathrm{~m}^{2 \circ} \mathrm{C} / \mathrm{W}$ and a SHGC of $61 \%$. The windows that cannot be secondary glazed retain the single glazed R-value $0.15 \mathrm{~m}^{2 \circ} \mathrm{C} / \mathrm{W}$ and a SGHC of $70 \%$. The climate used for the presented models is the Wellington climate. As such, all results presented in this report are representative of the home modelled under a Wellington climate with a magnetically-attached acrylic sheet secondary glazing retrofit.

In the interest of space only one report is provided per house however each house was simulated 20 times. Once with each of the 5 window variations and then each of these is simulated under all four climate files. 


\section{C.1House 1}

\section{ALF Calculation Report}

Current Design: Magnetic Acrylic

\section{NZ Building Code compliance}

In order to comply with the Energy Efficiency Clause H1 (2000) of the New Zealand Building Code a building $\mathrm{kWh} / \mathrm{m}^{2} / \mathrm{Deg}$ a Days if it is inan $0.13 \mathrm{~km} / \mathrm{m} / \mathrm{Degree}$ Days if $\mathrm{It}$ is in a warn location and less than 0.12 (May to August) degree days of less than 920. C001 locations are locations with 920 degree days or more. The currenly selected location (Wellington) is a warm location. The target BPI is therefore 0.13 .
Alternatively, the building complies if it is built to NZS 4218:1996. This standard has three different ALF checks the designed building for a BPI and for the NZS 4218:1996 Schedule and Calculation Methods. The currently selected NZS 4218 target R-values are for a "non-solid construction". The current design rates are:

$$
\begin{aligned}
& \text { BPI }=0.130 \\
& \text { NZS } 4218 \text { (Schedule) } \\
& \text { NZS } 4218 \text { (Calculation) }
\end{aligned}
$$$$
\text { H1 fail H1 fa: }
$$

The current building design does
Calculation target in NZS 4218:1996.

\section{$\frac{\text { Details of H1 Compliance }}{\text { BPI }}$}

NZS 4218 (Schedule)

Maximum: 0.13

$$
\begin{array}{clr} 
& \text { Minimum } & \text { Minimum achieve } \\
\text { Floor: } & 1.3 & 0.60 \\
\text { Roof: } & 1.9 & 1.96
\end{array}
$$

$\begin{array}{ll}\text { Floor: } & 1.3 \\ \text { Wall: } & 1.5 \\ \text { Raof: } & 1.9\end{array}$

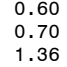

NZS 4218 (Calculation) ${ }_{\text {Maximum acceptable } h}$

\section{6}

of those in the Schedule:
$\begin{array}{lll}\text { Floor: } & 0.8 \\ \text { Wall: } & 0.9\end{array}$
imum Average achieved

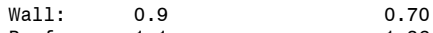
(excl. carpet)

$593 \mathrm{~W} /{ }^{\circ} \mathrm{C}$

$\begin{array}{cc}\text { Roof: } & 1.1 \\ \text { Copyright of the standard is property of Standards New Zealand and is protected as described in the NZS } & 1.36\end{array}$

Energy to evaluate the importance of the thermal performance of individual building components - for example, of

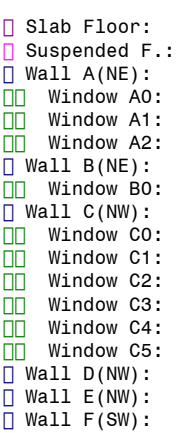

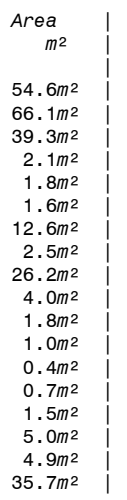

\begin{tabular}{rr} 
kWh/ & \multicolumn{2}{c}{ Loss } \\
year & $\%$ \\
553 & $4.4 \%$ \\
753 & $6.0 \%$ \\
556 & $4.4 \%$ \\
58 & $0.5 \%$ \\
50 & $0.4 \%$ \\
45 & $0.4 \%$ \\
179 & $1.4 \%$ \\
68 & $0.5 \%$ \\
371 & $3.0 \%$ \\
110 & $0.9 \%$ \\
50 & $0.4 \%$ \\
26 & $0.2 \%$ \\
11 & $0.1 \%$ \\
20 & $0.2 \%$ \\
42 & $0.3 \%$ \\
70 & $0.6 \%$ \\
69 & $0.6 \%$ \\
505 & $4.0 \%$
\end{tabular}

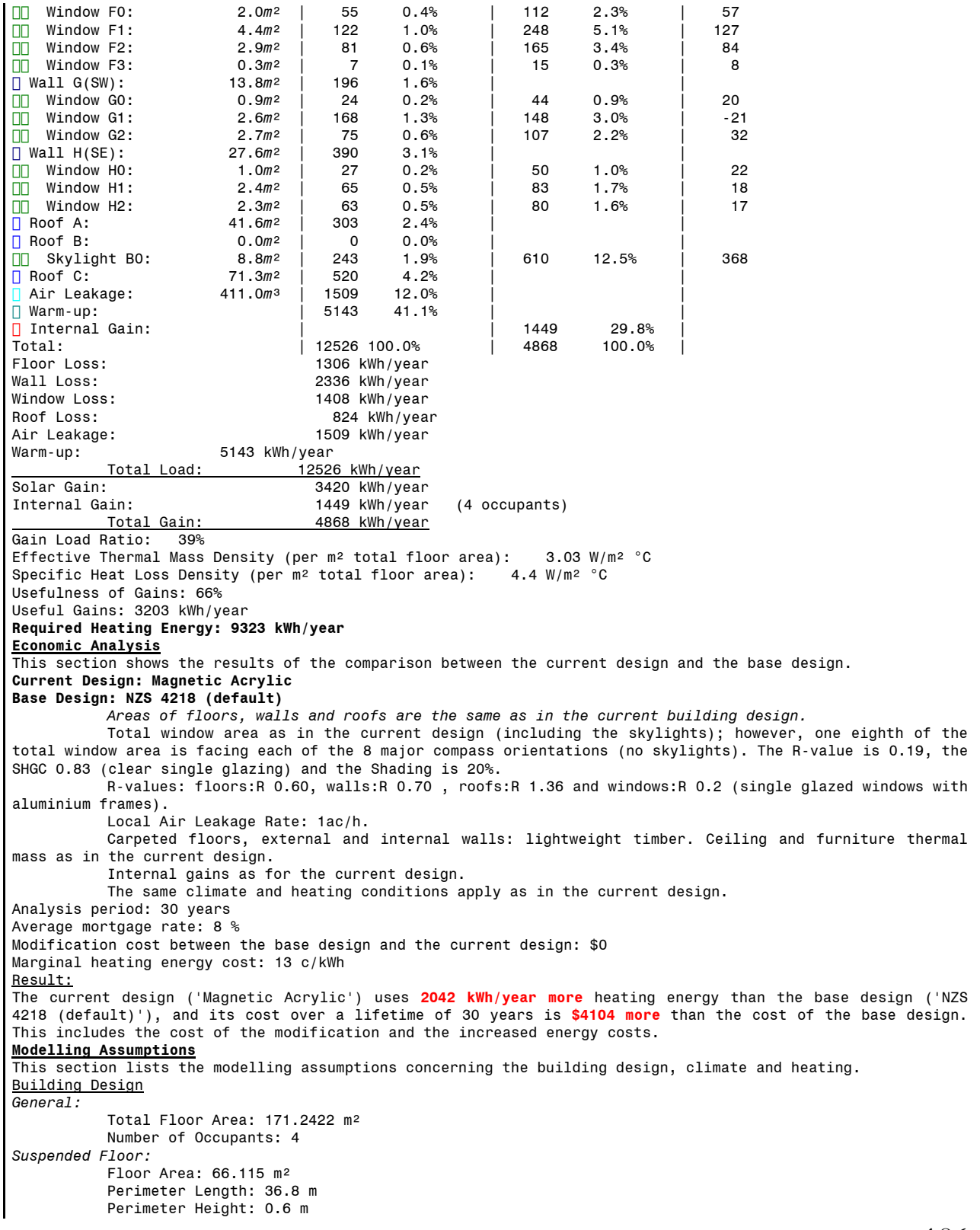

Nick Smith 
Perimeter Area: $22.08 \mathrm{~m}^{2}$

(sheltered)

loor Insulation: Uninsulated timber floor

Floor Insulation R-value: $0.3 \mathrm{~m}^{\circ}{ }^{\circ} \mathrm{C} / \mathrm{W}$

Total Suspended Floor R-value: $0.87 \mathrm{~m}^{\circ} \mathrm{C} / \mathrm{Wl}$
Tound

Slab Floor:

loor Area: $54.5772 \mathrm{~m}^{2}$

Perimeter Length: $32.22 \mathrm{~m}$

soil conductivity: $1.2 \mathrm{~W} / \mathrm{m}^{\circ} \mathrm{C}$

Slab and Ground R-value: $0.9773483 \mathrm{~m}^{\circ}{ }^{\circ} \mathrm{C} / \mathrm{W}$

Floor Covering R-value: $0 \mathrm{~m}^{2}{ }^{\circ} \mathrm{C} / \mathrm{W}$

Walls:
Type 1:

Timber Framed Wall, Bevelbacked Weatherboards, Insulation Within Framing - 100 mm Framing 2 Dwangs, Studs $400 \mathrm{~mm}$ ctr., Adhesive Blown Insulant

$\begin{array}{ccllll}\begin{array}{c}\text { truction } \mathrm{R} \text {-value: } 0.7 \mathrm{~m}^{\circ} \mathrm{C} / \mathrm{W} \\ \text { Name }\end{array} & \begin{array}{c}\text { Lenientation } \\ \text { Nenth }\end{array} & \text { Height } & \begin{array}{l}\text { Net } \\ \text { Area }\end{array} & \begin{array}{l}\text { Window } \\ \text { Area }\end{array} \\ & & m & m & \begin{array}{l}\mathrm{m}^{2} \\ \mathrm{~m}^{2}\end{array} \\ \text { Wall A } & \text { NorthEast } & 8.3 & 5.4 & 39.3 & 5.52 \\ \text { Wall B } & \text { NorthEast } & 5.8 & 2.6 & 12.6 & 2.457 \\ \text { Wall C } & \text { NorthWest } & 6.6 & 5.4 & 26.2 & 9.410999 \\ \text { Wall D } & \text { NorthWest } & 1.91 & 2.6 & 5.0 & 0 \\ \text { Wall E } & \text { NorthWest } & 2.04 & 2.4 & 4.9 & 0 \\ \text { Wall F } & \text { SouthWest } & 8.4 & 5.4 & 35.7 & 9.63695 \\ \text { Wall G } & \text { SouthWest } & 8.33 & 2.4 & 13.8 & 6.1425 \\ \text { Wall H } & \text { SouthEast } & 13.84 & 2.4 & 27.6 & 5.646\end{array}$

Roofs:

I:
illion Roof, Exposed Rafters, Metal Clad

Dummy Purlins ex $50 \mathrm{~mm}$, Height as required $+25 \mathrm{~mm}$ air gap to underside of building paper, 1200ctr. Construction R-value: $1.357143 \mathrm{~m}^{\circ}{ }^{\circ} \mathrm{C} / \mathrm{W}$

\begin{tabular}{|c|c|c|c|c|c|c|c|}
\hline \multirow{2}{*}{\multicolumn{8}{|c|}{ Name Length Width }} \\
\hline & Length & Width & $\begin{array}{l}\text { Net } \\
\text { Area }\end{array}$ & $\begin{array}{l}\text { Window } \\
\text { Area }\end{array}$ & & & \\
\hline & & & & & & & \\
\hline $\begin{array}{l}\text { Roof A } \\
\text { Roof B }\end{array}$ & & 6.6 & & & & & \\
\hline $\begin{array}{l}\text { Roof B } \\
\text { Roof C }\end{array}$ & 2.1 & 4.2 & 0.0 & 8.819999 & & & \\
\hline $\begin{array}{l}\text { Roof C } \\
\text { and Skyligh }\end{array}$ & 5.8 & 12.3 & 71.3 & 0 & & & \\
\hline & & & & & & & \\
\hline $\begin{array}{l}\text { Glass: Magicsea } \\
\text { Frame: Alumium }\end{array}$ & & & & & & & \\
\hline $\begin{array}{l}\text { Frame: Alumium } \\
\text { R-value: } 0.36 \mathrm{n}\end{array}$ & $\begin{array}{l}\text { ame } \\
\mathrm{C} / \mathrm{W}\end{array}$ & ermal break) & & & & & \\
\hline & Oeefficier & & & & & & \\
\hline Number & $\begin{array}{l}\text { Wall1 } \\
\text { Roof }\end{array}$ & Orientation & & Width & Height & $\begin{array}{l}\text { Net } \\
\text { Area }\end{array}$ & Shading \\
\hline & & & & $m_{2}^{m}, 1$ & 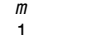 & $m^{2}$ & 60 \\
\hline $\begin{array}{l}\text { Winde. } 1 \\
\text { Wind. } 2\end{array}$ & Wall A & NorthEast & & 2 & 0.9 & 1.8 & $\begin{array}{l}60 \\
80\end{array}$ \\
\hline Wind. 3 & Wall A & NorthEast & & 1.8 & 0.9 & 1.62 & 0 \\
\hline Wind. 1 & Wall B & NorthEast & & 1.82 & 1.35 & 2.457 & 0 \\
\hline Wind. 1 & Wall c & Northwest & & & & & 0 \\
\hline Wind. 2 & Wall C & NorthWest & & 1.2 & 1.5 & 1.8 & 0 \\
\hline Wind. 3 & Wall c & NorthWest & & 1.2 & 0.8 & 0.96 & 0 \\
\hline Wind. 4 & Wall C & NorthWest & & 1.3 & 0.3 & 0.39 & 39 \\
\hline Wind. 5 & Wall c & Northwest & & 1.3 & 0.57 & 0.7409999 & 39 \\
\hline Wind. 6 & $\begin{array}{ll}\text { Wall C } \\
\text { Wall }\end{array}$ & NorthWest & & 0.8 & 1.9 & 1.52 & 39 \\
\hline $\begin{array}{l}\text { Wind. } 1 \\
\text { Wind } 2\end{array}$ & Wall $\mathrm{F}$ & $\begin{array}{l}\text { Southwest } \\
\text { SouthWest }\end{array}$ & & 2,95 & 1.5 & 4.425 & 0 \\
\hline Wind. 3 & Wall $\mathrm{F}$ & SouthWest & & 1.96 & 1.5 & 2.94 & 0 \\
\hline Wind. 4 & Wall $\mathrm{F}$ & SouthWest & & 0.185 & 1.47 & 0.27195 & 0 \\
\hline
\end{tabular}

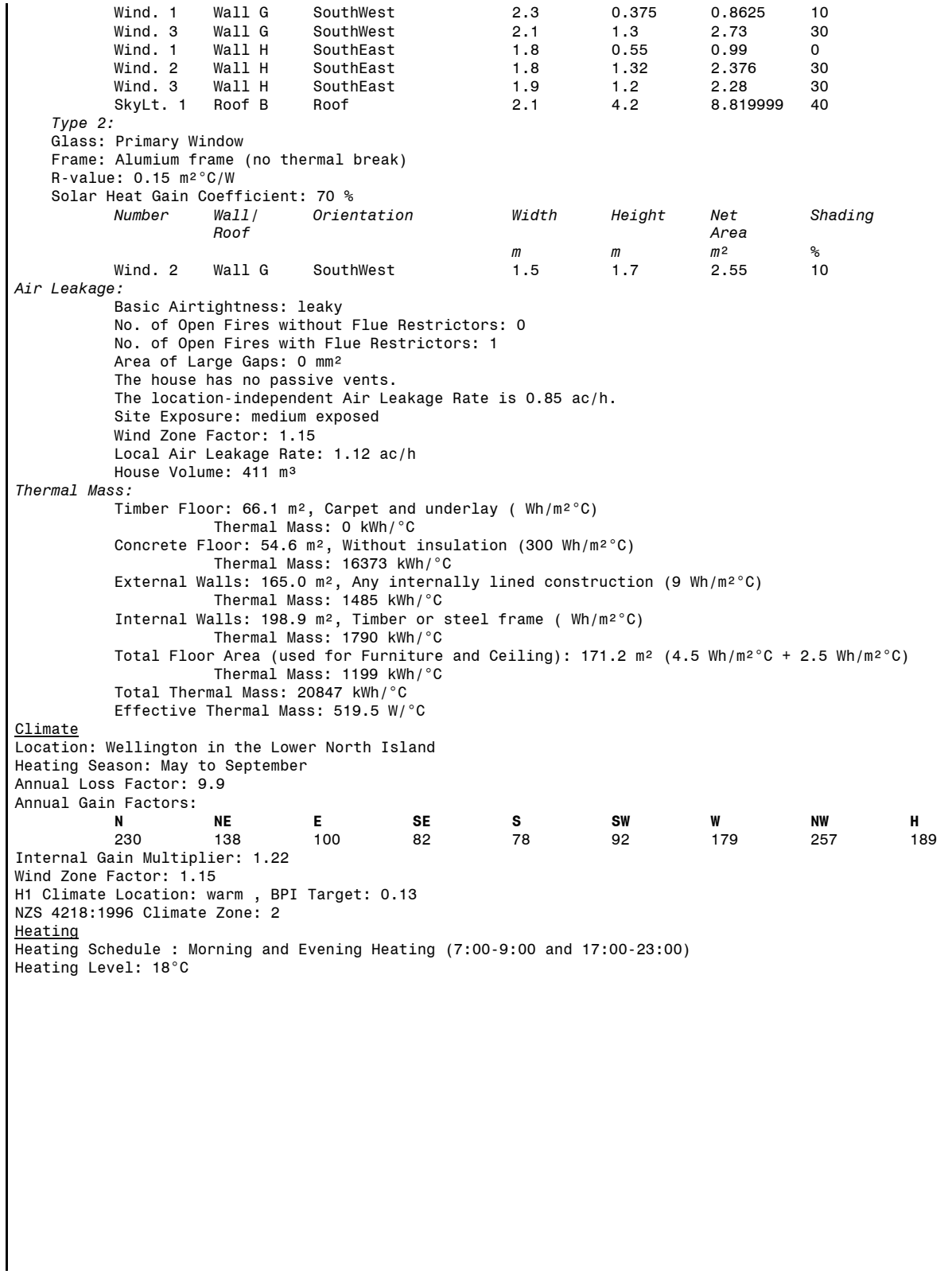




\section{C.2 House 2}

\section{ALF Calculation Report}

Project Descriptio

Current Design: Magnetic Acrylic

NZ Building Code Compliance has to have a BPI of less than $0.13 \mathrm{kWh} / \mathrm{m} 2 /$ Degree Days if it is in a warm location and less than 0.12 (May to August) degree days of less than 920. Cool locations are locations with 920 degree days or more. The currenly selected location (Wellington) is a warm location. The target BPI is therefore 0.13.

ALF checks the designed building for a BPI and for for a "non-solid construction".
The currently selected NZS 4218 target R-values are for tesign rates ar

$$
\begin{aligned}
& \text { BPI }=0.145 \\
& \text { NZS } 4218 \text { (Schedule) } \\
& \text { NZS } 4218 \text { (Calculation }
\end{aligned}
$$$$
\text { H1 fail H1 fail }
$$

NZS 4218 (Calculation)
The current building design does $n$ Details of $\mathrm{H} 1$ Compliance
NZS 4218 (Schedule)
Maximum: 0.13
Achieved: 0.145
Floor:
Wall:
Roof:$$
\begin{aligned}
& \text { Minim } \\
& 1.3 \\
& 1.5 \\
& 1.9
\end{aligned}
$$
inimum achieved
0.57
0.70
0.50
0.70
(excl. carpet)

NZS 4218 (Calculation)

$$
\begin{aligned}
& \text { Maximum acceptable heat loss: } \quad 443 \mathrm{~W} /{ }^{\circ} \mathrm{C} \\
& \text { Achieved heat loss: } \\
& 630 \mathrm{~W} /{ }^{\circ} \mathrm{C}
\end{aligned}
$$

For the individ
of those in the Schedul

$$
\begin{array}{llcl} 
& \text { Minimum } & \text { Average achieved } & \\
\text { Floor: } & 0.8 & 0.75 & \text { (excl. carpet) } \\
\text { Wall: } & 0.9 & 0.75 & \\
\text { Roof: } & 1.1 & 0.56 &
\end{array}
$$

Copyright of the standard is property of Standards New Zealand and is protected as described in the NZS
4218:1996 document.

Energy
This section gives you an overview of all the heat flows in and out of the designed building. It allows you
to evaluate the importance of the thermal performance of individual building components - for example, of to evaluate the imor
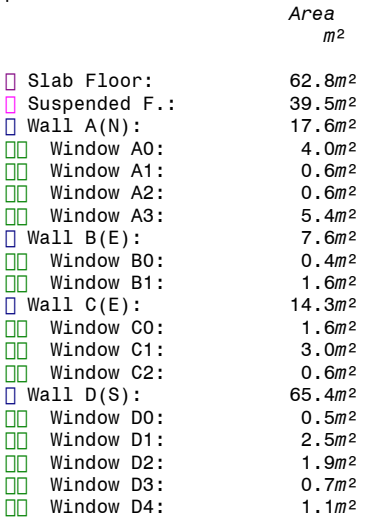

\begin{tabular}{|c|c|} 
kWh/ Loss & $\%$ \\
year & $\%$ \\
666 & $5.3 \%$ \\
466 & $3.7 \%$ \\
248 & $2.0 \%$ \\
111 & $0.9 \%$ \\
18 & $0.1 \%$ \\
18 & $0.1 \%$ \\
150 & $1.2 \%$ \\
49 & $0.4 \%$ \\
10 & $0.1 \%$ \\
45 & $0.4 \%$ \\
203 & $1.6 \%$ \\
45 & $0.4 \%$ \\
198 & $1.6 \%$ \\
15 & $0.1 \%$ \\
926 & $7.3 \%$ \\
15 & $0.1 \%$ \\
69 & $0.5 \%$ \\
53 & $0.4 \%$ \\
19 & $0.1 \%$ \\
31 & $0.2 \%$
\end{tabular}

\begin{tabular}{rr|r}
$\begin{array}{c}\text { kWh/ } \\
\text { year }\end{array}$ & $\%$ & $\begin{array}{l}\text { Net Gain } \\
\text { kWh/ } \\
\text { year }\end{array}$ \\
& & \\
565 & $14.6 \%$ & \\
90 & $2.3 \%$ & 455 \\
45 & $1.2 \%$ & 72 \\
382 & $9.8 \%$ & 27 \\
23 & $0.6 \%$ & 232 \\
99 & $2.5 \%$ & 13 \\
99 & $2.5 \%$ & 54 \\
21 & $0.5 \%$ & 54 \\
34 & $0.9 \%$ & -177 \\
8 & $0.2 \%$ & 19 \\
120 & $3.1 \%$ & -7 \\
28 & $0.7 \%$ & 51 \\
16 & $0.4 \%$ & -26 \\
53 & $1.4 \%$ & -3 \\
53 & &
\end{tabular}

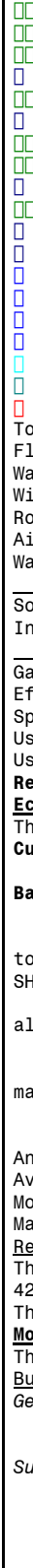

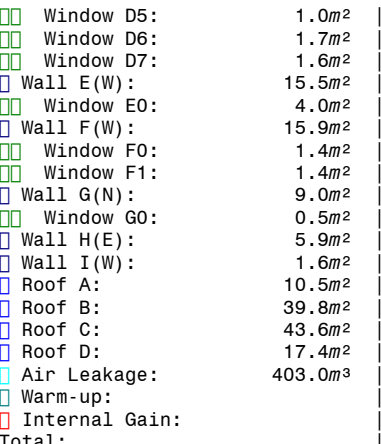

Floor Loss:
Wall Loss:
Window Los:

Window Loss:

Air Leakage:
Warm-up:

\begin{tabular}{lr} 
Warm-up: Total Load: & $\begin{array}{r}4961 \mathrm{kWh} / \mathrm{year} \\
12683 \mathrm{kWh} / \mathrm{year}\end{array}$ \\
\hline Solar Gain: & $2584 \mathrm{kWh} / \mathrm{year}$ \\
Internal Gain: & $1300 \mathrm{kWh} / \mathrm{year}$
\end{tabular}

\begin{tabular}{rr|}
26 & $0.2 \%$ \\
46 & $0.4 \%$ \\
43 & $0.3 \%$ \\
219 & $1.7 \%$ \\
111 & $0.9 \%$ \\
224 & $1.8 \%$ \\
40 & $0.3 \%$ \\
40 & $0.3 \%$ \\
58 & $0.5 \%$ \\
14 & $0.1 \%$ \\
83 & $0.7 \%$ \\
11 & $0.1 \%$ \\
208 & $1.6 \%$ \\
788 & $6.2 \%$ \\
863 & $6.8 \%$ \\
115 & $0.9 \%$ \\
1480 & $11.7 \%$ \\
4961 & $39.1 \%$ \\
2683 & $\mid$ \\
$1000.0 \%$ &
\end{tabular}

\begin{tabular}{ll|r}
23 & $0.6 \%$ & -4 \\
79 & $2.0 \%$ & 33 \\
74 & $1.9 \%$ & 31
\end{tabular}

\begin{tabular}{ll|r}
$440 \quad 11.3 \%$ & 329
\end{tabular}

\begin{tabular}{ll|l}
157 & $4.0 \%$ & 118 \\
157 & $4.0 \%$ & 118
\end{tabular}

\begin{tabular}{ll|l}
72 & $1.8 \%$ & 58
\end{tabular}

$13232100.0 \%$

$2022 \mathrm{kWh} /$ year

$1174 \mathrm{kWWh} / \mathrm{year}$
$1480 \mathrm{kWh} /$ year

Gective Thermal Mass Density (per $\mathrm{m}^{2}$ total floor area): $3.03 \mathrm{~W} / \mathrm{m}^{2}{ }^{\circ} \mathrm{C}$ Specific Heat Loss Density
Usefulness of Gains: $64 \%$

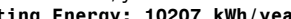

is section shows the results of the comparison between the current design and the base design.

Current Design: Magnetic Acrylic

Base Design: NZS 4218 (default)
Areas of floors, walls and roofs are the same as in the current building design.

Total window area as in the current design (including the skylights); however, one eighth of the
total window area is facing each of the 8 major compass orientations (no skylights). The R-value is 0.19 , the SHGC 0.83 (clear single glazing) and the shading is $20 \%$.

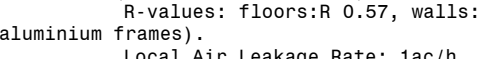

Carpeted floors, external and internal walls: lightweight timber. Ceiling and furniture thermal the current design.

The same climate and heating conditions apply as in the current design. Analysis period: 30 years

Average mortgage rate: $8 \%$
Modification cost between the base design and the current design: $\$ 0$

Marginal heating energy cost: $9 \mathrm{c} / \mathrm{kWh}$

The current design ('Magnetic Acrylic') uses $3387 \mathrm{kWh} /$ year more heating energy than the base design ('NZS 4218 (default)'), and its cost over a lifetime of 30 years is $\$ 4713$ more than the cost of the base design.

This section lists the modelling assumptions concerning the building design, climate and heating. Building Design

Total Floor Area: $165.155 \mathrm{~m} 2$
Number of Occupants: 2

Suspended Floor:

Floor Area: $39.545 \mathrm{~m}^{2}$
Perimeter Length: 24.42

Perimeter Height: $0.6 \mathrm{~m}$ 
Subfloor Exposure: Continuous Perimeter Wall (sheltered)

Subfloor R-value: $0.27 \mathrm{~m}^{2}{ }^{\circ} \mathrm{C} / \mathrm{M}$

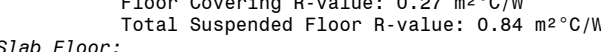

Floor Area: $62.805 \mathrm{~m}^{2}$

Perimeter Length: $39.32 \mathrm{~m}$

External Wall Thickness: 0.1

Soil Conductivity: $1.2 \mathrm{~W} / \mathrm{m}^{\circ} \mathrm{C}$

dge Insulation Width: $0 \mathrm{~m}$

Slab and Ground R-value: $0.9335064 \mathrm{~m}^{2}{ }^{\circ} \mathrm{C} / \mathrm{W}$

Total slab Floor R-Valu: $0.93 \mathrm{~m}^{\circ} \mathrm{C} / \mathrm{M}$

Walls:

Tither Framed Wall, Bevelbacked Weatherboards, Insulation Within Framing - 100 mm Framing Blown Insulant Insulation R-value: $0 \mathrm{~m}^{\circ}{ }^{\circ} \mathrm{C} / \mathrm{W}$
Construction R-value: $0.7 \mathrm{~m}^{\circ} \mathrm{C} / \mathrm{W}$

\begin{tabular}{|c|c|c|c|c|c|}
\hline Name & orientation & Length & Height & $\begin{array}{l}\text { Net } \\
\text { Area }\end{array}$ & $\begin{array}{l}\text { Window } \\
\text { Area }\end{array}$ \\
\hline & & & & $m^{2}$ & $m^{2}$ \\
\hline $\begin{array}{l}\text { Wall } \mathrm{A} \\
\text { Wall }\end{array}$ & $\begin{array}{l}\text { Nortn } \\
\text { East }\end{array}$ & $\begin{array}{l}11.8 \\
4\end{array}$ & $\begin{array}{l}2.4 \\
4.88\end{array}$ & $\begin{array}{l}17.6 \\
14.3\end{array}$ & $\begin{array}{l}10.15 \\
5.1725\end{array}$ \\
\hline Wall D & South & $\begin{array}{l}4 \\
15.66\end{array}$ & $\begin{array}{l}4.88 \\
4.88\end{array}$ & 65.4 & 10.975 \\
\hline Wall E & West & & 4.88 & 15.5 & 4.03 \\
\hline Wall $F$ & West & 7.81 & 2.4 & 15.9 & 2.88 \\
\hline
\end{tabular}
Imber Framed Wall, Bevelbacked Weatherboards, Insulation
Dwangs, Studs $400 \mathrm{~mm}$ ctr., Blanket and Segment Insulants Insulation R-value: $1.3 \mathrm{~m}^{\circ} \mathrm{C} / \mathrm{W}$

$\begin{array}{ccllll}\text { Name } & \begin{array}{c}\text { Lrientation } \\ \text { Nalion }\end{array} & \text { Length } & \text { Height } & \begin{array}{l}\text { Net } \\ \text { Area }\end{array} & \begin{array}{l}\text { Window } \\ \text { Area }\end{array} \\ \text { Wall B } & \text { East } & m & m & \begin{array}{l}\mathrm{m}^{2} \\ \mathrm{~m}^{2}\end{array} \\ \text { Wall G } & \text { North } & 4 & 2.4 & 7.6 & 1.998 \\ \text { Wall I } & \text { West } & 3.9 & 2.44 & 9.0 & 0.5100001 \\ & & 0.67 & 2.44 & 1.6 & 0\end{array}$

Type

Pitched Timber Framed Roof, Metal Clad, Flat Ceiling, Ceiling Dwangs, 94 mm Joists Joist $94 \times 47480 \mathrm{ctr}$.' Dwangs $69 \times 47900 \mathrm{ctr}$, Blown Insulant

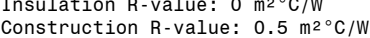

$$
\begin{aligned}
& \text { Name Length Width Net Window } \\
& \begin{array}{lllll} 
& m & m & \text { Area } & \begin{array}{l}
\text { Area } \\
m^{2}
\end{array} \\
m^{2} \\
\text { Roof A } & 3.9 & 2.7 & 10.5 & 0 \\
\text { Roof B } & 6.12 & 6.5 & 39.8 & 0 \\
\text { Roof C } & 5.45 & 8 & 43.6 & 0
\end{array}
\end{aligned}
$$

Type 2: Pitched Timber Framed Roof, Metal Clad, Flat Ceiling, Ceiling Dwangs, $94 \mathrm{~mm}$ Joists Joist $94 \times 47$ 480ctr., Dwangs $69 \times 47900 \mathrm{ctr}$, Blanket and Segment Insulan Insulation R-value: $1.4 \mathrm{~m}^{\circ}{ }^{\circ} \mathrm{C} / \mathrm{W}$
Construction R-value: $1.5 \mathrm{~m}^{\circ} \mathrm{C} / \mathrm{W}$

$$
\begin{aligned}
& \begin{array}{c}
\text { Construction R-value: } 1.5 \mathrm{~m}^{2} \mathrm{C} / \mathrm{W} \\
\text { Name Length }
\end{array} \\
& \begin{array}{llll}
\text { Length } & \text { Width } & \text { Net } & \text { Window } \\
m & m & \text { Area } & \begin{array}{l}
\text { Area } \\
m^{2}
\end{array} \\
3.9 & 4.47 & 17.4 & 0
\end{array} \\
& \text { Windows and Skylights: } \\
& \text { Type 1: } \\
& \text { Frame: Alumium frame (no thermal break) } \\
& \text { Solar Heat Gain Coefficient: } 61 \% \\
& \begin{array}{l}
\text { Heat Gain Coefficient: } 61 \% \\
\text { Number Wally Orientation }
\end{array} \\
& \text { Width } \\
& \text { Height } \\
& \begin{array}{l}
\text { Net } \\
\text { Area }
\end{array} \\
& \text { Shading }
\end{aligned}
$$

\begin{tabular}{|c|c|}
\hline & \\
\hline vind. 2 & Wall $A$ \\
\hline & Wall A \\
\hline $\begin{array}{lll}\text { Wind. } & \end{array}$ & \\
\hline $\begin{array}{l}\text { Wint. } \\
\text { Wind. }\end{array}$ & $\begin{array}{l}\text { Wall B } \\
\text { Wall } \\
\text { a }\end{array}$ \\
\hline Wind. 1 & Wall c \\
\hline Wind. 3 & Wall c \\
\hline Wind. 1 & Wall D \\
\hline $\begin{array}{l}\text { Wind. } \\
\text { Wind. }\end{array}$ & \\
\hline $\begin{array}{l}\text { Wind. } \\
\text { Wind. } 4\end{array}$ & $\begin{array}{l}\text { Wall } D \\
\text { Wall } D\end{array}$ \\
\hline Wind. 5 & Wall D \\
\hline Wind. 6 & Wall \\
\hline $\begin{array}{l}\text { Wind. } 7 \\
\text { Wind. } 8\end{array}$ & Wal \\
\hline $\begin{array}{l}\text { Winda. } \\
\text { Wind. }\end{array}$ & $\begin{array}{l}\text { Wall D } \\
\text { Wall E }\end{array}$ \\
\hline Wind. & Wall \\
\hline Wind & Wal1 \\
\hline & \\
\hline
\end{tabular}

Type 2:

$\begin{array}{llll}m & m & m^{2} & \% \\ 3.1 & 1.3 & 4.03 & 0 \\ 0.4 & 1.6 & 0.64 & 0 \\ 0.4 & 1.6 & 0.64 & 50 \\ 3.4 & 1.6 & 5.44 & 50 \\ 0.27 & 1.4 & 0.378 & 0 \\ 1.8 & 0.9 & 1.62 & 0 \\ 1.8 & 0.9 & 1.62 & 0 \\ 0.65 & 0.85 & 0.5525 & 0 \\ 0.6 & 0.9 & 0.54 & 70 \\ 2.8 & 0.9 & 2.52 & 0 \\ 2.15 & 0.9 & 1.935 & 70 \\ 0.75 & 0.9 & 0.675 & 50 \\ 1.4 & 0.8 & 1.12 & 0 \\ 0.6 & 1.6 & 0.96 & 50 \\ 1.85 & 0.9 & 1.665 & 0 \\ 1.2 & 1.3 & 1.56 & 0 \\ 3.1 & 1.3 & 4.03 & 0 \\ 0.9 & 1.6 & 1.44 & 0 \\ 0.9 & 1.6 & 1.44 & 0 \\ 1.7 & 0.3 & 0.5100001 & 0 \\ & & & \end{array}$

(no thermal break)

Avalue: $0.15 \mathrm{~m}^{2}{ }^{\circ} \mathrm{C} / \mathrm{W}$ (no thental bre

Heat Gain Coefficient: $70 \%$
Number
Walll
Roof

Wind. 2 Wall $\mathrm{C}$ East

${ }_{1.5}^{m}$

90

o. of Open Fires without Flue Restrictors:

. of Open Fires with Flue Restrictors:

The house has no passive vents.

endent Air Leakage Rate is $0.85 \mathrm{ac} / \mathrm{h}$.

ite Exposure: medium exposed

ocal Air Leakage Rate: $1.12 \mathrm{ac} / \mathrm{h}$

Thermal Mass:

Walls: $153.0 \mathrm{~m}^{2}$, Any internally lined construction $\left(9 \mathrm{Wh} / \mathrm{m}^{\circ}{ }^{\circ} \mathrm{C}\right.$

Internal Walls: $196.0 \mathrm{~m}^{2}$, Timber or steel frame $\left(\mathrm{Wh} / \mathrm{m}^{\circ}{ }^{\circ} \mathrm{C}\right)$

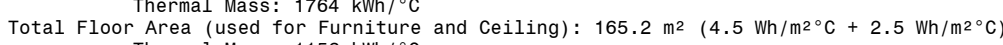

Wellington in the Lower North Island Heating Season: May to September

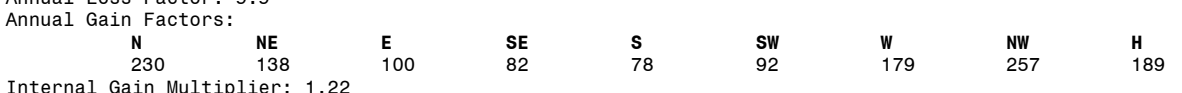
Internal Gain Multiplier: 1.22

H1 Climate Location: warm, BPI Target: 0.13

Heating

ting Schedule : Morning and Evening Heating (7:00-9:00 and 17:00-23:00) 


\section{C.3 House 3}

\section{ALF Calculation Report}

\section{Project Description}

Current Design: Magnetic Acrylic
Croject

\section{Designed by: Nick Smich}

In order to comply with the Energy Efficiency Clause H1 (2000) of the New Zealand Building Code a building has to have a BPY of less than $0.13 \mathrm{kWh} / \mathrm{m} / \mathrm{Degree}$ Days if It is in a warm location and less than 0.12 (May to August) degree days of less than 920. Cool locations are locations with 920 degree days or more. The currenly selected location (Wellington) is a warm location. The target BPI is therefore 0.13 . Alternatively, the building complies if it is built to NZS 4218:1996. This standard has three different ALF checks the designed building for a BPI and for the NZS 4218:1996 Schedule and Calculation Methods. The currently selected NZS 4218 target R-values are for a "non-solid construction". The current design rates are:

$$
\begin{aligned}
& \text { BPI }=0.155 \\
& \text { NZS } 4218 \text { (Schedule) } \\
& \text { NZS } 4218 \text { (Calculation) }
\end{aligned}
$$$$
\text { H1 fail H1 fai }
$$

The current building design does
Calculation target in NZS 4218:1996. Details of H1 compliance
NZS 4218 (Schedule)
Maximum: 0.13
Achieved: 0.155
$\begin{array}{lll}\text { Floor: } & 1.3 \\ \text { Wall: } & 1.5 \\ \text { Poof: } & 1.9\end{array}$
inimum Minimum achieved
0.74
0.70
0.50
(excl. carpet)

Maximum acceptable

NZS 4218 (Calculation)

$546 \mathrm{~W} /{ }^{\circ} \mathrm{C}$

For the individ
of those in the Schedule:
$\begin{array}{lll}\text { Floor: } & 0.8 \\ \text { Wall: } & 0.9\end{array}$
Aimum Average achieved
Wall: $\quad 0.9 \quad 0.70$
(excl. carpet)

$546 \mathrm{~W} /{ }^{\circ} \mathrm{C}$
$788 \mathrm{~W} /{ }^{\circ} \mathrm{C}$

$\begin{array}{ll}\text { Copyright of the standard is property of } & 0.50 \\ \text { Standards New Zealand and is protected as described in the NZS }\end{array}$ Energy
This section gives you an overview of all the heat flows in and out of the designed building. It allows you
to evaluate the importance of the thermal performance of individual building components - for example, of
particular windows.

\begin{tabular}{|c|}
\hline 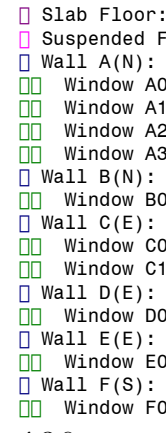 \\
\hline
\end{tabular}

\begin{tabular}{r|} 
Area \\
$m^{2}$ \\
$74.7 \mathrm{~m}^{2}$ \\
$66.9 \mathrm{~m}^{2}$ \\
$9.9 \mathrm{~m}^{2}$ \\
$4.2 \mathrm{~m}^{2}$ \\
$1.4 \mathrm{~m}^{2}$ \\
$1.4 \mathrm{~m}^{2}$ \\
$1.1 \mathrm{~m}^{2}$ \\
$29.2 \mathrm{~m}^{2}$ \\
$3.8 \mathrm{~m}^{2}$ \\
$16.4 \mathrm{~m}^{2}$ \\
$1.1 \mathrm{~m}^{2}$ \\
$1.1 \mathrm{~m}^{2}$ \\
$16.6 \mathrm{~m}^{2}$ \\
$1.0 \mathrm{~m}^{2}$ \\
$12.1 \mathrm{~m}^{2}$ \\
$1.2 \mathrm{~m}^{2}$ \\
$17.0 \mathrm{~m}^{2}$ \\
$2.5 \mathrm{~m}^{2}$
\end{tabular}

$\begin{array}{rc}\text { kWh/ Loss } \\ \text { year } & \% \\ 901 & 5.9 \% \\ 658 & 4.3 \% \\ 140 & 0.9 \% \\ 116 & 0.8 \% \\ 39 & 0.3 \% \\ 39 & 0.3 \% \\ 30 & 0.2 \% \\ 413 & 2.7 \% \\ 106 & 0.7 \% \\ 232 & 1.5 \% \\ 30 & 0.2 \% \\ 30 & 0.2 \% \\ 234 & 1.5 \% \\ 26 & 0.2 \% \\ 171 & 1.1 \% \\ 33 & 0.2 \% \\ 241 & 1.6 \% \\ 69 & 0.5 \%\end{array}$

\begin{tabular}{|c|c|c|}
\hline $\begin{array}{l}\text { Whi }{ }^{G} \\
\text { year }\end{array}$ & $\%$ & $\begin{array}{l}\text { Net Gain } \\
\text { kWh/ } \\
\text { year }\end{array}$ \\
\hline 295 & $6.5 \%$ & \\
\hline 137 & $3.0 \%$ & 99 \\
\hline 137 & $3.0 \%$ & \\
\hline 108 & $2.4 \%$ & 78 \\
\hline 377 & $8.3 \%$ & 272 \\
\hline $\begin{array}{l}66 \\
66\end{array}$ & $1.4 \%$ & 36 \\
\hline & $1.4 \%$ & \\
\hline 41 & $0.9 \%$ & 15 \\
\hline 15 & $0.3 \%$ & -18 \\
\hline 120 & $2.6 \%$ & 51 \\
\hline
\end{tabular}

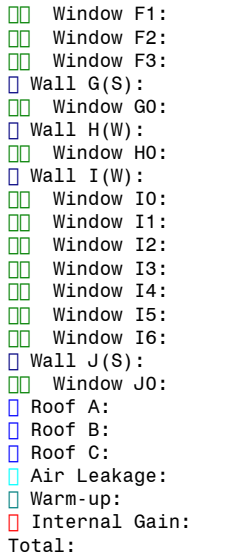
Floor Loss:

Wall Loss:
Window Loss:

Window Loss:
Roof Loss:

Warm-up:

$5699 \mathrm{kwh} / \mathrm{yer}$

Solar Gain:
Internal Gain:

$\begin{array}{cll}\text { Internal Gain: } & 1623 \mathrm{kWh} / \text { year } & (5 \text { occupants }) \\ \text { Total Gain: } & 4564 \mathrm{kWh} / \text { year }\end{array}$

\begin{tabular}{|c|c|c|c|c|c|}
\hline & & & 20 & & \\
\hline $1.2 \mathrm{~m}^{2}$ & 33 & $0.2 \%$ & 40 & $0.9 \%$ & \\
\hline $\begin{array}{l}2.5 \mathrm{~m}^{2} \\
5.7 m^{2}\end{array}$ & 69 & $0.5 \%$ & 120 & $2.6 \%$ & 51 \\
\hline & 317 & $\begin{array}{l}2.5 \% \\
2.1 \%\end{array}$ & 157 & $3.4 \%$ & -160 \\
\hline $11.2 \mathrm{~m}^{2}$ & 158 & $1.0 \%$ & & & \\
\hline $\begin{array}{r}2.1 \mathrm{~m}^{2} \\
\mathrm{~m}^{2}\end{array}$ & $\begin{array}{r}57 \\
577\end{array}$ & $0.4 \%$ & 23 & $0.5 \%$ & -34 \\
\hline $\begin{array}{r}40.8 m^{2} \\
0 . m^{2}\end{array}$ & 577 & $\begin{array}{l}3.8 \% \\
0.1 \%\end{array}$ & & & \\
\hline $0.8 m^{2}$ & $\begin{array}{l}17 \\
22\end{array}$ & $0.1 \%$ & 61 & $\begin{array}{l}0.1 \% \\
1.3 \%\end{array}$ & $\begin{array}{r}-13 \\
39\end{array}$ \\
\hline $1.4 \mathrm{~m}^{2}$ & 39 & $0.3 \%$ & 107 & $2.3 \%$ & \\
\hline $0.5 \mathrm{~m}^{2}$ & 15 & $0.1 \%$ & 3 & $0.1 \%$ & -12 \\
\hline $5.3 \mathrm{~m}^{2}$ & 146 & $1.0 \%$ & 407 & $8.9 \%$ & 260 \\
\hline $4.9 \mathrm{~m}^{2}$ & 135 & $0.9 \%$ & 375 & $8.2 \%$ & 240 \\
\hline $\begin{array}{l}1.8 \mathrm{~m}^{2} \\
8.2 \mathrm{~m}^{2}\end{array}$ & 50 & $0.3 \%$ & 197 & $4.3 \%$ & 147 \\
\hline $\begin{array}{l}8.2 m^{2} \\
1.4 m^{2}\end{array}$ & $\begin{array}{c}115 \\
39\end{array}$ & $\begin{array}{l}0.8 \% \\
0.3 \%\end{array}$ & 67 & $15 \%$ & 28 \\
\hline $36.5 \mathrm{~m}^{2}$ & 723 & $4.8 \%$ & & & \\
\hline $17.8 \mathrm{~m}^{2}$ & 352 & $2.3 \%$ & & & \\
\hline $67.4 \mathrm{~m}^{2}$ & 1335 & $8.8 \%$ & & & \\
\hline $464.9 \mathrm{~m}^{3}$ & $\begin{array}{l}1707 \\
5699\end{array}$ & $\begin{array}{l}11.2 \% \\
37.5 \%\end{array}$ & & & \\
\hline & & & 1623 & $35.6 \%$ & \\
\hline
\end{tabular}

$15207 \mathrm{kWh} / \mathrm{year}$

$362 \mathrm{kWh} / \mathrm{year}$
$\mathrm{kWh} /$ year

$2410 \mathrm{kWh} / \mathrm{year}$
$1707 \mathrm{kWh} / \mathrm{year}$

$1707 \mathrm{kWh} /$ year

Effective theral Mass Density (per $\mathrm{m}^{2}$ total floor area): $\quad 3.03 \mathrm{~W} / \mathrm{m}^{2}{ }^{\circ} \mathrm{C}$

Specific Heat Loss Density
Usefulness of Gains: 61\%

Required Heating Energy: $12410 \mathrm{kWh} / \mathrm{year}$

Economic Analysis

Base Design: NZS 4218 (default)
Areas of floors, walls and roofs are the same as in the current building design.

Areas of floors, walls and roofurent design (including the skylights); however, one eighth of the total window area is facing each of the 8 major compass orientations (no skylights). The R-values: floors:R 0.74 , walls: 0.70 , roofs: $R 0.50$ and windows:R 0.2 (single glazed windows with aluminium frames)
Local Air Leakage Rate: 1 ac $/ \mathrm{h}$

Aelling and furniture thermal mass as in the current design.

The same climate and heating conditions apply as in the current design.

Analysis period: 30 years

design and the current design: $\$ 0$

Marginal heating energy cost: $9 \mathrm{c} / \mathrm{kW}$

The current design ('Magnetic Acrylic') uses $4506 \mathrm{kwh} /$ year more heating energy than the base design ('NZS 4218 (default)'), and its cost over a lifetime of 30 years is $\$ 6270$ more than the cost of the base design. This includes the cost of the modification and the increased energy costs.

Modelling Assumptions Building Design

General: Total Floor Area: $189.7408 \mathrm{~m}^{2}$ 
Number of Occupants: 5
Suspended Floor:

Floor Area: $66.9163 \mathrm{~m}^{2}$

Perimeter Height: $0.6 \mathrm{~m}$

Perimeter Area: $15.312 \mathrm{~m} 2$

Subffoor Exposure: Continuous Perimeter Wall (sheltered)

Floor Insulation: Uninsulated timber floor

Floor Insulation R-value: $0.3 \mathrm{~m}^{\circ}{ }^{\circ} \mathrm{C} / \mathrm{W}$

Floor Covering R-value: $0.27 \mathrm{~m}^{\circ}{ }^{\circ} \mathrm{C} / \mathrm{W}$

Slab Floor:

Floor Area: $74.6532 \mathrm{~m}^{2}$

Perimeter Length: $55.19 \mathrm{~m}$

External Wall Thickness: 0.1

Under Floor R-value: $0 \mathrm{~m}^{\circ}{ }^{\circ} \mathrm{C} / \mathrm{W}$

Edge Insulation Width: $0 \mathrm{~m}$

lab and Ground R-value: $0.8204816 \mathrm{~m}^{\circ}{ }^{\circ} \mathrm{C} / \mathrm{W}$

Toor Covering R-value: $0 \mathrm{~m}^{2}{ }^{\circ} \mathrm{C} / \mathrm{W}$

Walls:
Type 1:

Timber Framed Wall, Bevelbacked Weatherboards, Insulation Within Framing - $100 \mathrm{~mm}$ Framing 2 Dwangs, Studs $400 \mathrm{~mm}$ ctr., Adhesive Blown Insulant

$\begin{array}{llllll}\begin{array}{c}\text { Lame } \\ \text { Name }\end{array} & \begin{array}{c}\text { Length } \\ \text { Orientation }\end{array} & \text { Height } & \begin{array}{l}\text { Net } \\ \text { Area }\end{array} & \begin{array}{l}\text { Window } \\ \text { Area }\end{array} \\ \text { Wall A } & \text { North } & m & m & \begin{array}{l}\mathrm{m}^{2} \\ \mathrm{~m}^{2}\end{array} \\ \text { Wall B } & \text { North } & 7.34 & 2.45 & 9.9 & 8.1 \\ \text { Wall C } & \text { East } & 6.3 & 5.25 & 29.2 & 3.84 \\ \text { Wall D } & \text { East } & 7.58 & 2.45 & 16.4 & 2.16 \\ \text { Wall E } & \text { East } & 3.65 & 4.8 & 16.6 & 0.96 \\ \text { Wall F } & \text { South } & 4.9 & 2.71 & 12.1 & 1.2 \\ \text { Wall G } & \text { South } & 9.74 & 2.45 & 17.0 & 6.84 \\ \text { Wall H } & \text { West } & 3.86 & 2.71 & 5.7 & 4.8 \\ \text { Wall I } & \text { West } & 4.9 & 2.71 & 11.2 & 2.08 \\ \text { Wall J } & \text { South } & 10.7 & 5.25 & 40.8 & 15.36 \\ & & 3.9 & 2.45 & 8.2 & 1.4\end{array}$

Roofs:

Pitched Timber Framed Roof, Metal Clad, Flat Ceiling, Ceiling Dwangs, $94 \mathrm{~mm}$ Joists Joist 94×47 480ctr. Dwangs $69 \times 47$ 900ctr, Blown Insulant Insulation R-value: $0 \mathrm{~m}^{2}{ }^{\circ} \mathrm{C} / \mathrm{W}$
Construction R-value: $0.5 \mathrm{~m}^{\circ} \mathrm{C} / \mathrm{W}$

\begin{tabular}{|c|c|c|c|c|}
\hline \multicolumn{5}{|l|}{ Name } \\
\hline & & & $\begin{array}{l}\text { Net } \\
\text { Area }\end{array}$ & $\begin{array}{l}\text { Windo } \\
\text { Area }\end{array}$ \\
\hline Roof A & 4.82 & ${ }_{7.58}^{m}$ & $\begin{array}{l}m^{2} \\
36.5\end{array}$ & $\begin{array}{l}m^{2} \\
0\end{array}$ \\
\hline Roof B & 2.52 & 7.05 & 17.8 & \\
\hline Roof C & 6.3 & 10.7 & 67.4 & 0 \\
\hline
\end{tabular}

Type

Glass: Magicse

Frame: Alumium frame (no thermal break)

R-value: $0.36 \mathrm{~m}^{\circ}{ }^{\circ} \mathrm{C} / \mathrm{W}$

\begin{tabular}{|c|c|c|c|c|c|c|}
\hline Number & $\begin{array}{l}\text { WallI } \\
\text { Roof }\end{array}$ & Orientation & Width & Height & $\begin{array}{l}\text { Net } \\
\text { Area }\end{array}$ & Shading \\
\hline & Wall A & North & $\begin{array}{l}m \\
3\end{array}$ & ${ }_{14}^{m}$ & $m^{2}$ & $\frac{\%}{50}$ \\
\hline Wind. 2 & Wall A & North & & & & 30 \\
\hline Wind. 3 & Wall A & North & 0.7 & 2 & 1.4 & 30 \\
\hline Wind. 4 & Wall A & North & 2.2 & 0.5 & 1.1 & 30 \\
\hline Wind. 1 & Wall B & North & 3.2 & 1.2 & 3.84 & 30 \\
\hline Wind. 1 & Wall c & East & 1.8 & 0.6 & 1.08 & 0 \\
\hline Wind. 2 & Wall c & East & 1.8 & 0.6 & 1.08 & 0 \\
\hline
\end{tabular}

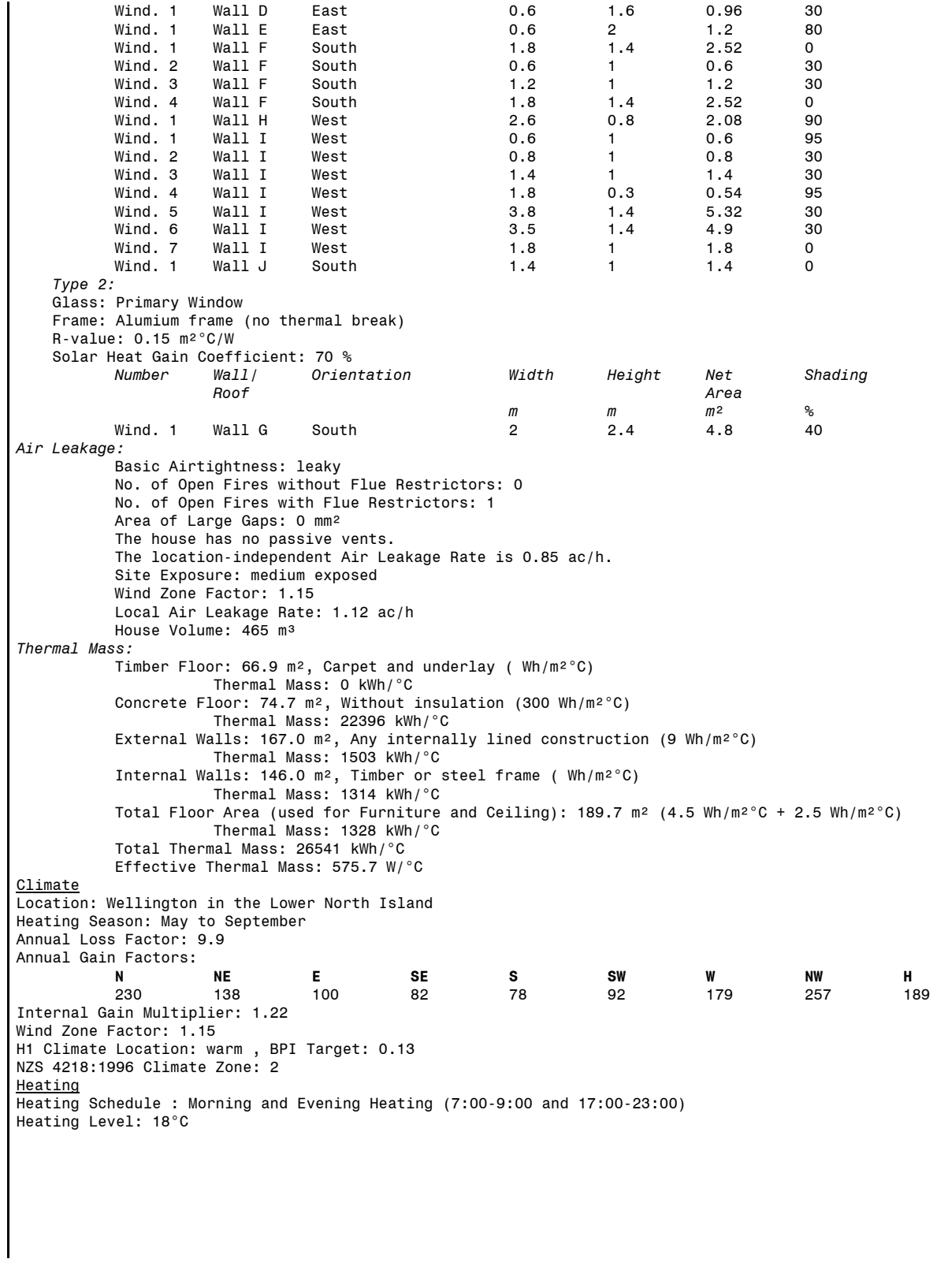




\section{C.4 House 4}

\section{ALF Calculation Report}

Current Design: Magnetic Acrylic

Designed by: Nick Smith

NZ Building code Compliance

Energy Efficiency Clause H1 (2000) of the New Zealand Building Code a $\mathrm{kWh} / \mathrm{m}^{2} /$ Degree Days if it is in a warm location and less average number of winter (May to August) degree days of less than 920. Cool locations are locations with 920 degree days or more. The currenly selected location (Wellington) is a warm location. The target BPI is therefore 0.13 .

different Method.

Methods.

Che

The current design rates are:
$\mathrm{BPI}=0.163$
Schedule)
H1 fail
NZS 4218 (Calculation)

The current building design does neither meet the BPI target in Clause H1 of the NZBC nor the Schedule or Calculation target in NZS 4218:1996.

Details of H1 Compliance

Achieved: 0.163

NZS 4218 (Schedule) Minimum Minimum achieved
1.3
1.5 $\begin{array}{llr}\text { Floor: } & 1.3 & 1.17 \\ \text { Wall: } & 1.5 & 0.70 \\ \text { Roof: } & 1.9 & 0.40\end{array}$ (excl. carpet)

NZS 4218 (Calculation) Maximum acceptable
Achieved heat loss:

$511 \mathrm{~W} /{ }^{\circ} \mathrm{C}$
For the indivieved heat loss: than $60 \%$ of those in the Schedule:
$\begin{array}{ll}\text { Floor: } & 0.8 \\ \text { Wall: } & 0.9\end{array}$
Average achieve
Roof: 1.1
1.17
(excl. carpet)

Copyright of the standard is property of Standards New Zealand and is protected as described in the NZS 4218:1996 document.

Energy

the heat flows in and out of the designed building. for example, of particular

\begin{tabular}{|c|c|c|c|c|c|c|}
\hline & Area & & & & & Net Gain \\
\hline & & kWh / & $\%$ & kWh / & $\%$ & kWh/ \\
\hline Slab Floor: & $113.3 \mathrm{~m}^{2}$ & 781 & $8.4 \%$ & & & \\
\hline Wall A(NE): & $21.6 m^{2}$ & 305 & $3.3 \%$ & & & \\
\hline Window A0: & $0.8 \mathrm{~m}^{2}$ & 21 & $0.2 \%$ & 64 & $1.8 \%$ & 43 \\
\hline Window $\mathrm{A} 1$ : & $0.6 m^{2}$ & 17 & $0.2 \%$ & 51 & $1.4 \%$ & 34 \\
\hline Window A2: & $1.5 \mathrm{~m}^{2}$ & 41 & $0.4 \%$ & 127 & $3.5 \%$ & 85 \\
\hline Window A3: & $1.5 \mathrm{~m}^{2}$ & 41 & $0.4 \%$ & 127 & $3.5 \%$ & 85 \\
\hline Window A4: & $1.6 \mathrm{~m}^{2}$ & 44 & $0.5 \%$ & 94 & $2.6 \%$ & 50 \\
\hline Window A5: & $1.6 \mathrm{~m}^{2}$ & 44 & $0.5 \%$ & 81 & $2.3 \%$ & 37 \\
\hline Window A6: & $1.5 \mathrm{~m}^{2}$ & 41 & $0.4 \%$ & 127 & $3.5 \%$ & 85 \\
\hline
\end{tabular}

\begin{tabular}{|c|}
\hline 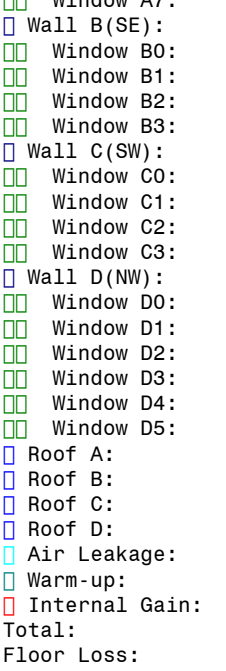 \\
\hline
\end{tabular}

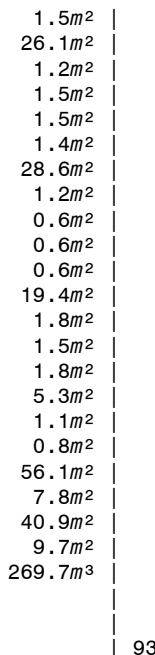

Wall Loss:

Window Loss:

Roof Loss:
Air Leakage:

Warm-up:

$3401 \mathrm{kWh} / \mathrm{y}$

Solar Gain: $\quad 9333 \mathrm{kWh} /$ year

$\begin{array}{ccc}\text { Internal Gain: } & 964 \mathrm{kWh} / \text { year } & (2 \text { occupants }) \\ \text { Total Gain: } & 3587 \mathrm{kWh} / \mathrm{vear} & \end{array}$

Effective Thermal Mess Density (per $\mathrm{m}^{2}$ total floor area): $5.3 .03 \mathrm{~W} / \mathrm{m}^{2}{ }^{\circ} \mathrm{C}$

Effective Thermal Mass Density (per $\mathrm{m}^{2}$ total floor area):
Specific Heat Loss Density (per $\mathrm{m}^{2}$ total floor area):
$5.3 \mathrm{~W} / \mathrm{m}^{2}{ }^{\circ} \mathrm{C} / \mathrm{C}^{2}$

Usefulness of Gains: $59 \%$

Useful Gains: $2109 \mathrm{kWh} / \mathrm{year}$
Required Heating Energy: $7224 \mathrm{kWh} / \mathrm{year}$

Economic Analysis

the comparison between the current design and the base design. gn: Magnetic Acrylic

\section{Base Design: NZS 4218 (default)}

Areas of floors, walls and roofs are the same as in the current building design.

Total window area as in the current design (including the skylights); however, one eight value is 0.19 , the SHGC 0.83 (clear single glazing) and the shading is 20\%. R-values: floors:
windows with aluminium frames). Local Air Leakage Rate: $\mathrm{Tac} / \mathrm{h}$

thermal mass as in the current design.

Internal gains as for the current design.
The same climate and heating conditions apply as in the current design.

Analysis period: 30 years

Average mortgage rate: $8 \%$

Modification cost between the base des
Marginal heating energy cost: $9 \mathrm{c} / \mathrm{kWh}$

Marginal
Result: 
The current design ('Magnetic Acrylic') uses $1965 \mathrm{kWh} /$ year more heating energy than the base design ('NZS 4218 (default)'), and its cost over a lifetime of 30 years is $\$ 2735$ more than the base design. This includes the cost of the modification and the increased energy costs.

\section{Building Design} Total Floor Area: $113.3 \mathrm{~m}^{2}$
Number of Occupants: 2

Slab Floo :

Floor Area: $113.3 \mathrm{~m}^{2}$

erimeter Length: $53.4 \mathrm{~m}$

External Wall Thickness: $0.1 \mathrm{~m}$

Under Floor R-value: $0 \mathrm{~m}^{2}{ }^{\circ} \mathrm{C} / \mathrm{Wl}$

Edge Insulation Width: $0 \mathrm{~m}$

lab and Ground R-value: $1.16703 \mathrm{~m}^{\circ}{ }^{\circ} \mathrm{C} / \mathrm{W}$

Toor Covering R-value: $0.27 \mathrm{~m}^{\circ} \mathrm{C} / \mathrm{W}^{\circ} \mathrm{C}$

Walls:

1:

Timber Framed Wall, Bevelbacked Weatherboards, Insulation Within Framing - $100 \mathrm{~mm}$ Framing 2 Dwangs, Studs $400 \mathrm{~mm} \mathrm{ctr}$., Blanket and Segment Insulants

$\begin{array}{ccllll}\begin{array}{c}\text { Length } \\ \text { Name }\end{array} & \begin{array}{c}\text { Height } \\ \text { Orientation }\end{array} & \begin{array}{l}\text { Net } \\ \text { Area }\end{array} & \begin{array}{l}\text { Window } \\ \text { Area }\end{array} \\ \text { Wall A } & \text { NorthEast } & m & m & m^{2} & m^{2} \\ \text { Wall B } & \text { SouthEast } & 13.5 & 2.38 & 21.6 & 10.5792 \\ \text { Wall C } & \text { SouthWest } & 13.3 & 2.38 & 26.1 & 5.5656 \\ \text { Wall D } & \text { NorthWest } & 13.3 & 2.38 & 28.6 & 3.058 \\ & & 13.3 & 2.38 & 19.4 & 12.2748\end{array}$

Roofs:

Pitched Timber Roof, Concrete or Clay Tiles, Flat Ceiling, Ceiling Battens Truss $94 \times 47$ 900ctr., Batten $35 \times 69$ <600ctr., Blanket and segment Insulants Insulation $\mathrm{R}$ -

\begin{tabular}{|c|c|c|c|c|}
\hline Name & Length & Width & $\begin{array}{l}\text { Net } \\
\text { Area }\end{array}$ & $\begin{array}{l}\text { Window } \\
\text { Area }\end{array}$ \\
\hline & & & $m^{2}$ & $\begin{array}{l}m^{2} \\
0\end{array}$ \\
\hline & 6 & 1.3 & 7.8 & 0 \\
\hline $\begin{array}{l}\text { Roof D } \\
\text { Roof D }\end{array}$ & $\begin{array}{l}\text { b } \\
2.7\end{array}$ & 3.6 & 9.7 & 0 \\
\hline
\end{tabular}

Type 2: Truss 94x47 900ctr., Batten $35 \times 69<600 \mathrm{ctr}$., Blanket and Segment Insulants Insulation R-value: $1.3 \mathrm{~m}^{\circ}{ }^{\circ} \mathrm{C} / \mathrm{W}$

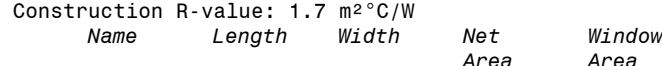

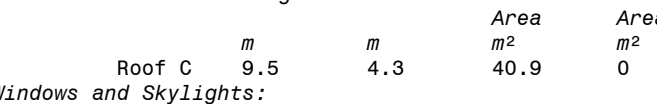

Windows and Skylights:

Type 1:

Glass: Magicseal

Frame: Alumium frame (no thermal break)

Solar Heat Gain Coefficient: $61 \%$

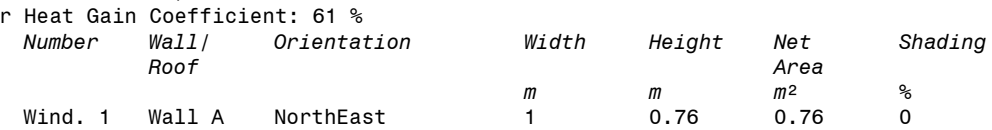

$\begin{array}{lllllll}\text { Wind. 2 } & \text { Wall A } & \text { NorthEast } & 0.3 & 2 & 0.6 & 0 \\ \text { Wind. 3 } & \text { Wall A } & \text { NorthEast } & 1.98 & 0.76 & 1.5048 & 0 \\ \text { Wind. 4 } & \text { Wall A } & \text { NorthEast } & 1.98 & 0.76 & 1.5048 & 0 \\ \text { Wind. 5 } & \text { Wall A } & \text { NorthEast } & 2 & 0.8 & 1.6 & 30 \\ \text { Wind. 6 } & \text { Wall A } & \text { NorthEast } & 2 & 0.8 & 1.6 & 40 \\ \text { Wind. 7 } & \text { Wall A } & \text { NorthEast } & 1.98 & 0.76 & 1.5048 & 0 \\ \text { Wind. 8 } & \text { Wall A } & \text { NorthEast } & 1.98 & 0.76 & 1.5048 & 0 \\ \text { Wind. 1 } & \text { Wall B } & \text { SouthEast } & 1.3 & 0.9 & 1.17 & 0 \\ \text { Wind. 2 } & \text { Wall B } & \text { SouthEast } & 1.98 & 0.76 & 1.5048 & 0 \\ \text { Wind. 3 } & \text { Wall B } & \text { SouthEast } & 1.98 & 0.76 & 1.5048 & 0 \\ \text { Wind. 4 } & \text { Wall B } & \text { SouthEast } & 1.98 & 0.7 & 1.386 & 0 \\ \text { Wind. 1 } & \text { Wall C } & \text { SouthWest } & 1.3 & 0.9 & 1.17 & 40 \\ \text { Wind. 2 } & \text { Wall C } & \text { SouthWest } & 0.8 & 0.8 & 0.64 & 30 \\ \text { Wind. 3 } & \text { Wall C } & \text { SouthWest } & 0.8 & 0.8 & 0.64 & 30 \\ \text { Wind. 4 } & \text { Wall C } & \text { SouthWest } & 0.8 & 0.76 & 0.608 & 30 \\ \text { Wind. 1 } & \text { Wall D } & \text { NorthWest } & 1.98 & 0.9 & 1.782 & 30 \\ \text { Wind. 2 } & \text { Wall D } & \text { NorthWest } & 1.98 & 0.76 & 1.5048 & 30 \\ \text { Wind. 3 } & \text { Wall D } & \text { NorthWest } & 1.98 & 0.9 & 1.782 & 30 \\ \text { Wind. 4 } & \text { Wall D } & \text { NorthWest } & 5.94 & 0.9 & 5.346 & 30 \\ \text { Wind. 5 } & \text { Wall D } & \text { NorthWest } & 1 & 1.1 & 1.1 & 0 \\ \text { Wind. 6 } & \text { Wall D } & \text { NorthWest } & 1 & 0.76 & 0.76 & 0\end{array}$

Air Leakage:

Basic Airtightnes: Leaky

Fires without Flue Restrictors: 0

with Flue Restrictors:

arge Gaps: $0 \mathrm{~mm}^{2}$

The house has no passive vents.

The location-independent Air

Wind Zxposure: medium exposed

Local Air Leakage Rate: $0.99 \mathrm{ac} / \mathrm{h}$

Thermal Mass:

Timber floor: $.0 \mathrm{~m} \mathrm{~m}^{2}$, Exposed timber $\left(10 \mathrm{Wh} / \mathrm{m}^{\circ}{ }^{\circ} \mathrm{C}\right)$

Concrete Floor: $23.2 \mathrm{~ms}^{2}$, Wihthout

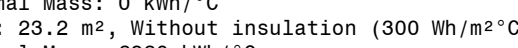

列

Internal Walls:

steel frame $\left(10 \mathrm{Wh} / \mathrm{m}^{\circ}{ }^{\circ} \mathrm{C}\right)$

Total Flormal Mass: $1020 \mathrm{kWh} /{ }^{\circ} \mathrm{C}$

$\begin{array}{ll} & \\ & \end{array}$ Total Thermal Mass: $0637 \mathrm{kWh} /{ }^{\circ} \mathrm{C}$

Effective Thermal Mass: $343.5 \mathrm{~W} /{ }^{\circ} \mathrm{C}$

ower North Island

Heating Season: May to September

Annual Loss Factor: 9.9

$\begin{array}{ccccccccc}\text { Annual Gain Factors: } & & & & & & & \\ \text { N } & \text { NE } & \text { E } & \text { SE } & \text { S } & \text { SW } & \text { W } & \text { NW } & \text { H } \\ 230 & 138 & 100 & 82 & 78 & 92 & 179 & 257 & 189\end{array}$

Wind Zone Factor: 1.15

H1 Climate Location: warm, BPI Target: 0.13

Heating Schedule : Morning and Evening Heating (7:00-9:00 and 17:00-23:00)

Heating Level: $18^{\circ} \mathrm{C}$ 


\section{C.5 House 5}

\section{ALF Calculation Report}

\section{Project Description}

Current Design: Magnetic Acrylic

\section{Designed by: Nick Smith}

In order to comply with the Energy Efficiency Clause H1 (2000) of the New Zealand Building Code a building has to have a BP of less than $0.13 \mathrm{kWh} / \mathrm{m} /$ Degree Days if 1 it is in a warm location and less than 0.12 (May to August) degree days of less than 920. Cool locations are locations with 920 degree days or more. The currenly selected location (Wellington) is a waril location. The target BPI is therefore 0.13 . Alternatively, the building complies if it is built to NZS 4218:1996. This standard has three different ALF checks the designed building for a BPI and for the NZS 4218:1996 Schedule and Calculation Methods. The currently selected NZS 4218 target R-values are for a "non-solid construction". The current design rates are:

$$
\begin{aligned}
& \text { BPI }=0.159 \\
& \text { NZS } 4218 \text { (Schedule) } \\
& \text { NZS } 4218 \text { (Calculation) }
\end{aligned}
$$$$
\text { H1 fail H1 fai }
$$

The current building design does
Calculation target in NZS 4218:1996.

\section{$\frac{\text { Details of H1 Compliance }}{\text { BPI }}$}

NZS 4218 (Schedule)

Maximum: 0.13$$
\text { H1 fail }
$$

$$
\begin{array}{llr} 
& \text { Minimum } & \text { Minimum achieved } \\
\text { Floor: } & 1.3 & 1.09 \\
\text { Wall: } & 1.5 & 1.10 \\
\text { Roof: } & 1.9 & 0.50
\end{array}
$$

NZS 4218 Roof:

$$
\begin{aligned}
& \text { Maximum acceptable heat loss: } \quad 455 \mathrm{~W} /{ }^{\circ} \mathrm{C} \\
& \text { Achieved heat loss: } \\
& 6066 \mathrm{~W} /{ }^{\circ} \mathrm{C}
\end{aligned}
$$

For the individual components also applies that the average R-values must also be larger than $60 \%$ of those in the Schedule:
Floor: $\quad \begin{array}{ll}\text { Min } \\ \text { Wall: } & 0.8\end{array}$
Average achieved
1.12
1.23
0.50
(excl. carpet)
Roof: $\quad 1.1 \quad 0.25$

\begin{tabular}{|c|c|c|c|c|c|c|}
\hline & \multirow{2}{*}{$\begin{array}{c}\text { Area } \\
\quad m^{2}\end{array}$} & \multicolumn{2}{|c|}{ Loss } & \multicolumn{2}{|c|}{ Gain } & \multirow{3}{*}{$\begin{array}{l}\text { Net Gain } \\
\text { kWh/ } \\
\text { year }\end{array}$} \\
\hline & & $\begin{array}{l}\text { kWhI } \\
\text { year }\end{array}$ & $\%$ & kWh I & $\%$ & \\
\hline Slab Floor: & $45.3 m^{2}$ & 329 & $2.9 \%$ & & & \\
\hline Suspended $F$. & $112.1 \mathrm{~m}^{2}$ & & $7.0 \%$ & & & \\
\hline Wall A(NE) : & $28.2 \mathrm{~m}^{2}$ & 215 & $1.9 \%$ & & & \\
\hline $\begin{array}{l}\text { Window A0: } \\
\text { Window A1: }\end{array}$ & $\begin{array}{l}1.5 m^{2} \\
0.5 m^{2}\end{array}$ & 41 & $0.4 \%$ & 126 & $\begin{array}{l}2.6 \% \\
0.9 \%\end{array}$ & 85 \\
\hline Window A2: & $\begin{array}{l}0.5 \mathrm{~m}^{2} \\
2.2 \mathrm{~m}^{2}\end{array}$ & $\begin{array}{l}15 \\
59\end{array}$ & $\begin{array}{l}0.1 \% \\
0.5 \%\end{array}$ & $\begin{array}{r}45 \\
182\end{array}$ & $\begin{array}{l}0.9 \% \\
3.8 \% \\
\end{array}$ & $\begin{array}{r}31 \\
122\end{array}$ \\
\hline Wall $B(S E)$ : & $1.4 \mathrm{~m}^{2}$ & 11 & $0.1 \%$ & & & \\
\hline Wall $\mathrm{C}(\mathrm{SW})$ : & $30.1 \mathrm{~m}^{2}$ & 229 & $2.0 \%$ & & & \\
\hline $\begin{array}{l}\text { Window co: } \\
\text { Window }\end{array}$ & $0.8 \mathrm{~m}^{2}$ & 22 & $0.2 \%$ & $\begin{array}{r}45 \\
101\end{array}$ & $0.9 \%$ & 23 \\
\hline WIIndow C1: & $\begin{array}{l}2.2 m^{2} \\
0.6 m^{2}\end{array}$ & 62 & $0.5 \%$ & & $2.1 \%$ & 39 \\
\hline 7 Window C2: & 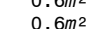 & 18 & $0.2 \%$ & 25 & $0.5 \%$ & 8 \\
\hline Window 3 & $1.6 \mathrm{~m}^{2}$ & $\begin{array}{l}18 \\
44\end{array}$ & $0.4 \%$ & $\begin{array}{l}25 \\
90\end{array}$ & $0.5 \%$ & 8 \\
\hline Wall $\mathrm{D}(\mathrm{NW})$ : & $15.6 m^{2}$ & 119 & $\begin{array}{l}1.4 \% \\
1.0 \%\end{array}$ & & $1.9 \%$ & \\
\hline Window DO: & $5.6 \mathrm{~m}^{2}$ & 154 & $1.4 \%$ & 878 & $18.2 \%$ & 724 \\
\hline I Window D1: & $3.2 \mathrm{~m}^{2}$ & 87 & $0.8 \%$ & 494 & $10.2 \%$ & 407 \\
\hline Window D2: & $4.8 m^{2}$ & 317 & $2.8 \%$ & 864 & $17.9 \%$ & 547 \\
\hline Window D3: & $2.8 m^{2}$ & 77 & $0.7 \%$ & & $9.1 \%$ & \\
\hline
\end{tabular}

Copyright of the standard is property of Standards New Zealand and is protected as described in the NZS

This section gives you an overview of all the heat flows in and out of the designed building. It allows you to evaluate the importance of the thermal performance of individual building components - for example, of

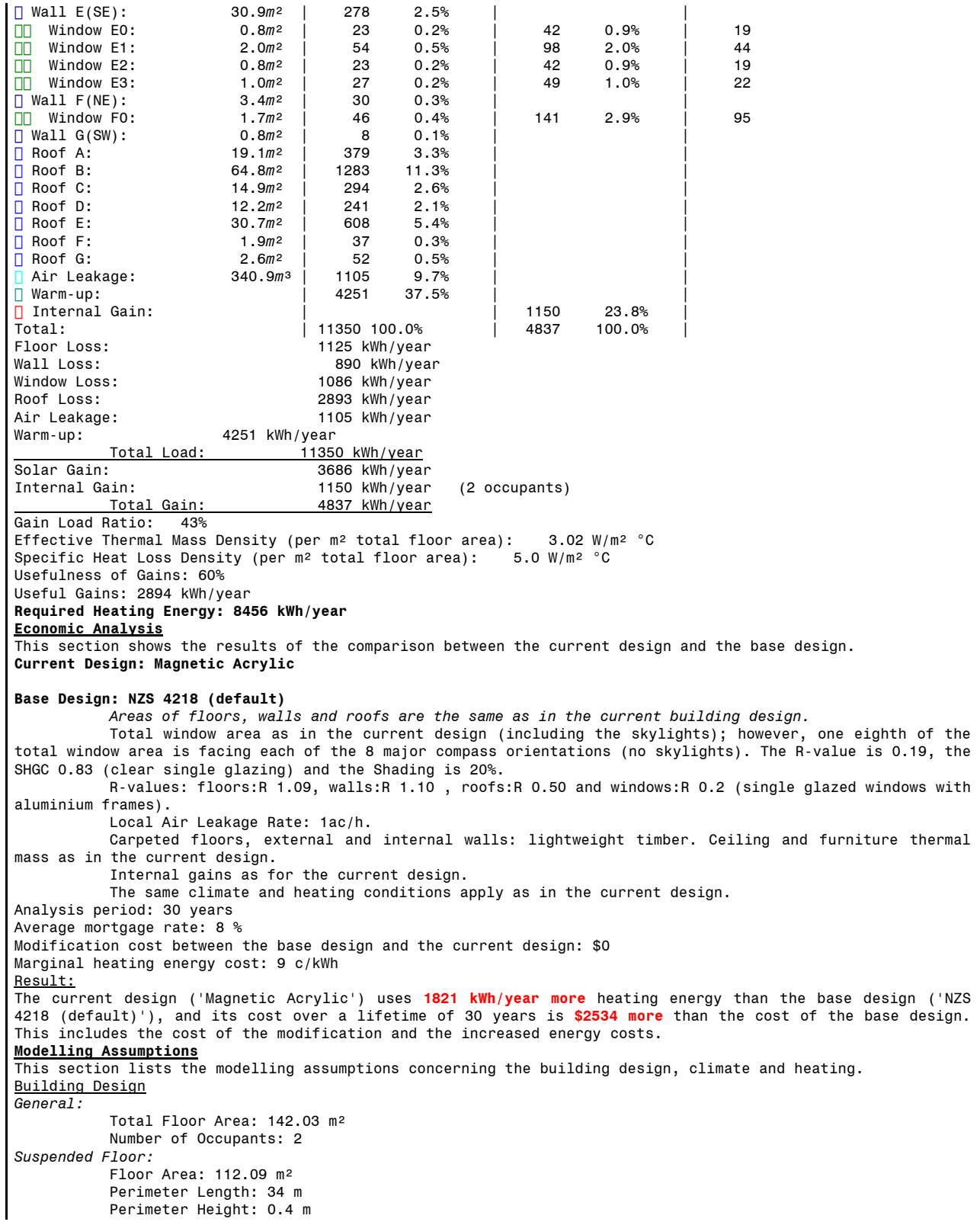


Perimeter Area: $13.6 \mathrm{~m}^{2}$

(sheltered)

loor Insulation: Uninsulated timber floo

loor Insulation R-value: $0.3 \mathrm{~m}^{\circ}{ }^{\circ} \mathrm{C} / \mathrm{W}$

Toor Covering R-value: $0.27 \mathrm{~m}^{\circ}{ }^{\circ} \mathrm{C} / \mathrm{W}$
Total Suspended Floor R-value: $1.39 \mathrm{~m}^{\circ} \mathrm{C} / \mathrm{Wl}$

Slab Floor:

loor Area: $45.34 \mathrm{~m}^{2}$

Perimeter Length: $23.2 \mathrm{~m}$

Soil Conductivity: $1.2 \mathrm{~W} / \mathrm{m}^{\circ} \mathrm{C}$

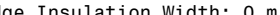

Slab and Ground R-value: $1.093603 \mathrm{~m}^{\circ} \mathrm{C} / \mathrm{W}$

Foor Covering R-value: $0.27 \mathrm{~m}^{2} \mathrm{C}^{\circ} \mathrm{W}$

Walls:

Timber Framed Wall, Bevelbacked Weatherboards, Insulation Within Framing - $100 \mathrm{~mm}$ Framing 2 Dwangs, Studs $400 \mathrm{~mm} \mathrm{ctr}$., Blanket and Segment Insulants

Construction $\mathrm{R}-\mathrm{v}$

\begin{tabular}{llllll} 
Name & $\begin{array}{c}\text { Length } \\
\text { Orientation }\end{array}$ & Height & $\begin{array}{l}\text { Net } \\
\text { Area }\end{array}$ & $\begin{array}{l}\text { Window } \\
\text { Area }\end{array}$ \\
Wall A & NorthEast & $m$ & $m$ & $m^{2}$ & $m^{2}$ \\
Wall B & Southeast & 13.5 & 2.4 & 28.2 & 4.2 \\
Wall C & SouthWest & 0.6 & 2.4 & 1.4 & 0 \\
Wall D & NorthWest & 15 & 2.4 & 30.1 & 5.93 \\
\hline
\end{tabular}

Type 2:
Timber Framed Wall, Brick/Block Veneer, Insulation Within Framing - $100 \mathrm{~mm}$ Framing 2 Dwangs, Studs $400 \mathrm{~mm} \mathrm{ctr}$., Blanket and Segment Insulants Construction R-value:

$\begin{array}{llllll}\text { Name } & \begin{array}{c}\text { Length } \\ \text { Orientation }\end{array} & \text { Height } & \begin{array}{l}\text { Net } \\ \text { Area }\end{array} & \begin{array}{l}\text { Window } \\ \text { Area }\end{array} \\ \text { Wall E } & \text { SouthEast } & m & m & m^{2} & m^{2} \\ \text { Wall F } & \text { NorthEast } & 12.7 & 2.8 & 30.9 & 4.62 \\ \text { Wall G } & \text { SouthWest } & 1.8 & 2.8 & 3.4 & 1.68 \\ & 0.3 & 2.8 & 0.8 & 0\end{array}$

Roofs:

Pitched Timber Framed Roof, Metal Clad, Flat Ceiling, Ceiling Dwangs, $144 \mathrm{~mm}$ Joist

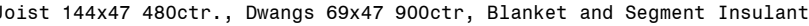
Insulation R-value: $0 \mathrm{~m}^{2}{ }^{\circ} \mathrm{C} / \mathrm{W}$
Construction R-value: $0.5 \mathrm{~m} 2^{\circ} \mathrm{C} / \mathrm{W}$

\begin{tabular}{|c|c|c|c|c|}
\hline $\begin{array}{c}\text { Construction } \\
\text { Name }\end{array}$ & Length & Width & $\begin{array}{l}\text { Net } \\
\text { Area }\end{array}$ & $\begin{array}{l}\text { Window } \\
\text { Area }\end{array}$ \\
\hline & & & & \\
\hline Roof A & 5.8 & 3.3 & 19.1 & 0 \\
\hline Roof B & 6 & 10.8 & 64.8 & 0 \\
\hline Roof C & 1.5 & 9.9 & 14.9 & 0 \\
\hline Roof D & 1.5 & 8.1 & 12.2 & 0 \\
\hline $\begin{array}{l}\text { Roof } \mathrm{E} \\
\text { Roof } \mathrm{F}\end{array}$ & $\begin{array}{l}9.3 \\
0.6\end{array}$ & $\begin{array}{l}3.3 \\
3.1\end{array}$ & $\begin{array}{l}30.7 \\
1.9\end{array}$ & $\begin{array}{l}0 \\
0\end{array}$ \\
\hline $\begin{array}{l}\text { Roof } F \\
\text { Roof } G\end{array}$ & $\begin{array}{l}0.6 \\
0.6\end{array}$ & $\begin{array}{l}.1 \\
4.4\end{array}$ & 2.6 & 0 \\
\hline
\end{tabular}

Type 1:

Glass: Magicseal

Frame: Alumium frame (no thermal break)

$\begin{array}{ccccccc}\text { Neat Gain } & \text { Coefficient: } \\ \text { Number } & \begin{array}{c}\text { Wall } \% \\ \text { Roof }\end{array} & \text { Orientation } & \text { Width } & \text { Height } & \begin{array}{l}\text { Net } \\ \text { Area }\end{array} & \text { Shading } \\ & & & m & m & m^{2} & \% \\ \text { Wind. } & \text { Wall A } & \text { NorthEast } & 1.5 & 1 & 1.5 & 0 \\ \text { Wind. 2 } & \text { Wall A } & \text { NorthEast } & 0.9 & 0.6 & 0.54 & 0 \\ \text { Wind. 3 } & \text { Wall A } & \text { NorthEast } & 2.4 & 0.9 & 2.16 & 0\end{array}$

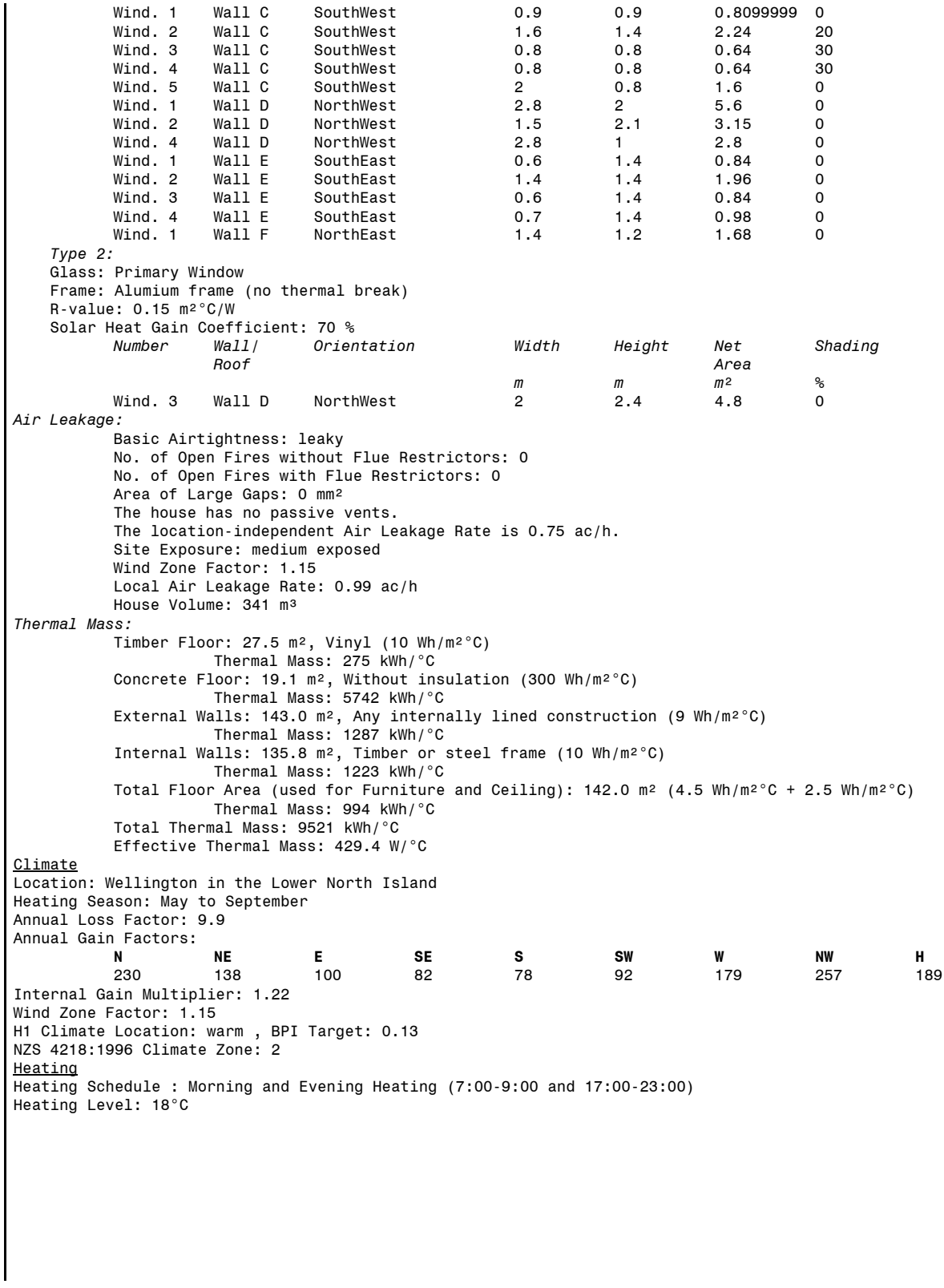




\section{C.6 House 6}

\section{$\frac{\text { ALF Calculation Report }}{\text { Project Description }}$}

Project: House 6
Current Design: Magnetic Acrylic

NZ Building Code Compliance

has to

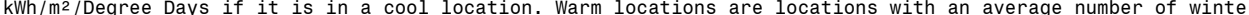
(May to August) degree days of less than 920. Cool locations are locations with 920 degree days or more. The Alternatively, the building complies if it is built to NZS 4218 : 1900 . This stand 0 . methods to show compliance: the Schedule Method, the Calculation Method and the Modelling Method.

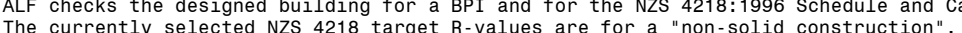

$$
\begin{aligned}
& \text { BPI }=0.175 \\
& \text { NZS } 4218 \text { (Schedule) } \\
& \text { NZS } 4218 \text { (Calculation }
\end{aligned}
$$$$
\text { H1 fail H1 fail }
$$$$
\text { H1 fail H1 fail }
$$

\section{The current building design does
Calculation target in NZS 4218:1996.} Details of H1 Compliance

NZS 4218 (Schedule)

$$
\text { Maximum: } 0.13
$$$$
\begin{array}{lll}
\text { Floor: } & 1.3 \\
\text { Wall: } & 1 \cdot 5 \\
\text { Roof: } & 1 \cdot 9
\end{array}
$$

$$
\begin{aligned}
& 1.3 \\
& 1.5 \\
& 1.9
\end{aligned}
$$

Maximum acceptable

$$
\begin{aligned}
& 1.23 \\
& 0.50 \\
& 0.30
\end{aligned}
$$

NZS 4218 (Calculation)

For the individual components also applies that the average $\mathrm{R}$-values must also be larger than 60

$$
\begin{array}{llrl} 
& \text { Minimum } & \text { Average achieved } & \\
\text { Floor: } & 0.8 & 1.33 & \text { (excl. carpet) } \\
\text { Wall: } & 0.9 & 0.65 & \\
\text { Roof: } & 1.1 & 0.50 &
\end{array}
$$

\begin{tabular}{|c|c|c|c|c|c|c|}
\hline & \multirow{2}{*}{$\begin{array}{c}\text { Area } \\
\quad m^{2}\end{array}$} & \multicolumn{2}{|c|}{ Loss } & \multicolumn{2}{|c|}{ Gain } & \multirow{3}{*}{$\begin{array}{l}\text { Net Gai, } \\
\text { kWh/ } \\
\text { year }\end{array}$} \\
\hline & & kWh/ & $\%$ & kWh I & $\%$ & \\
\hline $\begin{array}{l}\text { Slab Floor: } \\
\text { Suspended F. }\end{array}$ & $52.8 m^{2}$ & 381 & $2.4 \%$ & & & \\
\hline $\begin{array}{l}\text { Suspended F.: } \\
\text { Wall } A(N) \text { : }\end{array}$ & $\begin{array}{l}126.5 \mathrm{~m}^{2} \\
{ }^{33} 3 \mathrm{~mm}^{2}\end{array}$ & $\begin{array}{l}764 \\
338\end{array}$ & $\begin{array}{l}4.9 \% \\
2.2 \%\end{array}$ & & & \\
\hline Window A0: & $\begin{array}{r}23.9 \mathrm{~m} / 2 \\
2.3 \mathrm{~m}^{2}\end{array}$ & 63 & $0.4 \%$ & 323 & $4.2 \%$ & \\
\hline Window A1: & $0.8 \mathrm{~m}^{2}$ & 23 & $0.1 \%$ & 118 & $1.5 \%$ & 95 \\
\hline $\begin{array}{l}\text { Window A2: } \\
\text { Window A3: }\end{array}$ & $\begin{array}{l}0.8 m^{2} \\
0.8 m^{2}\end{array}$ & 23 & $0.1 \%$ & $\begin{array}{l}71 \\
71\end{array}$ & $0.9 \%$ & 48 \\
\hline $\begin{array}{l}\text { Window A3: } \\
\text { Window A4: }\end{array}$ & $\begin{array}{l}0.8 \mathrm{~m}^{2} \\
2.0 \mathrm{~m}^{2}\end{array}$ & $\begin{array}{l}23 \\
54\end{array}$ & $\begin{array}{l}0.1 \% \\
0.3 \%\end{array}$ & 274 & $\begin{array}{l}0.9 \% \\
3.6 \%\end{array}$ & $\begin{array}{l}48 \\
220\end{array}$ \\
\hline Wall $B(N)$ : & $8.2 m^{2}$ & 163 & $1.0 \%$ & & & \\
\hline $\begin{array}{l}\text { Window B0: } \\
\text { Wall } C(E) \text { : }\end{array}$ & $\begin{array}{r}0.8 m^{2} \\
22.7 m^{2}\end{array}$ & $\begin{array}{r}21 \\
322\end{array}$ & $\begin{array}{l}0.1 \% \\
2.1 \%\end{array}$ & 109 & $1.4 \%$ & 88 \\
\hline Window Co: & $1.0 \mathrm{~m}^{2}$ & 29 & $0.2 \%$ & 63 & $0.8 \%$ & 35 \\
\hline Wall $D(E)$ : & $12.4 \mathrm{~m}^{2}$ & 176 & $1.1 \%$ & 10 & & 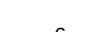 \\
\hline $\begin{array}{l}\text { Window Do: } \\
\text { Wall } E(S) \text { : }\end{array}$ & $\begin{array}{r}1.5 \mathrm{~m}^{2} \\
16.5 \mathrm{~m}^{2}\end{array}$ & $\begin{array}{r}98 \\
233\end{array}$ & $\begin{array}{l}0.6 \% \\
1.5 \% \\
\end{array}$ & 104 & $1.4 \%$ & 6 \\
\hline Window E0: & $8.0 \mathrm{~m}^{2}$ & 219 & $1.4 \%$ & 378 & $4.9 \%$ & 160 \\
\hline Window E1: & $2.2 \mathrm{~m}^{2}$ & 60 & $0.4 \%$ & 104 & $1.4 \%$ & 44 \\
\hline $\begin{array}{l}\text { Window E2: } \\
\text { Wali } F(S) \text { : }\end{array}$ & $\begin{array}{r}8.4 m^{2} \\
15.5 m^{2}\end{array}$ & $\begin{array}{l}554 \\
219\end{array}$ & $\begin{array}{l}3.6 \% \\
1.4 \%\end{array}$ & 459 & & \\
\hline Window Fo: & $1.6 \mathrm{~m}^{2}$ & 45 & $0.3 \%$ & 77 & $1.0 \%$ & 33 \\
\hline Window F1: & $2.2 \mathrm{~m}^{2}$ & 60 & $0.4 \%$ & 103 & $1.3 \%$ & 44 \\
\hline
\end{tabular}

copyright of the standard is property of Standards New Zealand and is protected as described in the NZS 4218:1996 document. Energy
This section gives you an overview of all the heat flows in and out of the designed building. It allows you
to evaluate the importance of the thermal performance of individual building components. for example, of

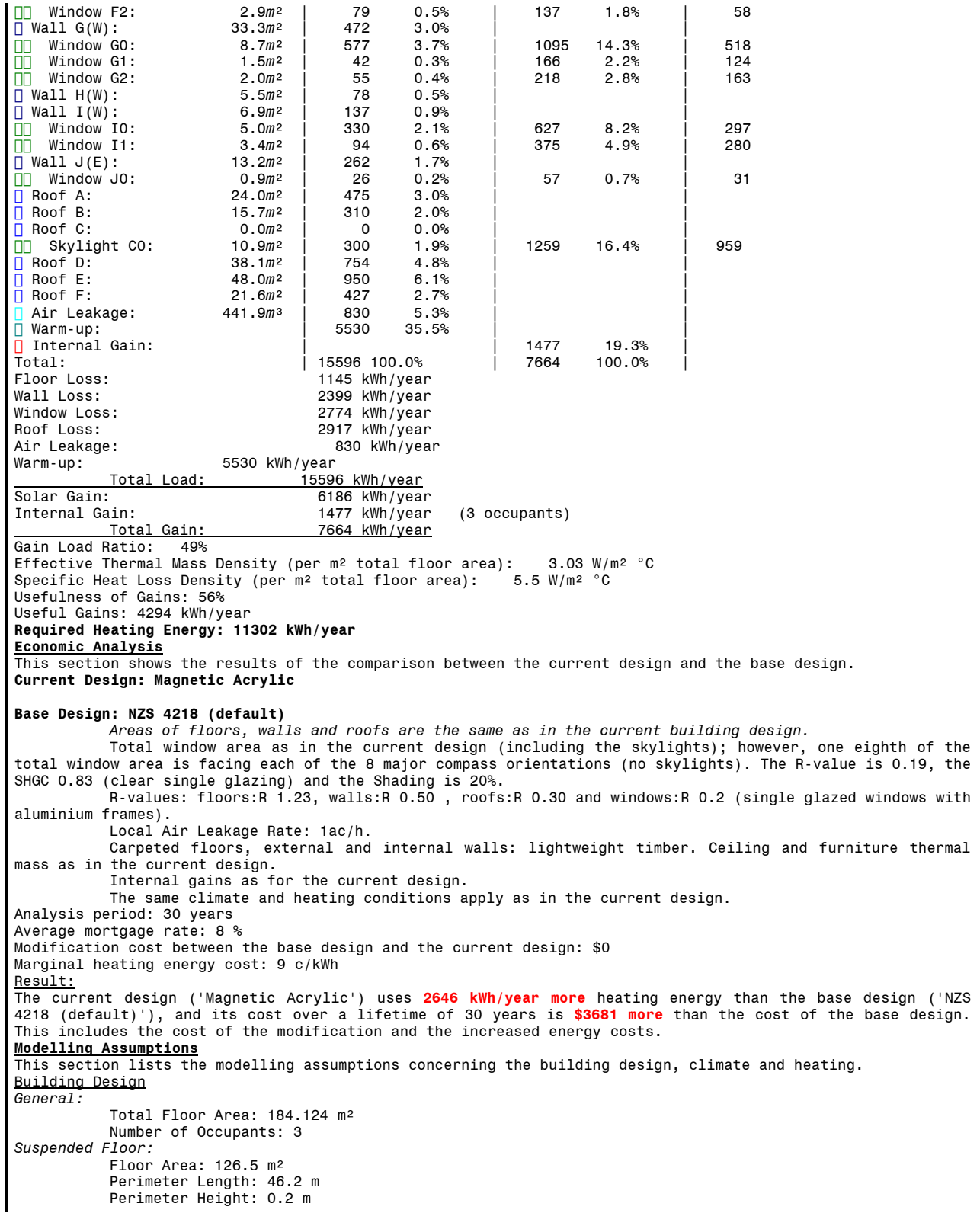


Perimeter Area: $9.240001 \mathrm{~m}^{2}$

Subfloor Exposure: Continuous Perimeter Wall (sheltered)

Foor Covering R-value: $0.27 \mathrm{~m}^{\circ} \mathrm{C} / \mathrm{W}$

Slab Floor:

Floor Area: $52.81 \mathrm{~m}^{2}$
Perimeter Length: 23.25

Perimeter Length: $23.25 \mathrm{~m}$

Under Floor R-value: $0 \mathrm{~m}^{\circ}{ }^{\circ} \mathrm{C} / \mathrm{W}$

slab and Ground R-value: 1 . $231912 \mathrm{~m}^{\circ} \mathrm{C} / \mathrm{W}$

Floor Covering R-value: $0.14 \mathrm{~m}^{\circ}{ }^{\circ} \mathrm{C} / \mathrm{W}$
Total Slab Floor R-value: $1.37 \mathrm{~m}^{2}{ }^{\circ} \mathrm{C} / \mathrm{W}$

Timber Framed Wall, Bevelbacked Weatherboards, Insulation Within Framing - 100 mm Framing 2 Dwangs, Studs $400 \mathrm{~mm} c t r$., Blanket and Segment Insulants

Construction R-value: $0.7 \mathrm{~m}^{\circ} \mathrm{C} / \mathrm{M}$

$\begin{array}{llllll}\text { Name } & \text { Orientation } & \text { Length } & \text { Height } & \begin{array}{l}\text { Net } \\ \text { Area }\end{array} & \begin{array}{l}\text { Window } \\ \text { Area }\end{array} \\ & & m & m & m^{2} & m^{2} \\ \text { Wall A } & \text { North } & 12.78 & 2.4 & 23.9 & 6.77 \\ \text { Wall C } & \text { East } & 9.91 & 2.4 & 22.7 & 1.04 \\ \text { Wall D } & \text { East } & 2.9 & 4.8 & 12.4 & 1.48 \\ \text { Wall E } & \text { South } & 7.3 & 4.8 & 16.5 & 18.539 \\ \text { Wall F } & \text { South } & 9.23 & 2.4 & 15.5 & 6.67 \\ \text { Wall G } & \text { West } & 9.5 & 4.8 & 33.3 & 12.256 \\ \text { Wall H } & \text { West } & 2.3 & 2.4 & 5.5 & 0\end{array}$

Type 2:

Concrete Block Wall, Strapped and Lined, Internally Insulated
$47 \times 22$ strap, Straps $400 \mathrm{~mm}$ ctr., Rigid and Semi-Rigid Insulants on internal side of wall construction R-value: $0.5 \mathrm{~m}^{\circ}{ }^{\circ} \mathrm{C}$

$\begin{array}{ccllll}\text { Name } & \begin{array}{c}\text { Lrientation } \\ \text { Nanth }\end{array} & \text { Length } & \text { Height } & \begin{array}{l}\text { Net } \\ \text { Area }\end{array} & \begin{array}{l}\text { Window } \\ \text { Area }\end{array} \\ \text { Wall B } & \text { North } & m & m & \mathrm{~m}^{2} & \mathrm{~m}^{2} \\ \text { Wall I } & \text { West } & 3.75 & 2.4 & 8.2 & 0.78 \\ \text { Wall J } & \text { East } & 6.4 & 2.4 & 6.9 & 8.43 \\ & & 5.9 & 2.4 & 13.2 & 0.9350001\end{array}$

Roofs:
Type $1:$
Pitch

Pitched Timber Framed Roof, Metal Clad, Flat Ceiling, Ceiling Dwangs, $144 \mathrm{~mm}$ Joist

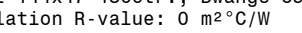

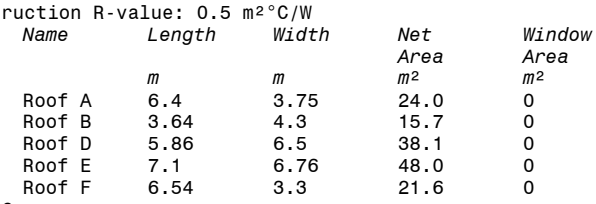

Type 2:
Flat Metal Deck Roof, Ceiling Battens

Ceiling Joist $144 \times 47$ 900ctr., Batten $35 \times 69<600 \mathrm{ctr}$., Blanket and Segment Insulants Insulation R-value: $0 \mathrm{~m}^{2}{ }^{\circ} \mathrm{C} / \mathrm{W}$
Construction R-value: $0.3 \mathrm{~m}^{\circ} \mathrm{C} / \mathrm{W}$

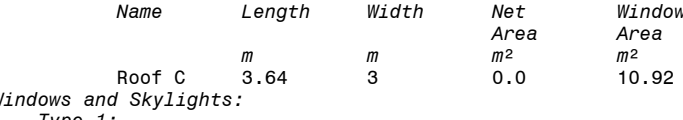

$$
\begin{aligned}
& \text { Type 1: } \\
& \begin{array}{l}
\text { Frame: Alumium frame (no thermal break) } \\
\text { R-value: } 0.36 \mathrm{~m}^{\circ}{ }^{\circ} \mathrm{C} / \mathrm{W}
\end{array}
\end{aligned}
$$

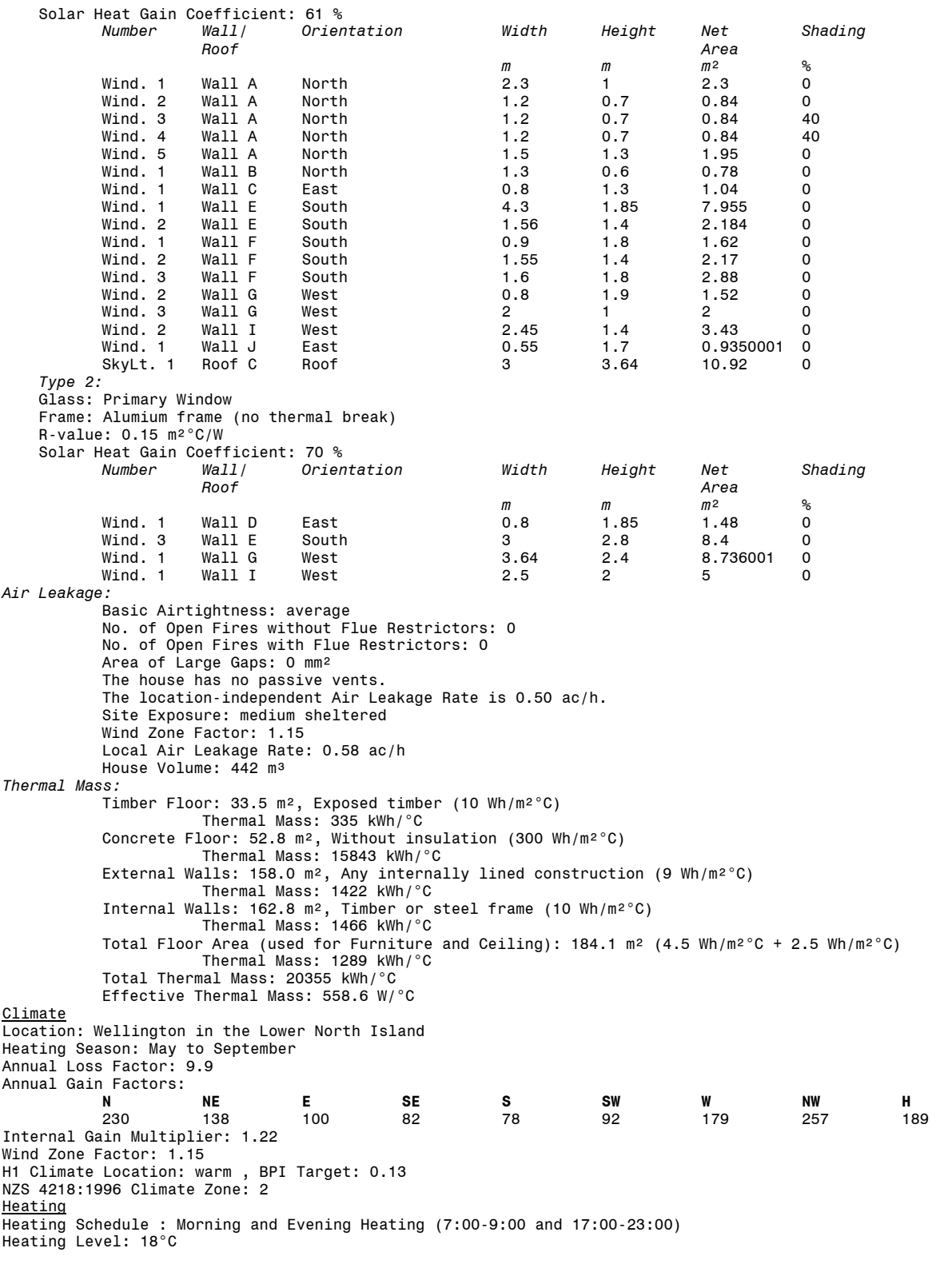




\section{C.7 House 7}

\section{ALF Calculation Report}

Current Design: Magnetic Acrylic
Designed by:
NZ Smith

In order to comply with the Energy Efficiency Clause $\mathrm{H1}$ (2000) of the New Zealand Building Code a building
has to have a BPI of less than $0.13 \mathrm{kWh} / \mathrm{m}^{2} /$ Degree Days if it is in a warm location and less than 0.12 $\mathrm{kWh} / \mathrm{m} 2 / \mathrm{Degree}$ a Days if it is in a cool location. Warm locations are locations with an average number of winter

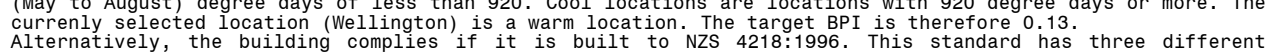
methods to show compliance: the schedule Method, the calculation Method and the Modellining Method.
ALF checks the designed building for a BPI and for the NZS 4218:1996 Schedule and Calculation Methods. ALF checks the designed building for a BPI and for the NZS 4218:1996 Schedle and Calculation Methods.

The current design rates are:

$$
\begin{aligned}
& \text { BPI }=0.097 \text { (Schedule) } \\
& \text { NZS } 4218 \text { (Sches } \\
& \text { NZS } 4218 \text { (Calculation }
\end{aligned}
$$$$
\text { H1 pas }
$$

\section{The current building design complies with Clause $H 1$ of the NZBC because it complies with at least one of the} (Moisture) of the NZBC.
The acceptable solution of Clause E3 of the NZBC requires that $R$-values for walls, roofs and ceilings shall a) For light timber frame wall or other framed wall constructions with cavities, 1.5. c) For solid timber wall systems no less than $60 \mathrm{~mm}$ thick, 0.6 . d) For roof and ceilings

Maximum: 0.13
Warning: Though complying with the BPI target some of the component R-values are extremely low and may lead to an unsatisfactory building performance.

$$
\begin{array}{llrl}
\text { Floor: } & \text { Minimum } & \text { Minimum achieved } & \\
\text { Wall: } & 1.3 & 0.73 & \text { (excl. carpet) } \\
\text { Roof: } & 1.9 & 0.50 &
\end{array}
$$
Maximum acceptable heat loss: $597 \mathrm{~W} /{ }^{\circ} \mathrm{C}$
Achieved heat loss:

For the individual components also applies that the average $\mathrm{R}$-values must also be larger than $60 \%$
of those in the Schedule $\begin{array}{lccc} & & \\ \text { Floor: } & \text { Minimum } & \text { Average achieved } & \text { (excl. carpet) } \\ \text { Wall: } & 0.9 & 1.05 & 0.69\end{array}$

copyright of the standard is property of standards New Zealand and is protected as described in the NZS
218:1996 document. Energy
This section gives you an overview of all the heat flows in and out of the designed building. It allows you
to evaluate the importance of the thermal performance of individual building components. - for example, of
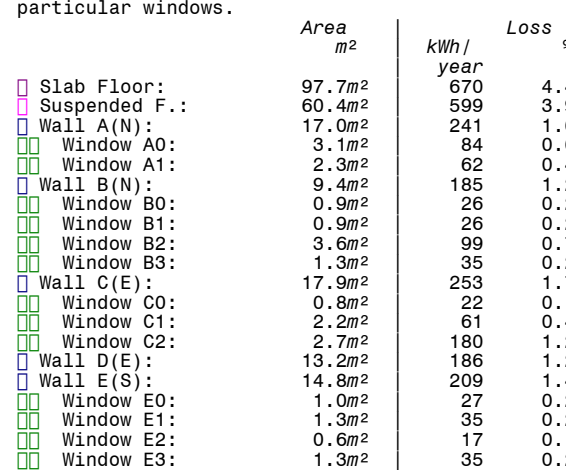

$\%$
$4.4 \%$
$3.9 \%$
$1.6 \%$
$0.6 \%$
$0.4 \%$
$1.2 \%$
$0.2 \%$
$0.2 \%$
$0.7 \%$
$0.2 \%$
$1.7 \%$
$0.1 \%$
$0.4 \%$
$1.2 \%$
$1.2 \%$
$0.4 \%$
$0.2 \%$
$0.1 \%$
$0.2 \%$

\begin{tabular}{cc|c} 
kWh/ $^{\text {kWin }} \begin{array}{c}\text { Gain } \\
\text { year }\end{array}$ & $\%$ & $\begin{array}{c}\text { Net Gain } \\
\text { kWh/ } \\
\text { year }\end{array}$ \\
& & \\
301 & $4.5 \%$ & 217 \\
221 & $3.3 \%$ & 159 \\
130 & $2.0 \%$ & 105 \\
130 & $2.0 \%$ & 105 \\
505 & $7.6 \%$ & 406 \\
177 & $2.7 \%$ & 142 \\
44 & $0.7 \%$ & 22 \\
135 & $2.0 \%$ & 74 \\
134 & $2.0 \%$ & -46 \\
& & \\
33 & $0.5 \%$ & 6 \\
42 & $0.6 \%$ & 7 \\
20 & $0.3 \%$ & 3 \\
60 & $0.9 \%$ & 25
\end{tabular}

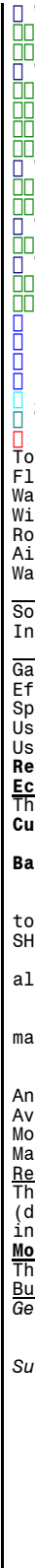

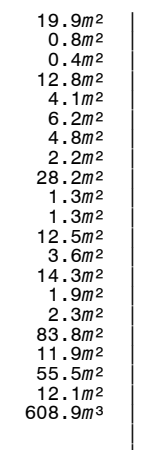

$\begin{array}{rl}393 & 2.6 \\ 22 & 0.1 \\ 12 & 0.1 \\ 83 & 0.5 \\ 111 & 0.7 \\ 170 & 1.1 \\ 317 & 2.1 \\ 59 & 0.4 \\ 558 & 3.7 \\ 34 & 0.2 \\ 34 & 0.2 \\ 80 & 0.5 \\ 99 & 0.7 \\ 93 & 0.6 \\ 52 & 0.3 \\ 64 & 0.4 \\ 486 & 3.2 \\ 78 & 0.5 \\ 361 & 2.4 \\ 79 & 0.5 \\ 1315 & 8.7\end{array}$

\begin{tabular}{l|l|}
$2.6 \%$ \\
$0.1 \%$ \\
$0.1 \%$ \\
$0.5 \%$ \\
$0.7 \%$ \\
$1.1 \%$ \\
$2.1 \%$ \\
$0.4 \%$ \\
$3.7 \%$ \\
$0.2 \%$ \\
$0.2 \%$ \\
$0.5 \%$ \\
$0.7 \%$ \\
$0.6 \%$ \\
$0.3 \%$ \\
$0.4 \%$ \\
$3.2 \%$ \\
$0.5 \%$ \\
$2.4 \%$ \\
$0.5 \%$ \\
$8.7 \%$ \\
$50.2 \%$ \\
$0 \%$
\end{tabular}

\begin{tabular}{rr|r}
27 & $0.4 \%$ & 5 \\
14 & $0.2 \%$ & 2 \\
442 & $6.6 \%$ & 331 \\
674 & $10.1 \%$ & 504 \\
601 & $9.0 \%$ & 285 \\
165 & $2.5 \%$ & 106 \\
136 & $2.1 \%$ & 102 \\
136 & $2.1 \%$ & 102 \\
505 & $7.6 \%$ & 406 \\
90 & $1.4 \%$ & 38 \\
110 & $1.7 \%$ & 46 \\
& & \\
& & \\
& & \\
1817 & $27.3 \%$ & \\
6652 & $100.0 \%$ &
\end{tabular}

$\begin{array}{rl}1682 & \mathrm{kWh} / \text { /year } \\ 1003 & \mathrm{kWh} / \text { year } \\ 115 & \mathrm{kWh} / \mathrm{year} \\ 7621 \mathrm{kWh} / \mathrm{year} & 5171 \mathrm{kWh} / \text { year }\end{array}$

Roof Loss:
Air Leakage:
Warm-up:

Solar Gain:
Internal Gain: $5171 \mathrm{kWh} / \mathrm{year}$
$4835 \mathrm{kWh} / \mathrm{year}$
$1817 \mathrm{kWh} / \mathrm{year}$
$6652 \mathrm{kWh} /$ year

(1 occupants)

\section{(6)}

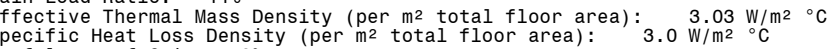

\section{Useful Gains: $5238 \mathrm{kWh} / \mathrm{year}$}

Required Heating Energy: $9933 \mathrm{kWh} /$ yea

This section shows the results of the comparison between the current design and the base design.

\section{Base Design: NZS atro}

gn: NZS 4218 (default)
Areas of floors, walls and roofs are the same as in the current building design

Total window area as in the current design (including the skylights); however, one eighth of the
total window area is facing each of the 8 major compass orientations (no skylights). The R-value is 0.19 , the

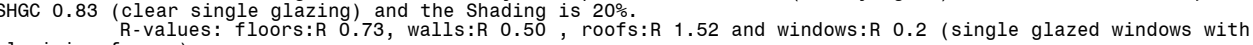
Local Air Leakage Rate: $1 \mathrm{ac} / \mathrm{h}$.
Carpeted floors external and

mass as in the current design.

walls: lightweight timber. Ceiling and furniture thermal

Analysis period: 30 years

Modification cost between the base design and the current design: \$0

Result: The current design ('Magnetic Acrylic') uses $180 \mathrm{kWh} /$ year more heating energy than the base design ('NZS 4218
(default)' ') and its cost over a lifetime of 30 years is $\$ 251$ more than the cost of the base design. This

his section lists the modelling assumptions concerning the building design, climate and heating. Building Design

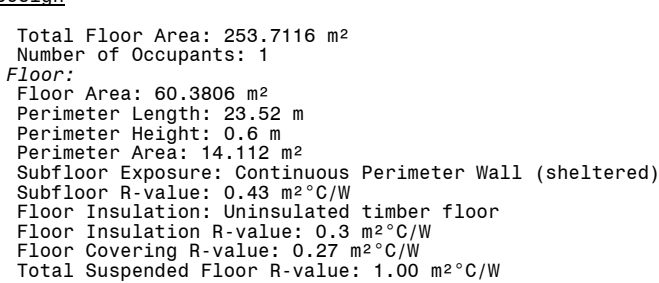

Floor covering R-value: $0.27 \mathrm{~m}^{\circ}{ }^{\circ} \mathrm{C} / \mathrm{W}$
Total Suspended Floor R-value: $1.00 \mathrm{~m}^{\circ} \mathrm{C} / \mathrm{W}$

Nick Smith 
Slab Floor:

$$
\begin{aligned}
& \begin{array}{l}
\text { Floor Area: } 97.707 \mathrm{~m}^{2} \\
\text { Perimeter Length: } 35.28 \mathrm{~m}
\end{array}
\end{aligned}
$$

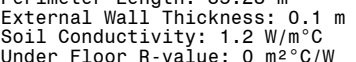

$$
\begin{aligned}
& \text { Slab and Ground Ri-value: } 1.443348 \mathrm{~m}^{\circ} \mathrm{C} / \mathrm{W} \\
& \begin{array}{l}
\text { Floor Covering R-value: } 0 \mathrm{~m}^{\circ}{ }^{\circ} \mathrm{C} / \mathrm{W} \\
\text { Total slab Floor R-value: } \\
1.44 \mathrm{~m}^{\circ} \mathrm{C} / \mathrm{W}
\end{array}
\end{aligned}
$$

Type 1:

Type 1:
Timber Framed Wall, Bevelbacked Weatherboards, Insulation Within Framing - $100 \mathrm{~mm}$ Framing
2 Dwangs, Studs $400 \mathrm{~mm}$ ctr., Blanket and Segment Insulants

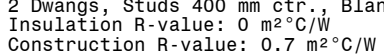

$\begin{array}{llllll}\text { Name } & \text { Orientation } & \text { Length } & \text { Height } & \text { Net } & \text { Window } \\ & & m & m & m^{2} & \text { Arrea } \\ \text { Wall A } & \text { North } & 9.3 & 2.4 & 17.0 & 5.3 \\ \text { Wall C } & \text { East } & 9.86 & 2.4 & 17.9 & 5.76 \\ \text { Wall E } & \text { South } & 7.86 & 2.4 & 14.8 & 4.11\end{array}$
Type 2:
Timber Framed wall, Brick/Block Veneer, Insulation Within Framing - $100 \mathrm{~mm}$ Framing
2 Dwangs, Studs 400 mm ctr., Blanket and Segment Insulants
Thents

construction $\mathrm{R}$-value: $0.5 \mathrm{~m}^{\circ} \mathrm{C}$

$\begin{array}{ccllll}\text { Name } & \begin{array}{c}\text { Length } \\ \text { Orientation }\end{array} & \text { Height } & \begin{array}{l}\text { Net } \\ \text { Area }\end{array} & \begin{array}{l}\text { Window } \\ \text { Area }\end{array} \\ & & m & m & m^{2} & m^{2} \\ \text { Wall B } & \text { North } & 6.7 & 2.4 & 9.4 & 6.72 \\ \text { Wall F } & \text { South } & 8.79 & 2.4 & 19.9 & 1.225 \\ \text { Wall H } & \text { West } & 12.78 & 2.4 & 28.2 & 2.5\end{array}$

Type 3:
Timber Framed Wall, Bevelbacked Weatherboards, Insulation Within Framing - $100 \mathrm{~mm}$ Framing 2 Dwangs, Studs $400 \mathrm{~mm} \mathrm{ctr}$., Adhesiv

\begin{tabular}{|c|c|c|c|c|}
\hline Name & $\begin{array}{l}\text { orientation } \\
\text { or }\end{array}$ & Length & Height & $\begin{array}{l}\text { Net } \\
\text { Area }\end{array}$ \\
\hline Wall D & East & $\begin{array}{l}m \\
5.48\end{array}$ & $\stackrel{m}{2.4}^{m}$ & $\begin{array}{l}\mathrm{m}^{2} \\
13.2\end{array}$ \\
\hline
\end{tabular}

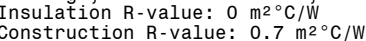

Type 4:
Timber Framed Wall, Bevelbacked Weatherboards, Insulation Within Framing - $100 \mathrm{~mm}$ Framin 2 Dwangs, Studs $400 \mathrm{~mm}$ ctr., Blanket and Segment Insulants Insulation $\mathrm{R}$-value: $1.3 \mathrm{~m}^{\circ}{ }^{\circ} \mathrm{C} / \mathrm{W}$
Construction R-value: $1.525 \mathrm{~m}^{\circ} \mathrm{C} / \mathrm{W}$

$$
\begin{array}{ccllll}
\begin{array}{c}
\text { Name } \\
\text { Nall }
\end{array} & \begin{array}{c}
\text { Lrientation } \\
\text { Wength }
\end{array} & \text { Height } & \begin{array}{l}
\text { Net } \\
\text { Area }
\end{array} & \begin{array}{l}
\text { Window } \\
\text { Area }
\end{array} \\
\text { Wall G } & \text { West } & m & m & m^{2} & m^{2} \\
\text { Wall J } & \text { South } & 12.5 & 2.4 & 12.8 & 17.184 \\
& & 7.7 & 2.4 & 14.3 & 4.2025
\end{array}
$$

Type 5: 2 Dwangs, Studs $400, \mathrm{~mm} \mathrm{ctr}$. $0^{\circ}$ Adhesive
Insulation R-value: $1.3 \mathrm{~m}^{\circ} / \mathrm{W}$

$$
\begin{aligned}
& \text { Name Orientation }{ }^{2} \mathrm{C} / \mathrm{W} \text { Length Height Net }{ }_{\text {Area }}^{\text {Window }}
\end{aligned}
$$

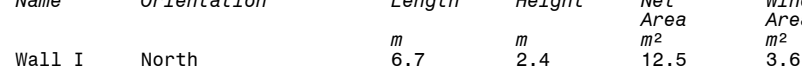

Roofs:

Type 1:
Pitched Timber Framed Roof, Metal Clad, Flat Ceiling

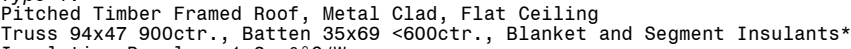
Insulation R-value: $1.3 \mathrm{~m}^{\circ} \mathrm{C} / \mathrm{W}$
Construction $\mathrm{R}$-value: $1.707143 \mathrm{~m}^{\circ} \mathrm{C} / \mathrm{W}$

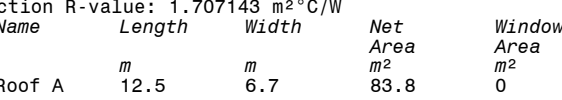

Type 2:
Pitched Timber

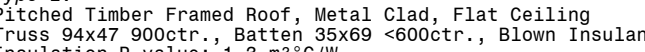
Insulation R-value: $11.3 \mathrm{~m}^{\circ}{ }^{\circ} \mathrm{C} / \mathrm{W}$
Construction R-value: $1.521429 \mathrm{~m}^{\circ} \mathrm{C} / \mathrm{W}$
Name Length

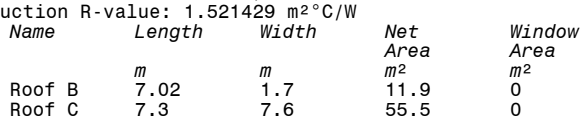

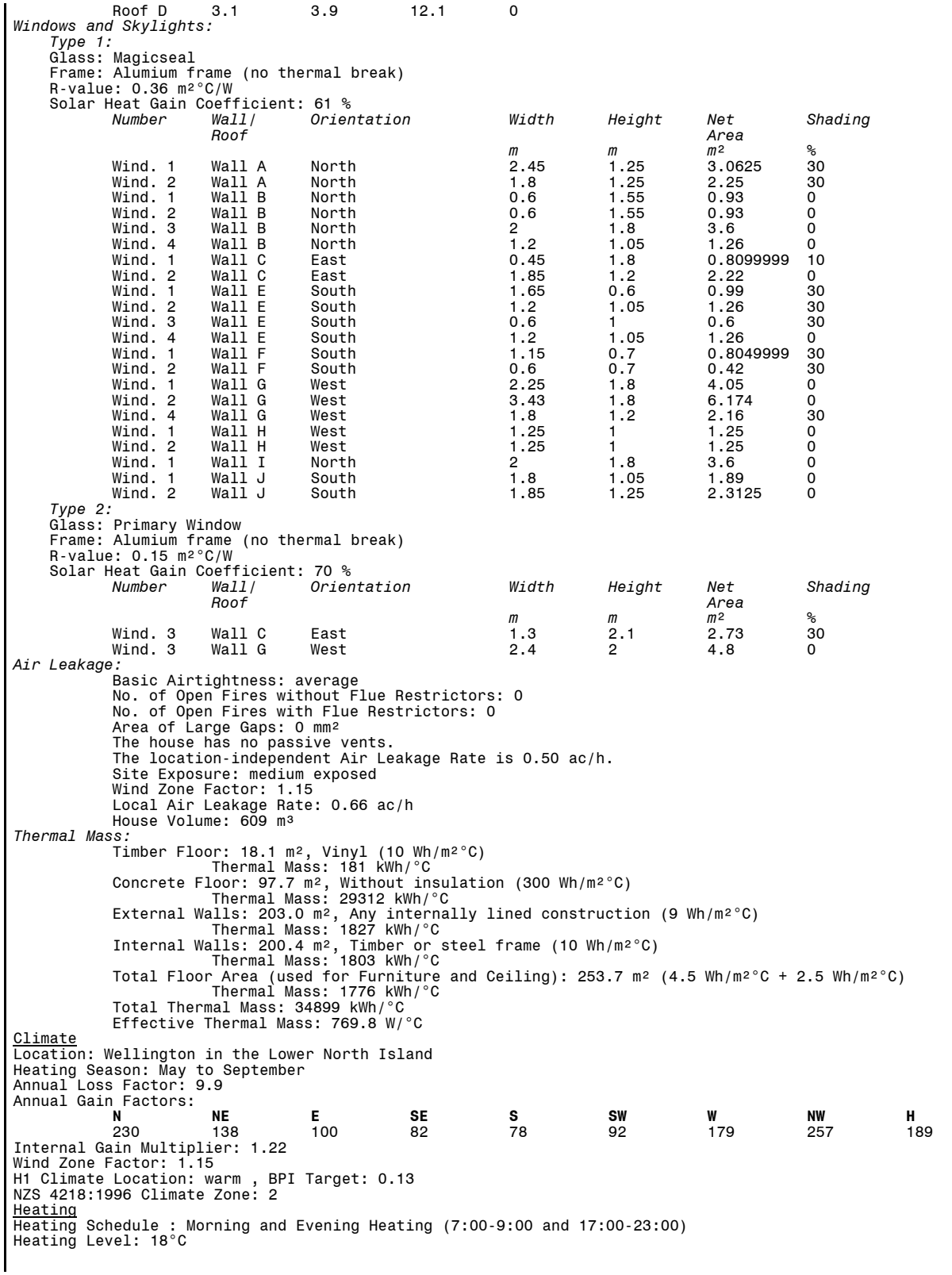




\section{C.8 House 8}

\section{ALF Calculation Report}

Project Description

Project: House 8
Current Design: Magnetic Acrylic

\section{Designed by: Nick Smich}

In order to comply with the Energy Efficiency Clause H1 (2000) of the New Zealand Building Code a building has to have a BP 1 of less than $0.13 \mathrm{kWh} / \mathrm{m} / \mathrm{Degree}$ Days $1 \mathrm{f}$ it is $1 \mathrm{n}$ a warn location and less than 0.12 (May to August) degree days of less than 920. Cool locations are locations with 920 degree days or more. The currenly selected location (Wellington) is a warm location. The target BPI is therefore 0.13 . Alternatively, the building complies if it is built to NZS 4218:1996. This standard has

ALF checks the designed building for a BPI and for the NZS 4218:1996 Schedule and Calculation Methods. The currently selected NZS 4218 target R-values are for a "non-solid construction". The current design rates are:

$$
\begin{aligned}
& \text { BPI }=0.127 \\
& \text { NZS } 4218 \text { (Schedule) } \\
& \text { NZS } 4218 \text { (Calculation }
\end{aligned}
$$$$
\text { H1 fail H1 pass }
$$
H1 compliance methods. However, in order to comply with the NZBC it also has to comply with clause E3 The acceptable solution of Clause E3 of the NZBC requires that R-values for walls, roofs and ceilings shall be no less than:

a) For light timber frame wall or other framed wall constructions with cavities, 1.5.
b) For single skin normal weight masonry based wall construction without a cavity, 0.6 . Details of H1 compliance

Maximum: 0.13
Warning: Though complying with 0.127 to an unsatisfactory building performance.

NZS 4218 (Schedule)

$$
\begin{array}{llrl} 
& \text { Minimum } & \text { Minimum achieved } & \\
\text { Floor: } & 1.3 & 0.59 & \text { (excl. carpet) } \\
\text { Wall: } & 1.5 & 0.70 & \\
\text { Roof: } & 1.9 & 1.50 &
\end{array}
$$

NZS 4218 Roof:

$$
\begin{aligned}
& \text { Maximum acceptable heat loss: } \quad 540 \mathrm{~W} /{ }^{\circ} \mathrm{C} \\
& \text { Achieved heat loss: } \\
& 583 \mathrm{~W} /{ }^{\circ} \mathrm{C}
\end{aligned}
$$

For the individual components also applies that the average R-values must also be larger than 60 \% of those in the schedule:
$\begin{array}{ll}\text { Floor: } & 0.8 \\ \text { Wall: } & 0.9\end{array}$
Average achieve
0.80
1.50
(excl. carpet)

$\begin{array}{ccc}\text { Roof: } & 1.1 \\ \text { Copyright of the standard is property of } & 1.50 \\ \text { standards New Zealand and is protected as described in the NZS }\end{array}$ Energy

\begin{tabular}{|c|c|c|c|c|c|c|}
\hline & \multirow{2}{*}{$\begin{array}{c}\text { Area } \\
\mathrm{m}^{2}\end{array}$} & \multicolumn{2}{|c|}{ Loss } & \multicolumn{2}{|c|}{ Gain } & \multirow{3}{*}{$\begin{array}{l}\text { Net Gain } \\
\text { kWh } 1 \\
\text { year }\end{array}$} \\
\hline & & kWhI & & $k W h /$ & $\%$ & \\
\hline Slab Floor: & $68.3 \mathrm{~m}^{2}$ & 500 & $4.1 \%$ & & & \\
\hline Suspended F.: & $\begin{array}{l}59.0 \mathrm{~m}^{2} \\
27.3 \mathrm{~m}^{2}\end{array}$ & $\begin{array}{l}678 \\
387\end{array}$ & $5.5 \%$ & & & \\
\hline Window A0: & $\begin{array}{r}27.3 m^{2} \\
2.0 m^{2}\end{array}$ & $\begin{array}{r}387 \\
56\end{array}$ & $\begin{array}{l}3.1 \% \\
0.5 \%\end{array}$ & 285 & $4.1 \%$ & \\
\hline $\begin{array}{l}\text { Window A1: } \\
\text { : }\end{array}$ & $\begin{array}{l}2.1 \mathrm{~m}^{2} \\
2\end{array}$ & $\begin{array}{l}56 \\
58\end{array}$ & $0.5 \%$ & $\begin{array}{l}285 \\
236\end{array}$ & $3.4 \%$ & $\begin{array}{l}229 \\
178\end{array}$ \\
\hline Window A2: & $4.2 m^{2}$ & 116 & $0.9 \%$ & 589 & $8.5 \%$ & 474 \\
\hline & $12.3 m^{2}$ & 97 & $0.8 \%$ & & & \\
\hline Window $\mathrm{B0}$ : & $\begin{array}{r}0.9 \mathrm{~m}^{2} \\
32.9 \mathrm{~m}^{2}\end{array}$ & $\begin{array}{r}25 \\
465 \\
\end{array}$ & $\begin{array}{l}0.2 \% \\
3.8 \%\end{array}$ & 128 & $1.8 \%$ & 103 \\
\hline
\end{tabular}

This section gives you an overview of all the heat flows in and out of the designed building. It allows you to evaluate the importance of the thermal performance of individual building components - for example, of

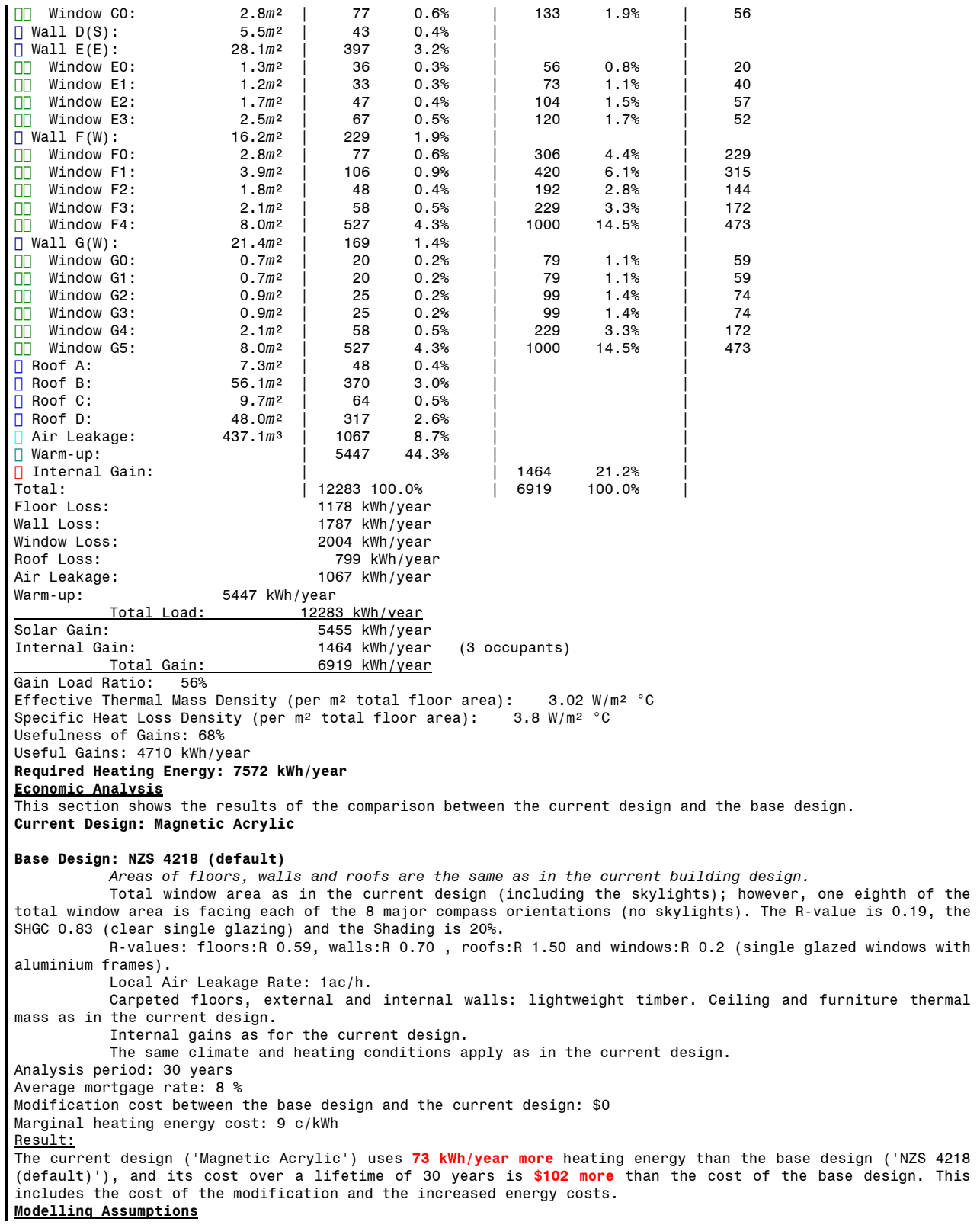

Nick Smith 
This section lists the modelling assumptions concerning the building design, climate and heating. Building Design

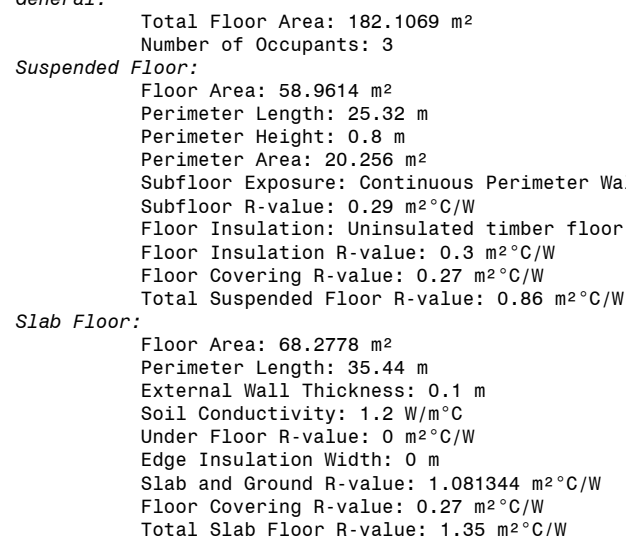

Timber Framed Wall, Bevelbacked Weatherboards, Insulation Within Framing - 100 mm Framing 2 Dwangs, Studs $400 \mathrm{~mm}$ ctr., Blanket and Segment Insulants Construction R-value: $0.7 \mathrm{~m}^{\circ} \mathrm{C}$

\begin{tabular}{|c|c|c|c|c|}
\hline Name & Orientation & Length & Height & $\begin{array}{l}\text { Net } \\
\text { Area }\end{array}$ \\
\hline & & $m$ & $m$ & $m^{2}$ \\
\hline & South & $\begin{array}{l}14.80 \\
14.86\end{array}$ & $\begin{array}{l}2.4 \\
2.4\end{array}$ & $\begin{array}{l}32.9 \\
32.9\end{array}$ \\
\hline & East & 14.46 & 2.4 & 28.1 \\
\hline Nal1 & West & 14.46 & 2.4 & 16.2 \\
\hline
\end{tabular}

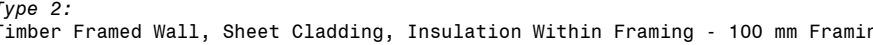
2 Dwangs, Studs $400 \mathrm{~mm} \mathrm{ctr}$., Blanket and Segment Insulants Construction $\mathrm{R}$-val $1.3 \mathrm{~m}^{\circ} \mathrm{C} / \mathrm{W} \mathrm{W}$

$\begin{array}{llllll}\text { Name } & \begin{array}{c}\text { Length } \\ \text { Orientation }\end{array} & \text { Height } & \begin{array}{l}\text { Net } \\ \text { Area }\end{array} & \begin{array}{l}\text { Window } \\ \text { Area }\end{array} \\ \text { Wall B } & \text { North } & m & m & m^{2} & m^{2} \\ \text { Wall D } & \text { South } & 5.5 & 2.4 & 12.3 & 0.91 \\ \text { Wall G } & \text { West } & 2.28 & 2.4 & 5.5 & 0 \\ \text { Weth } & 14.46 & 2.4 & 21.4 & 13.34\end{array}$

Roofs:

Pe 1:

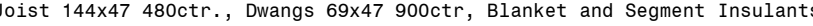
Insulation R-value: $1.4 \mathrm{~m}^{2} \mathrm{C} / \mathrm{W}$ Construction R-value: $1.5 \mathrm{~m}^{\circ} \mathrm{C} / \mathrm{W}$

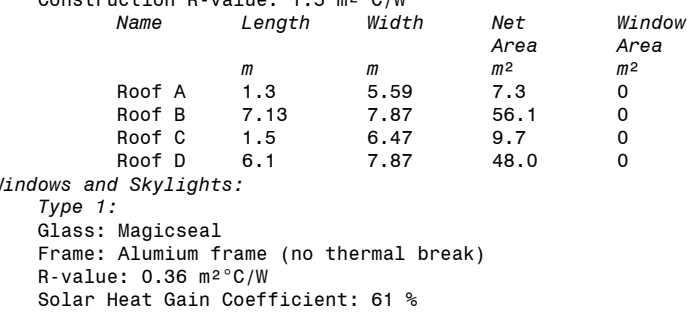

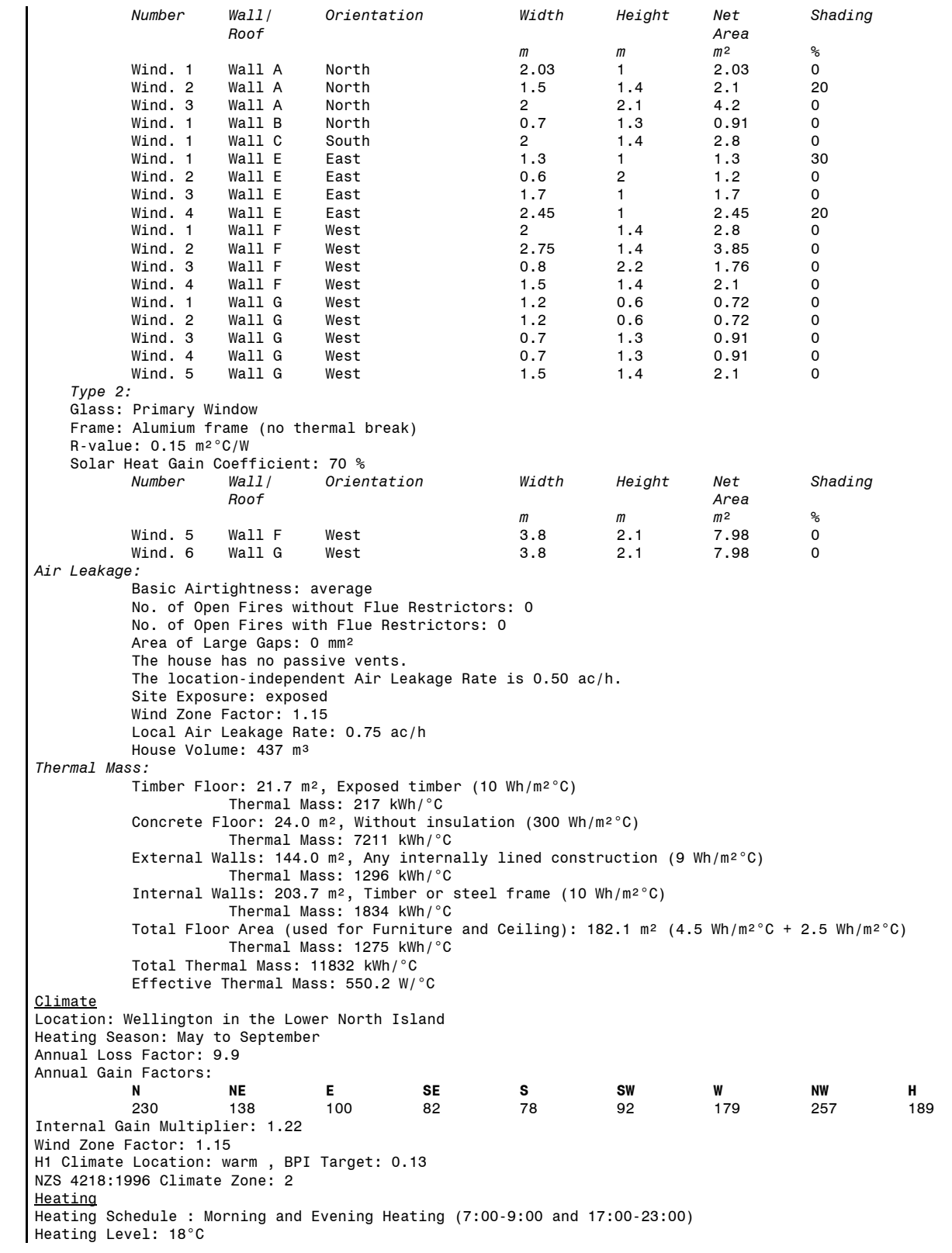




\section{C.9 House 9}

\section{ALF Calculation Report}

roject Description

Current Design: Magnetic Acrylic

\section{signed by: Nick Smith}

In order to comply with the Energy Efficiency Clause H1 (2000) of the New Zealand Building Code a building has to have a BPI of less than $0.13 \mathrm{kWh} / \mathrm{m} 2 /$ Degree Days if it is in a warm location and less than 0.12 (May to August) degree days of less than 920 . Cool locations are locations with 920 degree days or more. The

currenly selected location (Wellington) is a warm location. The target BPI is therefore 0.13 .
Alternatively, the building complies if it is built to NZS 4218:1996. This standard has three different ALF checks the designed building for a BPI and for the NZS 4218:1996 Schedule and Calculation Methods. The currently selected NZS 4218 target R-values are for a "non-solid construction". The current design rates are:

$$
\begin{aligned}
& \text { BPI }=0.112 \\
& \text { NZS } 4218 \text { (Schedule) } \\
& \text { NZS } 4218 \text { (Calculation }
\end{aligned}
$$$$
\text { H1 pass }
$$

The current building design complies with Clause $H 1$ of the NZBC because it complies with at least one of the (Moisture) of the NZBC. the no less than:

a) For light timber frame wall or other framed wall constructions with cavities, 1.5

construction without a cavity, 0.6 .

d) For roof and ceilings of any construction, 1.5

Details of H1 Compliance

Maximum: 0.13
Achieved: 0.112
Warning: Though complying with the BPI target some of the component R-values are extremely low and may lead

Maximum: 0.13
Achieved: 0.112
Warning: Though complying with the BPI target some of the component R-values are extremely low and may lead to an unsatisfactory building performance.

$\begin{array}{clrl}\text { NZS 4218 (Schedule) } & \text { Minimum } & \text { Minimum achieved } & \\ \text { Floor: } & 1.3 & 0.51 & \text { (excl. carpet) } \\ \text { Wall: } & 1.5 & 0.50 & \\ \text { Roof: } & 1.9 & 1.61 & \end{array}$

NZS 4218 (Caof :

$$
\begin{aligned}
& \text { Maximum acceptable heat loss: } 323 \mathrm{~W} /{ }^{\circ} \mathrm{C} \\
& \text { Achieved heat loss: } \\
& 354 \mathrm{~W} /{ }^{\circ} \mathrm{C}
\end{aligned}
$$

For the indiv
of those in the Schedule:

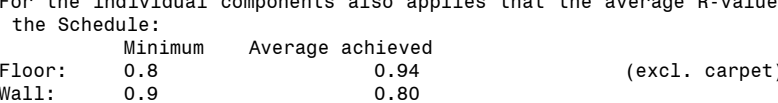

$\begin{array}{lll} & 0.80 \\ & 1.61\end{array}$

\begin{tabular}{|c|c|c|c|c|c|}
\hline \multirow{2}{*}{$\begin{array}{l}\text { Area } \\
\quad m^{2}\end{array}$} & \multicolumn{2}{|c|}{ Loss } & \multicolumn{2}{|c|}{ Gain } & \multirow{3}{*}{$\begin{array}{l}\text { Net Gair } \\
\text { kWh/ } \\
\text { year }\end{array}$} \\
\hline & $\begin{array}{l}\text { kWh } / \\
\text { year }\end{array}$ & $\%$ & $\begin{array}{l}\text { kWh/ } \\
\text { year }\end{array}$ & $\%$ & \\
\hline $50.1 \mathrm{~m}^{2}$ & 272 & $3.5 \%$ & & & \\
\hline $\begin{array}{l}23.6 \mathrm{~m}^{2} \\
14.8 \mathrm{~m}^{2}\end{array}$ & 295 & $3.9 \%$ & & & \\
\hline & $\begin{array}{c}96 \\
11 \epsilon\end{array}$ & $\begin{array}{l}1.2 \% \\
1.5 \%\end{array}$ & & & \\
\hline $2.4 \mathrm{~m}^{2}$ & 66 & $0.9 \%$ & 303 & $12.0 \%$ & $\begin{array}{l}\begin{array}{l}415 \\
237\end{array} \\
\end{array}$ \\
\hline $15.7 n$ & $10 \varsigma$ & $1.4 \%$ & & & \\
\hline & & $0.9 \%$ & 253 & $10.0 \%$ & 187 \\
\hline $\begin{array}{r}3.2 \mathrm{~m}^{2} \\
15\end{array}$ & 8 & $1.1 \%$ & 114 & $4.5 \%$ & 25 \\
\hline
\end{tabular}
Copyright of the standard is property of Standards New Zealand and is protected as described in the NZS
4218:1996 document.

This section gives you an overview of all the heat flows in and out of the designed building. It allows you
to evaluate the importance of the thermal performance of individual building components - for example, of

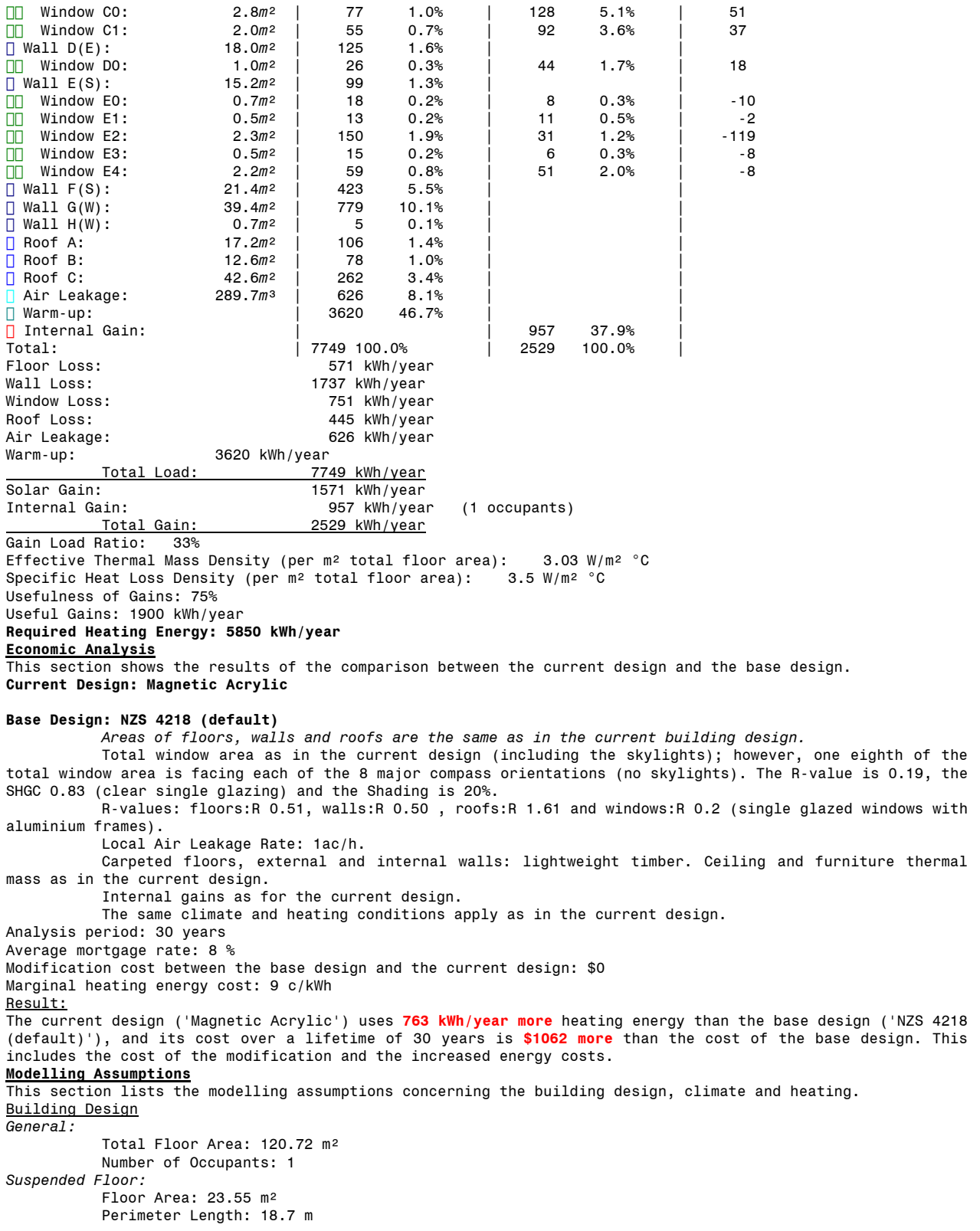

Nick Smith 
Perimeter Height: $0.6 \mathrm{~m}$
Perimeter Area: $11.22 \mathrm{~m}$

Subfloor Exposure: Continuous Perimeter wall (sheltered)

loor Insulation: Uninsulated timber floo

Floor Insulation R-value: $0.3 \mathrm{~m}^{\circ}{ }^{\circ} \mathrm{C} / \mathrm{W}$

Toor suspended Floor R-value: $0.78 \mathrm{~m}^{\circ}{ }^{\circ} \mathrm{C} / \mathrm{M}$

Slab Floor:

Floor Area: $50.05 \mathrm{~m}^{2}$

Perimeter Length: $16.5 \mathrm{~m}$
External Wall Thickness: 0.1

External Wall Thickness: $0.1 \mathrm{~m}$

Under Floor R-value: $0 \mathrm{~m}^{2}{ }^{\circ} \mathrm{C} / \mathrm{W}$

Edge Insulation Width: $0 \mathrm{~m}$

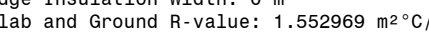

Hoor Covering R-value: $0.27 \mathrm{~m}^{\circ}{ }^{\circ} \mathrm{C} / \mathrm{W}$

alls: Type 1:

Timber Framed Wall, Bevelbacked Weatherboards, Insulation Within Framing - 100 mm Framing 2 Dwangs, Studs $400 \mathrm{~mm}$ ctr., Blanket and Segment Insulants

$\begin{array}{ccllll}\begin{array}{c}\text { Name } \\ \text { Name }\end{array} & \begin{array}{c}\text { Length } \\ \text { orientation }\end{array} & \text { Height } & \begin{array}{l}\text { Net } \\ \text { Area }\end{array} & \begin{array}{l}\text { Window } \\ \text { Area }\end{array} \\ \text { Wall A } & \text { North } & m & m & \begin{array}{l}\mathrm{m}^{2} \\ \mathrm{~m}^{2}\end{array} \\ \text { Wall C } & \text { East } & 8.9 & 2.4 & 14.8 & 6.6 \\ \text { Wall E } & \text { South } & 8.5 & 2.4 & 15.6 & 4.8 \\ \text { Wall H } & \text { West } & 8.9 & 2.4 & 15.2 & 6.12 \\ & & 0.3 & 2.4 & 0.7 & 0\end{array}$

Type 2: 2 Dwangs,

Insulation R-value: $1.3 \mathrm{~m}^{\circ} \mathrm{C} / \mathrm{W}$

\begin{tabular}{|c|c|c|c|c|c|}
\hline Name & $\begin{array}{l}\text { orientation } \\
\text { nats }\end{array}$ & Length & Height & $\begin{array}{l}\text { Net } \\
\text { Area }\end{array}$ & $\begin{array}{l}\text { Window } \\
\text { Area }\end{array}$ \\
\hline & North & $\begin{array}{l}m \\
8.9\end{array}$ & $\begin{array}{l}m \\
2.4\end{array}$ & $\begin{array}{l}m^{2} \\
15.7\end{array}$ & $\begin{array}{l}\mathrm{m}^{2} \\
5.6375\end{array}$ \\
\hline vall & East & 7.9 & 2.4 & 18.0 & 0.96 \\
\hline
\end{tabular}

Type 3:
Concrete Block Wall, Strapped and Lined, Internally Insulated

$47 \times 22$ strap, Straps $400 \mathrm{~mm} \mathrm{ctr}$., Rigid and Semi-Rigid Insulants on internal side of wall Insulation $\mathrm{R}$-value: $0 \mathrm{~m}^{\circ}{ }^{\circ} \mathrm{C} / \mathrm{W}$

Construction R-value: $0.5 \mathrm{~m}^{\circ}{ }^{\circ} \mathrm{C} / \mathrm{W}$

\begin{tabular}{|c|c|c|c|c|c|}
\hline Name & Orientation & Length & Height & $\begin{array}{l}\text { Net } \\
\text { Area }\end{array}$ & $\begin{array}{l}\text { Window } \\
\text { Area }\end{array}$ \\
\hline Wall & South & $\begin{array}{l}m \\
8.9\end{array}$ & $\begin{array}{l}m \\
2.4\end{array}$ & $\begin{array}{l}\mathrm{m}^{2} \\
21.4\end{array}$ & $m_{0}^{m^{2}}$ \\
\hline Wall $\mathrm{c}$ & West & 8.2 & 4.8 & 39.4 & 0 \\
\hline
\end{tabular}

1:

Truss 94x47 900ctr., Batten $35 \times 69<600 c t r .$, Blanket and Segment Insulants*

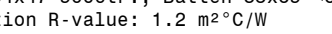

$\begin{array}{lllll}\text { Name } & \text { Length } & \text { Width } & \text { Net } & \text { Window } \\ & m & m & \text { Area } & \text { Area } \\ & m & m & m^{2} \\ \text { Roof A } & 8.2 & 2.1 & 17.2 & 0 \\ \text { Roof B } & 7.9 & 1.6 & 12.6 & 0 \\ \text { Roof C } & 8.2 & 5.2 & 42.6 & 0\end{array}$

Windows and Skylights:

Type 1:
Glass: Magicseal

Frame: Alumium frame (no thermal break)

R-value: $0.36 \mathrm{~m}^{\circ}{ }^{\circ} \mathrm{C} / \mathrm{W}$
Solar Heat Gain Coefficient: $61 \%$

\begin{tabular}{|c|c|c|c|c|c|c|}
\hline Number & $\begin{array}{l}\text { Wall1 } \\
\text { Roof }\end{array}$ & Orientation & Width & Height & $\begin{array}{l}\text { Net } \\
\text { Area }\end{array}$ & Shading \\
\hline Wind. 1 & Wall A & North & $\begin{array}{l}m \\
3\end{array}$ & ${ }_{1.4}^{m}$ & $\begin{array}{l}m^{2} \\
4.2\end{array}$ & $\begin{array}{l}\frac{0}{10} \\
10\end{array}$ \\
\hline Wind. 2 & Wall $\mathrm{A}$ & North & 2 & 1.2 & 2.4 & 10 \\
\hline Wind. 1 & Wall B & North & & 1.2 & 2.4 & 25 \\
\hline Wind. 2 & Wall B & North & 1.75 & 1.85 & 3.2375 & 75 \\
\hline Wind. 1 & Wall $\mathrm{C}$ & East & 2 & 1.4 & 2.8 & 25 \\
\hline Wind. 2 & Wall $\mathrm{C}$ & East & 2 & 1 & & 25 \\
\hline Wind. 1 & Wall D & East & 1.6 & 0.6 & 0.96 & 25 \\
\hline Wind. 1 & Wall E & South & 0.55 & 1.2 & 0.66 & 75 \\
\hline $\begin{array}{l}\text { Wind. } 2 \\
\text { Wind }\end{array}$ & Wall E & South & 0.6 & 0.8 & 0.48 & 50 \\
\hline $\begin{array}{l}\text { Wind. } 4 \\
\text { Wind. } 5\end{array}$ & $\begin{array}{l}\text { Wall } \mathrm{E} \\
\text { Wall } \mathrm{E}\end{array}$ & $\begin{array}{l}\text { South } \\
\text { South }\end{array}$ & 0.6 & 0.9 & 0.54 & $\begin{array}{l}75 \\
50\end{array}$ \\
\hline 2: & & Soutn & & & & \\
\hline \multirow{2}{*}{\multicolumn{7}{|c|}{$\begin{array}{l}\text { Primary Window } \\
\text { Alumium } \mathrm{frame} \text { (no thermal break) } \\
\text { ee: } 0.15 \mathrm{~m}^{\circ}{ }^{\circ} \mathrm{C} / \mathrm{W}\end{array}$}} \\
\hline & & & & & & \\
\hline \multirow{2}{*}{$\begin{array}{l}\text { Heat Gai } \\
\text { Number }\end{array}$} & & & & & & \\
\hline & $\begin{array}{l}\text { Wall/ } \\
\text { Roof }\end{array}$ & Orientation & Width & Height & $\begin{array}{l}\text { Net } \\
\text { Area }\end{array}$ & Shading \\
\hline Wind, 3 & Wall E & South & ${ }_{1.2}^{m}$ & $m 9$ & $\frac{m^{2}}{2.28}$ & $\begin{array}{l}\% \\
75\end{array}$ \\
\hline
\end{tabular}

Air Leakage:

. 3 Wall E South

without Flue Restrictor

No. of Open Fires with Flue Restrictors: 0

Area of Large Gaps: $0 \mathrm{~mm}^{2}$

The house has no passive vents.
The location-independent Air Leakage Rate is $0.50 \mathrm{ac} / \mathrm{h}$.

Site Exposure: medium exposed

Local Air Leakage Rate: $0.66 \mathrm{ac} / \mathrm{h}$

Timber Floor: $10.3 \mathrm{~m}^{2}$, Vinyl $\left(10 \mathrm{Wh} / \mathrm{m}^{2}{ }^{\circ} \mathrm{C}\right)$

Thermal Mass: $103 \mathrm{kWh} /{ }^{\circ} \mathrm{C}$
Concrete Floor: $20.7 \mathrm{~m} \mathrm{~m}^{2}$, without in

Thermal Mass: $6210 \mathrm{kWh} /{ }^{\circ} \mathrm{C}$

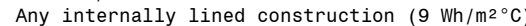

Thermal Mass: $937 \mathrm{kWh} /{ }^{\circ} \mathrm{C}$
Internal Walls: $117.1 \mathrm{~m}^{2}$, Timber or

Total Floor Area (used for Furniture and Ceiling): $120.7 \mathrm{~m}{ }^{2}\left(4.5 \mathrm{Wh} / \mathrm{m}^{\circ}{ }^{\circ} \mathrm{C}+2.5 \mathrm{Wh} / \mathrm{m}^{2}{ }^{\circ} \mathrm{C}\right)$

Thermal Mass: $845 \mathrm{kWh} /{ }^{\circ} \mathrm{C}$

Total Thermal Mass: $9150 \mathrm{kWh} /{ }^{\circ} \mathrm{C}$
Effective Thermal Mass: $365.6 \mathrm{~W} /{ }^{\circ} \mathrm{C}$

Climate Heating Season: May to September

Annual Loss Factor:

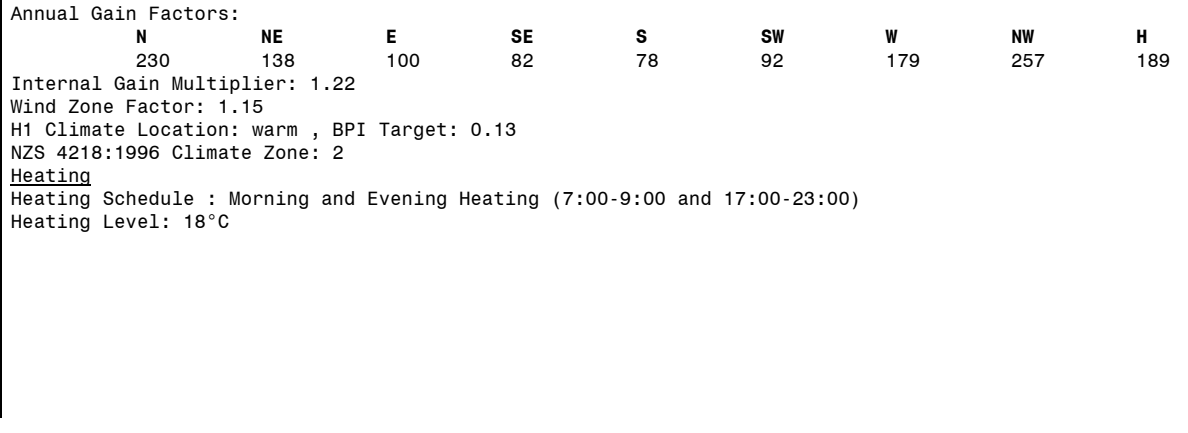




\section{C.10 House 10}

\section{ALF Calculation Report}

\section{Project Description}

Current Design: Magnetic Acrylic

\section{Designed by: Nick Smich}

In order to comply with the Energy Efficiency Clause H1 (2000) of the New Zealand Building Code a building has to have a BPI of less than $0.13 \mathrm{kWh} / \mathrm{m} / \mathrm{Degree}$ Days if $1 \mathrm{t}$ is in a warm location and less than 0.12 (May to August) degree days of less than 920. C001 locations are locations with 920 degree days or more. The currenly selected location (Wellington) is a warm location. The target BPI is therefore 0.13 .
Alternatively, the building complies if it is built to NZS 4218:1996. This standard has three different

ALF checks the designed building for a BPI and for the NZS 4218:1996 Schedule and Calculation Methods. The currently selected NZS 4218 target R-values are for a "non-solid construction".

The current design rates are:

$$
\begin{aligned}
& \text { BPI }=0.146 \\
& \text { NZS } 4218 \text { (Schedule) } \\
& \text { NZS } 4218 \text { (Calculation) }
\end{aligned}
$$$$
\text { H1 fail } \mathrm{H1} \mathrm{fa}
$$

The current building design does
Calculation target in NZS $4218: 1996$.

\section{Details of H1 Compliance}

Maximum: 0.13

$$
\begin{array}{llr} 
& \text { Minimum } & \text { Minimum achieve } \\
\text { Floor: } & 1.3 & 0.50
\end{array}
$$$$
\begin{array}{ll}
\text { Floor: } & 1.3 \\
\text { Wall: } & 1.5
\end{array}
$$$$
\begin{aligned}
& 1.5 \\
& 1.9
\end{aligned}
$$$$
\text { H1 fail }
$$

NZS 4218 (Calculation)

$$
\begin{aligned}
& \text { Maximum acceptable heat loss: } 478 \mathrm{~W} /{ }^{\circ} \mathrm{C} \\
& \text { Achieved heat loss: } \\
& 690 \mathrm{~W} /{ }^{\circ} \mathrm{C}
\end{aligned}
$$

For the individual components also applies that the average $\mathrm{R}$-values must also be larger than 600 of those in the Schedule:
Floor: $\quad 0.8$
Average achieved
.68
(excl. carpet)

Copyright of the standard is property of standards New Zealand and is protected as described in the NZS Energy
This section gives you an overview of all the heat flows in and out of the designed building. It allows you
to evaluate the importance of the thermal performance of individual building components - for example, of

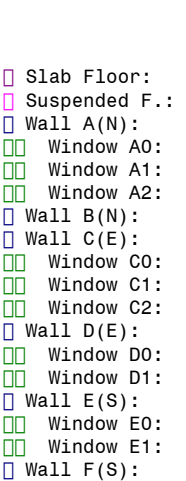

\begin{tabular}{r|} 
Area \\
$m^{2}$ \\
$58.3 m^{2}$ \\
$66.9 m^{2}$ \\
$17.9 m^{2}$ \\
$2.9 m^{2}$ \\
$2.9 m^{2}$ \\
$2.5 m^{2}$ \\
$3.0 m^{2}$ \\
$29.2 m^{2}$ \\
$2.9 m^{2}$ \\
$2.9 m^{2}$ \\
$1.9 m^{2}$ \\
$19.6 m^{2}$ \\
$1.0 m^{2}$ \\
$0.8 m^{2}$ \\
$13.8 m^{2}$ \\
$2.9 m^{2}$ \\
$2.9 m^{2}$ \\
$24.1 m^{2}$
\end{tabular}

\begin{tabular}{rc} 
kWh/ & \multicolumn{2}{l}{ Loss } \\
year & $\%$ \\
509 & $3.6 \%$ \\
856 & $6.0 \%$ \\
443 & $3.1 \%$ \\
78 & $0.6 \%$ \\
78 & $0.6 \%$ \\
69 & $0.5 \%$ \\
59 & $0.4 \%$ \\
723 & $5.1 \%$ \\
78 & $0.6 \%$ \\
78 & $0.6 \%$ \\
52 & $0.4 \%$ \\
388 & $2.7 \%$ \\
27 & $0.2 \%$ \\
22 & $0.2 \%$ \\
342 & $2.4 \%$ \\
78 & $0.6 \%$ \\
78 & $0.6 \%$ \\
478 & $3.4 \%$ \\
&
\end{tabular}

\begin{tabular}{cc|c|c}
$\begin{array}{c}\text { kWh/ } \\
\text { kain } \\
\text { year }\end{array}$ & $\%$ & $\begin{array}{c}\text { Net Gain } \\
\text { kWh } \\
\text { year }\end{array}$ \\
& & \\
280 & $6.7 \%$ & \\
280 & $6.7 \%$ & 202 \\
351 & $8.4 \%$ & 202 \\
& & \\
122 & $2.9 \%$ & 43 \\
122 & $2.9 \%$ & \\
93 & $2.2 \%$ & 43 \\
42 & $1.0 \%$ & 15 \\
49 & $1.2 \%$ & 27 \\
136 & $3.2 \%$ & 57 \\
136 & $3.2 \%$ & 57
\end{tabular}

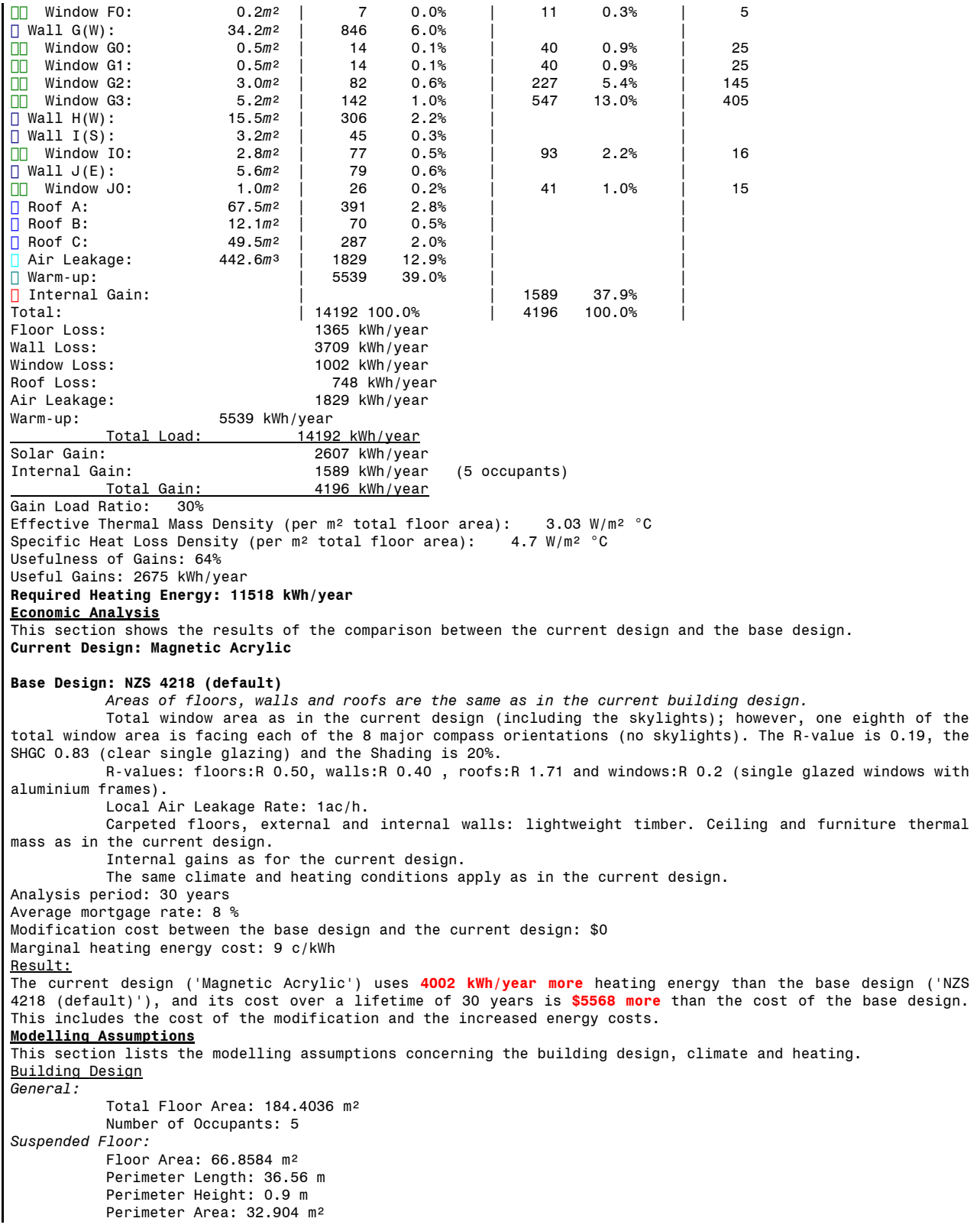


Subfloor Exposure: Continuous Perimeter Wall (sheltered)

Subfoor R-value: $0.20 \mathrm{~m}^{\circ}{ }^{\circ} \mathrm{C} / \mathrm{W}$

Floor Isculation: Uninsulated timber f

Floor Covering R-value: $0.27 \mathrm{~m}^{\circ}{ }^{\circ} \mathrm{C} / \mathrm{W}$

Slab Floo :

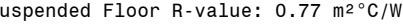

Floor Area: $58.2726 \mathrm{~m}^{2}$

External Wall Thickness: 0.1

Soil Conductivity: $1.2 \mathrm{~W} / \mathrm{m}^{\circ} \mathrm{C}$

Eder Insulation Width: 0 m

slab and Ground R-value: $1.133345 \mathrm{~m}^{\circ} \mathrm{C} / \mathrm{W}$

Floor Covering R-value: $0 \mathrm{~m}^{\circ}{ }^{\circ} \mathrm{C} / \mathrm{W}$
Total Slab Floor R-value: $1.13 \mathrm{~m}^{\circ}{ }^{\circ} \mathrm{C} / \mathrm{W}$

Walls:

Timber Framed Wall, Sheet Cladding, Insulation Within Framing - 100 mm Framin 2 Dwangs, Studs $400 \mathrm{~mm}$ ctr., Blanket and Segment Insulants

Construction R-value: 0.4 . $^{\circ} \mathrm{C}$

\begin{tabular}{ccllll} 
Name & $\begin{array}{c}\text { Length } \\
\text { Orientation }\end{array}$ & Height & $\begin{array}{l}\text { Net } \\
\text { Area }\end{array}$ & $\begin{array}{l}\text { Window } \\
\text { Area }\end{array}$ \\
Wall A & North & $m$ & $m$ & $\mathrm{~m}^{2}$ & $\mathrm{~m}^{2}$ \\
Wall C & East & 10.88 & 2.4 & 17.9 & 8.2 \\
Wall E & South & 15.33 & 2.4 & 29.2 & 7.6 \\
Wall G & West & 8.13 & 2.4 & 13.8 & 5.7 \\
\hline
\end{tabular}

Type 2:

$47 \times 22$ strap, Straps $400 \mathrm{~mm}$ ctr., Rigid and Semi-Rigid Insulants on internal side of wall Insulation R-value: $0 \mathrm{~m}^{2}{ }^{\circ} \mathrm{C} / \mathrm{W}$

$\begin{array}{clllll}\begin{array}{c}\text { Name } \\ \text { Nall }\end{array} & \begin{array}{c}\text { Length } \\ \text { Orientation }\end{array} & \text { Height } & \begin{array}{l}\text { Net } \\ \text { Area }\end{array} & \begin{array}{l}\text { Window } \\ \text { Area }\end{array} \\ \text { Wall B } & \text { North } & m & m & \begin{array}{l}\mathrm{m}^{2} \\ \mathrm{~m}^{2}\end{array} \\ \text { Wall D } & \text { East } & 1.24 & 2.4 & 3.0 & 0 \\ \text { Wall F } & \text { South } & 8.91 & 2.4 & 19.6 & 1.78 \\ \text { Wall H } & \text { West } & 10.15 & 2.4 & 24.1 & 0.24 \\ \text { Thest } & 6.44 & 2.4 & 15.5 & 0\end{array}$

Type 3:

Wall $\mathrm{H}$ West

The Framed Wall, Bevelbacked Weatherboards, Insulation Within Framing - 100 mm Framing 2 Dwangs, Studs $400 \mathrm{~mm}$ ctr., Blanket and Segment Insulants 至

$\begin{array}{ccllll}\begin{array}{c}\text { Length } \\ \text { Name }\end{array} & \begin{array}{c}\text { Height } \\ \text { Orientation }\end{array} & \text { Net } & \text { Window } \\ \text { Area } & \text { Area } \\ \text { Wall I } & \text { South } & m & m & \mathrm{~m}^{2} & \mathrm{~m}^{2} \\ \text { Wall J } & \text { East } & 2.48 & 2.4 & 3.2 & 2.79 \\ & & 2.74 & 2.4 & 5.6 & 0.96\end{array}$

Type 1:

Thed Timber Framed Roof, Metal Clad, Flat Ceiling

Truss $94 \times 47$ 900ctr., Batten $35 \times 69$ <600ctr., Blanket and Segment Insulants*

\begin{tabular}{|c|c|c|c|}
\hline Name & Length & Width & $\begin{array}{l}\text { Net } \\
\text { Area }\end{array}$ \\
\hline Roof $A$ & & $m$ & $m^{2}$ \\
\hline Roof & 2.74 & 4.4 & 12.1 \\
\hline Roof & 6.44 & 7.69 & 49.5 \\
\hline
\end{tabular}

Windows and Skylights:

Type 1 :

ass: Magicseal

$\begin{array}{ll} & \\ \mathrm{m}^{\circ} \mathrm{C} / \mathrm{W} & (n o \\ \end{array}$

Revalue: $0.36 \mathrm{~m}^{\circ}{ }^{\circ} \mathrm{C} / \mathrm{W}$

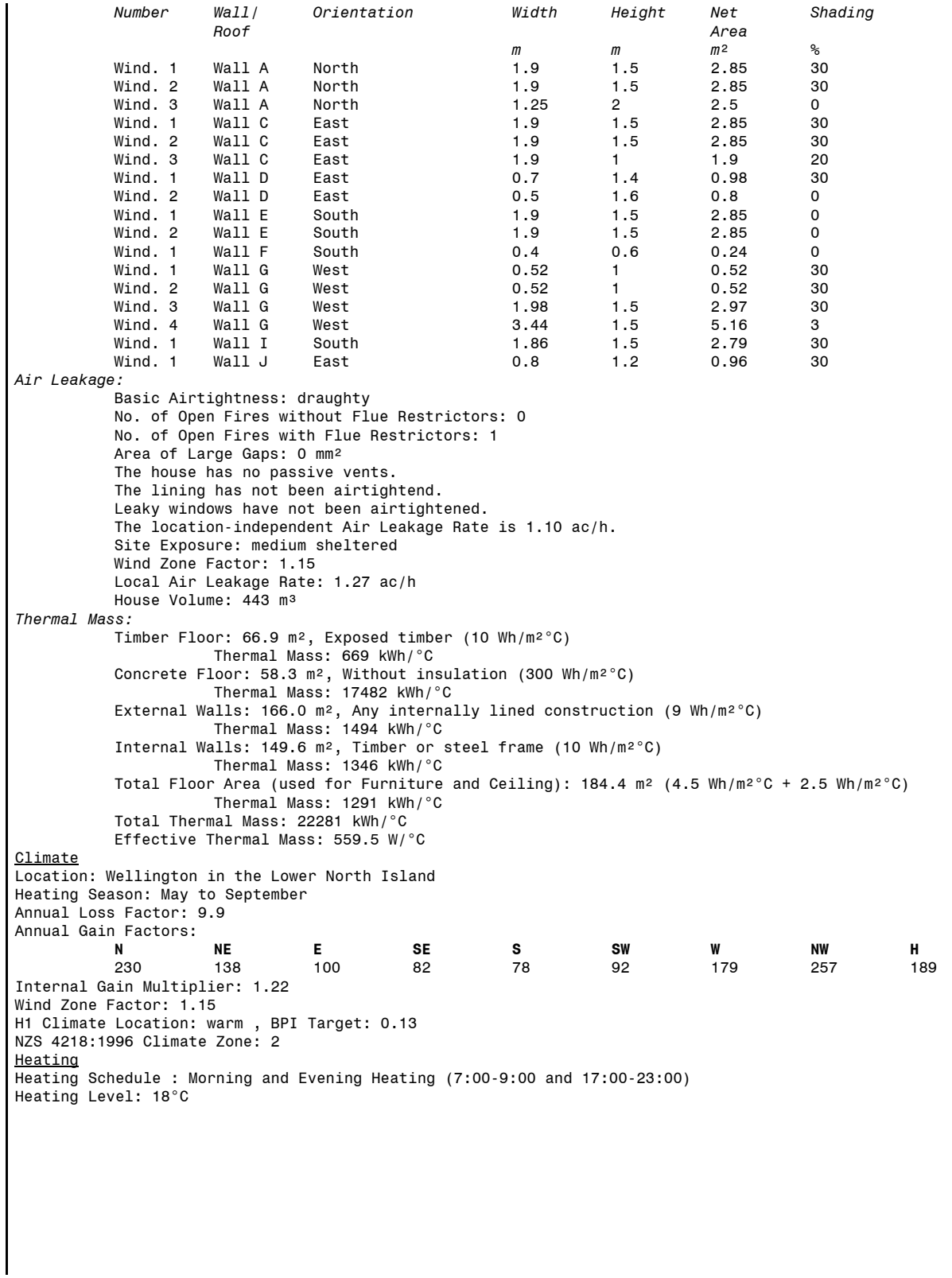

Nick Smith 
A Cost Benefit Analysis of Secondary Glazing as a Retrofit Alternative for New Zealand Homes 


\section{Appendix D Results}

This section presents a large tabulated spreadsheet of the final results and analysis from the 200 ALF simulations.

The tables are presented in order of climate; Auckland, Wellington, Christchurch and Dunedin. 


\section{D.1.1 Auckland}

\begin{tabular}{|c|c|c|c|c|c|c|c|c|c|c|c|c|c|c|c|c|}
\hline House \#1 & & Window Type & $\begin{array}{l}\text { Heating } \\
(\mathrm{kWh})\end{array}$ & $\begin{array}{l}\mathrm{kWh} / \mathrm{m} 2 \\
\text { Floor Area }\end{array}$ & $\begin{array}{l}\mathrm{kWh} / \mathrm{m} 2 \\
\text { Window Area }\end{array}$ & $\begin{array}{l}\mathrm{kWh} / \mathrm{m} 2 \\
\text { Glazing }\end{array}$ & $\mathrm{Sec}$ & Reduction \% & \begin{tabular}{|l} 
Reduction \\
$(\mathrm{kWh})$ \\
\end{tabular} & $\begin{array}{l}\mathrm{kWh} / \mathrm{m} 2 \\
\text { Floor Area }\end{array}$ & \begin{tabular}{|l|}
$\mathrm{kWh} / \mathrm{m} 2$ \\
Window Area
\end{tabular} & \begin{tabular}{|l|}
$\mathrm{kWh} / \mathrm{m} 2$ \\
Glazing
\end{tabular} & $\begin{array}{l}\text { Heating (\$) @ } \\
22.88 / \mathrm{kWh}\end{array}$ & \begin{tabular}{|l} 
Savings \\
(\$)
\end{tabular} & \begin{tabular}{|l|} 
Sec Glazing \\
Cost $(\$)$
\end{tabular} & \begin{tabular}{|l|}
$\begin{array}{l}\text { Payback } \\
\text { (years) }\end{array}$ \\
\end{tabular} \\
\hline Floor Area & 171.2 & Single & 5230.0 & 30.5 & 134.8 & & 144.1 & & & & & & 1196.6 & & & \\
\hline Window Area & 38.8 & Magnetic & 4265.0 & 24.9 & 109.9 & & 117.5 & 18.5 & 965.0 & 5.6 & 24.9 & 26.6 & 975.8 & 220.8 & 5587.2 & 25.3 \\
\hline Sec Glazing Area & 36.3 & Plastic Film & 4289.0 & 25.1 & 110.5 & & 118.2 & 18.0 & 941.0 & 5.5 & 24.3 & 25.9 & 981.3 & 215.3 & 218.0 & -2.7 \\
\hline$\%$ Glazing to floor & 22.7 & Aluminium & 4314.0 & 25.2 & 111.2 & & 118.8 & 17.5 & 916.0 & 5.4 & 23.6 & 25.2 & 987.0 & 209.6 & 5629.1 & 26.9 \\
\hline$\%$ Sec Glazed & 93.6 & Low-e & 4045.0 & 23.6 & 104.3 & & 111.4 & 22.7 & 1185.0 & 6.9 & 30.5 & 32.6 & 925.5 & 271.1 & 6403.4 & 23.6 \\
\hline House \#2 & & Window Type & kWh & $\mathrm{kWh} / \mathrm{m} 2$ & $\mathrm{kWh} / \mathrm{m} 2$ & $\mathrm{kWh} / \mathrm{m} 2$ & & $\%$ & $\mathrm{kWh}$ & $\mathrm{kWh} / \mathrm{m} 2$ & $\mathrm{kWh} / \mathrm{m} 2$ & $\mathrm{kWh} / \mathrm{m} 2$ & Cost \$ & Savings \$ & Cost \$ & Years \\
\hline Floor Area & 165.2 & Window & 5422.0 & 32.8 & 149.4 & & 162.8 & & & & & & 1240.6 & & & \\
\hline Window Area & 36.3 & Magnetic & 4753.0 & 28.8 & 130.9 & & 142.7 & 12.3 & 669.0 & 4.0 & 18.4 & 20.1 & 1087.5 & 153.1 & 7058.0 & 46.1 \\
\hline Sec Glazing Area & 33.3 & Plastic Film & 4770.0 & 28.9 & 131.4 & & 143.2 & 12.0 & 652.0 & 3.9 & 18.0 & 19.6 & 1091.4 & 149.2 & 269.6 & -120.4 \\
\hline$\%$ Glazing to floor & 22.0 & Aluminium & 4788.0 & 29.0 & 131.9 & & 143.8 & 11.7 & 634.0 & 3.8 & 17.5 & 19.0 & 1095.5 & 145.1 & 7751.0 & 53.4 \\
\hline$\%$ Sec Glazed & 91.7 & Low-e & 4607.0 & 27.9 & 126.9 & & 138.3 & 15.0 & 815.0 & 4.9 & 22.5 & 24.5 & 1054.1 & 186.5 & 8729.0 & 46.8 \\
\hline House \#3 & & Window Type & kWh & $\mathrm{kWh} / \mathrm{m} 2$ & $\mathrm{kWh} / \mathrm{m} 2$ & $\mathrm{kWh} / \mathrm{m} 2$ & & $\%$ & $\mathrm{kWh}$ & $\mathrm{kWh} / \mathrm{m} 2$ & $\mathrm{kWh} / \mathrm{m} 2$ & $\mathrm{kWh} / \mathrm{m} 2$ & Cost \$ & Savings \$ & Cost \$ & Years \\
\hline Floor Area & 189.7 & Window & 6715.0 & 35.4 & 143.8 & & 160.3 & & & & & & 1536.4 & & & \\
\hline Window Area & 46.7 & Magnetic & 5852.0 & 30.8 & 125.3 & & 139.7 & 12.9 & 863.0 & 4.5 & 18.5 & 20.6 & 1338.9 & 197.5 & 8194.6 & 41.5 \\
\hline Sec Glazing Area & 41.9 & Plastic Film & 5873.0 & 31.0 & 125.8 & & 140.2 & 12.5 & 842.0 & 4.4 & 18.0 & 20.1 & 1343.7 & 192.6 & 270.6 & -78.0 \\
\hline$\%$ Glazing to floor & 24.6 & Aluminium & 5896.0 & 31.1 & 126.3 & & 140.7 & 12.2 & 819.0 & 4.3 & 17.5 & 19.5 & 1349.0 & 187.4 & 8256.1 & 44.1 \\
\hline$\%$ Sec Glazed & 89.7 & Low-e & 5655.0 & 29.8 & 121.1 & & 135.0 & 15.8 & 1060.0 & 5.6 & 22.7 & 25.3 & 1293.9 & 242.5 & 9391.6 & 38.7 \\
\hline House \#4 & & Window Type & kWh & $\mathrm{kWh} / \mathrm{m} 2$ & $\mathrm{kWh} / \mathrm{m} 2$ & $\mathrm{kWh} / \mathrm{m} 2$ & & $\%$ & $\mathrm{kWh}$ & $\mathrm{kWh} / \mathrm{m} 2$ & $\mathrm{kWh} / \mathrm{m} 2$ & $\mathrm{kWh} / \mathrm{m} 2$ & Cost \$ & Savings $\$$ & Cost \$ & Years \\
\hline Floor Area & 113.3 & Window & 3996.0 & 35.3 & 126.9 & & 126.9 & & & & & & 914.3 & & & \\
\hline Window Area & 31.5 & Magnetic & 3344.0 & 29.5 & 106.2 & & 106.2 & 16.3 & 652.0 & 5.8 & 20.7 & 20.7 & 765.1 & 149.2 & 8194.6 & 54.9 \\
\hline Sec Glazing Area & 31.5 & Plastic Film & 3360.0 & 29.7 & 106.7 & & 106.7 & 15.9 & 636.0 & 5.6 & 20.2 & 20.2 & 768.8 & 145.5 & 306.4 & -160.9 \\
\hline$\%$ Glazing to floor & 27.8 & Aluminium & 3378.0 & 29.8 & 107.2 & & 107.2 & 15.5 & 618.0 & 5.5 & 19.6 & 19.6 & 772.9 & 141.4 & 8256.1 & 58.4 \\
\hline$\%$ Sec Glazed & 100.0 & Low-e & 3198.0 & 28.2 & 101.5 & & 101.5 & 20.0 & 798.0 & 7.0 & 25.3 & 25.3 & 731.7 & 182.6 & 9391.6 & 51.4 \\
\hline
\end{tabular}




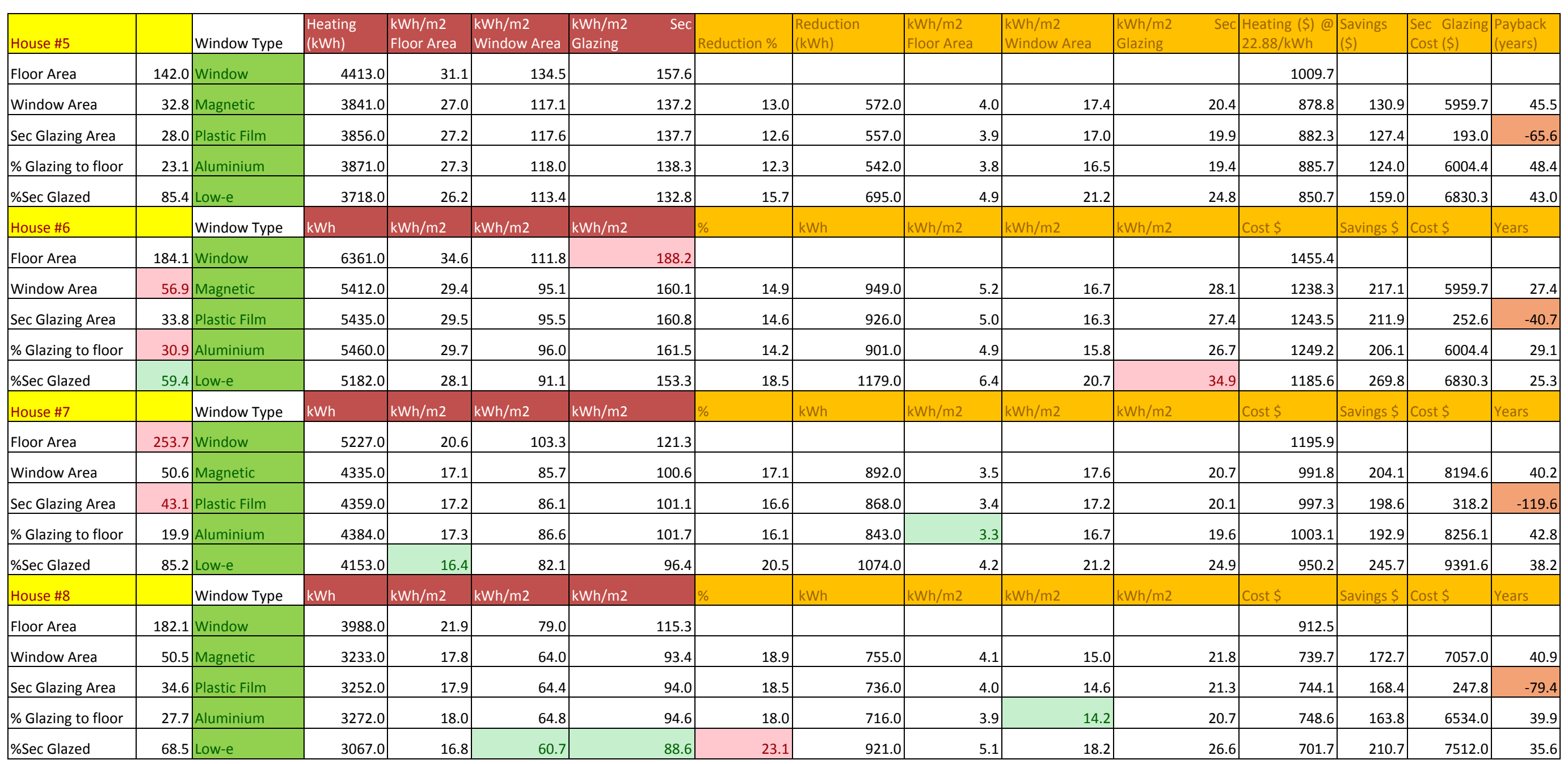




\begin{tabular}{|c|c|c|c|c|c|c|c|c|c|c|c|c|c|c|c|}
\hline House \#9 & & Window Type & $\begin{array}{l}\text { Heating } \\
\text { (kWh) }\end{array}$ & $\begin{array}{l}\mathrm{kWh} / \mathrm{m} 2 \\
\text { Floor Area }\end{array}$ & $\begin{array}{l}\text { kWh/m2 } \\
\text { Window Area }\end{array}$ & $\begin{array}{l}\mathrm{kWh} / \mathrm{m} 2 \\
\text { Glazing }\end{array}$ & Reduction \% & \begin{tabular}{|l}
$\begin{array}{l}\text { Reduction } \\
\text { (kWh) }\end{array}$ \\
\end{tabular} & $\begin{array}{l}\text { kWh/m2 } \\
\text { Floor Area }\end{array}$ & $\begin{array}{l}\mathrm{kWh} / \mathrm{m} 2 \\
\text { Window Area }\end{array}$ & $\begin{array}{l}\text { kWh/m2 } \\
\text { Glazing }\end{array}$ & $\begin{array}{l}\text { Heating (\$) @ } \\
\text { 22.88/kWh }\end{array}$ & $\begin{array}{l}\text { Savings } \\
\text { (\$) }\end{array}$ & \begin{tabular}{|l|} 
Sec Glazing \\
Cost (\$)
\end{tabular} & \begin{tabular}{|l}
$\begin{array}{l}\text { Payback } \\
\text { (years) }\end{array}$ \\
\end{tabular} \\
\hline Floor Area & 120.7 & Window & 3140.0 & 26.0 & 130.3 & 144.0 & & & & & & 718.4 & & & \\
\hline Window Area & 24.1 & Magnetic & 2692.0 & 22.3 & 111.7 & 123.5 & 14.3 & 448.0 & 3.7 & 18.6 & 20.6 & 615.9 & 102.5 & 4097.3 & 40.0 \\
\hline Sec Glazing Area & 21.8 & Plastic Film & 2703.0 & 22.4 & 112.2 & 124.0 & 13.9 & 437.0 & 3.6 & 18.1 & 20.0 & 618.4 & 100.0 & 157.2 & -57.2 \\
\hline$\%$ Glazing to floor & 20.0 & Aluminium & 2716.0 & 22.5 & 112.7 & 124.6 & 13.5 & 424.0 & 3.5 & 17.6 & 19.4 & 621.4 & 97.0 & 4128.0 & 42.6 \\
\hline$\%$ Sec Glazed & 90.5 & Low-e & 2595.0 & 21.5 & 107.7 & 119.0 & 17.4 & 545.0 & 4.5 & 22.6 & 25.0 & 593.7 & 124.7 & 4695.8 & 37.7 \\
\hline House \#10 & & Window Type & $\mathrm{kWh}$ & $\mathrm{kWh} / \mathrm{m} 2$ & $\mathrm{kWh} / \mathrm{m} 2$ & $\mathrm{kWh} / \mathrm{m} 2$ & $\%$ & $\mathrm{kWh}$ & $\mathrm{kWh} / \mathrm{m} 2$ & $\mathrm{kWh} / \mathrm{m} 2$ & $\mathrm{kWh} / \mathrm{m} 2$ & Cost \$ & Savings \$ & Cost $\$$ & Years \\
\hline Floor Area & 184.4 & Window & 6114.0 & 33.2 & 168.0 & 168.0 & & & & & & 1398.9 & & & \\
\hline Window Area & 36.4 & Magnetic & 5376.0 & 29.2 & 147.7 & 147.7 & 12.1 & 738.0 & 4.0 & 20.3 & 20.3 & 1230.0 & 168.9 & 6332.2 & 37.5 \\
\hline Sec Glazing Area & 36.4 & Plastic Film & 5394.0 & 29.3 & 148.2 & 148.2 & 11.8 & 720.0 & 3.9 & 19.8 & 19.8 & 1234.1 & 164.7 & 234.8 & -70.1 \\
\hline$\%$ Glazing to floor & 19.7 & Aluminium & 5413.0 & 29.4 & 148.7 & 148.7 & 11.5 & 701.0 & 3.8 & 19.3 & 19.3 & 1238.5 & 160.4 & 6379.7 & 39.8 \\
\hline \multirow[t]{4}{*}{$\%$ Sec Glazed } & 100.0 & Low-e & 5211.0 & 28.3 & 143.2 & 143.2 & 14.8 & 903.0 & 4.9 & 24.8 & 24.8 & 1192.3 & 206.6 & 7257.2 & 35.1 \\
\hline & & & $\mathrm{kWh}$ & $\mathrm{kWh} / \mathrm{m} 2$ & $\mathrm{kWh} / \mathrm{m} 2$ & $\mathrm{kWh} / \mathrm{m} 2$ & $\%$ & $\mathrm{kWh}$ & $\mathrm{kWh} / \mathrm{m} 2$ & $\mathrm{kWh} / \mathrm{m} 2$ & $\mathrm{kWh} / \mathrm{m} 2$ & Cost \$ & Savings \$ & Cost \$ & Years \\
\hline & & Maximum & 6715.0 & 35.4 & 168.0 & 188.2 & 23.1 & 1185.0 & 7.0 & 30.5 & 34.9 & 1536.4 & 271.1 & & 58.4 \\
\hline & & Minimum & 2595.0 & 16.4 & 60.7 & 88.6 & 11.5 & 424.0 & 3.3 & 14.2 & 19.0 & 593.7 & 97.0 & & 23.6 \\
\hline \multirow[t]{6}{*}{\begin{tabular}{|l|} 
Household \\
Average \\
\end{tabular}} & & Window Type & kWh & $\mathrm{kWh} / \mathrm{m} 2$ & $\mathrm{kWh} / \mathrm{m} 2$ & $\mathrm{kWh} / \mathrm{m} 2$ & $\%$ & kWh & $\mathrm{kWh} / \mathrm{m} 2$ & $\mathrm{kWh} / \mathrm{m} 2$ & $\mathrm{kWh} / \mathrm{m} 2$ & Cost \$ & Savings $\$$ & Cost \$ & Years \\
\hline & 170.6 & Window & 5060.6 & 30.1 & 128.2 & 148.8 & & & & & & 1157.9 & & & \\
\hline & 40.5 & Magnetic & 4310.3 & 25.7 & 109.4 & 126.9 & 14.8 & 750.3 & 4.5 & 18.8 & 22.0 & 986.2 & 171.7 & 6663.5 & 39.9 \\
\hline & 34.1 & Plastic Film & 4329.1 & 25.8 & 109.8 & 127.4 & 14.5 & 731.5 & 4.3 & 18.3 & 21.4 & 990.5 & 167.4 & 246.8 & -79.5 \\
\hline & & Aluminium & 4349.2 & 25.9 & 110.3 & 128.0 & 14.1 & 711.4 & 4.2 & 17.8 & 20.8 & 995.1 & 162.8 & 6719.9 & 42.5 \\
\hline & & Low-e & 4143.1 & 24.7 & 105.2 & 122.0 & 18.1 & 917.5 & 5.4 & 23.0 & 26.9 & 947.9 & 209.9 & 7643.3 & 37.6 \\
\hline
\end{tabular}

Table D-4: Auckland Results Spreadsheet 


\section{D.1.2 Wellington}

\begin{tabular}{|c|c|c|c|c|c|c|c|c|c|c|c|c|c|c|c|}
\hline House \#1 & & Window Type & $\begin{array}{l}\begin{array}{l}\text { Heating } \\
\text { (kWh) }\end{array} \\
\end{array}$ & $\begin{array}{l}\mathrm{kWh} / \mathrm{m} 2 \\
\text { Floor Area }\end{array}$ & \begin{tabular}{l|}
$\mathrm{kWh} / \mathrm{m} 2$ \\
Window Area
\end{tabular} & $\begin{array}{l}\mathrm{kWh} / \mathrm{m} 2 \\
\text { Glazing }\end{array}$ & Reduction \% & \begin{tabular}{|l|}
$\begin{array}{l}\text { Reduction } \\
\text { (kWh) }\end{array}$ \\
\end{tabular} & $\begin{array}{l}\mathrm{kWh} / \mathrm{m} 2 \\
\text { Floor Area }\end{array}$ & \begin{tabular}{|l|}
$\mathrm{kWh} / \mathrm{m} 2$ \\
Window Area
\end{tabular} & $\begin{array}{l}\mathrm{kWh} / \mathrm{m} 2 \\
\text { Glazing }\end{array}$ & $\begin{array}{l}\text { Heating (\$) @ } \\
22.85 / \mathrm{kWh}) \\
\end{array}$ & \begin{tabular}{|l} 
Savings \\
(\$)
\end{tabular} & \begin{tabular}{|l|} 
Sec Glazing \\
Cost (\$)
\end{tabular} & $\begin{array}{l}\begin{array}{l}\text { Payback } \\
\text { (years) }\end{array} \\
\end{array}$ \\
\hline Floor Area & 171.2 & Single & 11141.0 & 65.1 & 287.1 & 306.9 & & & & & & 2545.7 & & & \\
\hline Window Area & 38.8 & 3 Magnetic & 9323.0 & 54.5 & 240.3 & 256.8 & 16.3 & 1818.0 & 10.6 & 46.9 & 50.1 & 2130.3 & 415.4 & 5587.2 & 13.4 \\
\hline Sec Glazing Area & 36.3 & Plastic Film & 9366.0 & 54.7 & 241.4 & 258.0 & 15.9 & 1775.0 & 10.4 & 45.7 & 48.9 & 2140.1 & 405.6 & 218.0 & 187.6 \\
\hline$\%$ Glazing to floor & & Aluminium & 9412.0 & 55.0 & 242.6 & 259.3 & 15.5 & 1729.0 & 10.1 & 44.6 & 47.6 & 2150.6 & 395.1 & 5629.1 & 14.2 \\
\hline$\%$ Sec Glazed & & Low-e & 8896.0 & 52.0 & 229.3 & 245.1 & 20.2 & 2245.0 & 13.1 & 57.9 & 61.8 & 2032.7 & 513.0 & 6403.4 & 12.5 \\
\hline House \#2 & & Window Type & $\mathrm{kWh}$ & $\mathrm{kWh} / \mathrm{m} 2$ & $\mathrm{kWh} / \mathrm{m} 2$ & $\mathrm{kWh} / \mathrm{m} 2$ & $\%$ & kWh & $\mathrm{kWh} / \mathrm{m} 2$ & $\mathrm{kWh} / \mathrm{m} 2$ & $\mathrm{kWh} / \mathrm{m} 2$ & Cost \$ & Savings \$ & Cost \$ & Years \\
\hline Floor Area & 165.2 & Window & 11486.0 & 69.5 & 316.4 & 344.9 & & & & & & 2624.6 & & & \\
\hline Window Area & 36.3 & Magnetic & 10207.0 & 61.8 & 281.2 & 306.5 & 11.1 & 1279.0 & 7.7 & 35.2 & 38.4 & 2332.3 & 292.3 & 7058.0 & 24.2 \\
\hline Sec Glazing Area & 33.3 & Plastic Film & 10237.0 & 62.0 & 282.0 & 307.4 & 10.9 & 1249.0 & 7.6 & 34.4 & 37.5 & 2339.2 & 285.4 & 269.6 & 15.8 \\
\hline$\%$ Glazing to floor & & Aluminium & 10270.0 & 62.2 & 282.9 & 308.4 & 10.6 & 1216.0 & 7.4 & 33.5 & 36.5 & 2346.7 & 277.9 & 7751.0 & 27.9 \\
\hline$\%$ Sec Glazed & & Low-e & 9913.0 & 60.0 & 273.1 & 297.7 & 13.7 & 1573.0 & 9.5 & 43.3 & 47.2 & 2265.1 & 359.4 & 8729.0 & 24.3 \\
\hline House \#3 & & Window Type & $\mathrm{kWh}$ & $\mathrm{kWh} / \mathrm{m} 2$ & $\mathrm{kWh} / \mathrm{m} 2$ & $\mathrm{kWh} / \mathrm{m} 2$ & $\%$ & kWh & $\mathrm{kWh} / \mathrm{m} 2$ & $\mathrm{kWh} / \mathrm{m} 2$ & $\mathrm{kWh} / \mathrm{m} 2$ & Cost \$ & Savings \$ & Cost $\$$ & Years \\
\hline Floor Area & 189.7 & Window & 14050.0 & 74.1 & 300.9 & 335.3 & & & & & & 3210.4 & & & \\
\hline Window Area & 46.7 & Magnetic & 12410.0 & 65.4 & 265.7 & 296.2 & 11.7 & 1640.0 & 8.6 & 35.1 & 39.1 & 2835.7 & 374.7 & 8194.6 & 21.9 \\
\hline Sec Glazing Area & 41.9 & Plastic Film & 12448.0 & 65.6 & 266.6 & 297.1 & 11.4 & 1602.0 & 8.4 & 34.3 & 38.2 & 2844.4 & 366.1 & 270.6 & 95.5 \\
\hline$\%$ Glazing to floor & & Aluminium & 12489.0 & 65.8 & 267.4 & 298.1 & 11.1 & 1561.0 & 8.2 & 33.4 & 37.3 & 2853.7 & 356.7 & 8256.1 & 23.1 \\
\hline$\%$ Sec Glazed & & Low-e & 12022.0 & 63.4 & 257.4 & 286.9 & 14.4 & 2028.0 & 10.7 & 43.4 & 48.4 & 2747.0 & 463.4 & 9391.6 & 20.3 \\
\hline House \#4 & & Window Type & $\mathrm{kWh}$ & $\mathrm{kWh} / \mathrm{m} 2$ & $\mathrm{kWh} / \mathrm{m} 2$ & $\mathrm{kWh} / \mathrm{m} 2$ & $\%$ & kWh & $\mathrm{kWh} / \mathrm{m} 2$ & $\mathrm{kWh} / \mathrm{m} 2$ & $\mathrm{kWh} / \mathrm{m} 2$ & Cost $\$$ & Savings \$ & Cost \$ & Years \\
\hline Floor Area & 113.3 & Window & 8462.0 & 74.7 & 268.6 & 268.6 & & & & & & 1933.6 & & & \\
\hline Window Area & 31.5 & Magnetic & 7224.0 & 63.8 & 229.3 & 229.3 & 14.6 & 1238.0 & 10.9 & 39.3 & 39.3 & 1650.7 & 282.9 & 8194.6 & 29.0 \\
\hline Sec Glazing Area & 31.5 & Plastic Film & 7254.0 & 64.0 & 230.3 & 230.3 & 14.3 & 1208.0 & 10.7 & 38.3 & 38.3 & 1657.5 & 276.0 & 306.4 & -30.4 \\
\hline$\%$ Glazing to floor & & Aluminium & 7285.0 & 64.3 & 231.3 & 231.3 & 13.9 & 1177.0 & 10.4 & 37.4 & 37.4 & 1664.6 & 268.9 & 8256.1 & 30.7 \\
\hline$\%$ Sec Glazed & & Low-e & 6936.0 & 61.2 & 220.2 & 220.2 & 18.0 & 1526.0 & 13.5 & 48.4 & 48.4 & 1584.9 & 348.7 & 9391.6 & 26.9 \\
\hline
\end{tabular}




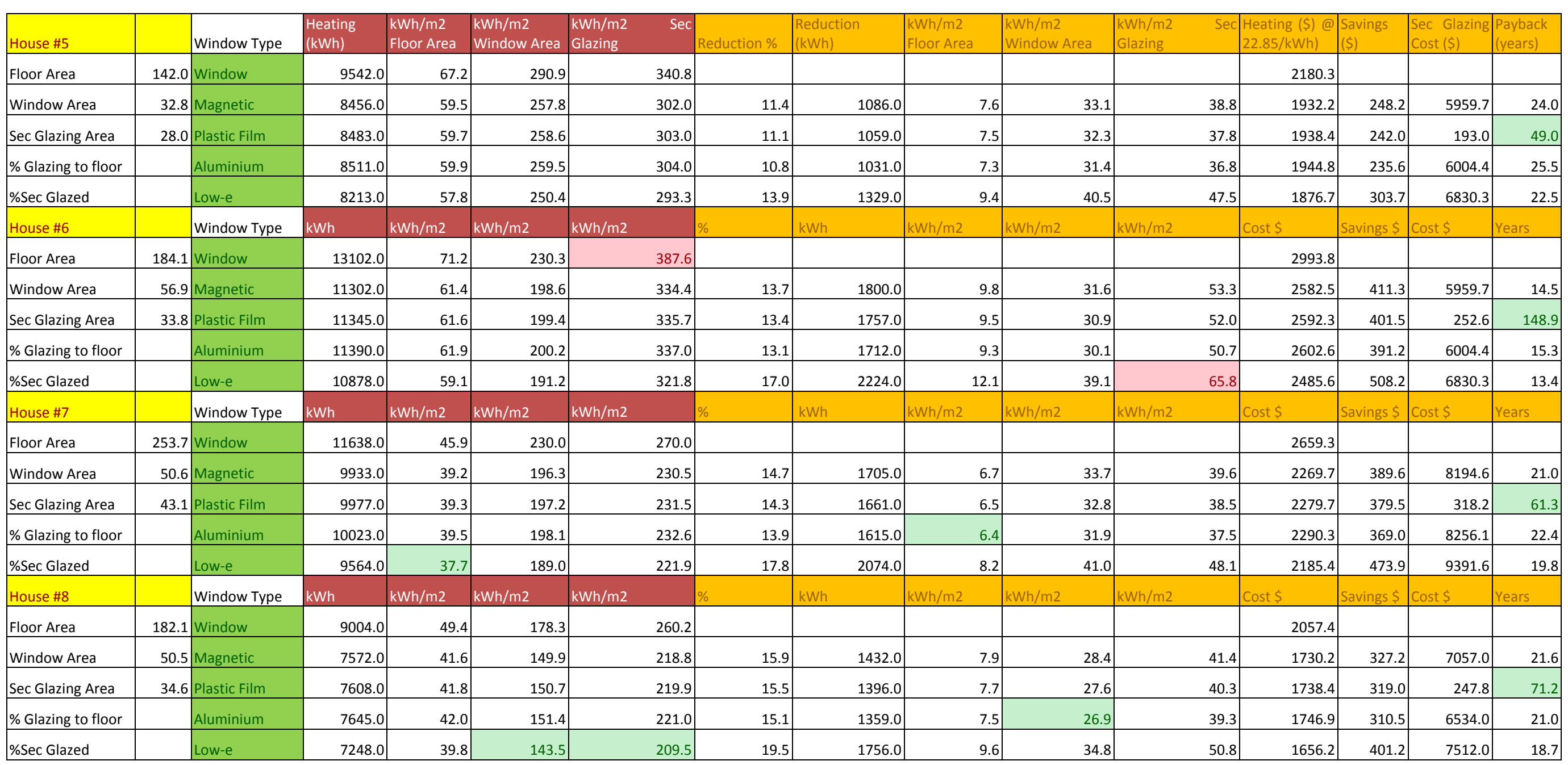




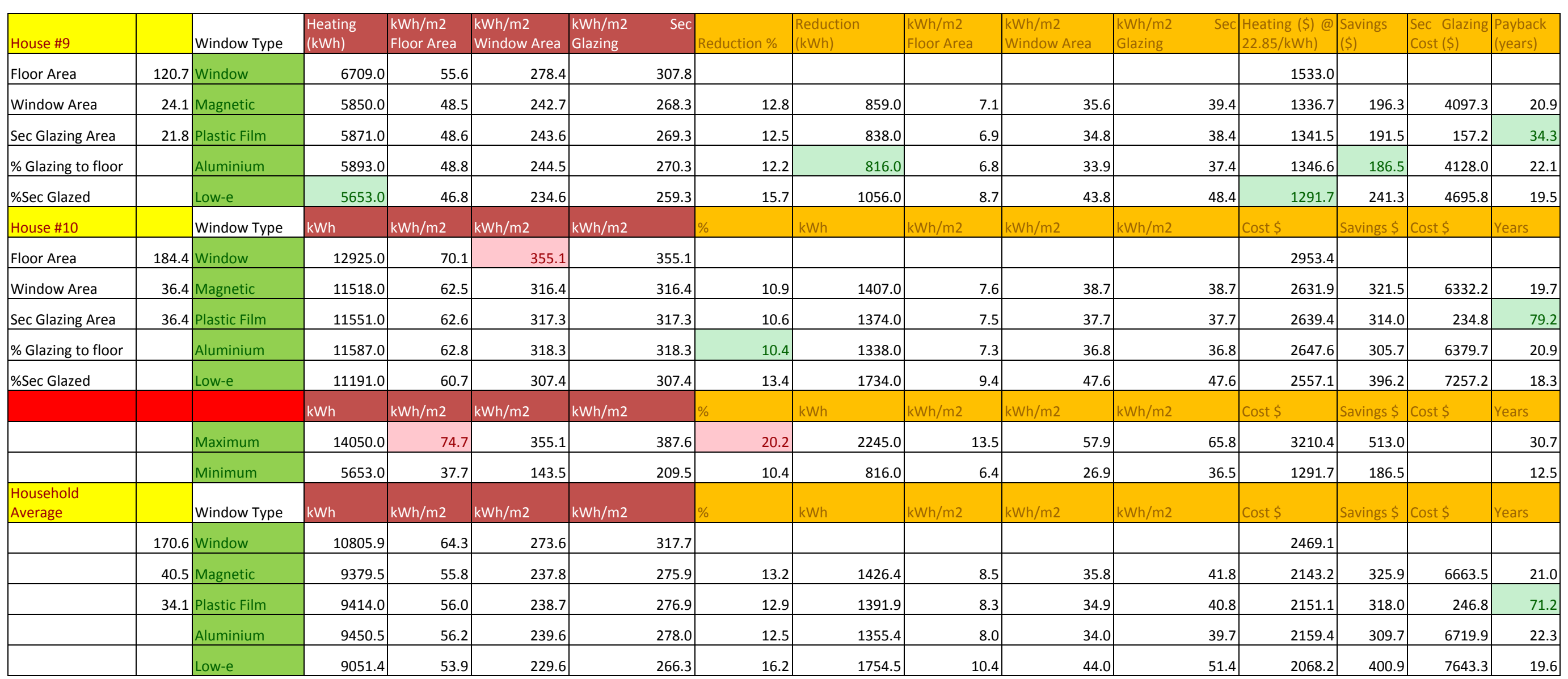

Table D-5: Wellington Results Spreadsheet 


\section{D.1.3 Christchurch}

\begin{tabular}{|c|c|c|c|c|c|c|c|c|c|c|c|c|c|c|c|}
\hline House \#1 & & Window Type & $\begin{array}{l}\begin{array}{l}\text { Heating } \\
(\mathrm{kWh})\end{array} \\
\end{array}$ & $\begin{array}{l}\mathrm{kWh} / \mathrm{m} 2 \\
\text { Floor Area }\end{array}$ & $\begin{array}{l}\mathrm{kWh} / \mathrm{m} 2 \\
\text { Window Area }\end{array}$ & $\begin{array}{l}\mathrm{kWh} / \mathrm{m} 2 \\
\text { Glazing }\end{array}$ & Reduction \% & \begin{tabular}{|l} 
Reduction \\
$(\mathrm{kWh})$ \\
\end{tabular} & $\begin{array}{l}\mathrm{kWh} / \mathrm{m} 2 \\
\text { Floor Area }\end{array}$ & \begin{tabular}{|l|}
$\mathrm{kWh} / \mathrm{m} 2$ \\
Window Area
\end{tabular} & \begin{tabular}{|l|}
$\mathrm{kWh} / \mathrm{m} 2$ \\
Glazing
\end{tabular} & $\begin{array}{l}\text { Heating (\$) @ } \\
21.43 / \mathrm{kWh})\end{array}$ & \begin{tabular}{|l} 
Savings \\
(\$)
\end{tabular} & \begin{tabular}{|l|} 
Sec Glazing \\
Cost $(\$)$
\end{tabular} & \begin{tabular}{|l|}
$\begin{array}{l}\text { Payback } \\
\text { (years) }\end{array}$ \\
\end{tabular} \\
\hline Floor Area & 171.2 & Single & 13031.0 & 76.1 & 335.9 & 359.0 & & & & & & 2792.5 & & & \\
\hline Window Area & 38.8 & Magnetic & 10814.0 & 63.2 & 278.7 & 297.9 & 17.0 & 2217.0 & 12.9 & 57.1 & 61.1 & 2317.4 & 475.1 & 5587.2 & 11.8 \\
\hline Sec Glazing Area & 36.3 & Plastic Film & 10867.0 & 63.5 & 280.1 & 299.4 & 16.6 & 2164.0 & 12.6 & 55.8 & 59.6 & 2328.8 & 463.7 & 218.0 & 245.7 \\
\hline$\%$ Glazing to floor & & Aluminium & 10923.0 & 63.8 & 281.5 & 300.9 & 16.2 & 2108.0 & 12.3 & 54.3 & 58.1 & 2340.8 & 451.7 & 5629.1 & 12.5 \\
\hline$\%$ Sec Glazed & & Low-e & 10298.0 & 60.2 & 265.4 & 283.7 & 21.0 & 2733.0 & 16.0 & 70.4 & 75.3 & 2206.9 & 585.7 & 6403.4 & 10.9 \\
\hline House \#2 & & Window Type & $\mathrm{kWh}$ & $\mathrm{kWh} / \mathrm{m} 2$ & $\mathrm{kWh} / \mathrm{m} 2$ & $\mathrm{kWh} / \mathrm{m} 2$ & $\%$ & $\mathrm{kWh}$ & $\mathrm{kWh} / \mathrm{m} 2$ & $\mathrm{kWh} / \mathrm{m} 2$ & $\mathrm{kWh} / \mathrm{m} 2$ & Cost \$ & Savings \$ & Cost \$ & Years \\
\hline Floor Area & 165.2 & Window & 13543.0 & 82.0 & 373.1 & 406.7 & & & & & & 2902.3 & & & \\
\hline Window Area & 36.3 & Magnetic & 11988.0 & 72.6 & 330.2 & 360.0 & 11.5 & 1555.0 & 9.4 & 42.8 & 46.7 & 2569.0 & 333.2 & 7058.0 & 21.2 \\
\hline Sec Glazing Area & 33.3 & Plastic Film & 12025.0 & 72.8 & 331.3 & 361.1 & 11.2 & 1518.0 & 9.2 & 41.8 & 45.6 & 2577.0 & 325.3 & 269.6 & 55.7 \\
\hline$\%$ Glazing to floor & & Aluminium & 12065.0 & 73.0 & 332.4 & 362.3 & 10.9 & 1478.0 & 8.9 & 40.7 & 44.4 & 2585.5 & 316.7 & 7751.0 & 24.5 \\
\hline$\%$ Sec Glazed & & Low-e & 11633.0 & 70.4 & 320.5 & 349.3 & 14.1 & 1910.0 & 11.6 & 52.6 & 57.4 & 2493.0 & 409.3 & 8729.0 & 21.3 \\
\hline House \#3 & & Window Type & $\mathrm{kWh}$ & $\mathrm{kWh} / \mathrm{m} 2$ & $\mathrm{kWh} / \mathrm{m} 2$ & $\mathrm{kWh} / \mathrm{m} 2$ & $\%$ & kWh & $\mathrm{kWh} / \mathrm{m} 2$ & $\mathrm{kWh} / \mathrm{m} 2$ & $\mathrm{kWh} / \mathrm{m} 2$ & Cost $\$$ & Savings \$ & Cost \$ & Years \\
\hline Floor Area & 189.7 & Window & 16603.0 & 87.5 & 355.5 & 396.3 & & & & & & 3558.0 & & & \\
\hline Window Area & 46.7 & Magnetic & 14608.0 & 77.0 & 312.8 & 348.6 & 12.0 & 1995.0 & 10.5 & 42.7 & 47.6 & 3130.5 & 427.5 & 8194.6 & 19.2 \\
\hline Sec Glazing Area & 41.9 & Plastic Film & 14655.0 & 77.3 & 313.8 & 349.8 & 11.7 & 1948.0 & 10.3 & 41.7 & 46.5 & 3140.6 & 417.5 & 270.6 & 146.9 \\
\hline$\%$ Glazing to floor & & Aluminium & 14705.0 & 77.5 & 314.9 & 351.0 & 11.4 & 1898.0 & 10.0 & 40.6 & 45.3 & 3151.3 & 406.7 & 8256.1 & 20.3 \\
\hline$\%$ Sec Glazed & & Low-e & 14139.0 & 74.5 & 302.8 & 337.4 & 14.8 & 2464.0 & 13.0 & 52.8 & 58.8 & 3030.0 & 528.0 & 9391.6 & 17.8 \\
\hline House \#4 & & Window Type & $\mathrm{kWh}$ & $\mathrm{kWh} / \mathrm{m} 2$ & $\mathrm{kWh} / \mathrm{m} 2$ & $\mathrm{kWh} / \mathrm{m} 2$ & $\%$ & kWh & $\mathrm{kWh} / \mathrm{m} 2$ & $\mathrm{kWh} / \mathrm{m} 2$ & $\mathrm{kWh} / \mathrm{m} 2$ & Cost \$ & Savings \$ & Cost \$ & Years \\
\hline Floor Area & 113.3 & Window & 10051.0 & 88.7 & 319.1 & 319.1 & & & & & & 2153.9 & & & \\
\hline Window Area & 31.5 & Magnetic & 8543.0 & 75.4 & 271.2 & 271.2 & 15.0 & 1508.0 & 13.3 & 47.9 & 47.9 & 1830.8 & 323.2 & 8194.6 & 25.4 \\
\hline Sec Glazing Area & 31.5 & Plastic Film & 8579.0 & 75.7 & 272.3 & 272.3 & 14.6 & 1472.0 & 13.0 & 46.7 & 46.7 & 1838.5 & 315.4 & 306.4 & 9.0 \\
\hline$\%$ Glazing to floor & & Aluminium & 8617.0 & 76.1 & 273.6 & 273.6 & 14.3 & 1434.0 & 12.7 & 45.5 & 45.5 & 1846.6 & 307.3 & 8256.1 & 26.9 \\
\hline$\%$ Sec Glazed & & Low-e & 8195.0 & 72.3 & 260.2 & 260.2 & 18.5 & 1856.0 & 16.4 & 58.9 & 58.9 & 1756.2 & 397.7 & 9391.6 & 23.6 \\
\hline
\end{tabular}




\begin{tabular}{|c|c|c|c|c|c|c|c|c|c|c|c|c|c|c|c|c|}
\hline House \#5 & & Window Type & $\begin{array}{l}\begin{array}{l}\text { Heating } \\
\text { (kWh) }\end{array} \\
\end{array}$ & $\begin{array}{l}\text { kWh } / \mathrm{m} 2 \\
\text { Floor Area }\end{array}$ & $\begin{array}{l}\mathrm{kWh} / \mathrm{m} 2 \\
\text { Window Area }\end{array}$ & $\begin{array}{l}\mathrm{kWh} / \mathrm{m} 2 \\
\text { Glazing }\end{array}$ & Sec & Reduction \% & $\begin{array}{l}\text { Reduction } \\
\text { (kWh) }\end{array}$ & $\begin{array}{l}\text { kWh/m2 } \\
\text { Floor Area }\end{array}$ & $\begin{array}{l}\mathrm{kWh} / \mathrm{m} 2 \\
\text { Window Area }\end{array}$ & $\begin{array}{l}\mathrm{kWh} / \mathrm{m} 2 \\
\text { Glazing }\end{array}$ & \begin{tabular}{|l|} 
Heating (\$) @ \\
$21.43 / \mathrm{kWh})$
\end{tabular} & \begin{tabular}{|l} 
Savings \\
(\$)
\end{tabular} & $\begin{array}{l}\text { Sec Glazing } \\
\text { Cost (\$) }\end{array}$ & $\begin{array}{l}\text { Payback } \\
\text { (years) }\end{array}$ \\
\hline Floor Area & 142.0 & Window & 11274.0 & 79.4 & 343.7 & & 402.6 & & & & & & 2416.0 & & & \\
\hline Window Area & 32.8 & Magnetic & 9952.0 & 70.1 & 303.4 & & 355.4 & 11.7 & 1322.0 & 9.3 & 40.3 & 47.2 & 2132.7 & 283.3 & 5959.7 & 21.0 \\
\hline Sec Glazing Area & 28.0 & Plastic Film & 9985.0 & 70.3 & 304.4 & & 356.6 & 11.4 & 1289.0 & 9.1 & 39.3 & 46.0 & 2139.8 & 276.2 & 193.0 & 83.2 \\
\hline$\%$ Glazing to floor & & Aluminium & 10020.0 & 70.6 & 305.5 & & 357.9 & 11.1 & 1254.0 & 8.8 & 38.2 & 44.8 & 2147.3 & 268.7 & 6004.4 & 22.3 \\
\hline$\%$ Sec Glazed & & Low-e & 9658.0 & 68.0 & 294.5 & & 344.9 & 14.3 & 1616.0 & 11.4 & 49.3 & 57.7 & 2069.7 & 346.3 & 6830.3 & 19.7 \\
\hline House \#6 & & Window Type & kWh & $\mathrm{kWh} / \mathrm{m} 2$ & $\mathrm{kWh} / \mathrm{m} 2$ & $\mathrm{kWh} / \mathrm{m} 2$ & & $\%$ & kWh & $\mathrm{kWh} / \mathrm{m} 2$ & $\mathrm{kWh} / \mathrm{m} 2$ & $\mathrm{kWh} / \mathrm{m} 2$ & Cost $\$$ & Savings \$ & Cost \$ & Years \\
\hline Floor Area & 184.1 & Window & 15891.0 & 86.3 & 279.3 & & 470.1 & & & & & & 3405.4 & & & \\
\hline Window Area & 56.9 & Magnetic & 13699.0 & 74.4 & 240.8 & & 405.3 & 13.8 & 2192.0 & 11.9 & 38.5 & 64.9 & 2935.7 & 469.7 & 5959.7 & 12.7 \\
\hline Sec Glazing Area & 33.8 & Plastic Film & 13415.0 & 72.9 & 235.8 & & 396.9 & 15.6 & 2476.0 & 13.4 & 43.5 & 73.3 & 2874.8 & 530.6 & 252.6 & 278.0 \\
\hline \% Glazing to floor & & Aluminium & 13807.0 & 75.0 & 242.7 & & 408.5 & 13.1 & 2084.0 & 11.3 & 36.6 & 61.7 & 2958.8 & 446.6 & 6004.4 & 13.4 \\
\hline \%Sec Glazed & & Low-e & 13186.0 & 71.6 & 231.7 & & 390.1 & 17.0 & 2705.0 & 14.7 & 47.5 & 80.0 & 2825.8 & 579.7 & 6830.3 & 11.8 \\
\hline House \#7 & & Window Type & kWh & $\mathrm{kWh} / \mathrm{m} 2$ & $\mathrm{kWh} / \mathrm{m} 2$ & $\mathrm{kWh} / \mathrm{m} 2$ & & $\%$ & kWh & $\mathrm{kWh} / \mathrm{m} 2$ & $\mathrm{kWh} / \mathrm{m} 2$ & $\mathrm{kWh} / \mathrm{m} 2$ & Cost \$ & Savings \$ & Cost \$ & Years \\
\hline Floor Area & 253.7 & Window & 13949.0 & 55.0 & 275.7 & & 323.6 & & & & & & 2989.3 & & & \\
\hline Window Area & 50.6 & Magnetic & 11880.0 & 46.8 & 234.8 & & 275.6 & 14.8 & 2069.0 & 8.2 & 40.9 & 48.0 & 2545.9 & 443.4 & 8194.6 & 18.5 \\
\hline Sec Glazing Area & 43.1 & Plastic Film & 11933.0 & 47.0 & 235.8 & & 276.9 & 14.5 & 2016.0 & 7.9 & 39.8 & 46.8 & 2557.2 & 432.0 & 318.2 & 113.8 \\
\hline$\%$ Glazing to floor & & Aluminium & 11990.0 & 47.3 & 237.0 & & 278.2 & 14.0 & 1959.0 & 7.7 & 38.7 & 45.5 & 2569.5 & 419.8 & 8256.1 & 19.7 \\
\hline$\%$ Sec Glazed & & Low-e & 11436.0 & 45.1 & 226.0 & & 265.3 & 18.0 & 2513.0 & 9.9 & 49.7 & 58.3 & 2450.7 & 538.5 & 9391.6 & 17.4 \\
\hline House \#8 & & Window Type & $\mathrm{kWh}$ & $\mathrm{kWh} / \mathrm{m} 2$ & $\mathrm{kWh} / \mathrm{m} 2$ & $\mathrm{kWh} / \mathrm{m} 2$ & & $\%$ & $\mathrm{kWh}$ & $\mathrm{kWh} / \mathrm{m} 2$ & $\mathrm{kWh} / \mathrm{m} 2$ & $\mathrm{kWh} / \mathrm{m} 2$ & Cost \$ & Savings \$ & Cost $\$$ & Years \\
\hline Floor Area & 182.1 & Window & 10588.0 & 58.1 & 209.7 & & 306.0 & & & & & & 2269.0 & & & \\
\hline Window Area & 50.5 & Magnetic & 8839.0 & 48.5 & 175.0 & & 255.5 & 16.5 & 1749.0 & 9.6 & 34.6 & 50.5 & 1894.2 & 374.8 & 7057.0 & 18.8 \\
\hline Sec Glazing Area & 34.6 & Plastic Film & 8882.0 & 48.8 & 175.9 & & 256.7 & 16.1 & 1706.0 & 9.4 & 33.8 & 49.3 & 1903.4 & 365.6 & 247.8 & 117.8 \\
\hline$\%$ Glazing to floor & & Aluminium & 8929.0 & 49.0 & 176.8 & & 258.1 & 15.7 & 1659.0 & 9.1 & 32.9 & 47.9 & 1913.5 & 355.5 & 6534.0 & 18.4 \\
\hline \%Sec Glazed & & Low-e & 8445.0 & 46.4 & 167.2 & & 244.1 & 20.2 & 2143.0 & 11.8 & 42.4 & 61.9 & 1809.8 & 459.2 & 7512.0 & 16.4 \\
\hline
\end{tabular}




\begin{tabular}{|c|c|c|c|c|c|c|c|c|c|c|c|c|c|c|c|}
\hline House \#9 & & Window Type & $\begin{array}{l}\text { Heating } \\
\text { (kWh) }\end{array}$ & $\begin{array}{l}\mathrm{kWh} / \mathrm{m} 2 \\
\text { Floor Area }\end{array}$ & $\begin{array}{l}\text { kWh/m2 } \\
\text { Window Area }\end{array}$ & $\begin{array}{l}\mathrm{kWh} / \mathrm{m} 2 \\
\text { Glazing }\end{array}$ & Reduction \% & \begin{tabular}{|l|}
$\begin{array}{l}\text { Reduction } \\
\text { (kWh) }\end{array}$ \\
\end{tabular} & $\begin{array}{l}\text { kWh/m2 } \\
\text { Floor Area }\end{array}$ & \begin{tabular}{|l|}
$\mathrm{kWh} / \mathrm{m} 2$ \\
Window Area
\end{tabular} & $\begin{array}{l}\mathrm{kWh} / \mathrm{m} 2 \\
\text { Glazing }\end{array}$ & $\begin{array}{l}\text { Heating (\$) @ } \\
21.43 / \text { kWh) }\end{array}$ & $\begin{array}{l}\text { Savings } \\
\text { (\$) }\end{array}$ & \begin{tabular}{|l|} 
Sec Glazing \\
Cost $(\$)$
\end{tabular} & \begin{tabular}{|l}
$\begin{array}{l}\text { Payback } \\
\text { (years) }\end{array}$ \\
\end{tabular} \\
\hline Floor Area & 120.7 & Window & 8137.0 & 67.4 & 337.6 & 373.3 & & & & & & 1743.8 & & & \\
\hline Window Area & 24.1 & Magnetic & 7095.0 & 58.8 & 294.4 & 325.5 & 12.8 & 1042.0 & 8.6 & 43.2 & 47.8 & 1520.5 & 223.3 & 4097.3 & 18.3 \\
\hline Sec Glazing Area & 21.8 & Plastic Film & 7120.0 & 59.0 & 295.4 & 326.6 & 12.5 & 1017.0 & 8.4 & 42.2 & 46.7 & 1525.8 & 217.9 & 157.2 & 60.7 \\
\hline$\%$ Glazing to floor & & Aluminium & 7147.0 & 59.2 & 296.6 & 327.8 & 12.2 & 990.0 & 8.2 & 41.1 & 45.4 & 1531.6 & 212.2 & 4128.0 & 19.5 \\
\hline$\%$ Sec Glazed & & Low-e & 6858.0 & 56.8 & 284.6 & 314.6 & 15.7 & 1279.0 & 10.6 & 53.1 & 58.7 & 1469.7 & 274.1 & 4695.8 & 17.1 \\
\hline House \#10 & & Window Type & $\mathrm{kWh}$ & $\mathrm{kWh} / \mathrm{m} 2$ & $\mathrm{kWh} / \mathrm{m} 2$ & $\mathrm{kWh} / \mathrm{m} 2$ & $\%$ & kWh & $\mathrm{kWh} / \mathrm{m} 2$ & $\mathrm{kWh} / \mathrm{m} 2$ & $\mathrm{kWh} / \mathrm{m} 2$ & Cost $\$$ & Savings \$ & Cost \$ & Years \\
\hline Floor Area & 184.4 & Window & 15179.0 & 82.3 & 417.0 & 417.0 & & & & & & 3252.9 & & & \\
\hline Window Area & 36.4 & Magnetic & 13470.0 & 73.0 & 370.1 & 370.1 & 11.3 & 1709.0 & 9.3 & 47.0 & 47.0 & 2886.6 & 366.2 & 6332.2 & 17.3 \\
\hline Sec Glazing Area & 36.4 & Plastic Film & 13511.0 & 73.3 & 371.2 & 371.2 & 11.0 & 1668.0 & 9.0 & 45.8 & 45.8 & 2895.4 & 357.5 & 234.8 & 122.7 \\
\hline$\%$ Glazing to floor & & Aluminium & 13554.0 & 73.5 & 372.4 & 372.4 & 10.7 & 1625.0 & 8.8 & 44.6 & 44.6 & 2904.6 & 348.2 & 6379.7 & 18.3 \\
\hline \multirow[t]{4}{*}{$\%$ Sec Glazed } & & Low-e & 13076.0 & 70.9 & 359.2 & 359.2 & 13.9 & 2103.0 & 11.4 & 57.8 & 57.8 & 2802.2 & 450.7 & 7257.2 & 16.1 \\
\hline & & & kWh & $\mathrm{kWh} / \mathrm{m} 2$ & $\mathrm{kWh} / \mathrm{m} 2$ & $\mathrm{kWh} / \mathrm{m} 2$ & $\%$ & $\mathrm{kWh}$ & $\mathrm{kWh} / \mathrm{m} 2$ & $\mathrm{kWh} / \mathrm{m} 2$ & $\mathrm{kWh} / \mathrm{m} 2$ & Cost \$ & Savings \$ & Cost \$ & Years \\
\hline & & Maximum & 16603.0 & 88.7 & 417.0 & 470.1 & 21.0 & 2733.0 & 16.4 & 70.4 & 80.0 & 3558.0 & 585.7 & & 26.9 \\
\hline & & Minimum & 6858.0 & 45.1 & 167.2 & 244.1 & 10.7 & 990.0 & 7.7 & 32.9 & 44.4 & 1469.7 & 212.2 & & 10.9 \\
\hline \multirow[t]{6}{*}{\begin{tabular}{|l|}
$\begin{array}{l}\text { Household } \\
\text { Average }\end{array}$ \\
\end{tabular}} & & Window Type & kWh & $\mathrm{kWh} / \mathrm{m} 2$ & $\mathrm{kWh} / \mathrm{m} 2$ & $\mathrm{kWh} / \mathrm{m} 2$ & $\%$ & $\mathrm{kWh}$ & $\mathrm{kWh} / \mathrm{m} 2$ & $\mathrm{kWh} / \mathrm{m} 2$ & $\mathrm{kWh} / \mathrm{m} 2$ & Cost \$ & Savings \$ & Cost \$ & Years \\
\hline & 170.6 & Window & 12824.6 & 76.3 & 324.7 & 377.4 & & & & & & 2775.2 & & & \\
\hline & 40.5 & Magnetic & 11088.8 & 66.0 & 281.1 & 326.5 & 13.5 & 1735.8 & 10.3 & 43.5 & 50.9 & 2399.6 & 375.6 & 6663.5 & 18.4 \\
\hline & 34.1 & Plastic Film & 11097.2 & 66.0 & 281.6 & 326.7 & 13.5 & 1727.4 & 10.2 & 43.0 & 50.6 & 2401.4 & 373.8 & 246.8 & 123.4 \\
\hline & & Aluminium & 11175.7 & 66.5 & 283.3 & 329.1 & 12.9 & 1648.9 & 9.8 & 41.3 & 48.3 & 2418.4 & 356.8 & 6719.9 & 19.6 \\
\hline & & Low-e & 10692.4 & 63.6 & 271.2 & 314.9 & 16.6 & 2132.2 & 12.7 & 53.4 & 62.5 & 2313.8 & 461.4 & 7643.3 & 17.2 \\
\hline
\end{tabular}

Table D-6: Christchurch Results Spreadsheet 


\section{D.1.4 Dunedin}

\begin{tabular}{|c|c|c|c|c|c|c|c|c|c|c|c|c|c|c|c|}
\hline House \#1 & & Window Type & $\begin{array}{l}\text { Heating } \\
(\mathrm{kWh})\end{array}$ & $\begin{array}{l}\mathrm{kWh} / \mathrm{m} 2 \\
\text { Floor Area } \\
\end{array}$ & \begin{tabular}{|l|}
$\mathrm{kWh} / \mathrm{m} 2$ \\
Window Area
\end{tabular} & $\begin{array}{l}\mathrm{kWh} / \mathrm{m} 2 \\
\text { Glazing }\end{array}$ & Reduction \% & $\begin{array}{l}\text { Reduction } \\
\text { (kWh) }\end{array}$ & $\begin{array}{l}\mathrm{kWh} / \mathrm{m} 2 \\
\text { Floor Area }\end{array}$ & \begin{tabular}{|l}
$\mathrm{kWh} / \mathrm{m} 2$ \\
Window Area
\end{tabular} & \begin{tabular}{|l}
$\mathrm{kWh} / \mathrm{m} 2$ \\
Glazing
\end{tabular} & \begin{tabular}{|l|l} 
Heating (\$) @ \\
$21.95 / \mathrm{kWh})$ \\
(
\end{tabular} & $\begin{array}{l}\text { Savings } \\
\text { (\$) }\end{array}$ & \begin{tabular}{|l|l} 
Sec Glazing & P \\
Cost $(\$)$
\end{tabular} & $\begin{array}{l}\text { Payback } \\
\text { (years) }\end{array}$ \\
\hline Floor Area & 171.2 & Single & 15035.0 & 87.8 & 387.5 & 414.2 & & & & & & 3300.2 & & & \\
\hline Window Area & 38.8 & Magnetic & 12449.0 & 72.7 & 320.9 & 342.9 & 17.2 & 2586.0 & 15.1 & 66.6 & 71.2 & 2732.6 & 567.6 & 5587.2 & 9.8 \\
\hline Sec Glazing Area & 36.3 & Plastic Film & 12511.0 & 73.1 & 322.4 & 344.7 & 16.8 & 2524.0 & 14.7 & 65.1 & 69.5 & 2746.2 & 554.0 & 218.0 & 336.0 \\
\hline$\%$ Glazing to floor & & Aluminium & 12577.0 & 73.5 & 324.1 & 346.5 & 16.3 & 2458.0 & 14.4 & 63.4 & 67.7 & 2760.7 & 539.5 & 5629.1 & 10.4 \\
\hline \%Sec Glazed & & Low-e & 11850.0 & 69.2 & 305.4 & 326.4 & 21.2 & 3185.0 & 18.6 & 82.1 & 87.7 & 2601.1 & 699.1 & 6403.4 & 9.2 \\
\hline House \#2 & & Window Type & $\mathrm{kWh}$ & $\mathrm{kWh} / \mathrm{m} 2$ & $\mathrm{kWh} / \mathrm{m} 2$ & $\mathrm{kWh} / \mathrm{m} 2$ & $\%$ & $\mathrm{kWh}$ & $\mathrm{kWh} / \mathrm{m} 2$ & $\mathrm{kWh} / \mathrm{m} 2$ & $\mathrm{kWh} / \mathrm{m} 2$ & Cost \$ & Savings \$ & Cost \$ & Years \\
\hline Floor Area & 165.2 & Window & 15701.0 & 95.0 & 432.5 & 471.5 & & & & & & 3446.4 & & & \\
\hline Window Area & 36.3 & Magnetic & 13889.0 & 84.1 & 382.6 & 417.1 & 11.5 & 1812.0 & 11.0 & 49.9 & 54.4 & 3048.6 & 397.7 & 7058.0 & 17.7 \\
\hline Sec Glazing Area & 33.3 & Plastic Film & 13933.0 & 84.3 & 383.8 & 418.4 & 11.3 & 1768.0 & 10.7 & 48.7 & 53.1 & 3058.3 & 388.1 & 269.6 & 118.5 \\
\hline$\%$ Glazing to floor & & Aluminium & 13979.0 & 84.6 & 385.1 & 419.8 & 11.0 & 1722.0 & 10.4 & 47.4 & 51.7 & 3068.4 & 378.0 & 7751.0 & 20.5 \\
\hline \%Sec Glazed & & Low-e & 13477.0 & 81.6 & 371.3 & 404.7 & 14.2 & 2224.0 & 13.5 & 61.3 & 66.8 & 2958.2 & 488.2 & 8729.0 & 17.9 \\
\hline House \#3 & & Window Type & kWh & $\mathrm{kWh} / \mathrm{m} 2$ & $\mathrm{kWh} / \mathrm{m} 2$ & $\mathrm{kWh} / \mathrm{m} 2$ & $\%$ & kWh & $\mathrm{kWh} / \mathrm{m} 2$ & $\mathrm{kWh} / \mathrm{m} 2$ & $\mathrm{kWh} / \mathrm{m} 2$ & Cost \$ & Savings $\$$ & Cost \$ & Years \\
\hline Floor Area & 189.7 & Window & 19244.0 & 101.4 & 412.1 & 459.3 & & & & & & 4224.1 & & & \\
\hline Window Area & 46.7 & Magnetic & 16918.0 & 89.2 & 362.3 & 403.8 & 12.1 & 2326.0 & 12.3 & 49.8 & 55.5 & 3713.5 & 510.6 & 8194.6 & 16.1 \\
\hline Sec Glazing Area & 41.9 & Plastic Film & 16973.0 & 89.5 & 363.4 & 405.1 & 11.8 & 2271.0 & 12.0 & 48.6 & 54.2 & 3725.6 & 498.5 & 270.6 & 227.9 \\
\hline$\%$ Glazing to floor & & Aluminium & 17031.0 & 89.8 & 364.7 & 406.5 & 11.5 & 2213.0 & 11.7 & 47.4 & 52.8 & 3738.3 & 485.8 & 8256.1 & 17.0 \\
\hline$\%$ Sec Glazed & & Low-e & 16373.0 & 86.3 & 350.6 & 390.8 & 14.9 & 2871.0 & 15.1 & 61.5 & 68.5 & 3593.9 & 630.2 & 9391.6 & 14.9 \\
\hline House \#4 & & Window Type & $\mathrm{kWh}$ & $\mathrm{kWh} / \mathrm{m} 2$ & $\mathrm{kWh} / \mathrm{m} 2$ & $\mathrm{kWh} / \mathrm{m} 2$ & $\%$ & $\mathrm{kWh}$ & $\mathrm{kWh} / \mathrm{m} 2$ & $\mathrm{kWh} / \mathrm{m} 2$ & $\mathrm{kWh} / \mathrm{m} 2$ & Cost \$ & Savings \$ & Cost $\$$ & Years \\
\hline Floor Area & 113.3 & Window & 11651.0 & 102.8 & 369.9 & 369.9 & & & & & & 2557.4 & & & \\
\hline Window Area & 31.5 & Magnetic & 9892.0 & 87.3 & 314.0 & 314.0 & 15.1 & 1759.0 & 15.5 & 55.8 & 55.8 & 2171.3 & 386.1 & 8194.6 & 21.2 \\
\hline Sec Glazing Area & 31.5 & Plastic Film & 9935.0 & 87.7 & 315.4 & 315.4 & 14.7 & 1716.0 & 15.1 & 54.5 & 54.5 & 2180.7 & 376.7 & 306.4 & 70.3 \\
\hline$\%$ Glazing to floor & & Aluminium & 9980.0 & 88.1 & 316.8 & 316.8 & 14.3 & 1671.0 & 14.7 & 53.0 & 53.0 & 2190.6 & 366.8 & 8256.1 & 22.5 \\
\hline \%Sec Glazed & & Low-e & 9488.0 & 83.7 & 301.2 & 301.2 & 18.6 & 2163.0 & 19.1 & 68.7 & 68.7 & 2082.6 & 474.8 & 9391.6 & 19.8 \\
\hline
\end{tabular}




\begin{tabular}{|c|c|c|c|c|c|c|c|c|c|c|c|c|c|c|c|c|}
\hline House \#5 & & Window Type & $\begin{array}{l}\text { Heating } \\
\text { (kWh) }\end{array}$ & $\begin{array}{l}\mathrm{kWh} / \mathrm{m} 2 \\
\text { Floor Area }\end{array}$ & $\begin{array}{l}\text { kWh/m2 } \\
\text { Window Area }\end{array}$ & $\begin{array}{l}\mathrm{kWh} / \mathrm{m} 2 \\
\text { Glazing }\end{array}$ & $\mathrm{Sec}$ & Reduction \% & \begin{tabular}{|l}
$\begin{array}{l}\text { Reduction } \\
\text { (kWh) }\end{array}$ \\
\end{tabular} & $\begin{array}{l}\text { kWh/m2 } \\
\text { Floor Area }\end{array}$ & $\begin{array}{l}\mathrm{kWh} / \mathrm{m} 2 \\
\text { Window Area }\end{array}$ & $\begin{array}{l}\mathrm{kWh} / \mathrm{m} 2 \\
\text { Glazing }\end{array}$ & \begin{tabular}{|l|} 
Heating (\$) @ \\
$21.95 /$ kWh) \\
\end{tabular} & \begin{tabular}{|l} 
Savings \\
(\$)
\end{tabular} & \begin{tabular}{|l|} 
Sec Glazing \\
Cost $(\$)$
\end{tabular} & \begin{tabular}{|l}
$\begin{array}{l}\text { Payback } \\
\text { (years) }\end{array}$ \\
\end{tabular} \\
\hline Floor Area & 142.0 & Window & 13050.0 & 91.9 & 397.9 & & 466.1 & & & & & & 2864.5 & & & \\
\hline Window Area & 32.8 & Magnetic & 11510.0 & 81.1 & 350.9 & & 411.1 & 11.8 & 1540.0 & 10.8 & 47.0 & 55.0 & 2526.4 & 338.0 & 5959.7 & 17.6 \\
\hline Sec Glazing Area & 28.0 & Plastic Film & 11548.0 & 81.3 & 352.1 & & 412.4 & 11.5 & 1502.0 & 10.6 & 45.8 & 53.6 & 2534.8 & 329.7 & 193.0 & 136.7 \\
\hline$\%$ Glazing to floor & & Aluminium & 11589.0 & 81.6 & 353.3 & & 413.9 & 11.2 & 1461.0 & 10.3 & 44.5 & 52.2 & 2543.8 & 320.7 & 6004.4 & 18.7 \\
\hline \%Sec Glazed & & Low-e & 11169.0 & 78.7 & 340.5 & & 398.9 & 14.4 & 1881.0 & 13.2 & 57.3 & 67.2 & 2451.6 & 412.9 & 6830.3 & 16.5 \\
\hline House \#6 & & Window Type & $\mathrm{kWh}$ & $\mathrm{kWh} / \mathrm{m} 2$ & $\mathrm{kWh} / \mathrm{m} 2$ & $\mathrm{kWh} / \mathrm{m} 2$ & & $\%$ & $\mathrm{kWh}$ & $\mathrm{kWh} / \mathrm{m} 2$ & $\mathrm{kWh} / \mathrm{m} 2$ & $\mathrm{kWh} / \mathrm{m} 2$ & Cost \$ & Savings $\$$ & Cost \$ & Years \\
\hline Floor Area & 184.1 & Window & 18319.0 & 99.5 & 322.0 & & 542.0 & & & & & & 4021.0 & & & \\
\hline Window Area & 56.9 & Magnetic & 15761.0 & 85.6 & 277.0 & & 466.3 & 14.0 & 2558.0 & 13.9 & 45.0 & 75.7 & 3459.5 & 561.5 & 5959.7 & 10.6 \\
\hline Sec Glazing Area & 33.8 & Plastic Film & 15822.0 & 85.9 & 278.1 & & 468.1 & 13.6 & 2497.0 & 13.6 & 43.9 & 73.9 & 3472.9 & 548.1 & 252.6 & 295.5 \\
\hline$\%$ Glazing to floor & & Aluminium & 15887.0 & 86.3 & 279.2 & & 470.0 & 13.3 & 2432.0 & 13.2 & 42.7 & 72.0 & 3487.2 & 533.8 & 6004.4 & 11.2 \\
\hline$\%$ Sec Glazed & & Low-e & 15164.0 & 82.4 & 266.5 & & 448.6 & 17.2 & 3155.0 & 17.1 & 55.4 & 93.3 & 3328.5 & 692.5 & 6830.3 & 9.9 \\
\hline House \#7 & & Window Type & $\mathrm{kWh}$ & $\mathrm{kWh} / \mathrm{m} 2$ & $\mathrm{kWh} / \mathrm{m} 2$ & $\mathrm{kWh} / \mathrm{m} 2$ & & $\%$ & $\mathrm{kWh}$ & $\mathrm{kWh} / \mathrm{m} 2$ & $\mathrm{kWh} / \mathrm{m} 2$ & $\mathrm{kWh} / \mathrm{m} 2$ & Cost \$ & Savings \$ & Cost \$ & Years \\
\hline Floor Area & 253.7 & Window & 16088.0 & 63.4 & 317.9 & & 373.3 & & & & & & 3531.3 & & & \\
\hline Window Area & 50.6 & Magnetic & 13673.0 & 53.9 & 270.2 & & 317.2 & 15.0 & 2415.0 & 9.5 & 47.7 & 56.0 & 3001.2 & 530.1 & 8194.6 & 15.5 \\
\hline Sec Glazing Area & 43.1 & Plastic Film & 13735.0 & 54.1 & 271.4 & & 318.7 & 14.6 & 2353.0 & 9.3 & 46.5 & 54.6 & 3014.8 & 516.5 & 318.2 & 198.3 \\
\hline$\%$ Glazing to floor & & Aluminium & 13802.0 & 54.4 & 272.8 & & 320.2 & 14.2 & 2286.0 & 9.0 & 45.2 & 53.0 & 3029.5 & 501.8 & 8256.1 & 16.5 \\
\hline$\%$ Sec Glazed & & Low-e & 13156.0 & 51.9 & 260.0 & & 305.2 & 18.2 & 2932.0 & 11.6 & 57.9 & 68.0 & 2887.7 & 643.6 & 9391.6 & 14.6 \\
\hline House \#8 & & Window Type & kWh & $\mathrm{kWh} / \mathrm{m} 2$ & $\mathrm{kWh} / \mathrm{m} 2$ & $\mathrm{kWh} / \mathrm{m} 2$ & & $\%$ & kWh & $\mathrm{kWh} / \mathrm{m} 2$ & $\mathrm{kWh} / \mathrm{m} 2$ & $\mathrm{kWh} / \mathrm{m} 2$ & Cost \$ & Savings $\$$ & Cost \$ & Years \\
\hline Floor Area & 182.1 & Window & 12151.0 & 66.7 & 240.6 & & 351.2 & & & & & & 2667.1 & & & \\
\hline Window Area & 50.5 & Magnetic & 10107.0 & 55.5 & 200.1 & & 292.1 & 16.8 & 2044.0 & 11.2 & 40.5 & 59.1 & 2218.5 & 448.7 & 7057.0 & 15.7 \\
\hline Sec Glazing Area & 34.6 & Plastic Film & 10158.0 & 55.8 & 201.1 & & 293.6 & 16.4 & 1993.0 & 10.9 & 39.5 & 57.6 & 2229.7 & 437.5 & 247.8 & 189.7 \\
\hline$\%$ Glazing to floor & & Aluminium & 10212.0 & 56.1 & 202.2 & & 295.1 & 16.0 & 1939.0 & 10.6 & 38.4 & 56.0 & 2241.5 & 425.6 & 6534.0 & 15.4 \\
\hline$\%$ Sec Glazed & & Low-e & 9648.0 & 53.0 & 191.0 & & 278.8 & 20.6 & 2503.0 & 13.7 & 49.6 & 72.3 & 2117.7 & 549.4 & 7512.0 & 13.7 \\
\hline
\end{tabular}




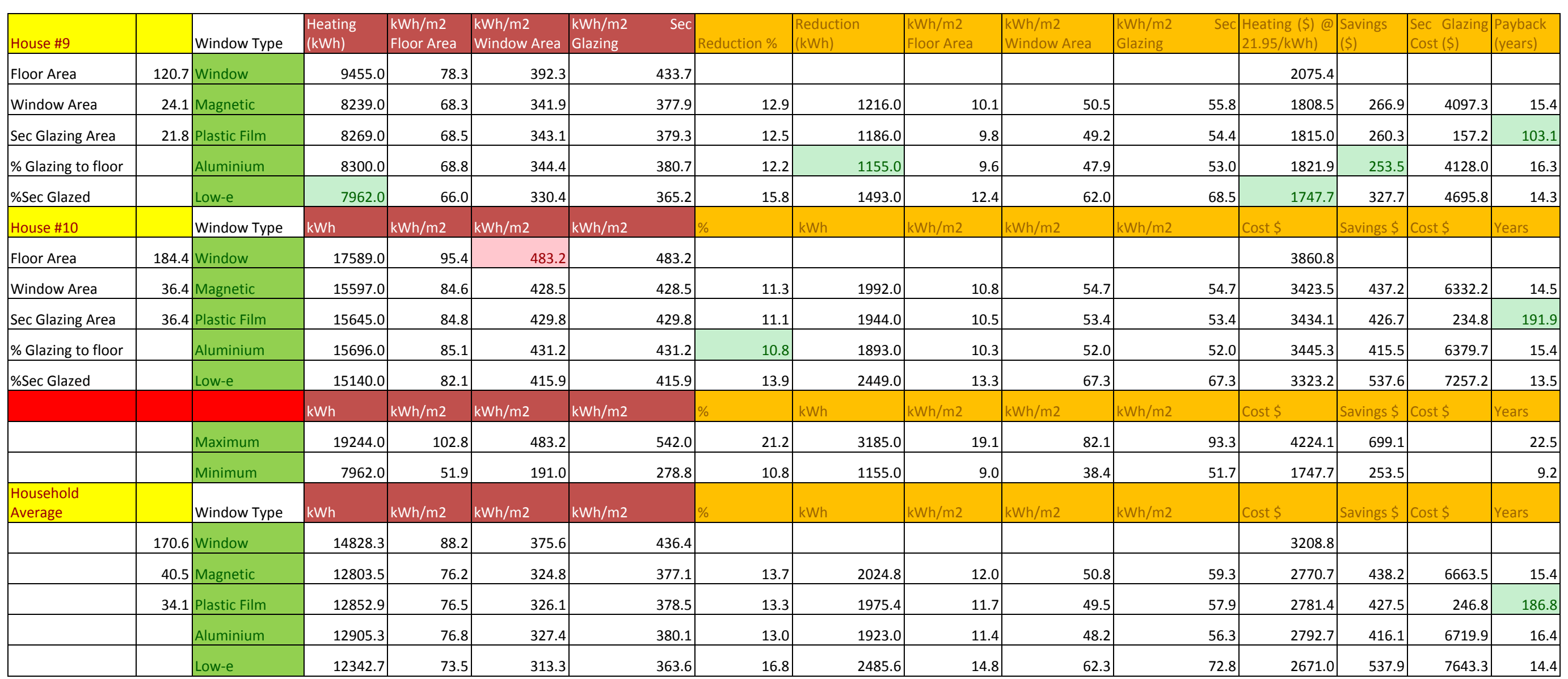

Table D-7: Dunedin Results Spreadsheet 
A Cost Benefit Analysis of Secondary Glazing as a Retrofit Alternative for New Zealand Homes 